OLD TESTAMENT QUDTATIONS IN THE SYNOPTIC GOSPELS 


\title{
OLD TESTAMENT QUOTATIONS IN THE SYNOPTIC GOSPELS, AND THE TWO-DOCUMENT HYPOTHESIS
}

\author{
By \\ DAVID STEWART NEW, B.SC., M.A., M.T.S. \\ A Thesis \\ Submitted to the School of Graduate Studies \\ in Partial Fulfilment of the Requirements \\ for the Degree \\ Doctor of Philosophy \\ McMaster University \\ (c) Copyright by David Stewart New, June 1990
}




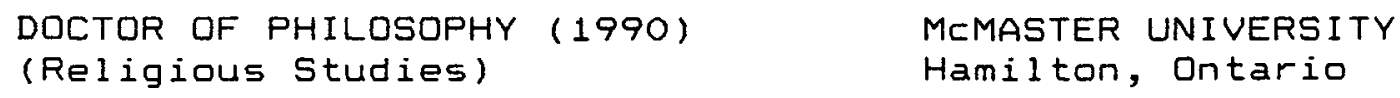

TITLE: Old Testament Quotations in the Synoptic Gospels, and the Two-document Hypothesis

AUTHOR: David Stewart New, B.Sc. (McMaster University)

$$
\begin{aligned}
& \text { M.A. (McMaster University) } \\
& \text { M.A. Princeton Theological } \\
& \text { Seminary } \\
& \text { M.T.S McMaster Divinity } \\
& \text { College }
\end{aligned}
$$

SUPERVISOR: Professor S. R. Westerholm

NUMBER OF PAGES: $v i, 303$ 


\section{ABSTRACT}

The two-document hypothesis (involving the claim that Mark is a source for Matthew and Luke) has long been regarded by the majority of New Testament scholars as firmly established. Recently its status has been challenged by proponents of the Griesbach hypothesis (by which Matthew is a source for Luke and Markj. Since much gospel research depends on the validity of the two-document hypothesis, resolution is urgently needed.

In 1863 Heinrich Julius Holtzmann argued that an examination of the old Testament quotations in these three gospels would favour the two-document position. His argument depends on the existence of two groups of quotations in Matthew: those of Septuagintal text-type which Matthew copied from Mark, and those similar to the Hebrew, which Matthew preferred when on his own. My research indicates that these two groups cannot be clearly demarcated. Some quotations peculiar to Matthew are Septuagintal, and on only four occasions do Matthew and Mark both quote the Septuagint verbatim. 


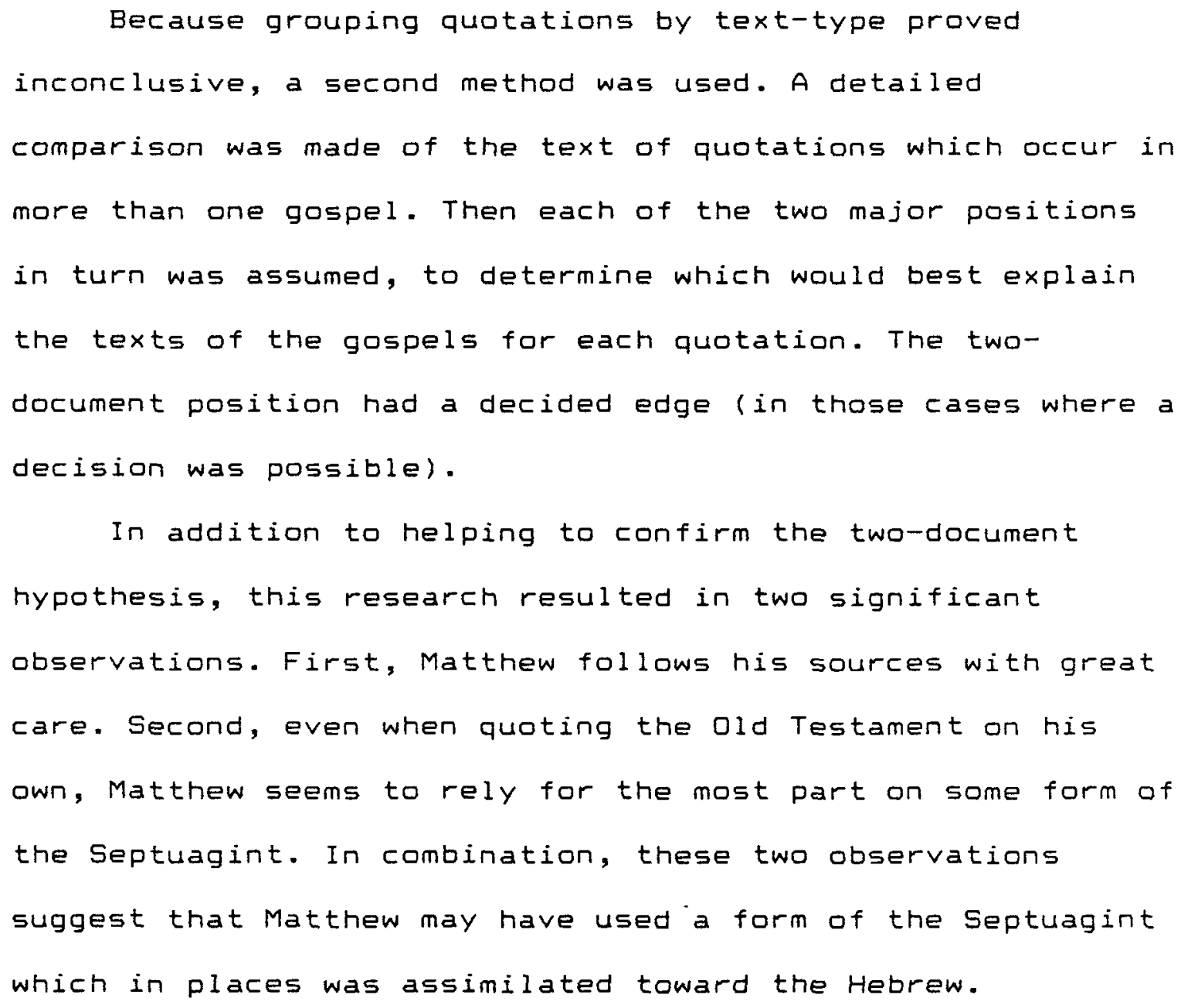




\section{ACKNOWLEDGEMENTS}

I wish to give special thanks to my supervisor, Dr. Stephen R. Westerholm. The time he spent in detailed criticism goes far beyond what could be expected of the jobdescription. His criticisms were to the point and explicit, and it always seemed that he dropped everything to look over my latest draft. Above all it would be difficult to imagine having a better working relationship for such a task than we had. For all of this I am deeply grateful.

I also wish to thank my two readers, Dr. A. Eugene Combs, and Dr. John T. Rook, for their interest and advice concerning this project and my career as a student over the years.

In addition I want to thank the helpful and friendly staff of McMaster's Mills Library, with a special vote of thanks to the hard-working women of the inter-library loan office, and our departmental secretaries for the congenial atmosphere they provide. 


\section{TABLE OF CONTENTS}

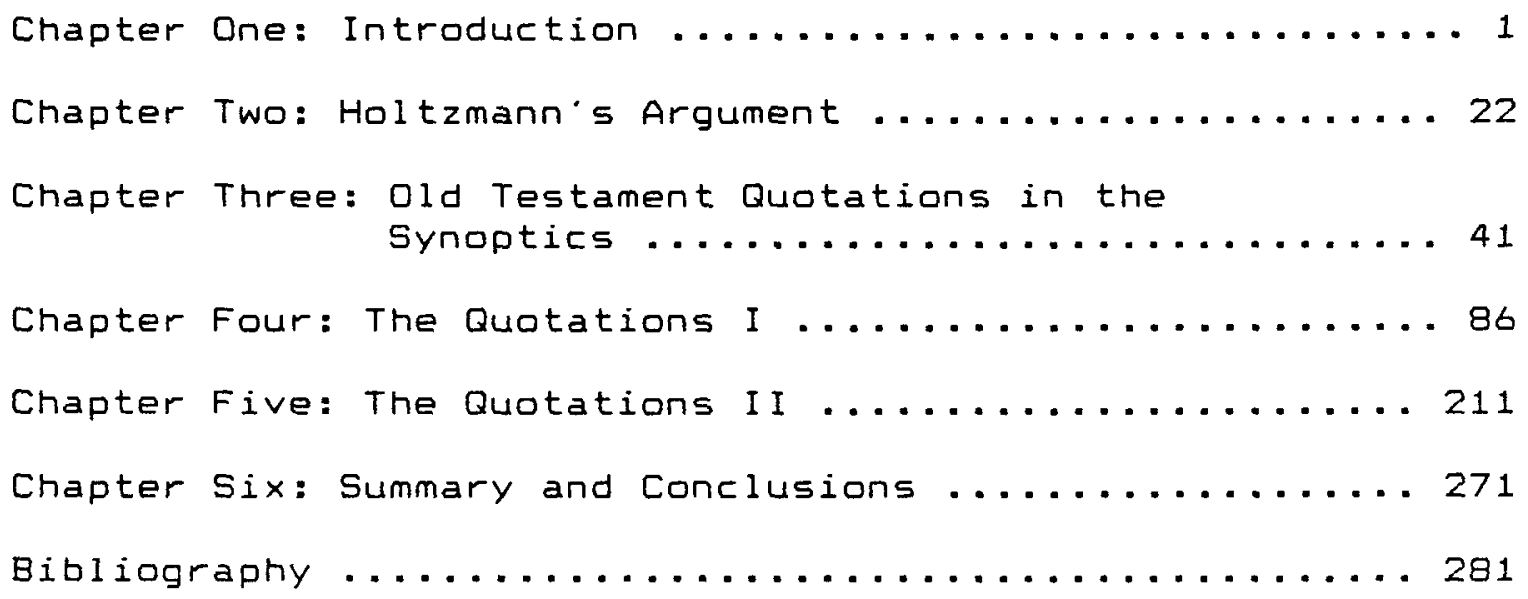




\section{CHAPTER ONE: INTRODUCTION}

The Synoptic Problem and the Two-Document Hypothesis

It is easily observed that the three gospels, Matthew, Mark, and Luke have a great amount of material in common; indeed, similarity among the three often extends to exact or nearly exact verbal agreement - hence, "synoptic gospels". At the same time, however, there are striking dissimilarities. Stated in simplest terms, the "synoptic problem" asks how we can account for the similarities and yet dissimilarities among the synoptic gospels.

For more than a century and a half the synoptic problem has been debated without a satisfactory solution. Nevertheless, the "two-document hypothesis" has appealed to the majority of twentieth-century New Testament scholars, to the degree that one part of the hypothesis, that Mark is the oldest of the three synoptics and was the principal source used by Matthew and Luke, has been commonly referred to as "the one absolutely assured result"1 of synoptic research. The two-document hypothesis also proposes that Matthew and Luke shared a second source, denoted by "Q".

A landmark in the development of the two-document 
hypothesis was the 1863 work, Die synoptischen Evangelien: Ihr Ursprung und geschichtlicher Character, by Heinrich Julius Holtzmann. = As Bo Reicke so succinctly put it, this publication "secured the final victory of this hypothesis in Protestant Germany." = Indeed, William R. Farmer, in his challenge to the two-document hypothesis ${ }^{4}$, seems by the very layout of his historical analysis to key on Holtzmann as the arch-culprit. = Farmer sees Holtzmann's synthesis as "essentially programmatic" because until this time there was virtually no consensus concerning the order of writing of the synoptic gospels and their sources."

Holtzmann is rather whimsically described by Stephen Neill as "a typical German professor of the late nineteenth century. Slow, ponderous in style, without a trace of humour and with no concessions to the possible weaknesses of his readers, he moves rather laboriously from point to point." But in the end of all this difficult labouring - and it seems that historians of biblical criticism are as ready to laud Holtzmann for the sheer volume of his painstaking research as for the importance of his results - just as surely as the Mounty gets his man, Holtzmann has his scholarly reward. He permits himself (and here his real interest in determining the order of writing of the synoptic gospels becomes apparent) to cap his work with a concluding twenty-nine page Lebensbild Jesu. 
Indeed, it would not be inaccurate to depict Holtzmann's quest as an assault on the bastion built by Strauss and the Tübingen school. Instead of the gospels providing only a reflection of the conflicts and tendencies of the early church as they did for the Tübingen school, they provide a source of historical information almost a century closer to the actual events of Jesus' life than that school had supposed. Whether one sees Holtzmann as a leader of those "liberals" who "searched the New Testament for a reflection of their own idea of religion as interior experience and ethical ideal", or as a "conservative" who sought to preserve the historicity of the gospels against the extreme views of F.C. Baur and companyio, it is clear that through Holtzmann's work the solution of the symoptic problem, the order of the writing of the three synoptic gospels, became an issue of prime importance, even if only as the servant of larger theological controversies.11 Holtzmann's presupposition, of course, was that the earlier the source the more accurate the historical evidence it would provide. According to Ben F. Meyer, it was this "simplistic equation of 'early sources' with guileless history that led ... to the exaggeration of the importance of the synoptic problem"; in fact, Meyer argues, the chronalogical order of the synoptic gospels does not in itself determine which of the traditions were the oldest.13 One of those who have recently opposed the two-document 
hypothesis, Bernard Orchard, claims that not only did the Griesbach hypothesis (that the order of dependence was Matthew, Luke, Mark) virtually disappear because it became identified with the passing theology of the Tübingen school, but that the two-document hypothesis became identified with the concept of the historicity of the gospel tradition. ${ }^{2}=$ Implicit in this claim is the suggestion that if the twodocument hypothesis gained scholarly acceptance on the coattails of a larger theological debate concerning historicity of the gospels, then, since we are now aware of the weakness of Holtzmann's presupposition linking order of dependence of the gospels with historical accuracy, the time has come to sever this umbilical cord of the two-document hypothesis, and place it in the real world of hard, critical scrutiny, and re-examine its grounds.

Contemporary Scholarship on the Two-document Hypothesis

In recent years the two-document hypothesis has been challenged, particularly in the person of William R. Farmer, who fired his first shot with the amusingly titled article, "A 'Skeleton in the Closet' of Gospel Research"14, and followed it up with the monograph, The Synoptic problem: A Critical Analysis. Consequent to these publications, the synoptic problem, and the two-document hypothesis in particular, is once again a current issue in the scholarly 
literature. A hasty survey of monographs published in the last few years yields as examples: The Two-Source Hypothesis: A Critical Appraisal 1=, The Roots of the Synoptic Gospels 10, and The Order of the Synoptics: Why Three Synoptic Gospels? 17. Several seminars and colloquia have been held over the past two decades involving scholars from around the globe: ${ }^{10}$ since 1966 the Society of Biblical Literature has fostered continuous research on the synoptic problem; starting in 1971 and continuing for several years, the Society of New Testament Studies did likewise; 1970 witnessed the Pittsburgh Festival of the Gospels held at Pittsburgh Theological Seminary; The Johann Jakob Griesbach Bicentenary Colloquium, 1776-1976, was held at Münster (Westphalia) in 197619; The Colloquy on the Relationships Among the Gospels at San Antonio in 1977; the Cambridge Conference on the Synoptic Gospels in 1979=0; the international symposium at Jerusalem in 1984.

If we no longer seek to know the order of the writing of the synoptic gospels in order to determine which gospel would give best access to the history of Jesus' time, why should present scholarship interest itself in the synoptic problem, other than the straightforward desire to satisfy intellectual curiosity and resolve an issue that has a long pedigree?

One reason a solution to the symoptic problem is desirable is that inasmuch as the gospels provide a window 
onto the life of the early church, according to the tenets of form criticism, a determination of the order of their dependence would help to elucidate that history. If one gospel writer, for example, used another gospel as a source, his church may have had contact with that of the other gospel's writer. Also, theological concepts peculiar to the writer of the second gospel may have been of particular interest to his church. These examples can easily be multiplied.

A second reason is that the two-document hypothesis served as a springboard for form criticism. The works of Dibelius and Bultmann quickly reveal such dependence. As Joseph A. Fitzmyer observes:

I am, however, aware that [form criticism is not] ... organically or necessarily tied to the Two-source Theory.... Yet, historically, it was applied to the Gospels on the basis of the Two-Source Theory, as the works of $M$. Dibelius and $R$. Bultmann manifest on almost every page. I know of no comparable form Critical studies that operate on the basis of another theory and have commanded the attention of scholars which can claim to rival the Dibelius-Bultmann approach.21

The two-document hypothesis is used in the service of form criticism to illustrate those changes in pericopes which are thought to have taken place in the movement of the gospel from the early Palestinian church to the hellenistic church. A third reason for a solution to the synoptic problem is that some solution of the synoptic problem, usually the two-document hypothesis, is generally assumed in redaction critical work. $2=$ Graham Stanton states the case quite 
clearly: "If the Griesbach hypothesis ... were to be accepted, many of the conclusions accepted by most Matthean specialists would be falsified, for they rest on the presupposition that Matthew used two sources, Mark and Q."Is In addition, if we did not know about Mark and Luke, we would find it very difficult to isolate Matthew's sources. This would mean that "redaction" critics would have a great deal of difficulty in distinguishing traditional material from its Matthean redaction.

Indeed, there has been a recent attempt to free redaction criticism from its problematic dependence on source critical hypotheses. W. G. Thompson, a leading figure in the attempt to study the individual gospels independently of source critical presuppostions, notes that the methods and procedure of most redaction critics is strongly influenced by their presupposition that Matthew used Mark. While he does not wish to repudiate "horizontal analysis" (the comparison of the gospels with each other), he does wish to emphasize "vertical analysis" (reading of a gospel in terms of that gospel). $=4$

In determining Matthean theology, there may be a need to address the fact that Matthew uses material from his sources in service of his own theological themes=s, rather than simply focusing on the material peculiar to Matthew which remains after that from his sources is stripped away. Nevertheless, the synoptic problem will remain of great 
significance. As George M. Soares Prabhu cogently points out in this regard, the gospels are not literary creations ex nihilo, but edited collections of material which existed in a more or less formulated state. 20 The redactors of the gospels are neither mere gatherers of traditions which they compile in scissors-and-paste fashion nor are they authors who freely create original 1 iterature. Rather, they must reckon with the force of tradition, perhaps incorporating material which has no significance for, and may even conflict with, their theologies, even though they may interpret tradition through selection, arrangement, and emendation. Indeed, redaction critical studies reveal strong tensions between the purposes of the evangelist and "the often intransigent tradition" he wishes to reshape. Soares Prabhu goes on to give an example. He notes that there are fifteen occurrences of "Galilee" in Matthew (which is otherwise sparing in its use of geographical detail). This might suggest some special significance for Matthew, except that most of these occurrences are paralleled in Mark. Here the significance of "Galilee" will depend on whether we think Mark was a source for Matthew or the reverse. If we assume the former, we cannot necessarily conclude that because Matthew took over these many instances of "Galilee" it had particular significance for him. Finding them in his source, he may simply have had no reason for leaving them out. As Soares Prabhu concludes, "uncontrolled vertical. 
analysis might arrive at very odd results here!" As. Stanton remarks, "Most scholars would agree that the attempt to make sense of ... [a] gospel as it stands without recourse to source critical hypotheses is rather like trying to play a violin or cello with one's left hand tied behind one's back: rather limited results are still possible, but that is all that can be said!"=7

The strong connection that does exist between redaction criticism and some solution of the synoptic problem can be seen in some recent proposals to reach conclusions concerning the latter based on findings of the former. C. M. Tuckett suggests using the redacted work to determine the sources of that redacted work. For example, to determine which of Luke or Mark-and-Q were the sources of Matthew, one would suppose that Luke was Matthew's source and determine the hypothetical modifications of Luke made by Matthew. The same process would be repeated for Mark-and-Q, and then the two groups of hypothetical redactions compared to see which gives the more coherent explanation of Matthean redaction. = J. M. Robinson claims that the success of redaction criticism in clarifying the theologies of Matthew and Luke on the assumption of dependence on Mark is perhaps the most important new argument for Marcan priority, just as the lack of a convincing Redaktionsgeschichte for Mark argues against those who oppose the two-document hypothesis. 20 
The strong connection between redaction criticism and the synoptic problem can also be documented by noting one effort to have nothing to do with the latter. Perhaps the seeming intractability of the synoptic problem has been a factor in the fascination of late with methods which exclude historical questions, although the application of structural Inguistics to biblical documents follows upon an international, interdisciplinary philological research into the interpretation of texts in general. In 1916 the comparative philologist, Ferdinand de Saussure, differentiated between "diachronic" (historical) and "synchronic" (logical) aspects of literary research. While de Saussure advocated synchronic studies in addition to diachronic studies, later developments emphasized or focused on synchronic studies to the point where, with the publication of a seminal textbook, A. J. Greimas Sémantique structurale: Recherche de methode ${ }^{11}$, structural exegetes avoided historical questions altogether. Hence, in their liberation from preoccupation with historical problems, one would hardly expect structuralists to be concerned with the synoptic problem. $=2$

Turning from a case where backs have been turned on the synoptic problem, we now cite a fourth reason for further work on the synoptic problem. Its solution is most taken for granted in textbooks, from which young minds get the impression that the problem has been forever resolved. This 
generates a whole new generation who perpetuate this myth. As J. A. T. Robinson has observed, "The consensus frozen by the success of 'the fundamental solution' propounded by $B$. H. Streeter has begun to show signs of cracking. Though it is still the dominant hypothesis, incapsulated in the textbooks, its conclusions can no longer be taken for granted as among the 'assured results' of biblical criticism." 33

A fifth reason for examining the status of the twodocument hypothesis is that presuppostions concerning some solution of the synoptic problem can affect textual choices. $=4$

Considering the importance for synoptic research of a solution to the symoptic problem, the recent challenge to the status of the two-document hypothesis and the increased interest in the synoptic problem is not inappropriate and none too early. If new weight can be added to the evidence either for or against the two-document hypothesis, then no time should be last in doing 50 .

Need for a Re-examination of OT Quotations in the Synoptics

In his 1863 publication Holtzmann points to a solution of the synoptic problem. With some nuancing, he noted that all of Mark's citations from the old Testament were from the Septuagint. On the other hand, Matthew's citations fell into 
two groups: Contextcitate, those in common with Mark and from the Septuagint, and Reflexionscitate, those not found in Mark and from the Hebrew text. Holtzmann then argued that Matthew shows his own preference for the Hebrew text when on his own but used Mark (actually a proposed Urmarcus) as his cue to the Septuagint in other instances.

Despite the fact that Holtzmann is acclaimed the figure who set the two-document hypothesis firmly in stone, his argument based on old Testament citations has not been the subject of systematic study. Even Burnett Hillman Streeter's monumental and comprehensive work, The four Gospels: A Study of Origins:a, which for more than a generation served to close the book on the synoptic problem in its presentation of the "final solution," makes no mention of this argument. I propose, therefore, on the suggestion of Holtzmann's argument, to examine the OT quotations in the synoptic gospels in order to determine if the variety of text-types exhibited fall into a pattern which supports either the twodocument hypothesis or the Griesbach position. Discussion will be limited to these two theories because they are the two most prominent theories regarding the synoptic problem. As well, for quotations appearing in more than one gospel, analyses will be made of the synoptic relationships for the individual quotations. Here the two-document and Griesbach hypotheses will be hypothetically assumed in turn to see which better explains the text of the quotation as it 
appears in the various gospels. For example, if Matthew clearly adapts his form of the quotation to the context of a narrative identical for Matthew and Mark, in such a way that Mark's alteration of the Matthean form of the quotation would make mo sense, the two-document hypothesis would be favoured for that quotation. Moreover, it is easy to see why a gospel writer might alter a quotation to conform it more closely to the septuagint, whereas movement away from the Septuagint, unless grammatically conditioned by the gospel context of the quotation, is less likely. Hence, closer conforming to the Septuagint may indicate that the less exact quotation has been copied and altered. These are a few of the kinds of argument that can be used to support one hypothesis over the other for an individual quotation. However, it is dangerous to generalize here. These arguments must be applied to the unique situation of each quotation.

This research will be limited to the analysis of explicit OT quotations and will not deal with mere allusions to OT passages. The reason for this is simply one of practicality. There are far too many allusions for their adequate study to be included here, but such a study is a project worthy of another day.

It is not always clear whether a text is an explicit quotation or an allusion. However, there are rough guidelines for distinguishing the two. A quatation will normally have an introductory formula indicating that the 
following text is a quotation. Should this formula be lacking, evidence that it is the intention of the writer to make an explicit quotation will suffice. This evidence could take the form of several words identical to an oT text. On the other hand, if the text has no more than a fleeting resemblance to a possible OT text, then even an introductory formula might not indicate a biblical quotation.

In Holtzmann's time there did not yet exist a reliable Greek text of the gospels or of the LXX. Today the existence of critical editions of old and New Testament texts and the advantage of recent advances in our knowledge of the status of old Testament texts in the first century, give an urgency to the need for a re-examination of the quotations. It has been remarked that Streeter's 1924 monumental work may have been the last comprehensive study which seriously related the two disciplines of textual and synoptic criticism. 30 The results of this proposed research could be of interest, as well, to those concerned with the status of old Testament texts in the first century. Graham stanton, in observing that the fluidity of both Hebrew and Greek texts has not been adequately dealt with by New Testament symoptic scholarship, quotes K. Stendahl:

New data are about to allow new and better founded hypotheses about text forms available in the first century A.D. Such a promising yet unfinished state of affairs both hinders and helps further progress in the study of the Matthean quotations. It makes it more probable that readings found in Matthew could witness to text forms actually available in Greek, prior to 
Matthew. It makes the recourse to testimonies less compelling as an explanation of textual peculiarities. $\$ 7$

Stanton continues, in his own words:

The importance of this work for the student of Matthew's gospel can hardly be over-estimated. Yet even though stendahl drew attention to these new advances in scholarly knowledge nearly twelve years ago, they have not yet been taken seriously in Matthean scholarship.

Outline of Proposed Research

Having introduced the significance of the proposed research within the context of contemporary scholarship on the two-document hypothesis, and, on a wider plane, synoptic scholarship in general, we shall now summarize the direction this research will take chapter by chapter.

Chapter two: This chapter will provide a detailed analysis of Holtzmann's argument.

Chapter three: Here will be given a detailed summary and analysis of three works in the scholarly literature on ald Testament citations in the symoptic gospels: Krister Stendahl, The School of St. Matthew and its Use of the Old Testamentre, Robert Horton Gundry, The Use of the old Testament in St. Matthew's Gospelsa, and George M. Soares Prabhu, The Formula Quotations in the Infancy Narrative of Matthew: An Enquiry into the Tradition History of Mt 1-2.40 This chapter has three purposes: to locate the investigation within the context of the scholarly literature, to further 
clarify where the specific problems within the work on citations lie, and to examine some of the methodological issues involved in work of this nature.

Chapter four: This chapter will examine all the citations of the old Testament which are common to at least two of the synoptic gospels. Here the primary objective is to determine the textual character of the citations.

One of the first questions to be answered is whether or not Matthew's citations can be as neatly grouped as Holtzmann's argument would suggest. Recent scholarship has focused on the "fulfilment quotations" in Matthew, which somewhat parallel Holtzmann's Reflexionscitate, but there is no consensus with regard to the definition of this group. Can the group be clearly defined as a group vis-a-vis Matthew's other citations? Could it be shown, for example, that all of these quotations have a common text-form, that they all come from a specific OT source or are handled in the same fashion by the evangelist? If so, and if it can also be demonstrated that the citations shared by Mark and Matthew are all of a text-type different from that shown in quotations unique to Matthew, this might suggest Matthew's dependence on Mark for common quotations.

As one approach to the above questions, we shall investigate the possibility that Matthew may have used in places a Greek text of the old Testament which showed revisions toward the Hebrew text. The existence of such 
texts in the first century has been demonstrated by

Dominique Barthelemy41. The relevance for the New Testament is evident from the work of Dietrich-Alex Koch on the OT quotations in the Pauline epistles ${ }^{42}$. If there is evidence that this is the case in Matthew, there would be less need for a number of hypotheses suggested by earlier scholarship to explain deviations in Matthew from standard Greek and Hebrew texts known to us: that Matthew used testimonies as his source of citations, that Matthew was a targumist (rendering his own eclectic translations), that Matthew was quoting freely from memory. If there is evidence that Matthew does use such texts, does he use them only in those citations unique to his gospel, or does he use them consistently throughout? If the former, this may suggest reliance on Mark. Here Matthew would use his favourite OT text when quoting on his own, but stay with Mark's version when Mark has the quotation. If Matthew had been first to cite a particular OT passage, it would be in his favourite OT text, and a common text-type might be expected in all the quotations of the gospel.

Chapter five: In this chapter all citations occurring in only one of the three synoptic gospels will be examined. Here we shall try to determine how each evangelist handles the OT text when on his own. Here too we shall have an opportunity to see what OT text(s) the evangelists prefer to use when they cite the OT. 
Chapter six: Here we shall draw conclusions. The examination of old Testament citations and their specific contexts can aid in the resolution of this particularly unruly problem in New Testament studies. 
NOTES

1 G. M. Styler, "The Priority of Mark", in C. F. D. Moule, The Birth of the New Testament (2d ed.; San Francisco: Harper \& Row, 1982) 285.

= Leipzig: Engelmann. In this early work Holtzmann posited a source (Urmarcus, which he designated "A") behind Mark. He later discarded this source (Lehrbuch der historisch-kritischen Einleitung in das Neue Testament ( $3 d$ ed.; Freiburg: J. C. B. Mohr, 1892) 351-3, 537.).

3 The Roots of the Synoptic Gospels (Philadelphia: Fortress, 1986) 5 .

4 The Synoptic Problem: A Critical Analysis (New York: Macmillan, 1964; 2d ed., Dillsboro, North Carolina: Western North Carolina Press, 1976).

- Farmer entitles his first two chapters, "The Essential Developments in the Pre-Holtzmann Period" and "The Holtzmannian synthesis", respectively, and then proceeds in the remainder of his history to show how this synthesis was adopted by the scholarly community.

- Ibid., 36.

7 The Interpretation of the New Testament, 1861-1961 (London: Oxford University Press, 1964) 110.

- To cite only one example from the many: Werner Georg Kümmel, The New Testament: The History of the Investigation of Its Problems (Nashville: Abingdon, 1972) 151. Ben F. Meyer, on the other hand, in what is perhaps a back-handed but witty compliment, disparages "the transition from Strauss to Holtzmann ... as a passing from ill-starred genius to professorial industry" (The Aims of Jesus (London: SCM, 1979) 37 .

- Ibid., 36.

10 Bernard Orchard, Matthew, Luke \& Mark (Manchester: Koinonia, 1976) 7.

11 Holtzmann himself, as he stated in the opening paragraph of his 1863 work, was quite aware that this work would impress many theological readers as an exercise in ingenuity of doubtful worth, and so went on to claim that 
this is the only way to initiate the debate on the history of Jesus' time (Die synoptischen Evangelien, 1).

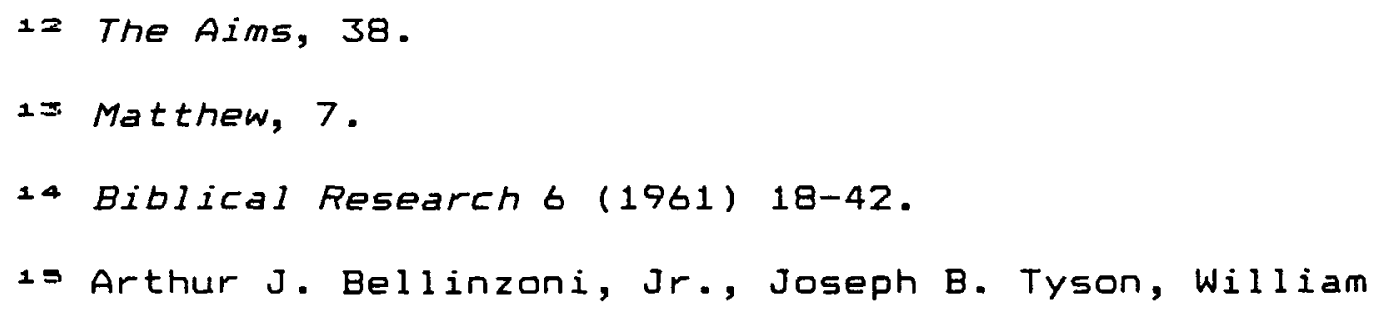

16 Bo Reicke, (Philadelphia: Fortress, 1986).

1) Bernard Orchard, Harold Riley, (Macon, Georgia: Mercer University Press, 1987).

19 For details on seminars, conferences, and colloquia previous to 1983 , even including lists of those noteworthies who attended these assemblies, see William R. Farmer (ed.), New Synoptic Studies: The Cambridge Gospel Conference and Beyond (Macon, Georgia: Mercer University Press, 1983) vii$x \times i i i$.

10 For papers presented here, see Bernard Orchard and Thomas R. W. Longstaff (eds.), J. J. Griesbach: Synoptic and Text-critical Studies, 1776-1976 (Cambridge: Cambridge University Press, 1978.

so For papers presented here, see farmer (ed.), New Synoptic Studies.

$=1$ "The Priority of Mark and the ' $Q$ ' Source in Luke", in Jesus and Man's Hope, vol. 1 (Pittsburgh: Pittsburgh Theological Seminary, 1970) 133.

$z=$ To mention only two examples: D. E. Garland, The Intention of Matthew 23 (Leiden: Bril1, 1979); J. D. Kingsbury, The Parables of Jesus in Matthew 13 (London, 1969).

as "The Origin and Purpose of Matthew"s Gospel: Matthean Scholarship from 1945 to 1980", in Wolfgang Haase (ed.), Aufstieg und Niedergang der römischen welt, 2.25 .3 (Berlin: Walter de Gruyter, 1985) 1899.

=4 Matthew's Advice to a Divided Community: Mt. 17:22 18:35 (Rome, 1970) 7-10. 
$=$ Armin Kretzer, Die Herrschaft der Himmel und die Söhne des Reiches (Würzburg: Echter, 1971).

zo The Formula Quotations in the Infancy Narrative of Matthew (Rome: Biblical Institute Press, 1976) 43.

$\Rightarrow$ "The Origin", 1896.

za "The Griesbach Hypothesis in the 19 th Century", Journal for the Study of the New Testament 3 (1979), 48.

29 "On the Gattung of Mark (and John)", in Jesus and Man's Hope, vol. 1 (Pittsburgh: Pittsburgh Theological Seminary, 1970) 101-102.

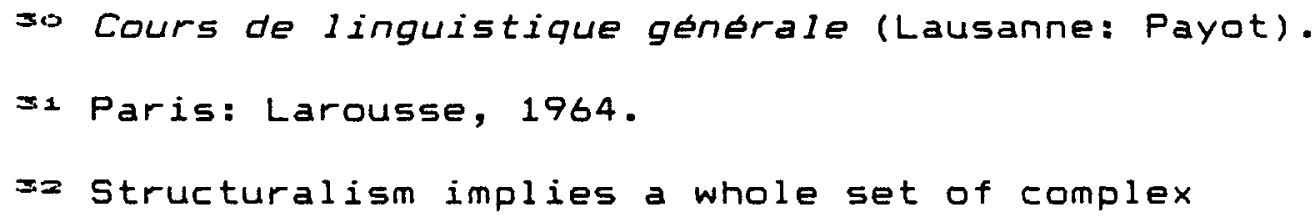


CHAPTER TWO: HOLTZMANN'S ARGUMENT

The Concept of an Urmarcus

To understand fully Holtzmann's argument from old Testament citations we need to see it within the context of his 1863 work, Die synaptischen Evangelien: Ihr Ursprung und geschichtlicher Charakter.

A major reason for doing so is to draw attention to one of Holtzmann's main sources for the synoptics, his "A" (Urmarcus) document. This source gets underplayed, at the same time that the priority of Mark is spotlighted, in standard histories of New Testament criticism. Werner Georg Kümmel, for example, writes, "[Holtzmann] demonstrated most convincingly... that Mark's Gospel was a source of the two other Synoptics .... Holtzmann differentiated a source back of Mark (that he called ' $A$ ') and tried to prove that Mark had abbreviated this source by deleting the discourses it contained, but all this was not an essential part of his argument." = Stephen Neill writes, "Holtzmann has, of course, his own eccentricity, such as must be allowed learned men. He invents a wholly unnecessary document $A$.... But, when allowance has been made for one such aberrant hypothesis, 
with Holtzmann we are in the main on solid ground. Mark is the original apostolic document." $=$ Why, we must ask, would someone of the acclaim of Holtzmann make such a centrepiece of $A$ (he devotes one of five major divisions of his book to "Quelle A"; another he devotes to "Quelle L", so that if we force his thesis into a "two-document" mould, Mark would not seem to be one of the two documents) if it is "not essential" ( qua Kümmel) or "unnecessary" (qua Neill)?

Holtzmann, in his survey of previous scholarship on the synoptic problem, believed there was only one point of consensus: that the three symoptic gospels are all dependent upon one common Grundschrift or ur-gospel.4 The concept of an ur-gospel allowed the agreements among the synoptic gospels to be explained by the three synoptic evangelists each using the same ur-gospel independently of one another, rather than, as an alternative explanation has it, copying one another. Holtzmann, in outlining the history of the synoptic problem, recognized this distinctive grouping of theories, placing them under the headings "Die Urevangeliumshypothese" and "Die Benutzungshypothese", respectively. =

There is narrative material found in both Matthew and Luke which is not in Mark and cannot be in the logia if this is regarded as simply a collection of sayings. Holtzmann gets around this difficulty by including it in his Urmarcus. 
Holtzmann entitles another part of his history "Die Marcushypothese". It is the Marcushypothese which Holtzmann states in the preface to his book will be his aim to establish. Nevertheless, just what Holtzmann means by "Marcushypothese" is not immediately clear.

Our quest for Holtzmann's definition of "Marcushypothese" comes up short in the section under this title. He rarely uses the word. Where he does, he lists some scholars who "mehr oder minder in dasselbe Fahrwasser der Marcushypothese lenkten ... ein". Here is represented a great diversity of theories: Mark as a source for Matthew, Matthew and Mark as mutual1y dependent, Matthew and Mark using a common source.?

Holtzmann, in writing about Karl Lachmann, speaks of the priority of Mark "in diesem Sinne":

Schon Lachmann hatte keineswegs in diesem Sinne für die Priorität des Marcus votirt, vielmehr kommt er auf einen ursprünglichen Kanon der evangelischen Geschichte hinaus, der besonders rein im Marcus erhalten wäre, während Matthäus und Lucas manches alterirt hätten.a

This suggests that for Holtzmann Marcan priority does not simply mean Mark is a source for the other two synoptics. Marcan priority could also mean priority in a non-temporal sense, that Mark is a more trustworthy witness to the urgospel than either Matthew or Luke. This is made more explicit when Holtzmann notes, "Besonders aber seit Ewald's Auftreten verstehen die Meisten unter der sogenannten Priorität des Marcus blos Dies, dass er im Verhältnisse zu 
den beiden Andern den ursprünglichsten Typus der Erzählung erkennen lasse."ه This makes clear the meaning of "Marcushypothese". It means Marcan priority, but not simply in the sense in which we would speak of Marcan priority today. Instead, "Marcushypothese" includes the theory that our Mark gives a better witness to the ur-gospel than the other two synoptics.

Holtzmann devotes several pages to the issue of whether it was an Urmarcus or our Mark that was a source for Matthew and Luke.10 He shows how passages found only in Mark, and others found only in Matthew and Luke against Mark, provide difficulties for those who would like to posit our Mark as a source rather than an Urmarcus.11

Taking the example of such passages as his lead, Holtzmann proceeds to elaborate five types of evidence he thinks demonstrate that our canonical Mark must have been preceded by an Urmarcus: ${ }^{2}=$ (1) In some places Mark abbreviates in such a way that the clarity of the narrative is destroyed. (2) Some narratives are obviously more original in the form in which they appear in Matthew, or in Mark contain more mythical elements. (3) Mark often shortens speeches to the point where they lose continuity. (4) Matthew and Luke use several words and expressions in common against Mark. (5) Matthew and Luke often agree in formulae and sentences which are left out, against Mark. Whether or not these cases are decisive is not at issue 
here. What is important is that Holtzmann believes he has a strong case against our Mark as source for the other two synoptics, and for an Urmarcus.13

Holtzmann characterizes Mark as, at minimum, leaving out much"4 of the Grundschrift which he labels "A"1=. He goes on to compare Mark with $A$, giving details of how the two differ.14 His research proceeds along two 1 ines: (1) to investigate the content and form of $A ;(2)$ to determine the relations of the synoptics. The latter is accomplished by a series of six critical studies: (1) the composition of Matthew, (2) the composition of Luke, (3) doublets, (4) 01d Testament citations, (5) stylistic characteristics, (6) the different modifications of the original by the three synoptics. Holtzmann then claims that any of the above studies (Hauptkriterien) by itself can determine the relationship of the synoptic gospels.17 In our case we shall examine Holtzmann's study of old Testament citations.

Holtzmann's Argument

Having set forth in earlier chapters his solution of the synoptic problem, that Matthew, Mark, and Luke independently used a common source $A$, and that Matthew and Luke independently used a common source L, Holtzmann proceededie to show how the form of the ald Testament quotations in the synoptic gospels can be explainedio by 
his solution, but not by other attempted solutions, of the synoptic problem.

Holtzmann's contribution here is to relate previous scholarly discussions of the OT quotations to the synoptic problem and show how his solution to the synoptic problem can explain difficulties discussed in earlier examinations of the quotations.

He makes special reference to two notable examinations of the quotations, those of Carl August Credner and Friedrich Bleek. The former concluded that Matthew quoted freely from a Septuagint ( $L X X$ ) text, but one which, in the case of certain messianic passages, had been compared with, and altered towards, the Urtext (MT). Holtzmann agreed with Bleek's view that those citations in Matthew which occurred "mitten im Context der Erzählung" originated in the LXX, while those which "aus der eigenen Reflexion des Evangelisten stammenden" came from the Grundtext (MT). $=0$ Citing other scholars, Holtzmann notes that the exception is Matt 1:23, which belongs to the evangelist but comes from the LXX.

Holtzmann applies Bleek's observations to the synoptic problem by claiming that those citations in Matthew which occurred "mitten im Context der Erzählung" not only originate in the LXX, but do so precisely because Matthew finds them in his A source, a source "in welcher allein der Grundsatz, nach LXX zu citiren, streng durchgeführt war". $=1$ 
On the other hand, those citations in Matthew which "aus der eigenen Reflexion des Evangelisten stammenden" came from the Grundtext (MT) because, while Matthew was a Jew who was familiar with, and equally fluent in, both the Hebrew and Greek versions of the OT, he nevertheless preferred the Hebrew text when quating the OT on his own.

Holtzmann begins his analysis by listing the ten OT citations which are found only in Matthew, and into which his characteristic formula, hina plêrothê, is inserted: 1:23 (Isa $7: 14-16) ; 2: 15$ (Hos $11: 1$ ), 18 (Jer 31:15), 23 (Isa $11: 1$ ); 4:15-16 (Isa $8: 23 ; 9: 1$ ); 8:17 (Isa 53:4); 12:17-21 (Isa 42:1-3); 13:35 (Ps 87:2); 21:5 (Zech 9:9); 27:9 (Zech $11: 12)$

of the above, 2:15,23 correspond accurately to the Hebrew (Urtext), which in this case has a different meaning than the LXX. Matt 27:9 renders the Hebrew very freely, but without any suggestion of the LXX. One citation, 1:23, predominantly agrees with the LXX, because only in this form, Holtzmann argues, does Isa $7: 14$ have a messianic sense. The rest of the above citations are based on the Hebrew text, "doch so, dass der Ausdruck der LXX Einfluss übt." For example, the first half of 13:35 agrees with the LXX, while the second half agrees with the Hebrew. Holtzmann believes that whenever Matthew adds to the tradition his own DT quotations, as opposed to those he finds in $A$ or some other gospel source, he shows influence 
of the Hebrew. On this basis he concludes that Matthew preferred the Hebrew text, with the one exception (Isa 7:14) for which he had a definite motive for departing from the Hebrew.

Holtzmann goes directly into a discussion of the Contextcitate without, unfortunately, first defining Contextcitat. That he prefaces the term with "sogenannten" suggests that the expression is not his, but one current in contemporary scholarship. Again, since Holtzmann does cite Bleek and credit him with the correct classification, we shall assume that this is whence he takes his definitions. In contrast to what we have assumed Holtzmann would call the Reflexionscitate (those introduced by the narrator), the Contextcitate appear in the context of the narrative on the lips of a character.

Holtzmann notes that the Contextcitate in Matthew bear clear witness in most cases to the LXX. However, there are exceptions, and these are such "dass nur die Annahme einer Quelle im Sinn von A, nicht aber... die Marcushypothese den Schlüssel zum vollen Verständnisse der Sachlage bietet."z= First Holtzmann notes that there are seventeen citations which Matthew and Mark have in common; these would have been taken from $A$. Ten of these agree verbally. Four contain "nur unbedeutende Variationen": Mark 7:10 = Matt 15:4; Mark 10:7-8 = Matt 19:5; Mark 12:29-30 = Matt 22:37; Mark 15:34 = Matt 27:46. In these cases Matthew often 
follows the LxX even where it differs from the Hebrew text. In two passages, Mark 4:12 = Matt 13:14-15; Mark 10:19= Matt 19:18-19, Matthew follows the LXX more closely than Mark. Here Matthew has clearly followed A more accurately than Mark. Holtzmann reminds us of Mark's propensity to abbreviate. He also notes that Matt 19:196, which refers to Lev 19:18, and the tês poimnês found in Matt 26:31 but not in the parallel Mark 14:27, are added by Matthew.

The final citation of the seventeen common to Matthew and Mark, Matt 22:24, presents a case where Matthew illustrates his preference for the Hebrew to such an extent that he modified the text found in A. Evidence for this is the influence of the Hebrew text found in the word epigambreuseis, which is missing in the parallel Mark 12:19. Holtzmann claims the word was also missing from A. Matthew took an allusion (as found in $A$ ) to Deut 25:5, and gave it the form of a direct citation.

Holtzmann then notes that the citations in the narrative on Jesus' temptation are from the LXX with slight modification. These citations are found only in Matthew and Luke, not in Mark. The narrative found in Mark abbreviates $A .=$ That Matthew and Luke derived the quotations from $A$ is clear from their septuagintal form.

The quotations in Matt $22: 32,37=4$ and their parallels in Mark present a problem. Holtzmann's theory would suggest that the source of these quotations must be $A$, and that, 
therefore, they must be based on the LXX. However, some scholars previous to Holtzmann had argued that they are based on the Hebrew, not the LXX. Here Holtzmann notes Ritschl's observation that $\vee 32$ corresponds to LXXA and $\vee 37$ corresponds more closely to a variant reading in the Lxx than to the Hebrew. He also counters the notion that Matt $3: 3$ is a Reflexion of Matthew by pointing out that all three synoptics have this citation, and therefore it is found in A; appropriately, it is Septuagintal.

The next major issue Holtzmann examines concerns those Contextcitate in Matthew which do not come from the Lxx. For these citations, he argues, Matthew is totally independent of A. In this group belongs "das Contextcitat der Vorgeschichte", Matt 2:6 (= Mic 5:1). While here some influence may be conceded to a Greek text like that of LXXA, the predominant witness is to the Hebrew text. Holtzmann claims that, unlike Bleek's theory which is unable to explain a citation which appears in the context of a narrative and is from the Hebrew, his theory can. His explanation is that Matthew himself created the Vorgeschichte in which the citation is situated.

Holtzmann mentions a few more Contextcitate which do not come from the $L x x$, and are, therefore, not from $A$. The citations of the sermon of the mount, Matt 5:31,33, bear witness neither to the LXX nor to the Hebrew text. This is because they come from a secondary Matthean sourcess. From 
this source as well comes Matt 5:4, which witnesses to LXX Ps $37: 11$

As Holtzmann sees it, in only one passage in Mark does the OT quatation not come from the LXX, and hence from $A$ : Mark 1:2 (= Mal 3:1). The citation of Mark 1:2, formed according to the Hebrew, is also found in Matt 11:10 = Luke 7:27. In the case of Matthew and Luke, Holtzmann believes the citation is taken from L; but how can the presence in Mark (who otherwise finds his citations in $A$, al though he may abbreviate these at times) of a citation based, not on the LXX, but on the Hebrew, be explained? Unless it can be shown how Mark derived the citation from a source other than A, the view that $A$ derives quotations exclusively from the LXX is invalidated.

Holtzmann begins by noting that contemporary scholarship had suggested treating Mark 1:2,3=- as a parenthetical expression. Holtzmann suggests $\vee 3$ was an insertion or marginal gloss found in $A$. Thus $A$ read, "The beginning of the gospel of Jesus Christ, the Son of God. (As is written in the prophet Isaiah, 'Behold the voice of one crying in the wilderness, "Prepare the way of the Lord, make straight his paths."') John the baptizer appeared in the wilderness." This avoids the difficulty of having A present a citation by another prophet under the name of Isaiah, as would be the case if A were identical to Mark. But the quotation from Malachi (which Matthew and Luke had taken 
from source $L$ ) came to be seen as describing the mission of John the baptizer. This led Mark to insert it between the citation formula in $A$, which introduces Isaiah as the speaker, and the actual citation from Isaiah. 2 Since Mark left the citation formula intact, the result was the anomaly of a quotation from Malachi preceded by a citation formula referring to Isaiah.

The next case Holtzmann examines is that of the double occurrence (Matt $9: 13 ; 12: 7$ ) of a citation from Hos 6:6, eleas thelo kai ou thysian. This comes from the LXX, he claims, because there hesed is usually translated as eleos. Because it comes from the LXX, we might next assume that it is a part of A which both Mark and Luke ignored. The two separated contexts in which the citation appears in Matthew (9:9-17; 12:1-8) are parallel with two consecutive passages in Mark (2:13-22, 23-28), suggesting that the citation may have been located in $A$ in the area which is parallel to this part of Mark. Dn the other hand, Holtzmann notes that in both locations in Matthew the citation appears to be an insert: at 12:7 it does not form a coherent whole with the preceding two verses; at 9:13 it falls between a universal maxim and its application. That Matthew uses gar in 9:13 and 12:8 does not conceal the fact that there is no real logical connection here. Holtzmann concludes that Matthew in both cases took the Septuagintal citation of Hos 6:o from the margin of $A(=$ Mark $2: 13-28)$ and worked it into both 
pericopes of this larger passage in such a way that at Matt 12:7 it referred back to its other use at Matt 9:13, making of the latter an instruction which was not followed.

Holtzmann offers a few characterizing remarks on each of the three evangelists. He claims that Matthew regularly abbreviates or omits parts of $A$ when introducing citations of his own. As examples, 8:16-17; 12:17-21; 13:35; and $21: 5$ are cited.

In Luke, with the single exception $7: 27=\operatorname{Matt} 11: 10=$ Mark 1:2, which is from the Hebrew, all citations are from the Lxx. Usually, when Luke cites the ald Testament, he uses A. Here, however, he uses $L$, in which citations are from both the Hebrew text and the LXX. When Mark's quotations differ from those of the other gospels, he "blos gedächtnissmässige Abweichungen bietet." Most of Mark's citations occur "im Context", that is, on the lips of the characters in the narrative. Only in the introductory passage is this not the case. Because Mark 15:28 is copied from Luke 22:37 and almost without exception deleted by contemporary critical authorities, Mark 1:3 presents the single Reflexionscitat found in $A$.

Holtzmann concludes his discussion of OT citations by listing other citations and allusions to OT passages found in Mark and, hence, in $A$. These are as follows: (1) explicit quotations: $7: 6,7,10 ; 11: 17 ; 12: 10,36 ; 14: 27 ;$ (2) less clearly defined quotations: $2: 25-26$; $12: 19,26$; 
references to the OT: 1:44; 13:24; 15:34; (4) allusions (although some are allusions only because Mark has suppressed the quotation: $4: 12 ; 9: 44,46,48,49 ; 10: 3,6,7,19$; $12: 29-31 ; 13: 14) .28$

In summary, source $A$, in which all DT quotations are Septuagintal, provides all the OT quotations found in Mark (apart from 1:2), all the OT quotations found in Luke (except $7: 27$, which is from $L$, and perhaps 10:27), and many of the OT quotations found in Matthew. With the exeeption of a few OT quotations which come from other sources, those OT quotations in Matthew which are not from $A$, Matthew selects himself, preferring the Hebrew over the LXX. 
NOTES

1 Leipzig: Engelmann.

= The New Testament: The History of the Investigation of Its Problems (Nashville: Abingdon, 1972) 151.

: The Interpretation of the New Testament, 1861-1961 (London: Oxford University Press, 1964) 110-111.

4 Die synoptischen Evangelien, 66.

= Ibid., 15-20.

- Ibid., xiv.

7 That "Marcushypothese" can serve as an umbrella term to designate several theories is confirmed in Holtzmann, Hand-commentar zum neuen Testament: Erster Band: Die Synoptiker (2d ed.; Freiburg: Mohr, 1892) xv. Here, with the introductory clause, "Die Marcustheorie in ihren verschiedenen Formen ist vertreten in folgenden werken", Holtzmann lists several works, among which is Weisse's 1838 publication in which Mark, rather than an ur-gospel, is posited as a source for Matthew and Luke, and Holtzmann's own 1863 book in which an ur-gospel serves as source for all three synoptics.

- Die synoptischen Evangelien, 58.

-Ibid., 59.

10 Ibid., $58-64$.

11 Ibid., 59.

$1=$ Ibid., 60-63.

$1=$ While Holtzmann, in Die synoptischen Evangelien, definitely sees Mark as merely a good witness to the urgospel but a document separate from it, he has adopted a different position by the time his later works were published.

An examination of Holtzmann's later works does little to resolve why he may have changed his position. In his Hand-Commentar, in fact, Holtzmann does not centre his attention on the Mark versus Urmarcus issue. He uses phrases, here and there, which indicate almost a neutrality: "Mc, resp. Urmc" (p.4.), "unser Me, bzw., falls die 
Urmchypothese Bestand haben soll" (p.24.). He relegates this issue to a mere point of historical interest, noting that some scholars vote for an Urmarcus of varying likeness to our Mark while others opt for the direct use of Mark by the other synoptics (p.4.). Holtzmann often writes in such a way that one could easily read him to mean that Mark was a source of Matthew and Luke; for example, in one of the only instances where he seems to state a position on this issue: Die Forschungen, deren Ergebniss in diesen Sätzen niedergelegt ist, führten mit Nothwendigkeit auf eine Ansicht, derzufolge die synopt. Texte ihre gemeinsame Wurzel im Mc-Text besitzen, und daraus wieder entsprang die Vermuthung, dass der ursprüngliche Plan der evang. Geschichtserzählung sich noch in unserem 2. Evglm erhalten habe. (p.6)

This could mean only that in Mark we have the best witness to an earlier ur-gospel, in the non-temporal sense of Marcan priority.

In all of this Holtzmann's main concern is to give an account of the history of the tradition concerning Jesus. life. He gives greater emphasis to the role of the oral tradition and the concerns and contributions of the early church in this book (especially pp.13-22). In this way one might almost see here in Holtzmann a foreshadowing of later form and tradition criticism. He seems open to the question whether any common source of the synoptics was oral tradition, a written ur-gospel, or a combination of both in several layers (p.3). He places great faith in Eusebius. witness to Papias ( $P .9$ ), which is why he sees Mark as best preserving the tradition concerning Jesus. Above all, Holtzmann here seems less concerned with the details of how the three synoptics came into being than with using what we can find in Mark as a mine of historical fact.

In Holtzmann's other later work, Lehrbuch oer historisch-kritischen Einleitung in das Neue Testament (3d ed.; Freiburg: Mohr, 1892), he states, in fine print, that he has changed his earlier position on several points (p.350). One of these is that he now believes Luke has a copy of Matthew. Because of this the most important reason for differentiating between Mark and an Urmarcus disappears. He quickly and summarily disposes of the ur-gospel position in a manner of writing which hardly falls short of sarcasm (pp.351-3). As one reason against an Urmarcus, vis-a-vis Mark itself as a source, Holtzmann asks how three evangelists could have known to arrange their material so that where one failed to follow the order of the original the other two would follow it faithfully. Holtzmann offers this point as a proposition in his new theory that Luke had access to Matthew, as well as Mark (although he does not make the connection here). 
14 Die synoptischen Evangelien, 103. In the following section (ibid., 103-107) Holtzmann shows how the three synoptic gospels are modifications of the ur-gospel.

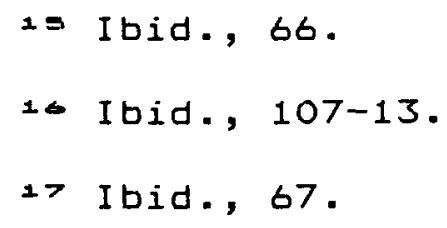


chapter provide proofs for the validity of Holtzmann's form of the two-document hypothesis. It could also mean that each section furnishes an experiment, a test, an example, or a check which, if the experiment goes the way the experimenter hopes it will, will provide further confirmation in the direction of a positive proof; Holtzmann does use the term Hauptkriterien which would suggest that an examination of old Testament citations could provide a criterion or test to confirm or deny some hypothesis, but which would not by itself fully prove the hypothesis. Holtzmann does not make any categorical statement that he claims to be giving a sufficient proof. At the end of the first paragraph of his discussion he says that he will present his results without examining in detail all the individual citations. This is not what one would expect if a complete and sufficient proof or argument were intended. Holtzmann, then, is offering his discussion of the OT citations, not as a sufficient proof of his solution to the synoptic problem, but as confirmation of his solution.

Perhaps the fact that Holtzmann offers his analysis of OT quotations as confirmation, rather than proof, might help to explain why his discussion of OT citations in relation to the two-document hypothesis has gone unnoticed in the scholarly literature on the subject.

=0 Bleek (Beiträge zur Einleitung und Auslegung der heiligen Schrift. I. Beiträge zur Evangelien-kritik (Berlin: G. Reimer, 1846) 56-9.) differentiated between two groups of ald Testament citations: (1) fulfilment (Erfüllung) citations in which Matthew presents his own idea of what event fulfils what citation and then translates from the Hebrew even where it differs from the LXX in wording and meaning; (2) the occasional reference to or use of old Testament citations on the lips of characters found in a narrative, in which Matthew uses the LXX sometimes verbatim and sometimes freely, with the possible exception of 11:10 and 26:31, where the Hebrew may have been considered. Bleek considered Matthew an educated Jew who wrote in Greek, knew the LXX and MT, and used one or more Greek gospels in which were old Testament citations of the second type.

$=1$ Die synoptischen Evangelien, 261.

$z=$ Here "Marcushypothese" has the narrow sense, the theory that Mark (the text we have today) was the source for Matthew and Luke.

2:= Mark adds ên meta tôn thêriôn. Holtzmann claims this could not have been in $A$ or Matthew and Luke would not have overlooked it. This confirms his position that all three synoptic gospels use a common source, in opposition to the 
Marcushypothese which posits our Mark as a source for the other two synoptics (Die synoptischen Evangelien, 69-70).

32.

=4 Holtzmann mistakenly refers to $\checkmark 31$ here, meaning $\vee$

$=$ This source which is used among the synoptics by Matthew alone, especially in chaps. 5 and 23 , is described by Holtzmann, ibid., 162-3.

26 Holtzmann says $v \vee 3,4$, but he must have meant $v v$ 2,3 , as he writes, "das hôs gegraptai als Parenthese zu nehmen, und archê mit egeneto zu verbinden".

27 One wonders where Holtzmann supposes Mark got this tradition that the Malachi citation was connected with John the baptizer, especially when he insists Mark had only one source, A (ibid., 163).

= The final list we present here, separate from the other four because, as Holtzmann disparagingly remarks, "Dass aber in ebenso bewusster Weise auch ... [the list] auf das Alte Testament hingezielt sei, ist Privatdogma der Wilke'schen Kritik geblieben." The list (we have retained Holtzmann's "ff.", rather than assume it means "the following two verses") is: $1: 12$; $3: 13 f f, 20-21 ; 6: 17 f f$; $7: 24 \mathrm{ff} ; 8: 11 \mathrm{ff} ; 9: 2 \mathrm{ff}, 14 \mathrm{ff} ; 11: 1 \mathrm{ff} ; 14: 26 \mathrm{ff} ; 15: 1 \mathrm{ff}$. It seems strange that $14: 26 \mathrm{ff}$ is included in this list, seeing that 14:27 made Holtzmann's "ausgesprochene Citate" 1 ist. 
CHAPTER THREE: OLD TESTAMENT QUDTATIONS IN THE SYNOPTICS

\author{
No effort of modern scholarship has pursued Holtzmann's \\ lead in systematically examining old Testament citations \\ with respect to the symoptic problem. Nevertheless, because \\ Holtzmann's argument relies on a distinct grouping of these \\ citations, it will be helpful to consider a few of the more \\ influential and recent studies of old Testament citations in \\ the synoptic gospels in order to clarify the issues \\ regarding classifying the citations into groups.' \\ Krister Stendahl \\ Stendahl's book, The School of st. Matthew and its Use \\ of the old Testamenta, was first published in 1954. In 1968 \\ it was reprinted as a "second edition", in which the body of \\ the work went unchanged and a preface was added. $=$ In this \\ preface Stendahl remarks that in spite of the prominence \\ given in the title to a school, the "primary justification" \\ for his study was the analysis of the OT text in the \\ gospel.4 Indeed, the original work grew out of Stendahl's \\ early involvement with the study of the Qumran texts. \\ Stendahl begins his analysis of the quotations in \\ Matthew by tracing discussion of the textual peculiarity of
}


Matthew's manner of quoting the oT back at least to Eusebius and Jerome.s He then makes the important observation that "the study of quotations from the OT standing in the NT can have many functions and the way in which it is handled is in part coloured by the purposes the various students had behind their studies. It is of value to note this to arrive at a true estimate of the different results." - Perhaps it would seem to go without saying that whenever proving a thesis is at stake, it would be naive not to expect some forcing of the data (if only in its very selection).? Nevertheless, Stendahl makes a point that can easily be lost sight of, particularly in an area such as textual studies where minutiae can seem to fill the whole field of vision. In this regard, therefore, it is of more than passing interest to note that the majority of major works on OT quotations in the NT are of the genre in which presentation of a thesis is of the essence, the doctoral dissertation.a Hence, this should be kept in mind when examining the minutiae.

Stendahl prefaces his examination of the quotations by defining a few terms. In decided understatement he observes, "The question of where to draw the line between quotations and allusions is a problem in itself." Stendahl tries to avoid this difficulty by restricting his investigation to those passages introduced by a formula and those which, although lacking a formula, are conscious 
quotations, judging from the context, or which agree verbatim with some passage in the LXX or MT.

Stendahl also begins with the conception of two general groups of quotations. Matthean quotations with parallels in one or more of the other symoptics are said to have a fairly pure LXX text. Contrasted with this group are the "formula quotations" (the same quotations as those referred to in German as "Reflexionscitate"). These have a text form which differs noticeably from the LXX.

Stendahl then examines in considerable detail the quotations in Matthew which have parallels in Mark or in Mark and Luke, and those in Matthew with parallels in Luke, including two quotations peculiar to Luke. He then examines the eleven formula quotations (Matt 1:23; 2:6; 2:15; 2:18; $2: 23 ; 4: 15-16 ; 8: 17 ; 12: 18-21 ; 13: 35 ; 21: 5 ; 27: 9-10)$. None of these has a symoptic parallel. Unlike the Matthean quotations which have parallels in the other synoptics, these quotations do not have a fairly pure LXX text. Sometimes they resemble variant readings attested in Greek OT manuscripts. Sometimes the formula quotations seem to be close to the MT. Sometimes they deviate from all known Greek, Hebrew, and Aramaic texts, simultaneously mixing influences from several of these. Instead of positing some unknown text as source for these quotations, Stendahl declares that what we have here is a different "citation technique" from that found in the 
quotations having parallels with other synoptics.10 While dependence on the MT is greater in the formula quotations, this is insufficient to explain fully the Matthean form of these quotations. Stendahl rules out the possibility that Matthew was simply correcting the LXX to greater agreement with the MT, or that Matthew used the MT but was consciously or unconsciously influenced by the LXX. Signs of an Aramaic version which was then nuanced with the LXX finds little support in agreement with known Targum texts. Stendahl concludes that Matthew wrote in Greek and selected freely from several OT traditions and methods of interpretation, in a process Stendahl calls "targumizing".11

Next on Stendahl's agenda is an examination of those quotations peculiar to Matthew but without the fulfilment formula, and occurring in some instances in a synoptic context. He finds these similar to those quotations in the other synoptics in that they are dependent on the LXX. Stendahl asks if the distinction between the formula quotations and the other Matthean quotations is a fundamental one or one which is only relative. In this regard he makes some summary observations and draws a number of conclusions regarding synoptic quotations.12 In general they do possess a fundamental LXX character. There is very close agreement between Matthew and Mark in common quotations. Luke tends to deviate more from the LXX, but this is only in form, in order better to merge his 
quotations with their context. The material common to Matthew and Luke shows fewer survivals of Semitic form than the Marcan quotations, and tends to be in the form of allusions rather than quotations, with clear dependence on the LXX. Material peculiar to Luke is even more Septuagintal, but it is mostly in the form of allusions. This suggests that $Q$ and other material common to Matthew and Luke were formed in "a consciously LXX milieu" and that Semitic indicators do not point to a tradition of Semitic quotations, but merely present surviving remnants.1=

It would give a clear picture of Matthew's quotation technique if all his quotations in common with other synoptics were based on the LXX, and all the rest deviated from the LXX in striking fashion. Unfortunately the real situation is far more complex. Matthew's formula quotations show familiarity with the LXX, and his peculiar but nonformula quotations are sometimes pure LXX. Add to this the fact that Matthew's genealogy of Jesus is Septuagintal in the forms of its names and in its allusions, and the fact that Matthew often adapts Marcan quotations to the LXX, and the fact that in the Psalm texts familiar through the liturgy the LXX is given purest witness, and stendahl feels compelled to conclude that Matthew's gospel developed in a church milieu in which the Bible was the LXX.14 On the other hand, some of the formula quotations would not have made sense in their context in Septuagintal form. 
Why Stendahl engages in his next discussion, quotations in different types of NT text ${ }^{13}$, is not entirely obvious. Is it to demonstrate that "different types" of text might be explained by different techniques of quotation? He does not say. He begins the discussion by asking how one quoted in classical times, and notes that classical authors practised great freedom in quoting, seemingly as a sign of mastery of their art. Considering, then, that Stendahl's overall approach is to seek the Sitz im Leben of the various types of quotation'4, especially the formula quotations, it would seem likely that our guess is correct. Another clue is that Stendahl asserts that "most of the quotations in the gospels have given us the impression of a conseious desire to reproduce the LXX text correctly."1> He also declares that this is "the impression" made by the NT in general. This, he argues, "gives us reason not to resort to the explanation of 'free quoting from memory' as soon as any differences appear."10 He has in mind, of course, the formula quotations, to which we cannot locate the vorlage. In other words, Stendahl wants all quotations to be accepted as appearing in the form in which they were intended. If they deviate from the OT text, they were meant to deviate. However, "the intention to quote literally, and the practice of checking the text with the Greek text available may be taken for granted in the synoptic material.19 The 
deviations in Luke are due to his desire to write good literature."

Among the different types of NT text Stendahl finds that apocalyptic texts seldom contain full-blown quotations. Instead, they contain allusions, often abounding in such, as in Revelation, which has not a single quotation but yet manifests OT material to a greater extent than any other NT book. Moreover, the aliusions found in Revelation are influenced by the Hebrew text. More than half of Paul's quotations cite the LXX exactly, and most of the rest are also from the LXX even where it deviates widely from the MT. However, he appears to use different versions of the LXX for different OT books. For example, for quotations from Isaiah Paul uses LXXA, from Leviticus LXXF, and from Job "he goes his own way, or follows a translation not known to us." $=0$ In the case of the epistles, Stendahl says it is quite natural to expect free quoting from memory. By contrast, however, Hebrews, which is an argumentum e scriptura, and therefore is written with an entirely different purpose, cites the LXX verbatim in many cases. Stendahl sees a School of St. John operating in the gospel of John. Evidence is found in John's manner of quoting, "consistent in its inconsistency".

Just as Stendahl has attempted to show the usual form critical connection between text-form and Sitz im Leben above, he claims that the formula quotations were part of 
the final stage of redaction and the quotations in common with other synoptics came from Mark and Q. It is in this vein that Stendahl writes, "This process of making the quotations conform to the LXX was a very early one, as can be seen from the fact that it is in the words of Jesus that we find the LXX character to be most consistent." $=1$ Stendahl here believes that the Jesus tradition took shape along parallel lines in Aramaic and in Greek.

Stendahl completes his discussion of the quotations in different types of NT text by removing a possible variable. He claims that for all of the NT, quotations do not seem to have been corrected towards the LXX in the manuscript variants. 22

Stendahl next discusses the oT texts.=s The key to this chapter is its last sentence: "It becomes still more obvious that the formula quotations cannot be used as evidence of 'a text' which was available to Matthew." The alternative to a text which Matthew used as source for the formula quotations, and which would explain their strange text type, is that Matthew used texts which we know but used different techniques of interpretation on them. The latter choice is Stendahl's, as his following chapter makes clear. It is this choice which allows him to posit his "School of St. Matthew."

Stendahl is convinced that the quotations common to two or more synoptics, especially those from Isaiah and the 
Minar Prophets, used a recension closer to LXXA than $L X X=.=4$ If it should be argued that this seems to be the case simply because $L X X^{A}$ has been influenced by the gospelsz=, Stendahl points out that Josephus, and to less extent Philo, are in agreement with LXXA.20 Nevertheless, each book of the LXX must be examined separately. Quotations from Psalms are in closer agreement with LXX. By noting manuscript variation in the LXX, the gap between the OT quotations in the symoptics and the LXX is diminished.

However, Stendahl finds it unsatisfactory that the LXX manuscripts with which the synoptic quotations are compared are all from Egypt. He continues, "These facts make the discovery of a Greek text to the OT in the Wilderness of Judaea in August 1952 most welcome." The text contains fragments of Micah, Jonah, Nahum, Habakkuk, Zephaniah, and Zechariah, dated at the end of the first century of our era. Stendahl notes D. Barthelemy's suggestion that this is a Septuagintal text corrected to a greater agreement with the MT, and relates this to earlier theories concerning an UrTheodotion. The Theodotonic recension is witnessed in a synoptic quotation from Daniel (Matt 24:30 = Mark 13:26), and in two formula quotations (Matt $4: 15 ; 12: 18$ ).

Stendahl ends this section asserting that Matthew did not use nor know another complete Greek version of the OT, even of the type discovered by Barthelemy, which strives for closer agreement with the MT. The variations in the formula 
quotations are of various kinds, and are unlikely to be explained by adherence to a single text. In addition, the variants within LxX manuscripts cannot explain the very marked differences offered by the formula quatations.

Stendahl next looks at the other side of the coin, the positive reason he does not think there is a single Vorlage behind the formula quotations. 27 Here he attempts to demonstrate the similarity between Matthew's formula quotations and one of the scrolls discovered at Qumran, the Habakkuk Commentary $(\mathrm{DSH})=0$. Just as in Matthew the quotations are interpreted as fulfilled by the words or deeds of Jesus, so in DHS the first two chapters of Habakkuk are applied to the Teacher of Righteousness. The references to Habakkuk are introduced by a formula which stendahl sees as functioning in the same way as the fulfilment formula in Matthew. Stendahl claims that while DHS falls generally under the genre midrash, it is so exclusively carried out from the viewpoint of the sect that it is more than simply a commentary, it is what Stendahl prefers to designate midrash pesher. His reason, although not made explicit, is quite transparent. He wishes to focus on the activity of engaging in a pesher type of translation and interpretation, and the group who specializes in this activity.

The text of DSH varies considerably from the MT, but mostly in such a way that it forms an organic part of the exposition of the text, to the degree that "the facts have 
affected the Habakkuk text"=9. Either the sect knew and used variant readings or made deliberate corrections to Habakkuk to achieve their purposes. Stendahl includes both possibilities but leans towards the latter, so that "in many cases DHS appears to be created ad hoc.":0

Stendahl considers this pesher manner of quotation to be consistent with his finding that apocalyptic 1 iterature does not quote scripture literally. That the DSH is apocalyptic explains the great degree of freedom exercised in its interpretation of scripture and its translation of it. It is Stendahl's hypothesis that in the formula quotations the biblical text is treated in somewhat the same manner as in the DSH quotations. On the other hand, nonformula quotations are considered to be taken from the Greek text common to the church and synagogue. $\$ 1$

Robert Horton Gundry Gundry's book, The Use of the old Testament in St. Matthew's Gospel with Special Reference to the Messianic Hape, $=2$ published in 1967, originated as a 1961 Ph.D. dissertation.

Stendahl is one of the prime figures to whom Gundry is reacting.s: Gundry claims that the Dead Sea Scrolls have demonstrated that the diversity of textual tradition we now possess did not exist in NT times. $\$ 4$ Hence, there exists little warrant for Stendahl's argument that the Habakkuk 
commentator and the Matthean school chose from among variant texts available to them. However, Gundry does concede that "this is probably true in a few cases in the Habakkuk Commentary", where there occur dual readings in 1QpHab. This is not the case for Matthew because it displays no instance of dual readings. Hence, "we cannot infer a Matthaean school similar to the Qumran community."

Gundry claims that on the whole the Habakkuk commentator used a mixed text, "the only kind of text then existent". He is willing to concede that "an individual exegete of the OT" in composing a gospel may likewise have used a mixed text for his quotation material. Here he is saying something totally at odds with Stendahl. Stendahl saw the formula quotations as a textually distinctive group. Gundry claims that he held this position largely because he neglected to study the allusions. Gundry notes that study of the Dead Sea Scrolls has shown that allusive quotation of the OT was a conscious 1 iterary practice. Is That the variation in allusions cannot all be credited to poor memory or a lack of concern to quote accurately is evidenced in the fact that the same variant readings sometimes occur in different Qumran manuscripts, and the same variant characteristics appear in explicit quotations.

It is with respect to detailed study of the text-form of "allusive quotations" that Gundry breaks new ground. $\$ \infty$ The major portion of his work is an examination in detail of 
both the formal and allusive quotations which Matthew has in common with Mark, and the formal and allusive quotations which Matthew has in common with Luke, and the formal and allusive quotations which are peculiar to Matthew.

Gundry suggests that allusive quotations had not been considered important in earlier research because they were thought to have been the result of memory, so that any textual variation could not be seen as significant $=7$. Gundry asserts that this was not an adequate reason for neglecting study of allusions. He notes that the ancient mode of recitation was extremely accurate. Also, easy access to synagogue scrolls in addition to private possession of individual OT books made reliance on memory unnecessary. Furthermore, many of even the minor divergences from the LxX in NT quotations of the OT appear to be deliberate. In addition, NT writers sometimes agree verbally against all known OT texts. In this issue Gundry accords with Stendahl: faulty memory ought not to be used as an explanation of textual variants.

A second reason allusive quotations have not been taken seriously is because it has been assumed that an allusion is not an attempt to cite the OT accurately.se Gundry concedes that allowance must be made for working an allusion into its context, with the attendant changes in grammatical forms, but he emphasizes in italics that "an allusive quotation rather reflects the language and phrase-forms with which the 
writer is most familiar and in which he habitually thinks". Gundry suggests that allusive quotations are more revealing than formal quotations because the former attest to "the firmest grasp and appreciation of a subject".

How does Gundry distinguish between what he calls "formal quotations" and what he calls "allusive quotations"? He confesses that it is a distinction not always easily made. His criterion is "whether the quoted words flow from and into the context (allusive) or stand apart (formal)." $=0$ In this way an allusive quotation may be of some length. Deciding whether an instance of verbal parallelism between OT and NT is an allusive quotation "often presents a delicate task".40 Gundry is forced to admit that there is no rule of thumb which will fit all cases. It is not adequate, for example, to require a certain number of parallel words41. Sometimes parallel phraseology is due only to similar circumstances, for example, the flights to Egypt of the Holy Family and Jeroboam (Matt 2:13-15; 1 Kgs 11:40). Instead, Gundry looks for "recognizable thought-connection ... between the OT and NT passages". Gundry's thesis is two-fold.4z One segment of it concerns our interests only in that it sets an agenda which possibly influences the way in which Gundry interprets the quotations and conclusions he derives from his research4:. Gundry wishes to demonstrate that Matthew was not innovative in his hermeneutics, but that his principles of 
interpretation were those of Jesus himself44. The OT passages which Matthew interpreted as messianic are $50.4=$ In this way "specific fulfilments of individual Messianic prophecies provide a basis for the broader Christian view of the divine purpose guiding OT history toward Jesus Christ."

A prime, perhaps motivating, concern of Gundry is to "support the early date and the historical worth of the synoptic tradition."40 Indeed, he devotes several pages ${ }^{4}$ to criticizing "left-wing form-critical study" for its "historical pessimism". He next tackles the problem of the extent to which the fulfilment motif exercised a formative or creative influence on the synoptic tradition. 4 Among other things he notes that Septuagintal flavour in a quotation does not constitute grounds for questioning that the words were actually spoken by the person in the narrative. Greek and Semitic material was embedded in the earliest layers of the synoptic tradition. He claims that the very looseness of many Matthean quotations shows that the direction is from tradition to prophecy and not the reverse. Indeed, some of the OT passages quoted are so obscure that no one could have thought of them as messianic prohecies unless given the gospel traditions first. Descriptive phraseology in the synoptics is conformed to OT language to make obvious the latent correspondence between prophecy and event. 
Gundry observes that the foundation of Stendahl's school hypothesis is the distinctiveness of the text form of the formula quotations in Matthew, when compared to other Matthean OT quotations. That part of Gundry's thesis which is more relevant to our interests is that "contrary to former opinion, the Matthaean formula-citations do not stand out from other synoptic quotation material in their divergence from the LXX, but the formal quotations in the Marcan (and parallel) tradition stand out in their adherence to the LXX."40

Following are some of Gundry's summary observations. =0 The formal quotations in Mark are almost slavishly Septuagintal, even where the LXX departs markedly from the Hebrew text. In the parallel quatations Mathew tends to depart slightly from both Mark and the LXX. By contrast the allusive quotations common to Matthew and Mark (and Luke, where present) display a great variety of text-forms, often within a single quatation.91 Here Matthew tends to expand quotation material and to add "targumic embellismments". Dccasionally Matthew conforms Mark to the LxX, but in every instance this is due to stylistic considerations. The only formal quotations common to Matthew and Luke but absent in Mark occur in the temptation narrative. Two of these are Septuagintal; the other two likely are not. The allusive quotations common to Matthew and Luke display the same mixed text-type as in the allusive quotations common to Matthew 
and Mark. Often Luke's phraseology is more distant from the OT than Matthew's, possibly due to a preference for his own literary style. The formal quotations peculiar to Matthew, the formula quotations, are not homogeneous in text-form; they range from purely Septuagintal to wholly nonSeptuagintal. This observation, as well as that the Matthean formula quotations present the same variety of text-forms as the allusive quotations in all layers of the synoptic tradition, are the factors which most clearly separate Gundry from other scholarship on the subject. Finally, the allusive quotations peculiar to Matthew present the same mixed text-form found in all quotations except the formal quotations common to Matthew and Mark. While Gundry is willing to concede room for disagreement on the appraisal of text-form in some individual cases and on the inclusion and exclusion of some allusive quotations, he finds "two facts... outstanding and indisputable": (1) the formal quotations in the Marcan tradition are almost purely Septuagintal; (2) all quotations in every other stratum of the synoptic material present a mixed textual tradition. The latter stands in contrast to the prevailingly Septuagintal form of OT quotations in the rest of the NT.

In light of Gundry's observations regarding OT quotations in Matthew, his criticism of Stendahlsa is more understandable. Gundry asserts that Stendahl separated off 
the mixed text-form formula quotations as a final stage in the development of the book of Matthew. Picking up just one comment among others of similar vein, "devaluation of historicity and source-criticism tends toward fanciful overinterpretation of the theological motives of the evangelists"s:, we can see that Gundry leans toward greater reliance of Matthew on his sources, and the historicity of the tradition therein, over form critical and redaction critical positions which set more value in the contributions of the early church and the final redactor of the synoptic gospels.

Gundry attacks Stendahl's position by undermining the monolithic character of the formula quotations. In general, Gundry notes that stendahl failed to give serious consideration to non-Septuagintal quotations outside the formula quotations. While Stendahl did concede some Semitic features in quotations outside the formula quotations, he regarded them as a survival of an earlier Aramaic form which happened in a few cases to escape assimilation to the LXX. However, counters Gundry, if a non-Septuagintal form stands at the beginning of the process it cannot be proved that the non-Septuagintal form of the formula quotations makes them stand at the end of the process. Rather, the formula quotations might belong to the most primitive layer of tradition. 
The general attack on Stendahl above becomes more specific in the following observations. First, the quotations peculiar to Matthew in the sermon on the mount, which are not preceded by fulfilment formulae, differ from the LXX as much as the formula quotations do. Second, those quotations which are located in the course of the double or triple tradition but are found only in Matthew are Septuagintal. If these come from the Matthean school, one would expect non-Septuagintal form. If they are not from the Matthean school, why are the quotations peculiar to Matthew in the sermon on the mount not likewise Septuagintal? Having attacked Stendahl's view concerning the formula quotations in Matthew, Gundry offers his own source-critical proposal $=4$. He does this to avoid the scylla and Charybdis of form-critical and redactional-critical positions, and allow himself a Matthew who is a faithful follower of tradition and an early, reliable historical source.

Gundry proposes that the apostle Matthew was a notetaker during the earthly ministry of Jesus and that his notes provided the basis for most of the apostolic gospel tradition. Matthew the apostle stood apart from the other, unlettered apostles in his literacy. As a Levite he would have been familiar with the OT in its Semitic forms. As an ex-publican near Capernaum he would be fluent in Greek and have the habit of note-taking. "We can then understand how all strands of textual tradition made their way into the 
whole of the synoptic material, for the looseness and informality of such notes made it possible for Hebrew, Aramaic, and Greek all to appear in them." Gundry argues that there was only one place where Hebrew, Aramaic, and Greek were all used in NT times: Palestine.ss Hence, Palestine must have been the origin of a document in which textual elements from all three languages were so intimately intertwined, even within single quotations, as to defy unravelling and preclude the supposition of redactional stages.

The location of the origin of such a document in Palestine is further confirmed by the fact that we can assume knowledge of the OT in Hebrew nowhere else.so Serolls of the Hebrew OT must have been confined largely to Palestine. $\$ 7$ Use of the Hebrew text suggests an early date for Matthew, since access to Hebrew scrolls must have been difficult after the complete break with the synagogue.so The fact that the Septuagintal flavour was not dominant indicates that material containing the allusive quotations originated before the church expanded into Hellenistic regions. Later the formal quotations in Mark were assimilated to the LXX in the Roman milieu of Mark's origin. While the formal quotations were thus assimilated because they were recognized as Septuagintal, the allusive quotations were not assimilated because they were not recognized as quotations; and even where they were, they 
were so grammatically interwoven into their contexts that assimilation would have been difficult.

The notes of the apostle Matthew circulated in varying forms, from which the three evangelists drew. Some forms of the notes may have been expanded; sections of the notes may have circulated independently. This would explain the fact that Matthew and Luke do not always agree exactly in the $Q$ material, and the difficulty in defining the boundaries of Q. It would also explain why there is broad agreement among the synoptics concerning the material included in the story of Jesus' Iife and ministry, when only a fraction of what took place and was spoken has been selected. Otherwise, the tradition would have been "hopelessly fragmented, and no synoptic problem would exist". Such a single authoritative apostolic source would also explair the persistent feeling that Mark is sometimes parallel to $Q$ or used $Q$. When the mixed text of much of the synoptic tradition is held up against the predominantly Septuagintal form of quotations in the rest of the NT, and when it is noted that this mixed text occurs in all three synoptics, a common body of tradition behind all three gospels seems feasible. Gundry notes the problems of the $Q$ hypothesis in this connection, in particular B. H. Streeter's strained attempts to explain away the minor agreements of Matthew and Luke against Markso. For example, Streeter locates various pieces of narrative found in Matthew and Luke but not in Mark, such as 
John the Baptist's preaching, Jesus' baptism and temptation, the Beelzebub controversy, the mission charge, and the parable of the mustard seed, in Q.6 But, Gundry asks, what kind of document would contain only these bits of narrative? Furthermore, if this much narrative material is allowed in Q, what prevents the inclusion of the mixed text (composed of textual elements from Greek, Hebrew, and Aramaic) in all three gospels so that $Q$ becomes "an Ur-Matthaean gospel, or a body of note-material [such as that Gundry suggests the apostle Matthew composed]"-1? Here Gundry states the dilemma of the $Q$ hypothesis as follows:

In other words, if one does not include a sizeable amount of narrative material in $Q$, the agreements of $M t$ and Lk against Mk become an insuperable problem. But if one does include a sizeable amount of narrative material in $Q$, the very nature of the document becomes a problem - and the door is opened for further hypotheses concerning its nature. $6=$

As Gundry notes, one standard hypothesis suggested to serve the purpose of a common body of material behind all three symoptics is that of our old friend, the Urmarcus. $6=$ An Urmarcus, of course, would not be of sufficient breadth to include material traditionally incorporated into $Q$. Therefore, a better alternative would be an Ur-Matthew. It might be thought that this Ur-Matthew would need to be Semitic to agree, among other things, with such early church traditions as that of Papias.44 The next step in the history of gospel tradition would be the composition of Greek Mark based on this Ur-Matthew. Next a Greek translator 
of Ur-Matthew would use Mark's Septuagintal form of the quotationsss and passages which paralleled Ur-Matthew, to produce a Greek Matthew. os In this connection Gundry remarks:

That the Matthaean parallels to Marcan formal quotations are almost as purely Septuagintal as Mk confirms that Greek-Mt utilized Mk .... We cannot argue for Marcan priority [i.e. prior to Ur-Matthew or any original form of Matthew] from assimilation of Mk by Mt toward the LXX ... because the assimilation is usually stylistic and because the opposite, Mt straying from Mk and the LXX, is seen in 15:4a; 19:5,18,19; 22:32,37; $26: 31.07$

There is, however, a basic difficulty with the Semitic character of such an Ur-Matthew, according to Gundry. It does not account for the Septuagintal flavour which is "woven into the warp and woof of the synoptic tradition". Nor can this be the result of partial assimilation to the LXX. The allusive quotations are "too subtle". The combinations of text-forms within single quotations are "too intricate". Sometimes the quotation depends on the unique character of passages in the LxX. Hence, the basic language of the Ur-Matthew must have been Greek. Gundry asserts that the Matthean formula quotations were "obviously" inserted in the final stage of composition of the gospel. The quotations peculiar to Matthew, including the formula quotations, "most certainly" come from the author of the gospel.s If it is accepted that the apostle Matthew stands behind the mixed text elsewhere, "it 
is natural to think the same concerning the formulacitations and the first gospel itself." $>0$

The problem with the apostle Matthew's authorship of the gospel ${ }^{>1}$, under these terms, is that such an eyewitness would not have used another source (Mark). Gundry is forced to offer a strained defence of his position here. If Mark represents Petrine tradition, and if Peter used Matthew's notes 72 , Matthew would be using a form of his own tradition. Matthew used Mark in order to preserve the unity of the gospel tradition. To ease what must be the embarrassment of the situation, Gundry suggests the word "agreement" might be more suitable than "dependence" to describe the relationship between Matthew's gospel and Mark, but then immediately goes on to indicate ways in which Matthew maintains an independence from Mark.

George M. Soares Prabhu:

As its subtitle suggests, Soares Prabhu's book, The Formula Quotations in the Infancy Narrative of Matthew: An Enquiry into the Tradition History of Mt 1-2, has as its goal the illumination of the tradition history of the infancy narrative of Matt 1-2, rather than the formula citations themselves. He explicitly states that, unlike Stendahl, he is not primarily concerned with the text-type of these quotations. Instead, his interest lies in the context of the quotations. His "aim is to study the way in 
which these quotations have been integrated into the Infancy Narrative, in the hope that this will throw light on its tradition history: show us, that is, the sources which Matthew may have used in composing his narrative, and the way in which he has adapted and integrated them." $7=$ To achieve this aim Soares Prabhu examines the formula quotations in Matthew's triple tradition narratives, where the synoptic parallels are available, to determine how Matthew edits his sources when he inserts his formula quotations. Using the results of this examination, he examines the formula quotations in the infancy narrative, where there are no parallels, in order to determine its redactional and pre-redactional elements.

Such a method makes several presuppositions and Soares Prabhu is not loath to admit these: The most fundamental of these is the two-source hypothesis.74 The others are>s: (1) The formula quotations of Matthew are a unified group with a common origin and a common function, so that what has been determined about those in the triple tradition contexts may be presumed true of those in the infancy narrative. (2) The formula quotations were inserted by the latest editor of the gospel, Matthew. (3) The relation between formula quotation and context is not substantially different in the infancy narrative from that in the rest of Matthew.

Soares Prabhu establishes numbers (1) and (2) above in his first two chapters.>o He begins by confronting the dual 
problem with which such an analysis must deal, that of the definition of "formula quotation" and the identification of the formula quatations.

Soares Prabhu defines or characterizes the formula quotations as possessing three features. The first of these is that they are introduced by a fulfilment formula unlike anything else found in the NT, $>>$ found only occasionally in the OT (1 Kgs 2:27; 2 Chr 36:21,22; Ezra 1:1) and absent in post-biblical Jewish literature.7e Matthew himself created the Grundform of these formulae, based on its OT analogues. He then modified this Grundform so that in every case it was adapted to its particular context of usage. Such an exact adaptation to the context of the finished gospel, Soares Prabhu reasons, can scarcely be the chance result of bringing together disparate sources, and provides evidence that this was at the redactional stage. All formulae are constructed around the verb plêroun, and present an OT text as having been fulfilled by the event narrated.

The second characteristic of the formula quotation is that it serves a commentary function, in that it is an "aside" of the evangelist and not part of his narrative. On this basis these quotations have been called "Reflexionszitate", in contrast to the "Kontextzitate" which are part of the gospel narrative itself.70 The term Reflexionszitate has been replaced by the more descriptive Erfüllungszitate and "formula quotations":o. 
The third characteristic of the formula quotations is that they have a mixed text form, different from the strongly Septuagintal form of Matthew's other citations. "The formula quotations of Mt have a text-type which agrees neither with the LXX, nor with the Masoretic Hebrew, nor with any version we know - though there are sporadic resemblances to the OT Peschitta, and even to one or other of the newer Greek versions."1 In addition, the formula quotations do not present a uniform text-type. Their degree of agreement with or difference from the LXX and/or the MT differs from quotation to quotation. Soares Prabhu then provides profusive examples from Stendahl and Gundryes, but unlike Gundry, who sees some Septuagintal formula quotations (Matt $1: 23 ; 3: 3 ; 13: 14-15$ ), he asserts that "the formula quotations are ... by and large distinctly non-Septuagintal - though some are more non-Septuagintal than others." $=$ The problem of text-type is, for soares prabhu, intimately bound to the question of the origin of the text of the formula quotations. Soares Prabhu first examines Matthew's context quotations to determine whether or not the LXX was Matthew's Bible.e4 If the context citations should prove to be Septuagintal, then the non-Septuagintal formula quotations will not be Matthean. Soares Prabhu concludes that the LXX was not Matthew's Bible. He was unable to find even "one certain instance" where Matthew assimilated to the LXX any quotation borrowed from Mark. as In fact, he found 
two cases (Matt 19:4-5; 22:37) in which Matthew's version is less Septuagintal than Mark's. Three others (Matt 22:32; $26: 31 ; 27: 46)$ were ambiguous, with some elements more Septuagintal than in Mark, other less so. In only three cases (Matt 15:8-9; 19:18-19;22:24) did he see even the possibility of assimilation to the LXX, "but even here, the contacts with the LXX are so slight (15:8-9), so indecisive (19:18-19), or so uncertain (22:24), that it would be rash to affirm positively that these are examples of a deliberate assimilation of non-septuagintal (or rather, not fully Septuagintal) Markan quotations to the LXX." Based on this mixed evidence Soares Prabhu's conclusion is that any systematic redactional revision is ruled out. If there was any assimilation to the LXX, it took place at a preredactional stage, by means of staridardization for the liturgical and catechetical use of the community. Such a pre-redactional adaptation would explain the confused textual condition of Matthew's synoptic context quotations. Having demonstrated to his satisfaction that the context quotations in Matthew are Septuagintal only in that they come to Matthew this way in his sources, Soares Prabhu can still claim that it is possible to attribute the formula quotations to Matthew. His next step is to examine the meaning of the original Hebrew and of the parallel versions (the LXX, the Targum, Matthew's version) of one "typical" formula quotation, Matt 4:14-16, to show that each version 
provides a targumization of the original, a free, interpretative translation which would be relevant to a given theological tradition. Soares Prabhu claims that "quite adequate studies" which merely note the similarity or dissimilarity of this or that text in Matthew with one or other of the OT texts, have been carried out by such scholars as Stendahl and Gundry. He need not repeat their work. Instead, he will provide an in depth analysis which will "situate these differences in the context of the quotation as a whole, and show how (if at all) the text as quoted by Mt differs in meaning from its parallel versions, and why."0o In this way, Soares Prabhu hopes to demonstrate that the mixed text of the typical quotation is the product of some sort of targumic translation/interpretation technique that produced the $L X X$ and the Targum, that such a close adaptation of quotation to context will exclude the possibility of random borrowing by Matthew and provide evidence of the Matthean origin of the quotation. His analysis of Matt 4:14-16 allows him to conclude that the quotation is an "ad hoc translation from the Hebrew, with perhaps a reminiscence of the LXX, and made in view of the context into which the quotation has been inserted." Because the quotation is so closely adapted to the final context of Matthew, the targumist must be Matthew himself and not some earlier layer of the history of the 
book's development. Soares Prabhu then makes his final step in his argument:

Given, then, that the formula quotations have all, as Stendahl, Gundry, and Rothfuchs have amply demonstrated, the same adaptive, context-directed character, it seems safe to generalize from our single typical example to the formula quotations as a whole, and to conclude that these too are free targumic translations made from the original Hebrew by Matthew, in view of the context into which he has inserted them.

Soares Prabhu concedes that it is possible that some non-

Septuagintal Palestinian form of the Greek text was available to Matthew, but "it is clear... that the peculiarities of the text-type of the formula quotations are overwhelmingly due to the context-oriented adaptation of Matthew. Whatever vorlage they derive form, the formula quotations would still be the work of Matthew the targumist." $\approx$

Soares Prabhu suggests that Matthew's Vorlage, however, is the Hebrew text. He bases this on the freedom of the translation techniques of the time, as witnessed in the LXX and the Targum. At the same time Matthew would have used the Lxx, the Bible of his church, to correct the Septuagintal quotations of his sources, and even to add new ones. The LxX/Hebrew dichotomy between the context and the formula quotations is not a rigid one. There are traces of Septuagintal language in the formula quotations, and the context quotations are not all from the LXX. 
Soares Prabhu claims that the the formula quotations are not simply a convenient way of collecting "a heterogeneous collection of superfically similar quotations", but an objective group of quotations which have a common origin and a common function. It is the caincidence of the three distinctive features which puts this beyond doubt. "That just those quotations which are introduced by fulfilment formulas should be the ones that are comments of the evangelist, and have the same unusual text-type can scarcely be accidental!" $\rightarrow 0$ That the formula quotations are dispersed widely over the whole gospel, in material of varied origin (triple, double, and special traditions), indicates that these quotations belong to the final redactional stratum of the gospel, to Matthew himself. 1 Having defined the formula quotations, then, as "a group of quotations with a common origin, and a common function, all belonging to the same tradition-historical stratum"l=, Soares Prabhu next turns his attention to the identification of these quotations. Surveying the literature, he finds ten quotations which appear on every 1 ist: Matt $1: 22-23 ; 2: 15 ; 2: 17-18 ; 2: 23 ; 4: 14-16 ; 8: 17$; $12: 17-21 ; 13: 35 ; 21: 4-5 ; 27: 9-10.93$ The status of four others $(2: 5-6 ; 13: 14-15 ; 26: 54 ; 26: 56)$ appears apen to discussion. These have some, but not all, of the three defining features of the formula quotations. Hence, their appearance on, or absence from, a list of formula quotations 
will depend on which of these features has been chosen as the distinguishing mark of the group. One other quotation $(3: 3)$ is sometimes included because it is introduced by a formula resembling the fulfilment formulae, and it is a Reflexionszitat. Finally, the quotation from Ps 22:19 is found at Matt 27:35 in some manuscripts, but appears on none of the lists because it is an obvious interpolation, possibly from John 19:24. Soares Prabhu affirms the usual ten quotations and adds only Matt 2:5-6 to his ist of formula quotations. The latter, he believes, was originally a context quotation belonging to the pre-redactional Herod narrative. Later it was redactionally assimilated into the formula quotation group.

\section{Summary}

Holtzmann believed there were two major text-types in Matthew's OT quotations: (1) those from the LXX, and in common with Mark, (2) those reflecting the Hebrew text, and peculiar to Matthew. He suggested that these two text-types indicate that Matthew incorporated into his text those Septuagintal quotations he found in source $A$ (preserved in our Mark), and added others based on the Hebrew text. For Holtzmann, then, the OT quotations in Matthew fall into a pattern of text-types that supports the two-document hypothesis. 
While it was the purpose of neither Stendahl, Gundry, nor Soares Prabhu to demonstrate the relevance of the OT quotations in the synoptics to the study of the synoptic problem, their work is important for our study because they have attempted to determine the various text-types evident in the Matthean quotations.

Like Holtzmann, Stendahl finds that the quotations common to Matthew and Mark are of a fairly pure Septuagintal text-type, and that the formula quotations in Matthew are non-Septuagintal. However, against Holtzmann, he finds that the formula quotations of Matthew are of a mixed text-type, not simply based on the Hebrew. What is more significant for our purpose is that stendahl finds some quotations peculiar to Matthew which are Septuagintal. This group militates against Holtzmann's overly simplistic use of the two texttypes to affirm Marcan priority.

Contrary to Stendahl, Gundry claims that in Matthew all the formal quotations shared with Mark are purely Septuagintal. All other OT quotations in Matthew are of mixed text-types, and some of these are Septuagintal.

Soares Prabhu, like Stendahl, divides the Matthean OT quotations into two groups: (1) the formula quotations (which for Stendahl are of mixed text-type), (2) the remaining quotations (which for stendahl are Septuagintal). Unlike Stendahl, Soares Prabhu sees all formula quatations as free translations of the Hebrew, rather than eclectic 
texts. As well, he considers some non-formula quotations non-septuagintal. At the same time, like stendahl, he grants that some formula quotations closely resemble the LXX. These perceptions badly blur the boundary between Holtzmann's two groups.

Soares Prabhu notes that scholars do not agree on what quotations comprise the group called "formula quotations". Their choice depends on which characteristic(s), of the three Soares Prabhu considers to define what a formula quotation is, they stress. It should come as no surprise, then, that there are at least three designations for this group of quotations: Reflexionscitate, Erfüllungszitate94 (fulfilment quotations), formula quotations.

Indeed, there is so much debate over the characterization and selection of this group of quotations that G. Stanton asks whether the introductory formula is the only thing that distinguishes this group. 9 However, Ulrich Luz claims that fluidity in the form of the introductory formula allows for "gradations" from the formula quotations to "normal" quotations, so that that distinctions between the former and the latter are "not unambiguous". os Luz asks why all the Matthean OT quotations did not become formula quotations. $\rightarrow 7$ He suggests that in some cases the quotation did not refer directly to Jesus and so plêrố was not a suitable introduction; in other cases Matthew knew that the quotation did not come from a prophetic book. When Matthew 
did use an introductory formula, it was to emphasize a theological theme. $\rightarrow 0$

If, as Luz suggests, the use of an introductory formula has a lot to do with the content of the quotation, it should not be surprising that Gundry and Soares Prabhu find that the text-form of the formula quotations is sometimes similar to, or the same as, that of non-formula quotations. Stendahl, Gundry, and Saares Prabhu all agree with Holtzmann that the OT quotations common to Mark and Matthew are Septuagintal. Holzmann's second claim, that all peculiarly Matthean quotations are based on the Hebrew, finds no support among the other three. Soares Prabhu comes closest when he says that the formula quotations are based on the Hebrew, but he also remarks that the non-formula, peculiarly Matthean quotations are Septuagintal, and even some of the formula quotations are almost Septuagintal. Gundry takes the latter claim one step further: some of the formula quotations are Septuagintal.

We can look at the peculiarly Matthean quotations in two ways. First, we can divide them into formula quotations and non-formula quotations. Stendahl, Gundry, and Soares Prabhu agree that some or all of the formula quotations are of a mixed-text type. Soares Prabhu says some are almost Septuagintal. Gundry asserts some are Septuagintal. Concerning the non-formula quotations, Stendahl and Soares 
Prabhu claim they are Septuagintal, while Gundry says they are of mixed text-types.

The second way of looking at the peculiarly Matthean quotations is to divide them into septuagintal and nonSeptuagintal. Concerning the septuagintal quotations, Holtzmann is alone in finding none of these. Stendahl finds them only in non-formula quotations. Soares Prabhu finds them in non-formula quotations and almost in some formula quotations. Gundry finds them in formula and non-formula quotations.

What is immediately clear is that there is a decided difference of opinion among Stendahl, Gundry, and Soares Prabhu concerning the text-types of peculiarly Matthean $0 T$ quotations. Despite these differences, however, there is general agreement among the three that there are peculiarly Matthean Septuagintal quotations; the difference of opinion lies in their distribution. This point, if confirmed, would weaken, if not demolish, Holtzmann's argument. Because there exists such a range of opinion, and because the existence of peculiarly Matthean Septuagintal quotations militates against the good health of Holtzmann's case, the quotations need re-examination. Hence, we shall examine in detail the OT quotations in the synoptic gospels to see if the variety of text-types exhibited fall into a pattern which supports either the two-document hypothesis or the Griesbach position. 


\section{NOTES}

1 The works I have chosen to discuss are major monographs on the subject. To deal with two separate areas in the literature as vast as that of the synoptic problem and that of old Testament citations in the synoptics is much like bringing two universes into contact for the first time and watching the sparks fly. Would that our task were as simple as that of following the ingenious method of one of Charles Dickens" characters who "wrote learnedly on 'Chinese metaphysics' by consulting an encyclopaedia under 'Chinese' and then under "Metaphysics'." (For this amusing excursus into methodology, although his referents were different, I am indebted to George M. Soares Prabhu, The Formula Quotations in the Infancy Narrative of Matthew: An Enquiry into the Tradition History of Mt 1-2 (Rome: Biblical Institute Press, 1976) 1.

= Lund: C. W. K. Gleerup.

= Along with a list of corrections to the text of the book, and a list of reviews of it, the preface provides some insight into directions future research on the formula quotations might take. Stendahl furnishes a cursory look at relevant literature for the years between his two editions, defends his original position on small points vis-a-vis some of this literature, and offers the concluding suggestion that Matthew was a Jew living in a Hellenistic Christian community composed of Jews and gentiles, which had made the transition to an increasingly gentile constituency without suffering the usual tension and problems. Matthew's community stood in sharp contrast to the Jewish community in town, but lacked the internal friction so common to other contemporary Christian communities of mixed ethnic backgrounds. Hence, Jewish traditions which in other communities would be suspect, here could be preserved and elaborated.

Along with the observation that NT scholarship on the quotations is dependent on OT scholarship's reaching "more synthetic hypotheses concerning the oT text" (p.iii), Stendahl's major reservation about his first edition is that the explosion in findings at Qumran makes it "clear that a wider variety [of OT text types] - actually demonstrated and reasonably projected - minimizes to some extent the degree of textual creativity which this study assigns to the School of st. Matthew'" (p.vi). Nevertheless, some explanation for the peculiar text form of the Matthean formula quotations must still be sought. 
4 Ibid., i. This remark is quickly confirmed by a glance at the contents of the original book. Scarcely more than ten per cent falls under the general heading, "The School", while the remainder is under "The Quotations from the old Testament". Perhaps the fact that the concept of a school is there at all, is more the result of the original work being of the genre, dissertation, with its need to furnish an original (and even controversial?) thesis, than anything else.

Ibid., 39-40.

- Ibid., 40 .

7 I do not in any way wish to imply that this "forcing" is intentional on the part of the researcher. Instead, it is usually noticed only by critics who have not been so engrossed in the research that perspective has dimmed.

- All of the works most important to our interests, for example, fall into this category: Stendahl, The School; Robert Horton Gundry, The Use of the old Testament in $5 t$. Matthew's Gospel with Special Reference to the Messianic Hope (Leiden: Brill, 1967), [1961]; Soares Prabhu, The Formula Quotations, [1969]. (The date of publication of the first edition is given; the date in the square brackets is the date of completion of the doctorate.) It should be noted that these works have a subtitle (or in Stendahl's case, the major title) which indicates the stream in which is caught up the detailed research on the quotations. Because the stream for our research is different, it is necessary to examine the details of the quotations anew, rather than be content with the conclusions of our predecessors.

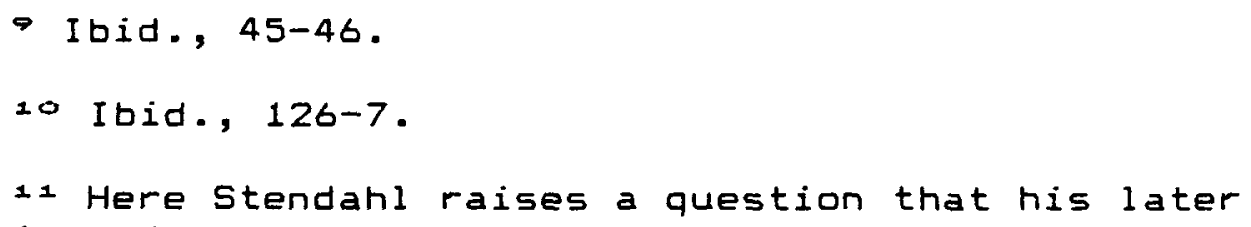
solution of a school seems inadequate to answer. He asks how the texts of Matthew's formula quotations could claim the authority they must have had to be useful, considering that the Targums did not obtain authority in Judaism (ibid., 127).

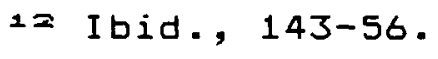
odds with what we would expect in $Q$. If $Q$ is the same as Papias Logia, one would expect it to be Semitic. Instead, Stendahl finds that "precisely those quotations which 
consist of the words of Jesus are most clearly LXX in their nature" (ibid., 150).

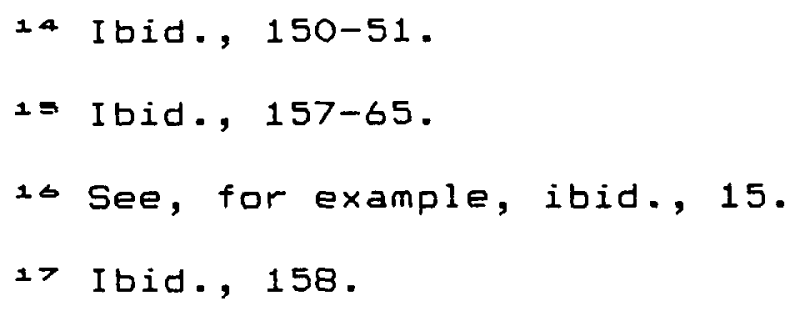

10 There is an alternative to the hypothesis of free quoting from memory for passages in which a text is quoted which does not agree with the LXX. Seeing how accurately Matthew quotes the $L X X$, even to the degree of correcting Mark (if we can assume that he used Mark, which in our case, of course, is precisely what is at issuel, we could propose that he followed a text with which we are not familiar. Stendahl says that in many places the formula quotations do not resemble any "known" text (ibid., 97), and "known" is the key word here.

$1 \rightarrow$ Ibid., 163-4. If this is true, how does stendahl explain that Matthew corrects Mark towards the LXX (a claim Stendahl himself makes (Ibid., 148.) 1? Surely would not Mark himself have confirmed the accuracy of his quotations with the LXX? What is happening here is that two of Stendahl's lines of thought are operating at cross purposes. He wants the synoptic quotations in Matthew to have come from Mark (and therefore not be Matthew's) and at the same time he wants the synoptic quotations to be accurate to the LxX, because he wants the deviations of the formula quotations to be intentional.

20 Ibid., 159. Here we see Stendahl offering the two alternatives which we noted above!

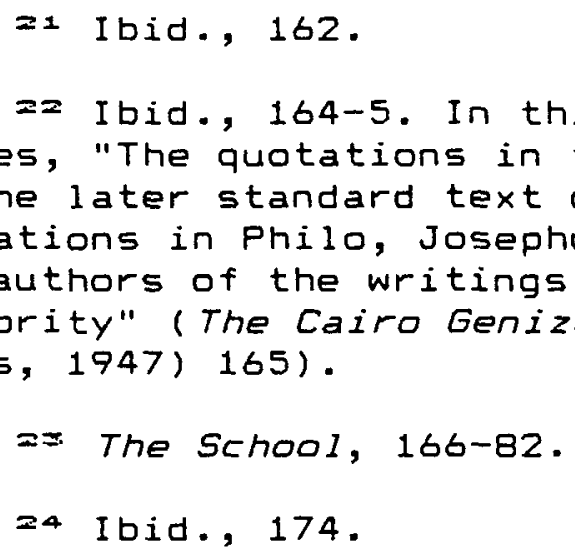


$=$ Stendahl seems strangely ambivalent here. At ibid., 173-4, he writes, "In a number of cases the question of the NT's influence upon the LXXA-te. must be left open."

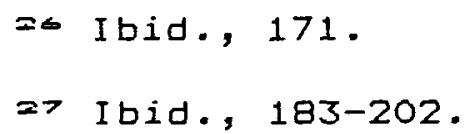

a B. Gärtner, "The Habakkuk Commentary (DSH) and the Gospel of Matthew", ST 8 (1954), 1-24, offers a critique of this portion of Stendahl's argument. He denies that the Habakkuk scroll was produced by a pesher type of exegesis.

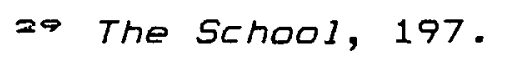


textual traditions which are relevant for study of references to the OT in Matthew is still unrivalled. But his hypotheses concerning the authorship of Matthew's gospel and the origin of the gospel traditions raise more questions than they answer" ("Matthew", in D. A. Carson and H. G. M. Williamson (eds.), It is Written: Scripture Citing Scripture (Cambridge: Cambridge University Press, 1988) 210.).

$=4$ In The Use of the 01d Testament, $158, \pi .7$, he lists his references for this statement.

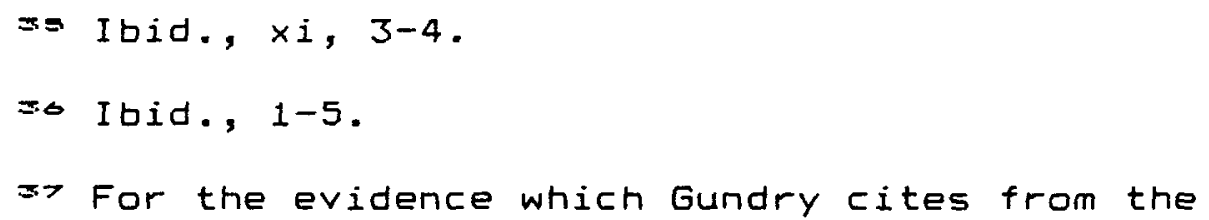

41 Gundry refrains from word-counting not only with respect to determining whether or not a passage is an allusive quotation. He gives five reasons for not using this method (Ibid., 147, ח.3.):

(1) it would be hazardous in the extreme when one is dealing with allusive quotations; (2) it gives a misimpression when there is little room for disagreement in the translation of the Hebrew; (3) the word-counting method distorts the picture where a few long quotations because of their high number of words outweigh many more short quotations; (4) the oft-times important significance of textual points of contact involving a single word or a very few words is lost in mere word-counting and percentage figures; (5) sometimes there is complete agreement between texts in wording, but the words in context show mutually exclusive interpretations of the Hebrew text.

The mention of word-counting technique cannot help but bring to mind Sir John C. Hawkins' Horae Symopticae (2d ed.; oxford: Clarendon, 1909). It is probably this work which Gundry has at the back of his mind. For example, he mentions disparagingly that Stendahl uses Hawkins' statistical analysis of Matthew's OT quotations as his starting-point for his argument concerning the special text-form of the formula quotations (The Use of the 01d Testament, 157.). 
$4=$ This is stated explicitly at ibid., 5 .
$4=$ This part of Gundry's work is found at ibid., 189234 .

44 Ibid., xii-xiii. Contrary to the "atomization" of the QT text (hermeneutics in which the context of the OT quotation is often blatantly disregarded) found in Qumran and rabbinical hermeneutics, Matthew does not search for isolated proof-texts but confines himself to areas of the OT which the church recognized as bearing upon Jesus christ. The church recognized this because they were found in the teachings of Jesus himself (ibid., 205-15).

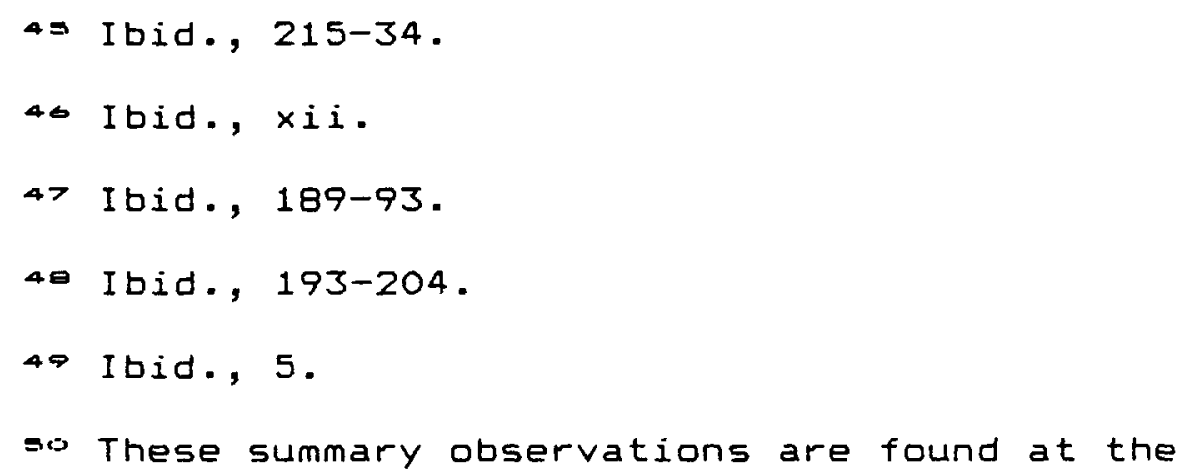
beginning of each group of quotations and in even greater detail at ibid., 147-50.

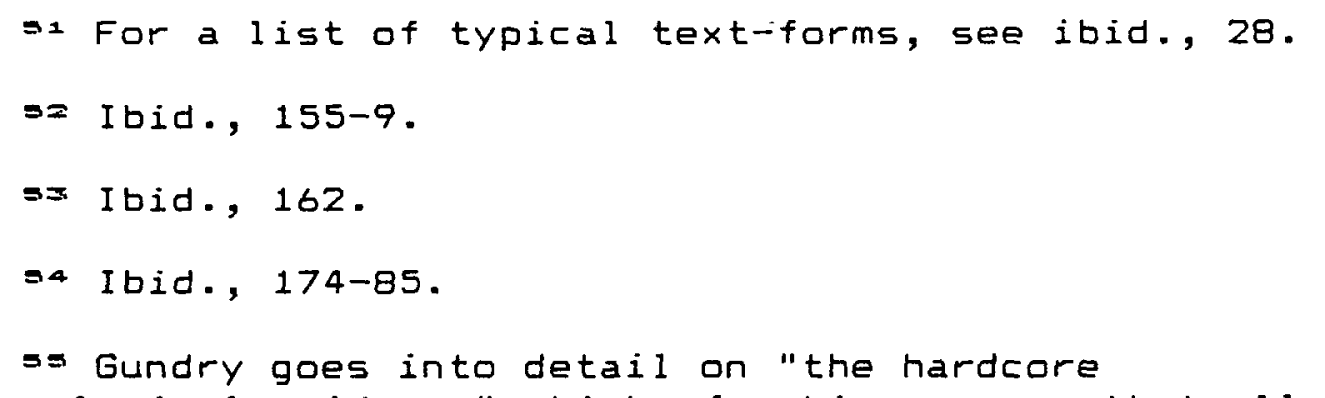
archaeological evidence" which, for him, proves that all three languages were commonly used by Jews in first-century Palestine. He even suggests that it is likely that Jesus himself and the apostles commonly spoke Greek in addition to the Semitic languages. Hence, much of the gospel tradition would originally have been cast into all three languages (Ibid., 174-8.).

St Francis Crawford Burkitt, The Gospel History and its Transmission (2d ed.; Edinburgh: T. and T. Clark, 1907) 1278 .

$s$ Here Gundry cites Paton James Gloag, Introduction to the Synoptic Gospels (Edinburgh, T. and T. Clark, 1895) 150. 
- Arthur Gabriel Hebert, The Authority of the ald Testament (London, Faber and Faber, 1947) 204.

so The Four Gospels: A Study of Origins (London: Macmillan, 1924) 295-331.

-o The logic behind this move is seen, for example, in the words of Vinton Adams Dearing, "From the textual point of view, the agreements explained as arising from common dependence upon $Q$ are simply clearer and larger manifestations of the state of affairs indicated by the "minor agreements" (A Manual of Textual Analysis (Berkeley: University of California Press, 1959) 95.).

$$
\begin{aligned}
& \Leftrightarrow \text { The Use of the 0ld Testament, } 180, \pi .4 \text {. } \\
& =\text { Ibid., } 180, \mathrm{n} .4 \text {. }
\end{aligned}
$$

-3 Here Gundry lists several other hypotheses all of which serve the same purpose as the Urmarcus, and it could be argued that all are virtually the same thing under different name and dress (Ibid., 180-1.).

-4 Gundry is assuming this position temporarily only to knock it down later. If Gundry opts for a Greek Ur-Matthew, how does he deal with the Papias tradition? He suggests that a Semitic Ur-Matthew, if indeed there was such, bore no relationship to the Greek Matthew. Both documents may have worked largely with the same traditions. A second possibility is that Papias did not mean that Matthew wrote a Semitic gospel (for further details, see ibid., 185.).

$\rightarrow$ Gundry uses the two quatations from Mic 7:6 to illustrate his point. The one peculiar to Matthew $(10: 35-36)$ is non-Septuagintal. The one paralleled in Mark $110: 21=$ Mark 13:12) is Septuagintal.

- Such a step is postulated, for example, by Marie Joseph Lagrange, Evangile selon Saint Matthieu (4th ed.; Paris: J. Gabalda, 1927) cxxii-cxxiv.

$\leftrightarrow$ The Use of the Dld Testament, 179, 179,n.3.

te Ibid., 179. The "obviously" here suggests Gundry thinks proof is unnecessary.

t Ibid., 184.
$>0$ Ibid., 184. 
71 Gundry 1 ists some of the usual reasons offered for and against authorship by the apostle Matthew at ibid., 184, n.4. Among the former are: the early tradition, the popularity of the gospel, the unlikelihood that the gospel would be falsely ascribed to an apostle of Matthew's obscurity, the special mention of Matthew the publican's hometown of Capernaum, the dropping of autou (Mark 2:15) from en tê oikia autou with reference to the house of Matthew the publican, the special interest in money, and the juggling of figures in the genealogy.

$>=$ Gundry suggests here that Mark may appear to be abridged simply because Peter has (without significant change or expansion?) used Matthew's notes, which by definition are "abridged" (Ibid., 184, n.1.).

I The Formula Quotations, 1.

74 Soares Prabhu is to be credited both with admitting that this does form a platform on which his work is built, and with realizing that it is "a convenient working hypothesis" and not simply to be accepted as "a dogma of critical orthodoxy". He states that he "would heartily endorse" the assertion of E. P. Sanders that "the difficulty with the present situation is not that there is a dominant hypothesis, but that the dominant hupothesis is frequently held too rigidly ... and is accorded a degree of certainty it does not merit" (Ibid., 42, 43, n.218.).

$>$ Ibid., 42 .

$\rightarrow$ Ibid., 18-106.

$>$ The subject of the formula itself is dealt with at ibid., 46-63.

>o B. M. Metzger finds none in the Mishnah ("The Formulas Introducing Quotations of Scripture in the New Testament and the Mishnah", JBL (1951), 307, n.18.).

J. Fitzmyer finds none in the Qumran material ("The Use of Explicit old Testament Quotations in Qumran Literature and in the New Testament", NTS 7 (1960-61), 330.).

$\rightarrow$ Soares Prabhu seems almost to define "formula quotations" negatively. He notes, for example, that, except for Mark $1: 2$ and its parallels, they are the only quotations in the synoptic gospels which are not part of the direct speech of Jesus or some other character in a narrative (The Formula Quotations, 19.). 
so This term was used by 5 . E. Johnson ("The Biblical Quotations in Matthew", HTR 36 (1943), 135.) although he did not indicate that he initiated its use.

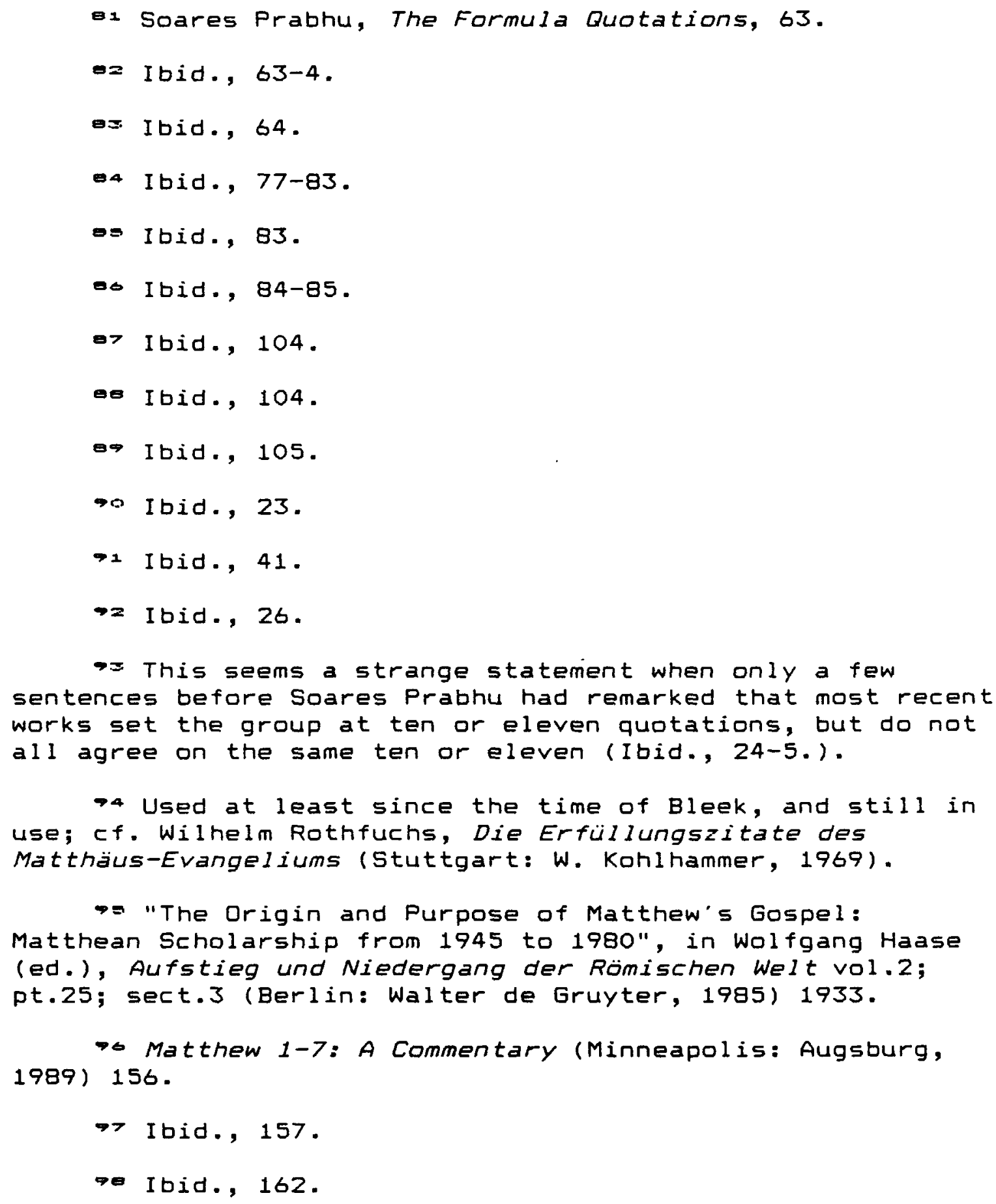


CHAPTER FOUR: THE QUIOTATIONS I

In the following discussion of the citations a common procedure has been maintained. Where a citation appears in Matthew, this form of the citation will be given first. The text of a citation supplied in full, as it is found in the NT, will be the text found in the twenty-sixth edition of Nestle-Aland. The text of the LXX supplied in full will be that of the Gottingen edition, except for that of Exodus which will be from the Cambridge (Brooke-McLean) edition. The text of the MT supplied in full will be from Biblia Hebraica Stuttgartensia. The texts of these major editions of the NT and OT will often be referred to as "the preferred text" of the NT and $L X X$. Where $H, D$, and Th are not named with a NT variant, they can be assumed to agree with the cited "preferred" NT text.1 Any punctuation supplied is that of normal English usage, not that found in editions of the Greek.

For the sake of precision the numerical code is given for uncials. This is to avoid any possible, even if unlikely, confusion. "Vaticanus", for example, under any normal circumstances, means uncial 03 , but uncial 028 is 


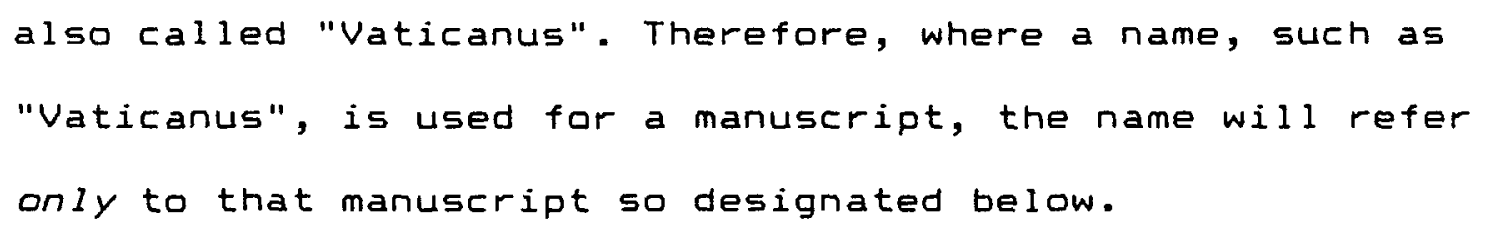

The following symbols are used for NT manuscript designation: $=$

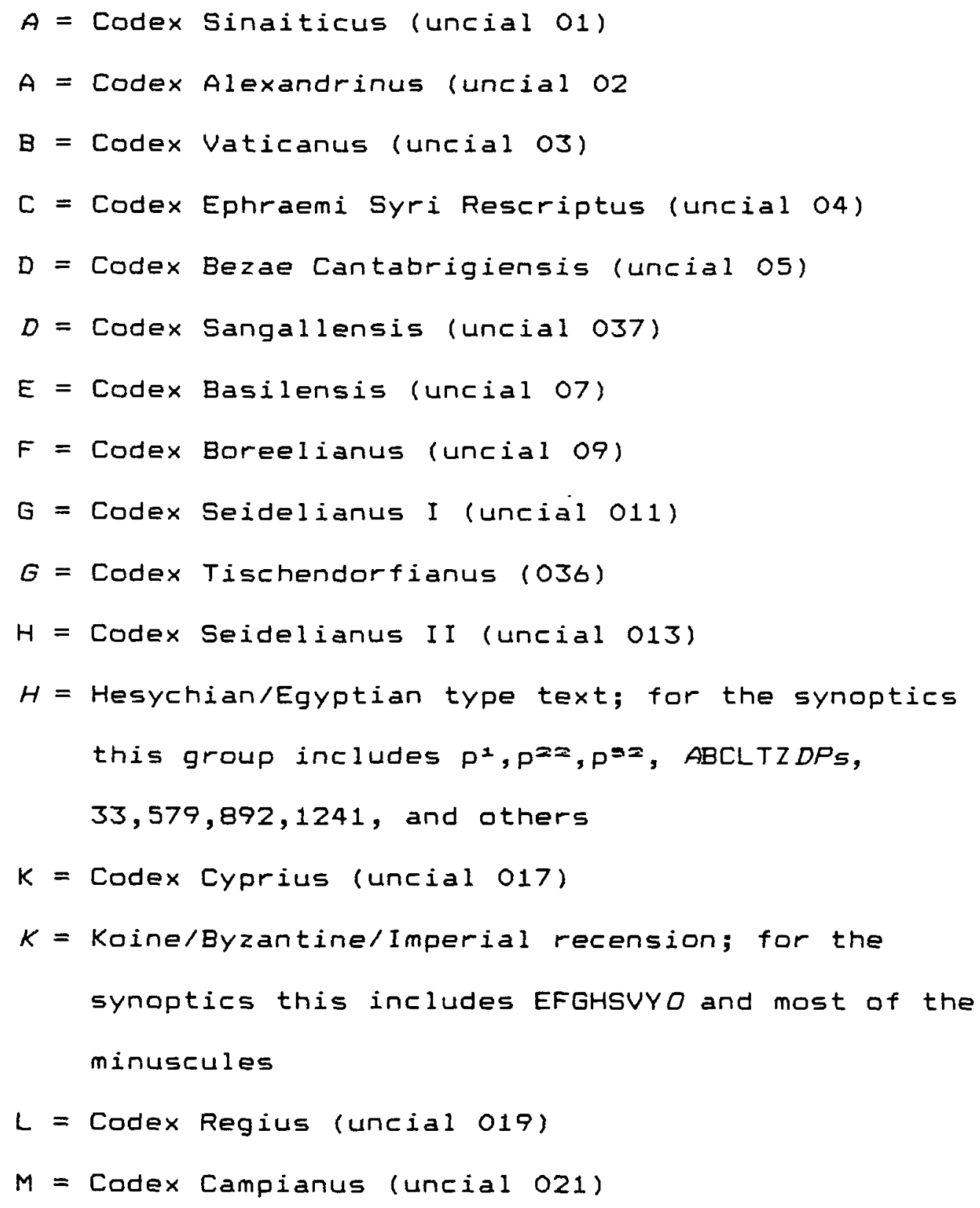




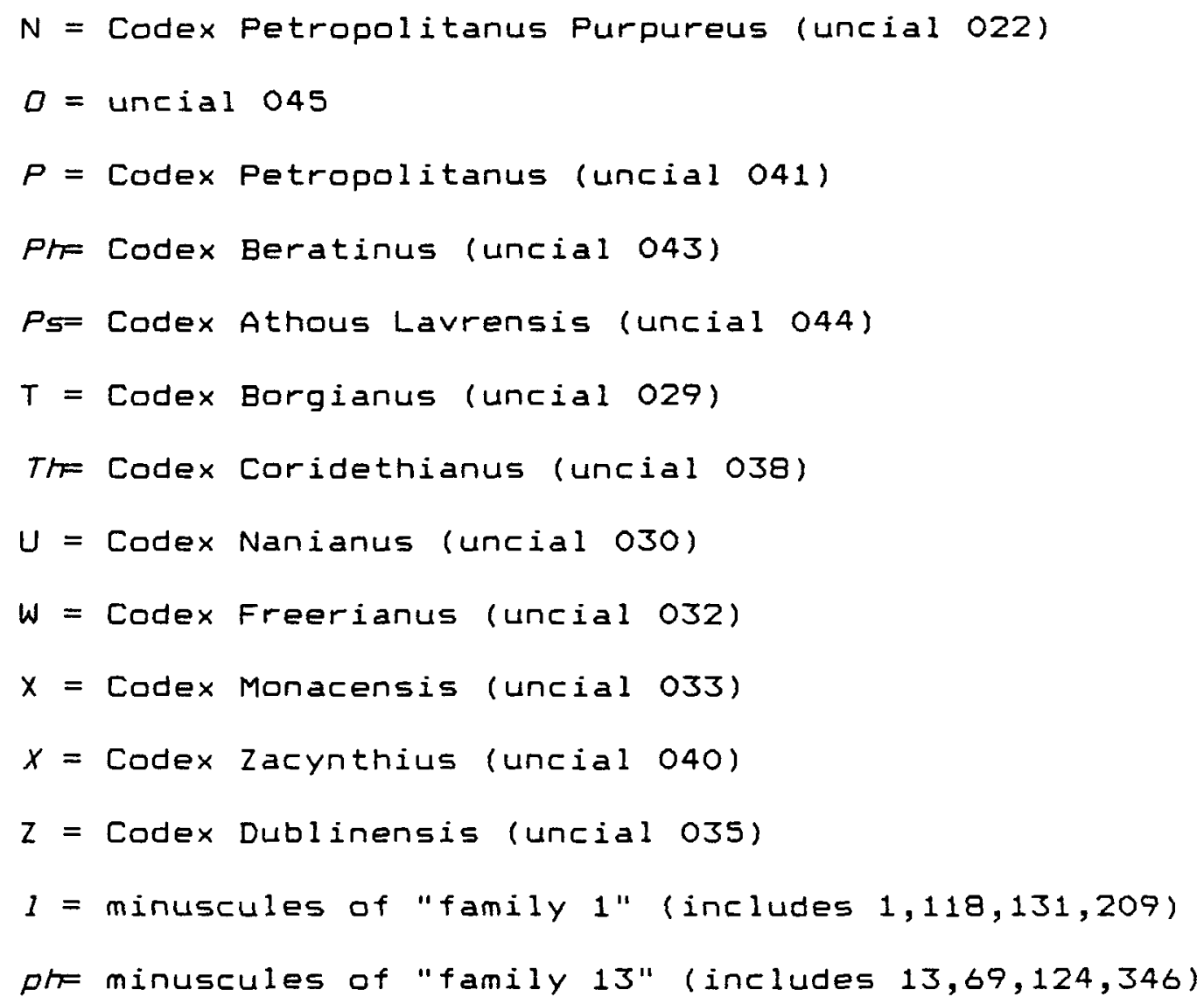

Matthew 22:44:

eipen kyrios tô kyriô mou:

kathou ek dexiôn mou heôs an thô tous echthrous sou hypokatô tôn podôn sou.:

The text without the article before kyrios is found in $A B D Z$; the article ho is found preceding kyrios in the remaining manuscripts; hypokatô is replaced by hypopodion in $K$ and a great many others.

Manuscripts $A$ and $B$ (proto-Alexandrian) are two of the best for determining the original text. These are confirmed by the later Alexandrian manuscript $Z$, and by $D$, the best representative of the western group, which, although it is 
characterized in many passages by additions, striking

omissions, and a generally wild and inconsistent revision of an earlier text, can preserve the original reading. All of this gives the preferred text strong support.

The question of whether or not the article ho was in Matthew's text is the most complex problem in the determination of the text of this passage. The fact that the LXX in all manuscripts cited by Rahlfs except one, and that the weak witness ${ }^{4}$ of the Verona psalter, the chief example of the Western text-form for Psalmss, uses the article, would suggest the easy solution, that the Matthean text must have lacked the article originally because typically later groups (like the Koine) would probably have undergone assimilation to the LXX. However, other complicating dimensions furnish a caveat for such a pleasantly simple solution. The idea that it was part of Matthew's peculiar style to use kyrias without the article is debated. Feelings about Greek style, and the influence of Aramaic in connection with the title kyrios may have led copyists to delete the article.> Considering its complexity, we shall bracket discussion of this part of the text from any decisions that relate to our central problem.

The only other variant for the Matthean text is hypokatô versus hypopodion. Nestle-Aland suggests that hypopodion crept in with later assimilation to Luke. It might just as easily be suggested that the assimilation was 
to the LXX. In many manuscripts it was (the Koine group, for example). Hence, whether assimilation was to Luke or the LXX seems to vary with the manuscript, but assimilation can explain hypopodion. The original Matthean text, then, contained hypokatô. The preferred text for this Matthean citation, then, is confirmed.

The preferred text of Mark 12:36 is identical to the preferred Matthean text. Marcan variants include: kyrios (BD and a few others)] ho kyrios (HKTh and most other manuscripts); kathou] kathison (B); hypokatô (BDorw, 28 ,

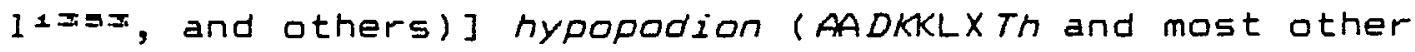
witnesses).

The problem of the article ho is again so complex that it would be wise to bracket it with respect to our interests. Much of what was said above regarding the Matthean text applies here as well. Codex D, for example, has its own characteristic way of dealing with the article before kyrios, and so its witness must be discounted. Here the witness of the best manuscripts, $B$ and $A$, goes in opposite directions. Codex Th is known to be of uneven qualitye, and although regarded by many as the chief representative of the Caesarean text, it is also copied by a scribe evidently unfamiliar with Greek. The fact that the Caesarean text-group is the most mixed of all the groups, mixing at least Alexandrian and Western readings, the late date of $T h$, and the late date and secondary nature of the 
Koine group, all suggest that assimilation was likely the key factor operating here. Under such reasoning, the original Mark probably had kyrios. Nevertheless, we must enter the same caveat as in the case of Matthew, and leave the matter in an inconclusive state.

The case of kathou versus kathison is difficult. While kathison is witnessed by only one manuscript, it is the important $B$. That all other manuscripts, including the rest of the Alexandrian group, witness kathou, could be simply a matter of assimilation to the LXX or one of the other synoptics. General text-critical methods would suggest kathison here because it could be explained as the one manuscript which did not get assimilated. Nevertheless, where would kathison come from, and why would it be used?

Regarding the third variant in the Marcan text, Bruce M. Metzger suggests that because hypokatô occurs in the preferred text of the Matthean parallel, as opposed to hypopodion of the LXX, Mark likely contained the former. Copyists working later on the book of Mark would have altered the original hypokato to hypopodion because this is the "correct" reading found in the Septuagint, 9 and witnessed in the parallel Luke 20:43 and in Acts 2:35.10 Metzger's words are, "the preferred text of Matthew (22.44) supports Mark's substitution of hypokatô... for the Septuagint's hypopodion." This wording, and the argument above for the original occurrence of hypokatô in Mark, 
implies the hypothesis that Matthew used Mark, which is, for our purposes, in question.

Metzger considers "the priority of the Gospel according to Mark" to be one of the criteria used in choosing among conflicting readings in the witnesses, in the practice of NT text criticism.11

The text given for Mark (hypokatô) in this case is given a "C" rating. This means that in the opinion of the editorial committee of the third edition of the United Bible Societies' Greek New Testament, the text of which is identical to that of the twenty-sixth edition of the NestleAland Novum Testamentum Graece, "there is a considerable degree of doubt whether the text or the apparatus contains the superior reading". ${ }^{1}=$ Considering this ambivalence on the part of the committee, and the reasoning supplied by Metzger, which in this case assumes the very proposition we are attempting to investigate, Metzger's argument must be thrown out of court.

External evidence is split; Alexandrian manuscripts $A$ and $L$, and the Caesarean Th witness hypopodion, while the Alexandrian $B$ and the Western $D$ witness hypokato.1= Considering that $D$ is particularly subject to parallel influence from the other gospels ${ }^{14}$, the weight tips to hypopodion, if it tips at all.1' The preferred text for this citation in Mark is confirmed, then, except for a possible preference for the variant hypopodion. 
Luke 20:42-43 has the same preferred text as Matthew except that hypopodion is in place of hypokatô. Lucan variants include: eipen] legei (D, it); kyrios (BD, 579)] ho kyrios for all other witnesses; hypopodion (all other manuscripts)] hypokatô (D, it, syce).

The first Lucan variant, legei, has only weak witnesses, and so is easily dismissed. As for the article ho the discussions above for Matthew and Mark suffice. The variant hypokatô is usually assumed to be an assimilation to Mark and Matthew. ${ }^{16}$ This is particulary likely with the weak witnesses and the fact that $D$ tends to assimilate to parallel passages. The preferred text for this Lucan citation, then, is confirmed.

The preferred LXX text (Ps 109:1) is identical to the Matthean text with the following exceptions: kyrios] ho kyrios; hypokatô] hypopodion. There is only one variant cited in Rahlfs for the LXX text: ho kyrios] kyrios in the Verona Psalter (designated R by Rahlfs; not to be confused with the NT manuscript $R=$ uncial 027).

Since the use or non-use of the article ho is problematic to the point where we have decided to bracket this variant from the discussion of our central problem, there is no need to discuss this variation with regard to the LXX text.

The MT text (Ps 110:1) is:

$n$ 'm yhwh I'dny sb Iymyny 
'd-'syt 'ybyk ham lrglyk.

Verbatim agreement with the LXX virtually throughout indicates that this was the text used by the evangelists.17

The only part of the citation which remains to offer any leverage for our main concern is hypokatôl hypopodion. The original Matthean text had hypokato, 1 while the original Lucan text had hypopodion.

If both used Mark, as the two-document hypothesis suggests, why do their texts differ? Gundry notes "the occasional assimilation to the LXX in Lk."10 Heinrich Julius Holtzmann claimed that Luke would on occasion simply open the LXX and copy. $=0$ It could be argued that in this citation Luke has strictly copied the LXX. The fact that the article ho does not appear in the preferred Lucan text should offer no difficulty. Witness for the article is found in more Alexandrian texts than witness against, and that $D$ has no article may only indicate assimilation to the other gospels. Hence, if anything, it is more likely that Luke originally had the article, than not. Therefore, if Luke did directly use the LXX, this could explain the occurrence of hypopodion in Luke, while Matthew had hypokatô, and allow the two-document position.

However, this would require that Mark had hypokatô. This is the preferred text, to be sure, but we have noted that assumption of the two-document position tipped the balance in what otherwise was a split decision between 
hypokato and hypopodion. If hypopodion was the original Marcan text - and the fact that hypokatô is found in D, suggesting that $D$ assimilated the Marcan text to that of Matthew, would help confirm this - the evidence of this citation would favour the Griesbach position. Here Matthew would have hypokatô, Luke would use Matthew (and therefore use this Psalm citation in the same narrative context) but correct the citation to the LXX, and Mark, who refers to both Matthew and Luke, noting the difference in the citation, would check the LXX and go with Luke's version.

Matt 3:3:

phônê boôntos en tề erêmô: hetoimasate tên hodon kyriou, eutheias poieite tas tribous autou.

Variations from the preferred text include: kyriou] kyriô (sya, sy=); eutheias poieite tas tribous autou] omitted by $k$, sy-); autou] tou theou hêmôn (b, syc).

Syriac manuscripts all labour under one heavy weight: they all can be traced back to Tatian's second century gospel harmony, the Diatessaron, rather than the four individual canonical gospels. To this, as with all versions, can be added the general problem of translation. In this citation the variants are supported by two manuscripts of the old Syriac. Manuscript sy" (called "Sinaiticus", to be distinguished from the Greek uncial commonly referred to by the same name) dates from the late fourth century, while syc 
(Curetonianus) is slightly later and probably a revision of the former. The exemplar is also likely from the fourth century. These texts are characterized by additions, omissions, transpositions, and paraphrases. In general, the old Syriac version represents the western text, which is not a strong witness to the original text.

The old Latin versions also represent the western text. They offer so many variant readings that Jerome once complained that there were almost as many versions as manuscripts. Therefore, although manuscript $k$ dates from around 400 and may have been copied from a second-century papyrus, and b dates from the fifth century, they offer poor witness to the original text.

For all three variant texts the only witnesses are from the versions; support of the major uncials, particularly the strong Alexandrian group, totally favours the preferred text. In addition, the use of tou theou hêmôn represents assimilation to the LXX. Hence the preferred text stands.

The parallel citation in Mark 1:3 has a text identical to that of the preferred Matthean text. It has two variant readings: autou] tou theou hêmôn ( $D$ and the majority of old Latin witnesses); after autou, whas Luke's continuation of the citation.

The first variant is poorly supported, with $D$ and the old Latin representing the western text. As with Matthew, tou theou hêmôn is simply an assimilation to the LxX. Codex 
w, for this part of Mark, is also Western. Therefore, the second variant not only has poor support, it is likely a mere assimilation to Luke. Hence, the preferred text stands. The preferred text of the citation in the parallel Luke $3: 4$ is also identical to the Matthean text as far as the latter goes. However, Luke continues on in $v v 5,6$ with the Isaiah text in fairly close agreement with the LXX:

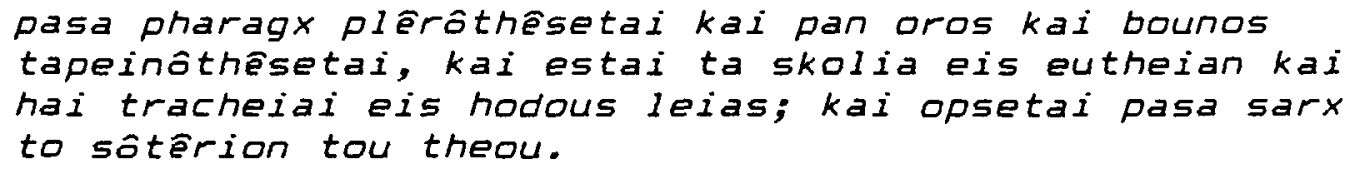

Variant readings include: after hodon, A and some other manuscripts add tou; autou] hymôn (D), tô theô hêmôn $\left(r^{2}\right.$, all of the important syriac manuscripts); eutheian (HKAWTh, I, ph and most other witnesses)] eutheias BD and some other manuscripts, and Origen; after leias, the Sahidic version and sy", sye insert kai apokalyphthêsetai hê doxa tou kyriou; to sôtêrion tou theou] ton sôtêra tou theou (Bohairic version), hoti elalesev to stoma tou kyriou (syc), to stama kyriou (D).

Codex $A$ is merely the oldest witness to the Koine text for the synoptics. Hence, it offers no real support for the variant insertion of tou after hodon. The variant reading, hymôn, does not stand, as it receives only the support of the Western text in $\mathrm{D}$. The variant reading tô theô hêmôn must also be rejected, because it is only supported by the 
seventh-century old Latin manuscript $r^{1}$ and the Syriac, both of which are Western.

The insertion, kai apokalyphthêsetai hê doxa tou kyriou, is found in the Sahidic version. Sahidic is an Upper Egyptian dialect of Coptic. The earliest extant Sahidic manuscript dates from the fourth century, but this version probably began in the second or third century. Usually it agrees with the Alexandrian text. However, in the gospels it has many western readings. This is the case here, as the only other support for this variant is the old Syriac, which is also Western. Scholars have recently discovered that there are many more dialects of Coptic than hitherto recognized. The history of the development of the coptic version and a critical edition of the Coptic version must await a consensus on these linguistic problems. Hence, at this stage, caution must be exercised with the Coptic versions. For this reason, and that the preferred text has the support of the proto-Alexandrian witnesses and those of most other text-types, the variant insertion, kai apokalyphthêsetai hê doxa tou kyriau, must be rejected.

In like manner the replacement of to sôtêrion tou theou by ton sôtêra tou theou in the Bohairic version must be rejected. The Bohairic version is a Coptic version, the earliest manuscript of which dates from the fourth century. Although this version probably originated in the third century, and may be related to the later Alexandrian text- 
type, the majority of manuscripts are quite late. In the case of our variant text, the majority of witnesses, including the strong proto-Alexandrian, supports the preferred text.

It is only with the twenty-sixth edition of NestleAland that eutheian replaced eutheias in $\vee 5$ as the preferred text. It is not difficult to see why this is such a close decision. In favour of eutheian, is the majority of Alexandrian witnesses, including the proto-Alexandrian $A$, the Koine, the Caesarean ( $T h, 1, p h)$, and most other manuscripts. In support of eutheias, there is the protoAlexandrian $B$, and the western $D$.

Origen also witnesses to eutheias. While Origen can sometimes be consistent with the proto-Alexandrian texttype, he is notorious for seldom citing a passage twice in exactly the same words. In addition, there are the problems which plague all attempts to rely on patristic citations. Since, as is the case for the NT text itself, the works of the Fathers also underwent modification in the course of transcription, we must ask if we have the correct text of the particular Father. Scribes would be tempted to assimilate sciptural quotations in the Fathers to the form of text with which the scribes were familiar. Hence, even though the importance of Origin's quotations is evidenced in such things as that the existence and character of the Caesarean text must finally rest upon Origen's quotations $=1$, 
his quotations are slippery ground indeed upon which to base any argument for the determination of the original text.

The external evidence, then, seems to favour eutheian, although the case is not a decisive one by any means. One of the arguments likely offered in favour of eutheias would have been that it is a different text than that of the LXX, and so, unlike eutheian, would not result from assimilation. Indeed, there are not even any variant readings of the LXX text which have eutheias. The preferred text stands in its entirety.

The LXX for Isa 40:3 differs from the Matthean citation only in that instead of autou there is tou theou hêmôn. The only variant text of any significance is the addition after poieite of dia tês abatou in the margin of $Q$ and in several late minuscules. This reflects an assimilation to the MT in the minuscules and is of no importance in the determination of the original text. Notes in the margin of $Q$ are often useful for determining the Hexaplaric text. In this case, however, as often is the case, there is no accompanying note to indicate that the addition was Hexaplaric.

The preferred text of the LXX for that part of Isa 40:4,5 cited by Luke differs from the Lucan citation in the following respects: panta is inserted in the LXX after estai; hai tracheiai] hê tracheia; the whole of Isa 40:5 in the LXX reads kai ophthêsetai hê doxa kyriou, kai opsetai pasa sarx to sôtêrion tou theou; hoti kyrios elalesse of 
which Luke selected only kai opsetai pasa sarx to sôtêrion tou theou.

Variations in the LXX for that part of Isa 40:4,5 cited by Luke include: tapeinôthêsetai] tapeinôthêsontai in several minuscules; panta] omitted by $A V$ and several minuscules, marked with an obelus (indicating that this is not found in the Hebrew) by $Q$ and the Syro-Hexaplar; he tracheia] hai tracheiai in several minuscules; hodous leias] pedion (V), pedian (A), pedia (B, the Hexaplaric and Lucianic recensions).

The replacement of tapeinôthêsetai by tapeinôthêsontai is simply to correspond to the plural form of the verb found in the Hebrew. It is unimportant in a search for the original text because it has only the support of some minuscules. The same applies to the replacement of hê tracheia by hai tracheiai, except that here the assimilation was probably to Luke. The preferred text stands in these two cases.

The omission of panta by $A V$ and several minuscules is simply an assimilation to the Hebrew, or even to Luke. What argues for its retention in the original text is that it is found in the strongest witness to the Alexandrian text, $Q$, but marked with an obelus, indicating that the scribes of $Q$ were aware that panta was not in the Hebrew. That they kept it indicates it was in their exemplar. 
Forms of pedia, on the other hand, are assimilations to the Hebrew and should be rejected for the original text because they are found in the Hexaplaric text (including its strongest witness, B) and the Lucianic text, which is a descendant of the Hexaplaric. Both of these recensions altered the LXX toward the Hebrew text, so the change we find here is not unexpected. The preferred text stands as it is witnessed by the strongest Alexandrian manuscripts $Q$ and A. Hence, the preferred text stands in its entirety.

The MT text for Isa $40: 3$ reads:

qw1 qwr

bmmdbr pninw drk yhwh

yssrw b'roh mslih l'ihynw.

That part of Isa 40:4,5 cited by Luke alone, in the MT reads:

kl-gy' ynnw' wkl-hr wgb'h ysplw whyh h'qb Imyswr whrksym 1 bq' $h$; wiglh kbwd yhwh wr'w kl-bsr yhdw.

The preferred text of the LXX for the Matthean citation (Isa 40:3) follows the MT closely in the first part (k1 ... yhwh; phône... kyriou). Both use the imperative for both verbs. However, the phrase b'rbh finds no equivalent in the Greek, and the plural tas tribous does not accurately render the singular mslh. The gospel citation is, therefore, taken from the LXX:2. The autou replaces tou theou hêmôn, because the application is to Christ and not to Yahweh.= = Hexaplaric variations on the LXX include: boôntos] kalountos (Aquila, as indicated in Eusebius); eutrepisate 
tên hodon kyriou omalisate en abatô hodon tô theô hêmôn

(Symmachus, according to Eusebius; Aquila and Theodotion

have aposkeuasate for eutrepisate, according to 86).

Here b'rbh, missing in the LXX, is rendered by en

abatô, and the singular mslh is rendered by the singular

hodon, unlike the plural tas tribous of the LXX. The order

of the words in the Hebrew has been preserved in these

Hexaplaric variants. Clearly, however, the gospels have not

used a Greek text assimilated to the Hebrew in these

respects.

A comparison of the citation of Isa $40: 4,5$ as found in

Luke with that in the LXX and the MT proves of value in

determining what text Luke uses when on his own. First, his

omission of kai ophthêsetai hê doxa kyriou, as found in the

LXX, makes sense considering the application to Christ. Luke

omits hoti kyrios elalese as superfluous for his purposes.

For Isa 40:5, then, Luke appears to use the Lxx with

reasonable omissions.

Luke's omission of panta in $\vee 4$ might seem to suggest

that Luke is not using the LXX. LXXA also lacks panta. As a caveat in this respect, however, it ought to be noted that Ziegler characterizes $A$ as assimilating in several places to the NT.=4 In this case $Q$ presents a better witness to the Alexandrian text than $A$, so that if Luke was using the Alexandrian text he would have used something closer to $Q$. He was not, as Q had panta. 
Did Luke use the Hebrew as a comparison, or did he use some other Greek text which assimilated to the Hebrew? A look at the witnesses to the Hexapla indicate several texts which Luke did not use: plêrôthêsetai (LXX, Luke)] eparthêsetai (Aquila, according to 86), hypsôthêtô (Symmachus, according to 86); ta skolia eis eutheian] to perikampes eis euthytêta (Aquila, according to 86 and Chrysostom); hodous leias] pedion (Aquila, Symmachus, according to marginal notation in Codex Q), pedia (Theodotion, according to marginal notation in Codex $Q$ ). Hence, it appears that Luke did not use a text heavily assimilated to the Hebrew, such as we find in the Hexaplaric witnesses.

Luke is similar to the Hebrew in that he uses the plural hai tracheiai corresponding to the plural rksym, rather than the singular hê tracheia found in the LXX. He also omits panta. This would all seem to indicate that Luke uses the standard LXX text, but alters it himself to conform to the Hebrew. However, if this were the case, why does Luke not make other changes as well? For example, why did he not make the change so many late minuscules made, tapeinôthêsetai to tapeinôthêsontai? Why did he not make changes similar to those which the Hexapla made, especially to the obvious forms of pedia which would correspond to the Hebrew lbq'h? Hence, he does not seem to have used the Hebrew as a corrective to the $L X X$. 
The question remains, then, where did he get the change hai tracheiai from hê tracheia? Likely Luke made this change himself as a matter of style. He selected the plural to correspond to the plural predicate eis hodous leias, and the plural ta skolia eis eutheias of the previous parallel clause.

In conclusion, Luke does not use the Hebrew to make his own translation. He is too close to the LXX (plêroô instead of epairó for ynns', for example) in everything but the omission of panta and his own stylistic change to hai tracheiai from hê tracheia to have used any other source. Even the amission of panta could have been for style, to give an exact parallelism between the two clauses, ta skolia eis eutheias and hai tracheiai eis hodous leias. What is of significance, and what has made this lengthy discussion worthwhile, is that in places where, on first glance, Luke may have appeared to have altered the LXX to the Hebrew, it is possible that he has simply made stylistic changes that coincidentally corresponded to places where the Hebrew differed from the $L X X$. A second possibility is that Luke's Isaiah text showed this much assimilation to the Hebrew, but we have no evidence for this.

Since the citation of Isa $40: 3$ is in an identical form for all three gospels, $x=$ and yet differs from the form found in the LXX in that tou theou hêmôn is replaced by autou, little can be said except that the LXX was used but 
with an adaptation for Christian purposes. To be able to say anything about the symoptic relationship, we must go outside the citation itself.

Against Matthew and Luke, Mark has the Isaiah quotation preceded by a quotation from Exodus and/or Malachi found also in Matt 11:10 and Luke 7:27.:5 The idea connecting the citations in Mark is that of preparing (although two different verbs are used in Greek $2>$ ) tên hodon.

The problem for the Griesbach position here is why Mark omits the narrative common to Matthew (11:7-19) and Luke (7:24-35), but inserts its quotation at $1: 2$.

Under the two-document hypothesis the narrative common to Matthew and Luke but missing in Mark must be assigned to source $Q$. Coincidentally, Mark used at the beginning of his gospel (1:2) a quotation from Exodus/Malachi found also in $Q$ (cf. Matt 11:10; Luke 7:27). Matthew and Luke, working independently of each other, would have both chosen to omit the Exodus/Malachi quotation, perhaps because they realized that it could not follow an introductory formula naming Isaiah as the source for the quoted material. That the quotation was to be cited later in their gospels may also have been a factor in the omission. $=0$ The coincidental omission of Mark 1:2 in Matthew and Luke is problematic, but perhaps easier explained than the procedure required by the Griesbach hypothesis. Thus the evidence for this quotation seems to favour the two-document hypothesis. 
Matt $21: 42:$

Lithon hon apedokimasan hoi oikodomountes, houtos egenêthê eis kephalên gônias; para kyriou egeneto hautê kai estin thaumastê en ophthalmois hêmôn.

There are no significant variants from the preferred text of the twenty-sixth edition of Nestle-Aland.

The preferred text of this citation in the parallel Mark 12:10-11 is identical to that in Matthew. There are no variant manuscripts 1 isted in Nestle-Aland for the Marcan text.

The preferred text of this citation in the parallel Luke 20:17 is identical to that of the first two lines in Matthew and Mark (Lithon hon apedokimasan hoi oikodomountes, houtos egenêthê eis kephalên gônias), but omits the last two lines (para kyriou egeneto hautê kai estin thaumastê en ophthalmois hêmôn). 20 There are no variant manuscripts listed in Nestle-Aland for the Lucan text.

The preferred text of the LXX (Ps 117:22-23) is identical to that of Matthew and Mark. Variants in the LxX text as cited by Rahlfs are few and insignificant, occurring only in a few Latin manuscripts and other late material.

The MT text (Ps 118:22-23) is:

'bn m'sw hbwnym hyth 1r's pah

$m^{\prime} t$ yhwh hyth $z^{\prime} t$ hy' npl't b'ynymw.

The LXX and the MT correspond closely for this passage, except for the kai before the last clause of the Greek. The 
exact wording, including the $k a i$, of the $L X X$ is found in all three gospels, indicating that the LXX was the source of this citation. That this quotation, common to all three synoptics, is of Septuagintal form supports Holtzmann.

Matthew could have used Mark here, or Mark could have used Matthew. Because the form of quotation is identical in both books, there are no grounds for choosing either of the Griesbach or two-document positions over the other. The fact that Luke lacks Ps 117:23 (LXX) does not help a decision. In Griesbach terms, Mark would have chosen Matthew's longer version over Luke's abbreviated quotation. On the basis of the two-document hypothesis, Matthew does not know Luke. In a discussion of this quotation, Luke is not a necessary source in either viewpoint. The only question would be why Luke abbreviated the quotation he found in his source (Mark or Matthew), and this does not bear on our problem.

Matt 15:4b:

ho kakologôn patera ê mêtera thanatô teleutató.

There are no textual variations in Nestle-Aland for this citation.

The parallel preferred text of Mark 7:10b is identical to that of Matthew. The Marcan text has no significant variants.

Codex $B$ of the $L X X=0$ for Exod 21:16 has the same text as the Matthean citation with the following exceptions: 
autou is found after patera and mêtera; thanatô teleutatô] teleutêsei thanatô.

There is one significant variant: teleutêsei thanatô] thanatô teleutatô (AFM, several minuscules, the Greek works of Origen).

Codex $A$ is often an eclectic text. $=1$ Codex $F$ (Ambrosianus), where it differs from $B$, tends to agree with A, particularly in Exodus.:= Codex M (Coislinianus) frequently agrees with $A_{.}=:$Here we have a case where $A, F$, and $M$ do agree. However, the possibility of assimilation to the gospel citation cannot be ruled out, especially considering that $v \vee 15,17$ of $A$ render the Hebrew mwt ywmt with thanatô thanatousthô.

The MT text for Exod 21:17 reads:

wmal11 'byw w'mmw mwt ywmt.

The LXX shows some variance to the Hebrew. The usual Lxx rendering for $q 1 i l$ is katarasthai, rather than the kakologein employed here. Some texts, such as that of Philo, lack the possessive autou's which correspond to the Hebrew pronominal suffixes. Philo lacks these in the previous verse, as well.

The Hebrew mwt ywmt, which in English yields "will surely be put to death", is construed differently in various manuscripts. These two Hebrew words end $v v$ 15-17 (corresponding to $v v 15,17,16$ in the LXX), yet Codex $B$ renders the same Hebrew words in three different ways: 
thanatô thanatousthô ( $v$ 15), teleutesei thanato ( $v 16$ ), thanató teleutató ( $v 17$ ). Philo has thanatô teleutatô ( $v$ 15), and thanatô teleutató ( $v 16)$. Codex A has thanato thanatousthô ( $\vee 15)$, thanatô teleutató ( $\vee 16)$, and thanatô thanatousthô ( $v 17)$. In not even one of these verses, then, do all three of these witnesses bear the same text.

The gospel form of the citation comes from the LXX, rather than the Hebrew. It uses kakologein which does not correspond to the Hebrew q111. It lacks the possessive autou, suggesting it may have come from a form of the LXX like that known to Philo. The use of thanatô teleutatô, with teleutatô found in Philo but not in LXX”, also suggests the citation may have come from a form of LXX like that of Philo. However, we should also reckon with the possibility of confusion with the other renderings of the same Hebrew in the immediate context.

Because the Matthean and Marcan citations are identical, and there is nothing in the citation which indicates it would fit more meatly into either the Matthean or Marcan context, it is impossible to derive any conclusions regarding the synoptic relationship here. Nevertheless, some useful observations can be made. since the wording in the context of the quatation is so different in the two gospels, it is remarkable that the wording of the citation itself is identical, particularly when it is apparently not the same as the LxX, and, on the 
other hand, clearly is not a direct translation of the Hebrew. This suggests that Matthew used Mark, Mark used Matthew, or they both used a common source. In other words, unless we are to attribute the identical quotation in the gospels to scribal assimilation that has been so early and complete that no manuscript evidence remains to show this has happened, this citation offers very cogent evidence that some synoptic relationship does exist. The Septuagintal form of this quotation, common to Matthew and Mark, confirms Holtzmann.

Matt $19: 4:=4$

arsen kai thêly epoiêsen autous. There is only one variant listed in Nestle-Aland: autous] omitted in a fourth or fifth century Syriac palimpsest, and an eleventh century Latin manuscript. This word has likely been omitted because it has no antecedent in the text as it is cited. It has an antecedent in its context in the Lxx, however. The preferred text, therefore, offers the lectio difficilior, and all the major strong witnesses, and clearly stands.

The preferred text of the parallel, Mark 10:6, is identical to the preferred text of Matthew. It is followed immediately by another OT citation, whereas in Matthew the two citations are separated by $k a i$ eipen, which refers back to the speaker, Jesus. However, there is no attempt to 
combine the two citations into one, or even to give the appearance that one citation is being offered.

Variants in the Marcan text are: autous] omitted by DW and most of the 0ld Latin witnesses; the addition after autous of ho theos by ADKTHW, a number of other uncials, 1 and $p h$, the Vulgate and some old Latin witnesses, and the majority of Syriac witnesses.

The omission of autous occurs only in weaker witnesses. Uncials DW both tend to be irregular and relatively free. While they are capable of preserving the original text, in this case there is no confirmation by such strong witnesses as the Alexandrian group. The omission of autous is likely for the same reason as posited for the Matthean text. Some assimilation between variant texts may have occurred, as well.

The addition of ho theos to the Marcan text also occurs in the weaker witnesses to the original text. For example, codex $A$ is merely the oldest witness to the Byzantine family of manuscripts, in the synoptics. $=5$ W (uncial 032), a fifth century manuscript $=4$, shows almost equal agreements with the Alexandrian, Koine, and Western groups in this part of Mark. I7 The Lake family of minuscules (1) and the Ferrar group of minuscules $(\rho h)$ preserve a Caesarean/Western text current in Caesarea in the third and fourth centuries, which for Mark is also found in codex Th. These simply confirm the witness of $w$. 
The preferred Marcan text, which lacks ho theos, is witnessed by $A B C L D$ and a few other uncials, and the sahidic and Bohairic texts. Uncials AB, as members of the protoAlexandrian group, furnish strong witness to the original text. Manuscripts $D$ and Bohairic represent the later Alexandrian group in Mark. Codex L (uncial 019) is an Egyptian text, which group ranks just after the Alexandrian group as a strong witness to the original text. Codex $C$ is also considered a strong witness. External evidence, then, strongly favours the preferred text.

It is not difficult to explain the addition of ho theos by later scribes. $=0$ It is the subject of the citation as it occurs in the OT. Matthew has ho ktisas as the subject, which appears outside the citation, but forms a sentence which is completed by the citation: Mark, however, lacks ho ktisas. The subject of the verb epoiesen is the implicit "he". Hence, copyists would want an explicit subject, since one has not been given earlier in the text. They chose the subject provided in the LXX. $=9$

The preferred text of the LXX for that part of Gen 1:27 cited in Matthew and Mark is identical to the latter. The full text for the verse reads:

kai epoiêsen ho theos ton anthrôpon, kat eikona theou epoiêsen auton, arsen kai thêly epoiêsen autous.

There are no significant variant texts for the cited passage. 
The MT text for that part of Gen 1:27 which is cited in Matthew and Mark reads:

$z k r$ wrigbh br' 'tm.

Since the LXX and the MT texts agree, the evangelists could have used either but, in view of the verbatim agreement with the LXX we must assume the LXX. Because the preferred texts of Matthew and Mark are identical, this citation itself offers an example which can provide no evidence vis-a-vis the synoptic problem.

The only hint of direction of usage lies outside the citation itself. It is possible that, realizing the verb epoiêsen had only an implicit subject in Mark, Matthew added ho ktisas ap' archês to provide an explicit subject. It is worth noting that he did not use ho theos from the LXX. It is difficult to imagine Mark's chariging Matthew's explicit subject to an implicit one. In this case the two-document position is favoured over the Griesbachian.

A second possible alteration by Matthew of the Marcan text, also outside the citation itself, is the replacement of de with ouk anegnôte. There are no textual variants for this in Matthew or Mark, and it is difficult to imagine why, if Matthew were used by Mark, Mark would have deleted the ouk anegnôte. On the other hand, one can easily imagine Matthew adding this to Mark to draw attention to the fact that the following citation is a citation from the Torah, 
and, hence, makes it a valid reply by Jesus to the Pharisees.

Matt 22:39:

agapêseis ton plêsion sou hôs seauton.

There are no variants 1 isted in Nestle-Aland for this text.

The parallel preferred text in Mark 12:31 is identical to the Matthean version. Here, as well, there are no significant textual variants.

The preferred text of the parallel citation in Luke 10:27b is identical to the Matthean and Marcan versions, provided the agapeseis from the beginning of the verse in the previous citation is understood to be repeated immediately before ton plession. There are no textual variants here either. The principal difference is that in Matthew and Mark this citation is spoken by Jesus, whereas in Luke it is not.

This citation is identical to part of Lev 19:18 in the LXX. There are no significant textual variants.

The citation as it appears in the gospels is taken from the middle of Lev 19:18; in the MT this reads:

w'hbt ir'k kmwk.

Because the gospel citation is identical with the Lxx, even in the use of the future agapesseis, it has come from 
the LXX. Once again, the Septuagintal form of a quotation common to all three synoptics confirms Holtzmann. The Lucan quotation is placed in a different setting than that of Matthew and Mark. Here the discussion concerns eternal life and a lawyer utters the quotation; in Matthew and Mark the discussion concerns the commandments and the quotation appears on Jesus' lips. However, in both the twodocument and Griesbach hypotheses Luke is not the primary source; either Matthew or Mark is. Because these two have identical wording in the citation, and there is no adaptation of context to citation in either case, it is impossible to draw any conclusions on which came first.

Matt 21:13:

ho oikos mou oikos proseuchês klêthêsetai.40

There are no textual variants 1 isted in Nestle-Aland for this passage.

The Marcan parallel (Mark 11:17) is identical in its preferred text to the Matthean citation, but adds pasin tois ethnesin. There are no significant variants.

The preferred text (found in Nestle-Aland) of the parallel in Luke 19:46 differs from the Matthean text in that estai is added to the beginning and klêthesetai is missing. As well, there are the following textual variants: estai] replaced with hoti in CADKW and a great many other 
witnesses; estin is added to the end by CKADW and many other witnesses.

The two textual variants are essentially one. It is simply a matter of having estin or estai to replace the missing verb klêthêsetai. For this part of Luke AW are Koine, and, therefore, give no additional support. Codex D is a weak witness for the original text. This leaves only codex $C$ of the uncials. This manuscript, although it dates from the fifth century and in some places can be grouped with the later Alexandrian text-type, is compounded from al the major text-types, agreeing frequently with the koine, as it does here. Hence, c offers no additional support for the variant text. All of the strong support (such as $A B$ ) favours the preferred text; hence, it stands.

The preferred text of Isa 56:7 in the LXX differs from the Marcan text in two places: it inserts gar, beginning ho gar oikos; it has pasi where Mark has pasin. The latter is simply an orthographic difference. The gar is a conjunction joining the clause following to what goes before. Since Mark is not citing the whole verse, it makes sense to omit the gar.

There is only one variant manuscript cited in Ziegler. The twelfth century minuscule 538 omits pasi tois ethnesin. This is probably due to assimilation to the Matthean and Lucan texts.

The MT for Isa $56: 7$ reads: 
ky byty byt-tplih yppr' lk1-h'mmym.

The LXX and MT texts correspond closely. Verbatim agreement with the LXX indicates that it is the source for the quotation in the gospels.

Speculation on the symoptic dimension of this citation appears to lead nowhere. If we assume Markan priority, Gundryal has suggested that Matthew omits pasin tois ethnesin to avoid diverting Jewish readers from the main point, which supposedly is that the temple is a place for prayer, not business. Alternatively, if Matthew and Luke are both post-70 (as nearly all agree), there was no longer any point in calling the temple a place of worship for all nations, and coincidental omission of the Marcan phrase is not impossible. But this is far from certain.4= If we assume the Griesbach position, Luke would have largely reproduced the quotation as he found it in Matthew; Mark, on the other hand, would have added pasin tois ethnesin, perhaps for theological reasons, to show a mission to the gentiles. This might seem a simpler explanation than the coincident omission of a phrase in Mark by Matthew and Luke, as required by the two-document position. But the theological explanation for Mark's procedure is not entirely satisfactory either; a Mark writing after Matthew and Luke would surely know of the temple's destruction, and there was little to be gained by labelling the temple a location for the worship of all nations at such a time. Incidentally, 
Matthew's omission of pasin tois ethnesin requires

explanation on either hypothesis, either as an omission from Mark (the two-document position) or as one from Isaiah (the Griesbach position).

Theological arguments or arguments which presuppose the solution of introductory problems like audience and purpose of writing are not the best criteria for solving the synoptic problem, since usually the procedure is to go the other way and presuppose a solution to the synoptic problem before resolving introductory and theological issues.

Finally, Luke's use of estai instead of the Hebraism klêthêsetai cannot tell us whether he used Mark or Matthew, or even rule out that he himself was the prior gospel, because Matthew and Mark could always have simply reverted to the Lxx. This quotation is at least an example of the Septuagintal character of a quotation common to all three gospels, as Holtzmann's argument suggests.

Matt $4: 4:$

ouk ep' artô monô zêsetai ho anthrôpos, all' epi panti rhêmati ekporeuomenô dia stomatos theou. Variations in the text are as follows: epi] en (CD and others); al1.... theou is omitted by the old Latin codex $k$ and Irenaeus; ekporeuomenô dia stomatos is omitted by $D$, the old Latin codices a $b g^{1}$, and Clement of Alexandria. None of the witnesses cited for any of these variant readings are 
strong evidence for the original text. The critical notes in Nestle-Aland suggest, with good reason, that the longer omission is an assimilation to the Lucan text. Hence, the preferred text stands.

The preferred text of the parallel citation in Luke 4:4 is identical to that of Matthew except that all... theou is lacking. There is only one variant: al $1^{\prime}$ epi panti rhêmati theou is added by KADTh and a great many other manuscripts. In Matthew and Luke codex Th is among the Byzantine group, so that it and codex A only confirm the Koine and offer no additional witness. Codex $D$ is always suspect of assimilation to the other synoptics. Nestle-Aland suggests assimilation to the Matthean text here, as does Metzger.4: This is likely the case. If the longer form had been original with Luke, it would be necessary to explain why so great a variety of text-types (including manuscripts like $A B$ ) have chosen to omit this latter clause. Hence, the preferred shorter text stands.

The preferred text of the LXX for Deut 8:3 is identical to that of Matthew except that it repeats zêsetai ho anthrôpos at the end, and uses the article tô with ekporeuomenâ.

There is only one textual variant which poses even the slightest pretext for discussion: tâ] omitted by AF and much of the Catena group. Since $A$ is lacking in Deuteronomy, and $B$ is not always the best text for Deuteronomy, 44 A thus 
gains in stature. This is particularly the case because, for the passages to which it witnesses, papyrus 458 (about 50 BCE) shows remarkable agreement with $A$, and likewise for the second-century papyrus 963.4: Therefore, although scholarly opinion on the value of $A$, in general, may be quite varied, and although it does possess an eclectic character, A must be considered a valuable manuscript for Deuteronomy.

In this case BMV and the vast preponderance of textual witnesses bear the preferred text. Since this reading is in conflict with the witness of $A$, the case is a difficult one. Internal evidence favours neither the omission nor the retention of the article, as grammatical practice is indifferent to both. Hence, the evidence allows no decision here.

The MT text for Deut 8:3 for the part cited in Matthew reads:

$$
\text { 1. 1-hlhm lbdw yhyh h'dm ky'1-k1-mws' py-yhwh. }
$$
It repeats yhyh $h^{\prime} d m$ at the end, corresponding to the repetition at the end of the LXX verse.

The LXX and MT correspond fairly closely except that the Hebrew $k l$ is expanded upon to yield the Greek panti rhemati, yhwh is rendered by theou, and dia is added. It is clear that the evangelists used the LXX version. 40 The fact that the article to before ekporeuomenô is not found in the gospels does not indictate the use of a non-LxX text, because its inclusion in the LXX text is debatable. 
As to the synoptic relationship regarding this citation, the Griesbach position would be in difficulty to explain why Luke would have omitted the last half of the citation as it appears in Matthew. On the other hand, if this is $Q$ material, in the two-document hypothesis, the shorter version would be in Q,47 and Matthew would have filled it out with the LXX, the clause ekporeuomenô dia stomatos showing how accurately he followed the LXX. It is worth noting that here is a case of a non-Marcan quotation with Septuagintal form.

Matt $4: 6:$

tais aggelais autou enteleitai peri sou ... epi cheirôn arousin se, mêpote proskopsês pros lithon ton poda sou.

There is only one textual variant 1 isted: after peri sou two manuscripts of the ald Syriac, sy= and syp, add tou diaphylaxai se. Manuscript sy= is a fourth century palimpsest, often called Sinaiticus (not to be confused with codex A, called Codex Sinaiticus). It bears a close relationship to Tatian's second century gospel harmony, the Diatessaron, and is characterized by additions and omissions. It is usually grouped with the western text-type. Manuscript syp is the Peshitta, the most widely attested and most consistently transmitted of the Syriac NT versions. Tradition credits it to Rabbula, bishop of Edessa (411-435), who sought a revision which would supplant the divergent old 
Syriac translations. It is now believed that he was responsible for an early stage of development of the Peshitta, of which we have the final stage. In the gospels it is closest to the Koine text-type. Considering the character and text-types of these two Syriac manuscripts, there seems Iittle doubt that the addition of tou diaphylaxai se to the Matthean text resulted from assimilation to the Lucan text. Hence, the preferred text of Matthew stands.

The preferred Lucan text (Luke 4:10-11) is identical to the preferred Matthean text except that tou diaphylaxai se is found after peri sou at the end of $v 11$. There are no significant textual variants.

The preferred text of the LXX for Ps 90:11-12 is identical to the citation in Luke except that after tou diaphylaxai se is found en pasais tais hodois sou. There are no significant variants for that portion which is cited.

The MT for Ps $91: 11-12$ reads:

ky $m 1$ 'kyw yswh-lk lsmrk bkl-drkyk

' l-kpym ys'wnk pn-tgp b'bn rglk.

The LXX renders the Hebrew closely. The gospels probably used the LXX, because it is unlikely that if they had translated directly from the MT they would have used the same order of wording as that used in the LXX.

This citation provides a good example of a case where the LXX is cited accurately but part of it is left out as 
unnecessary for the narrative context. Here the devil challenges Jesus to leap from the pinnacle of the temple. The second verse cited, epi cheirôn... ton poda sou, specifically covers protection from an incident such as that specified in the challenge. Therefore, it is only necessary to cite that part of the OT which mentions God commanding his angels to offer protection. It is unnecessary to include the elaboration of this protection for all cases (en pasais tais hodois sou), when the narrative is dealing with only one case, and that one covered in the detail of the second verse cited.

Whoever in NT times was the first to use this citation, be it source $Q$, Matthew, Luke, etc., assuming they wished to omit whatever was not necessary in the context of the narrative, could do two things. They could omit only en pasais tais hodois sou, leaving the infinitive phrase tou diaphylaxai se as the natural continuation of the verb enteleitai, or they could also omit tou diaphylaxai se understanding enteleitai peri tou in the sense of "give orders concerning you" or, as the RSV translates, "he will give his angels charge of you", so that tou diaphylaxai se is simply in apposition to enteleitai peri tou. We see each of these options in Matthew and Luke. The problem is which option appeared first.

It would appear to make little sense to remove the infinitive phrase tou diaphylaxai se, if this were the form 
in which the NT tradition first appeared. Therefore, either Matthew was used by Luke, as Griesbach would have it, or Matthew's version appeared in $Q$, as the two-document hypothesis would have it. The longer version in Luke is a result of Luke's understanding the need for an infinitive to complete enteleitai. Observations regarding this citation, then, favour neither the Griesbach hypothesis nor the twodocument hypothesis over the other.

Matt $4: 7:$

ouk ekpeiraseis kyrion ton theon sou. There is only one variant manuscript listed: ouk ekpeiraseis] ou peiraseis in D. This is a fine example of the tendency of $D$ to differ from other text-types. Here the verb peirazo, which is found abundantly throughout the NT, is substituted for ekpeirazo, which, other than in the parallel text in Luke, is found only in two other NT locations, Luke $10: 25$ and 1 Cor 10:9. The change from ouk to ou is, of course, simply a matter of the usual orthographic change which accompanies the change to a consonant at the beginning of the following word. The preferred text stands.

The parallel text in Luke 4:12 is identical to its Matthean counterpart. It has no significant textual variants.

For Deut 6:16 the LXX has a text identical to that cited in Matthew. There are no significant textual variants. 
The preferred text stands, particularly in this case where the second century papyrus 963 supports it.4e

In the MT Deut 6:16 reads:

l' tnssw't-yhwh' Ihykm.

Unlike the Hebrew, which uses the second plural in the cited passage, the LXX uses the second singular. In the LXX this is a consistent difference throughout the chapter, and probably is a result of understanding the people of Israel as a single entity, whereas here the Hebrew speaks to the people as many people.

On the other hand, the LXX slavishly copies the Hebrew tense. The Hebrew has the imperfect, which, in combination with the particle of negation l', constitutes a prohibition. The LXX has translated tnssw, which is in the imperfect, as future indicative (ekpeiraseis).

Here the gospels have used the LXX, because they have maintained the singular, which makes sense since a single figure, namely the devil, is being addressed in the gospel narrative, and because they have maintained the future indicative.

Because the texts of Matthew and Luke are identical, nothing can be said regarding their synoptic relationship.40 Note, however, the Septuagintal form of this non-Marcan quotation.

Matt $4: 10:$ 
kyrion ton theon sou proskynesseis kai autô monô latreuseis.

There are no variants listed in Nestle-Aland for this text.

The preferred text of the parallel Luke 4:8 is identical to the Matthean text. There is one variant text cited in Nestle-Aland: kyrian ton theon sou proskynaseis (HDWIph, the Vulgate and some of the old Latin manuscripts, and a great many others)J proskyneseis kyrion ton theon sou (KATh, the Latin manuscripts a and $r^{1}$, and others).

Since the variant reading was the preferred text of the twenty-fifth edition of Nestle-Aland, we should expect evidence for each reading to be nearly equal. Strangely, this is not the case. In support of the variant reading are $A$ and $T h$, both Koine in Luke. so for the preferred reading, $A B$ are proto-Alexandrian, among the very strongest witnesses to the original text, $W$ is later Alexandrian for this part of Luke, 1 and $p h$ are early Caesarean, and $D$ is western. Hence, there is a great geographical spread among witnesses to the preferred text. Why was the variant the favoured text for so long? One can only guess. Probably it was due to the consideration of such possible internal evidence as that kyrion ton theon sou proskynesseis could be simply an assimilation to the Matthean text. The preferred text stands. 
For the cited text as found in Deut $6: 13$, the LXX has two variations from the Matthean citation: proskynêseis] phobêthêsê; monô] omitted.

The LXX text has only two variations of significance: phobêthêsê] proskynêseis (A); the addition of monô after autô (AFV, 963, and several whole families of manuscripts).

Because these are the very same variations that are in the text of the gospels there is the problem of whether the gospels used a text with the variations, such as one akin to $A$, or $A$ was assimilated to the gospels.si

since proskyneseis is found only in $A$, the

trustworthiness of which is a long-debated issue, the possibility of assimilation to the gospel text must certainly be explored. There are several strong points on the side of assimilation: (1) proskyneseis is not used to translate $y r^{\prime}$ anywhere else in the LXX; (2) Codex A has used proskynêseis in place of phobêthêsê, and added manô after autô in Deut 10:20, as well, again against the rest of the Lxx tradition; (3) proskynesseis is found in the preceding verse in both Matthew and Luke. This suggests that a change was made in the citation to correspond to this part of the narrative context.

The fact that papyrus 963 supports Codex A for the addition of monô but not for the use of proskynesseis should not suggest that the former variation constituted the original text. Rather, this likely points to gradual 
assimilation to the gospel text. The witness of papyrus 963 really may only indicate that such assimilation started in the secand century.s= Considering all of the above, the LxX preferred text stands.

For that part of the text in the citation, the MT for Deut $6: 13$ reads:

$$
\text { 't-yhwh 'Ihyk tyr' w'tw t'bd. }
$$

The LXX corresponds exactly to the MT. The verbs are in the singular in both cases. The Hebrew uses the imperfect $(=$ jussive) and the LXX uses the future. The order of the wording is identical.

Here is a case where the gospels or the gospel tradition has used a text differing from both the LXX and the MT, s: the latter two corresponding exactly. There certainly is no attempt to approach the MT.

If Codex $A$ was assimilated to the gospel tradition, the question remains as to whence came proskynēseis and monô. The fact that proskynessis is found in the preceding verse in both Matthew and Luke suggests that the change was made in the citation to correspond to this part of the narrative comtext. The devil has just offered Jesus all the kingdoms of the world if Jesus will only worship (proskynesês) him. Jesus then answers by soundly rebuffing the devil with this OT citation. As well, the context would make the addition of monô quite natural. Jesus is stressing that one should have "only" one master, God, not the devil nor God and the devil. 
Both gospels have the identical text. Both have adapted the LxX text in the same way to the narrative setting. The narrative and its neatly fitting citation may have been in a tradition used by both, such as $Q$.

Matt 11:10:

idou egô apostellô ton aggelon mou pro prosôpou sou, hos kataskeuasei tên hodon sou emprosthen sou.

There are no variant texts 1 isted in Nestle-Aland. We shall examine the Lucan parallel next, because the Marcan citation is found in a different context. The preferred text of Luke 7:27 differs from the Matthean text only in that egô is lacking.

The Lucan text has the following variant readings: egô inserted after idou ( $K A T h, p h$, and most other minuscules); emprosthen sou] omitted by $D$ and a few other uncials, and the greater proportion of the ald Latin witnesses. Manuscript Th is Koine for Luke and $A$ is Koine for the synoptics. Family $13(p h)$ is Caesarean. Since there are only Koine and Caesarean witnesses for egô, the preferred text stands. The insertion of egô was probably due to assimilation to the Matthean text.

Both D and the old Latin manuscripts are Western. This is poor support for the omission of emprosthen sou. Here there is possible assimilation to Mark, so the preferred text stands. 
The citation as it appears in Mark 1:2 differs from the Matthean text in that it lacks ego and emprosthen sou. Variant texts include these: egô (AKAW and most other uncials), the preferred text (BDTh and a few other uncials, and most of the old Latin manuscripts); emprosthen sou ( $K A$ and several versions).

For the first variant text the external evidence is almost evenly balanced; for the inclusion of ego there is a proto-Alexandrian witness in $A$, a Western witness in $W$ (for this part of Mark), and Koine witnesses ( $K A)$; against, there is the proto-Alexandrian B, the Western D, and the Caesarean Th. Perhaps the Caesarean witness might be considered to have slightly more weight than the koine witnesses, but this is not enough to tip the balance. NT assimilation could go either way, to egô as assimilation to Matthew, or excluding ego as assimilation to Luke. The argument for assimilation is stronger in the direction of the LXX, which in Exod 23:20 includes egô. Hence, there is a leaning toward the exclusion of egô, but the decision is not a clear one.

The second variant reading of the Marcan citation offers no difficulty. Here emprosthen sou must be excluded because it finds support only in such weak witnesses as the Koine text and some versions.

The first part of the Matthean citation, idou ... prosoppou sou, corresponds exactly to Exod 23:20 as found in the LXX. The only variant of interest in the LXX text is the 
omission of egô in about one half of the Greek copies of Philo.

That portion of Exod 23:20 which is found in the Matthean citation, in the MT reads:

hnnh 'nky slh $\mathrm{ml}$ 'k lpayk.

For the MT $m l^{\prime} k$, the LXX with, according to BHS, the Samaritan Pentateuch and the Vulgate, read "my messenger", as though from the Hebrew $m l^{\prime} k y$. The wording $m l$ 'ky lpnyk appears in $\checkmark$ 23. It is possible that the eye of a scribe could have wandered here and he may have inadvertently transcribed this into $\vee 20$. On the other hand, scribal assimilation to $\vee 23$ may have been intentional. In either case, if this did occur, this copy may have been the source for other copies, and even some of the versions.

The original text of the Vulgate for Exodus is not extant, nor is it any simple matter to determine this text, since later revisions, such as that of Alcuin, and the many 0ld Latin variants, have mutually influenced one another. In addition, where Jerome differs from the MT he may be following one of his Greek versions (the LXX, Aquila, Symmachus, Theodotion) which may not be the same as the Greek versions we possess. It does not prove that Jerome's Hebrew text differed from the MT. Hence, the Vulgate is best disregarded.

The value of the Samaritan Pentateuch for text criticism has been widely debated. No satisfactory critical 
edition is available.54 The oldest manuscripts date from the thirteenth century, with a fragment from the eleventh century covering the main part of Num 35 to Deut 34 . In about one-third of the passages in which it deviates from the MT, it agrees with the LXX. This in addition to its agreements with Qumran texts suggests that it may witness to a text that once enjoyed widespread use.ss whether the LxX can be cited as an additional witness to that of the Samaritan Pentateuch here depends on whether one thinks that the agreement of the $L X X$ and the Samaritan Pentateuch indicate that the LXX manuscripts at this point have been contaminated by the Greek translation of the Samaritan Pentateuch (the Samareitikon)=0. In summary, the witness of the Samaritan Pentateuch must be noted, although there is yet no consensus on how it ought to be evaluated. In this case the MT gets a slight edge in that it is different from $\checkmark 23$, thereby eliminating the possibility of assimilation. The LXX corresponds to the MT particularly in rendering hnnh with idou, 'nky with ego, and lpnyk with pro prosopou sou, in quite literal fashion. For example, the only reason the Hebrew has ' $n k y$ is that this is grammatically necessary with the participle slh; there is no reason for it to be translated in the Greek.

The use of the pronoun mou in the LXX, which has no corresponding word in the preferred MT, might be explained by the use of a Hebrew Vorlage with the pronominal suffix 
(cf.the Samaritan Pentateuch). In any case, all three gospels retain this word in contrast to the MT, which indicates that the gospel tradition used the LXX here or some Hebrew text which resembled the Samaritan Pentateuch. Evidence that it is the former is found in the use of apostello rather than the participle, which might result from a direct translation of the Hebrew. As well, the gospels have followed the literal tranlation of lpnyk by pro prosôpou sou.

Matthew follows the Lxx verbatim, as he includes egô, whereas Mark (if the preferred Marcan text is correct) and Luke do not. The omission of ego in Mark (?) and Luke might indicate either reference to a Lxx text like that of Philo or a stylistic change in the Greek.

The remainder of the citation as found in Matthew, has kataskeuasei tên hodon sou emprosthen sou, is often considered to come from Mal $3: 1.37$ However, even a hasty glance at the LXX text of this passage proves that the dependence is at least not Septuagintal. It reads: $=$ idou egô exapostellô ton aggelon mou, kai epiblepsetai hodon pro prosópou mou.

To begin with, the first line of the citation in Matthew is identical to the Exodus passage in the LXX.so On the other hand, the word exapostello from the Malachi passage is not found in the gospel citation. Moreover, the phrase pro prosôpou sou, found in the gospels, is lacking in the first 
line of the Malachi passage, although the slightly different form, pro prosopou mou, is found at the end of the second line. The second line of the gospel citation bears only faint resemblance to the second line of the Malachi passage in the LXX, namely the word hodon. Clearly the Septuagint of Malachi was not a source for our quotation. Was, then, the MT for Mal 3:1 the source of the gospel citation, or of a part of it? It reads: hnחy slh ml'ky wpmnh-drk lpay. Stendahl thinks that the MT and LXX texts differ, and uses this perceived difference to show that the gospel citation has been derived from the Hebrew text rather than the LXX.so He notes that the gospels' use of kataskeuasei assumes the MT reading of pnh in the piel, while the LXX reads the qal, "for which reason the Symoptics" dependence on the Hebrew text is obvious".ox That the gospel quotation adds a possessive pronoun after hodon and (in Matthew and Luke) changes the Hebrew "before me" to "before you" can be explained by the need to adapt the OT quotation to its context in the gospels.

Stendahl's argument is based on the assumption that the Malachi passage was the basis for the gospel citation. To be consistent he then must interpret the gospels' use of kataskeuasei rather than the LXX's epiblepsetai as Hebrew influence in the citation. While this goes against the usual view that the gospels use the $L X X, s=$ there is always 
the possibility that Aramaic-speaking Christians who used the Hebrew text might have influenced gospel tradition. The MT of Mal 3:1 may, then, have been the basis of the gospel citation. It is at least not likely that the second part of the citation came from Exod 23:20. True, the tên hodon of the gospels may reflect the tê hodo of the latter part of the Exodus passage, but this is not enough on which to build a case. Then whence came hos kataskeuasei tên hodon sou emprosthen sou as found in Matthew and Luke, and hos kataskeuasei tên hodon sou as found in Mark?

The citation is introduced by a simple gegraptai in Matthew and Luke. No prophet is claimed as the authority. Isaiah is claimed as the source in Mark, and this presents an obvious problem as this is simply not correct. To save face for the writer of the Marcan text, some, such as Holtzmannos, have suggested that the whole citation, idou egô apostellô ton aggelon mou pro prosôpou sou, hos kataskeuasei tên hodon sou emprosthen sou, was a late interpolation. While the suggestion of an interpolation is commonly made here, this should only be seen as a last resort.

Because this citation does not fit into the regular pattern which Stendahl perceives, he makes an exception in this case and concedes that "it is reasonable to count on the possibility of testimonies"\$4, even though he launches a lengthy attack against such later in his book.os If nothing 
else, this indicates the refractoriness of this citation. The problem with Stendahl's concession is that it solves nothing.

By suggesting the source is a testimony, to stendahl indicates that the combination of the Exodus and Malachi texts predated the composition of any of the gospels.or This seems reasonable. It is found in Christian tradition and shows up in both Mark's source and the source which Matthew and Luke used. It remains to determine what these sources were; in other words, what is the synoptic relationship here?

The form of the citation shows some differences over the three gospels. The pronoun egô is lacking in Mark (?) and Luke, and Mark lacks emprosthen sou.

In terms of the Griesbach hypothesis the deletion of egô (it might have been in Mark) in Luke could be explained as simply a matter of style. The omission of emprosthen sou in Mark could be explained as redundant of pro prosôpou sou. The problem for the Griesbach position regarding this quotation is why Mark would omit the whole narrative common to Matthew and Luke, yet detach its quotation and insert it at $1: 2.60$

In terms of the two-document hypothesis the citation would appear in Mark (or his source) as it appears now. It 
would also appear in $Q$ So but in a form including emprosthen sou. This would explain the appearance of this phrase in both Matthew and Luke but not in Mark. In both sources, Mark and $Q$, egô would be lacking, perhaps because there is no reason for an emphatic personal pronoun here. Alternatively, egô could have been in $Q$ but have been omitted by Luke on stylistic grounds. In conclusion, then, this evidence yielded by a study of this citation favours the two-document hypothesis over the Griesbach hypothesis.

Matt $15: 8-9:$

ho laos houtos tois cheilesin me tima, hê de kardia autôn porrô apechei ap' emou; matên de sebontai me didaskontes didaskalias entalmata anthrôpôn.

Variant readings include: ho laos houtos] eggizei moi ho laos houtos tô stomati autôn kai (CKNWGPTh,0106, 1, and many other minuscules; apechei] estin ( $D$, the Vulgate and some 0ld Latin manuscripts, part of the corpus of clement of Alexandria).

For the first variant, eggizei moi ho laos houtos tô stomati autôn $k a i$, the best witnesses are uncial 0106 and family 1 minuscules (1) which are on equal value with the Caesarean text-type; the rest of the witnesses are all Koine. Since all the strong witnesses support the preferred text, it stands. In addition, this variant represents some 
kind of combined assimilation to the LXX, other Greek OT texts, and perhaps the MT.

Any of the witnesses for the second variant reading could preserve an original reading. Clement of Alexandria died in 212, and so is very early, but use of his works suffers the problems encountered with any of the fathers. Estin was probably substituted for apechei ("to be distant") because it was felt that the phrase porró ("far") apechei was somewhat redundant. The text stands.

The preferred text for the parallel citation in Mark 7:6-7 differs from the Matthean text only in a small change in word order: ho laos houtos] houtos ho laos.

Variant readings for the Marcan text include: houtos ho laos] ho laos houtos (BD and a few others, the vulgate and some 01d Latin manuscripts); tima] agapa (DW, Old Latin manuseripts $a, b, c$, Clement of Alexandria, Tertullian); apechei] aphestêken (D), apestê (D), apestin (LTh, 565,892, the Vulgate and some old Latin manuscripts); kai inserted after didaskalias in papyrus 45 and most of the $01 d$ Latin).

The support of the Alexandrian manuscript $B$ for the second variant, ho laos houtos, forces the decision onto internal evidence. Here this is likely a case of assimilation to the Matthean text. Since the Matthean text does not have ho laos houtos as a variant, the preferred text stands. 
Papyrus 45 dates from the third century and tends to be a free text, partly Alexandrian, partly Western. Lack of other strong support, and the fact that insertion of $k a i$ makes the text read easier ("the doctrines and precepts of men"), decides the case in favour of the preferred text. None of the other variant readings have strong manuscript support, except for the Alexandrian manuseripts, Codex L and minuscule 892, in support of apestin. But here the majority of Alexandrian manuscripts, particularly the protoAlexandrian Codices $A$ and $B$, support the preferred text. Hence, the preferred text stands in all of these instances. The LXX for Isa 29:13 differs in the following ways from the preferred Matthean citation: ho laos houtos tois cheilesin me tima] eggizei mai ho laos houtos tois cheilesin autôn timôsi me; didaskontes didaskalias entalmata anthrôpôn] didaskontes entalmata anthrôpôn kai didaskalias. $>0$

Variant readings for the LXX text include: (1) moi] mou (the first hand of Codex A); (2) after ho laos houtos the following alternative insertions are added: (a) en tô stomati autou kai en (some members of the Hexaplaric group (Codex $B$ and the minuscules 109 and 736), minuscule 538, and the Bohairic version), (b) tô stomati autou kai en (some members of the Lucianic recension (minuscules $48,231,763,62,147,90,36,96,46)$, minuscules 403,770 ), (c) en tô stomati autôn kai en (Codex $V$ of the Hexaplaric 
recension), (d) tô stomati autôn kai en (manuscripts from the Lucianic recension (minuscule 233 and the eighth-century uncial 926), manuscripts from the Alexandrian recension (minuscules 106 and the corrected copy of 86 ), (e) tô stomati kai (eleventh-century mixed-text minuscule 534), ( $f$ ) tô stomati autou kai (the mixed-text minuscules 393 and 613 , the Lucianic minuscule 456, and Jerome), (g) kai en (Hexaplaric minuscule 88 and the Syro-Hexaplar), (h) kai (the fourteenth-century Lucianic minuscule 46, and the tenth-century minuscule 564 of the Catena group); (3) omit the first autôn (most of the Catena group, including its most important members); (4) timôsi me] me timôsi (eleventhcentury Catena minuscule 377), timousin me (first hand of Codex A), tima me (46); (5) first de omitted by the eleventh-century Lucianic minuscule 62; (6) apechei] apestin (Clement of Rome), estin (Clement of Alexandria); (7) entalmata anthrôpôn kai didaskalias] didaskalias entalmata anthrôpôn (the Alexandrian minuscule 106, the Hexaplaric Codex $v$, the Catena minuscule 566, the Lucianic minuscule 233, and Clement of Alexandria), kai didaskalias entalmata anthrôpôn (the mixed-text minuscule 301), didaskalias kai entalmata anthrôpôn (the Lucianic minuscule 46), entalmata anthrôpôn didaskalias (the Hexaplarie minuscule 88 , the Lucianic minuscules 311 and 130 , and the mixed-text minuscule 410), entalmata didaskalias anthrôpôn (Syro- 
Hexaplar), mandata et doctrinas hominum (Cyrian), entalmata anthrôpôn (the tenth-century Alexandrian minuscule 26 ).

The favoured recension for approximating the original text in Isaiah is the Alexandrian, with Codex $Q$ the strongest witness, followed by Codex A. Variant (1) is ruled out on grounds that $Q$ and the majority of the Alexandrian group support the preferred text, while only $A$, which is not included in any of the text-groups because on different occasions it agrees with the Alexandrian, the Hexaplaric, or the mixed text-types or simply goes its own way, supports the variant. Variants (2a-f) are alternative attempts to correspond to the Hebrew bpyw. This is to be expected in both the Hexaplaric and Lucianic recensions. The variant which best corresponds to the MT is en tô stomati autou kai en or tô stomati autou kai (the dative of respect). It comes as no surprise that Jerome had the latter, with his, for the time, unusual aptitude for a non-Jew for Hebrew, nor that Codex B, the best witness to the Hexaplaric text, had the former. These and all the other variants must be ruled out because the preferred text has the support of the majority of the Alexandrian manuscripts, particularly the strongest witnesses, $Q$ and $A$.

While determination of the LXX text offers no real difficulties, despite the plethora of variants, the latter furnish some interesting features. That clement of Alexandria had estin in the Isaiah text and in his Matthew 
text, suggests assimilation. Likewise, that clement of Rome had apestin in the Isaiah text and in his Mark. The use of the singular verb in tima me in one Lucianic manuscript could be a transposed assimilation to the gospel text, but likely exhibits a connection to the use of the singular in the same strain which is witnessed in the Syriac, old Latin, and the vulgate.

Hexaplaric variants include: after houtos Aquila, Symmachus, and Theodotion add en tô stomati autou (witnessed in the margins of Codex $Q$ and the Syro-Hexaplar, accompanied with an asterisk, indicating that this is material added to correspond to the MT); timôsi] edoxasan (Aquila, Symmachus, and Theodotion, according to marginal notation in minuscule 86); matên de sebontai me didaskontes entalmata anthrôpôn kai didaskalias] kai egeneto to phobeisthai autous eme entolê anthrôpôn didaktê (Aquila, Symmachus, and Theodotion, according to marginal notation in minuscule 86).

The MT for Isa 29:13 reads:

nggs $h \cdot m$ hzzh, bpyw wbsptyw kbbdwny wlbbw rha mmmnny wt thy $y r^{\prime} t m$ 'ty mswt 'nsym mlmmdh. 71

The text of the LXX clearly differs from that of the MT. The whole syntactical relationship of $\vee 13$ to $\vee 14$ is different, and the smaller textual differences result from this major difference. In the Hebrew the words of the Lord begin with $y$ 'n ky ("because"). The rest of $v 13$ is one long causal clause formed by a series of smaller coordinate 
clauses. The result clause ( $v 14)$ is also long and composed of several smaller coordinate clauses. The Greek dia touto, which introduces $v 14$, mirrors the Hebrew $1 k n$, and so suggests a result clause such as that found in the Hebrew. R. R. Ottley suggests that in the case of maten the LXX translator read wthw ("in vain") for wthy ("and is") and then altered the syntax by treating the following yr'tm as a verb to replace the lost one.7= This mistake occurred because the $w$ and the $y$ were difficult to distinguish.> The relationship of the MT to the LXX is problematic for this text.>4 In the face of such great variation in the OT texts, the virtual equivalence of the Matthean and Marcan forms of the citation stands out all the more clearly. There are simply too many differences between the gospel citations and all known OT texts for any facile explanation of the origin of the citation. $7=$ Nevertheless, the gospel citations appear to have telescoped the two initial clauses of the LXX's rendition into one, and differ from the LXX in word order at the end. About all that can be said for sure is that the gospel citation is much closer to the preferred text of the LXX (the Alexandrian form exemplified in such manuscripts as $A$ and $Q$ ) than it is to either the Hexaplaric form of the Greek (as seen in extant witnesses such as Codex B, or as in Aquila, Symmachus, and Theodotion) or the Hebrew of the MT. 
The specifics in which the gospel text differs from the LXX version do not suggest in any obvious way that the citation might have been altered to fit better into its gospel context.

The only way in which the preferred texts of Matthew and Mark differ from one another with respect to this citation, the transposition of the first three words, ho laos houtos / houtos ho laos, does not offer any clue to the synoptic relationship here. If it is proposed that Matthew has corrected Mark toward the LXX, one might ask why only this phrase. Partial assimilation here is not impossible, but this is no sure indication of the priority of Mark. On the other hand, to suggest any reason why Mark would alter what was in Matthew away from the LXX, in the absence of any other reason for the alteration, would indeed be an exercise of a vivid imagination.

However, it could be argued that the Matthean context of the citation suggests a reworking of the order of the narrative better to incorporate the citation. Just as in Mark 1:1-11, here also Mark has the OT citation precede that which points to the citation. Immediately following the citation Mark writes, "Having neglected [aphentes] God's commandment, you hold fast the tradition of men" ( $v 8$ ). This summarizes the citation. Mark then virtually repeats $v 8$ in $\checkmark 9$ adding the sarcastic kalós, which serves to emphasize 
and add irony to the contrast set up in the citation between the worship of God and the teaching of men.

Just as in Matt $3: 1-17$, here also Mathew has not placed the citation first. The scribes and Pharisees have asked Jesus why his disciples do not wash their hands before they eat, thereby transgressing (parabainein) the tradition of the elders. Jesus immediately counters ( $v 3$ ), "And why do you transgress [parabainein] the commandment of God for the sake of your tradition?" Matthew's double use of the verb parabainein sets up an ironic parallel between the Pharisees' question and Jesus' counter-question, which emphasizes the contrast between the worship of God and the teaching of men. Instead of a mere neglect (apheinai) of God's commandments as in Mark, Matthew has the transgression (parabainein) of God's commandments - moreover, the transgression of God's commandments in order to fulfil Pharisaic tradition. Matthew then uses the example of breaking God's commandment to honour father and mother, which Mark gives after the citation. Following this example of how Pharisaic tradition has transgressed God's commandment, Matthew has Jesus say, "You hypocrites! Well did Isaiah prophesy of you ..." and concludes with the citation. Here the citation provides a forceful, emphatic way of finishing the lesson and rounds it out by pointing back to the gist of the citation which was given in $v 3$. 


\begin{abstract}
Matthew's compact form of the narrative and his artful placement of the citation seems to drive home its point better than does Mark's rendition. It is unlikely, then, that Mark would have altered Matthew's version to a less artful form. This favours the two-document hypothesis.70
\end{abstract}

Matt 22:32:

ego eimi ho theos Abraam kai ho theos Isaak kai ho theos Iakob.

The only variant text is that of Codex $A$ which omits the last two ho's. While this is a manuscript of the very strong proto-Alexandrian group, its singular witness must be balanced against the only other proto-Alexandrian witness, Codex $B$, and all other Alexandrian witnesses, and all other manuscripts. All that can be said is that here is a case where $A$ does not agree with the rest of its group. The text stands.

The parallel citation in Mark 12:26 in the preferred text differs from Matthew in one way: eimi is omitted. Variants for the Marcan text include: omission of the first ho (DW and a few minuscules); the last two ho's are included in ACKATh, $l$ and $p h$, but omitted in BDW.

The first variant, supported by only the western $D$ and $w$ does not stand. The second text poses a problem, as indicated by the fact that Nestle-Aland had preferred text and variant reversed until the twenty-sixth edition. Even in 
the latter edition square brackets around the last two articles indicate indecision on the part of the editors. Their indecision is not unwarranted. The two protoAlexandrian witnesses, $A$ and $B$ are split. The preferred text has more Caesarean witnesses $(T h, 1, p h)$ than the variant (w), and the Koine group. Earlier editions of Nestle-Aland suggested that inclusion of the articles was the result of assimilation to the Matthean text. This theory runs into difficulty. Codex $A$ is the only manuseript which omits these articles in Matthew, yet it has the articles in Mark. Moreover, BDW have the articles in Matthew, but lack them in Mark. Hence, some of the strongest witnesses to the original text not only do not assimilate, they send mixed signals. Nor is there assimilation to the Lucan text. First, Luke has the accusative case, being merely an allusion. Second, Lucan witnesses to the use of the article in the last two places are Koine. The Marcan text, then, simply remains enigmatic. The parallel passage in Luke 20:37 is not a direct citation but an allusion. Luke writes, "in the passage about the bush, where he [Moses] calls the Lord the God of Abraham, and the God of Isaac, and the God of Jacob." This indirect reference requires certain changes of case: ton theon Abraam kai theon Isaak kai theon Iakôb. Variants for the Lucan text are: inclusion of the article ton in the last two places in a large number of Koine witnesses; omission of kai theon Iakôb in W. 
Supported by only the Koine text-type, the first variant does not stand. The second is supported by $W$, which for this part of Luke is usually Koine. Here w goes its own way, so the preferred text stands.

Codex $B$ for the LXX of Exod $3: 6$ reads: ego eimi ho theos tou patros sou, theos Abraam kai theos Isaak kai theos Iakôb.

Variant readings include: ho theos tou patros sou] omitted by several of the patristics; theos Abraam (BFM, and several minuscules)] ho theos Abraam ( $A$ and the rest of the Greek manuscripts); Abraam kai (under the obelisk in the Syro-Hexaplar)] Abraam (in some copies of some patristics); theos Isaak (BAFM, and several minuscules)] ho theos Isaak (the rest of the Greek manuscripts); theos Iakab (BAFM, several minuscules)] ho theos Iakob (the rest of the Greek manus(ripts).

The first variant reading is quickly rejected in favour of the preferred text. Witnessed to by only some of the patristics, outside of the gospels, this variant is clearly an assimilation to the gospels.

The omission of the article or its inclusion is simply a matter of Greek style. Its inclusion should not be regarded as an attempt to match the Hebrew construct state, any more than its omission should be regarded as a variation from the Hebrew. That Codex A should have one of the articles, against the other major witnesses, should be of 
little concern. This codex is characterized as eclectic in. the Pentateuch, $>7$ and there is no scholarly consensus regarding its value for text criticism. The preponderance of uncial support for the text of $B$ argues in its favour.

That the use of kai after Abraam is under the obelisk in the Syro-Hexaplar indicates that in the fifth column of Origen's Hexapla this sign was present. Hence, the conjunction was not in Origen's copy of the Hebrew.

The MT for Exod 3:6 reads:

$$
\text { 'nky' Ihy 'byk 'Ihy 'brhm' Ihy ysha w' lhy y'ab. }
$$

Variant readings cited in BHS are: 'byk] 'btyk (the Samaritan Pentateuch, two LXX minuscules, Acts $7: 32$, Justin Martyr; 'Ihy] w'lhy (some Hebrew manuscripts, the Samaritan Pentateuch, the $(X X)$.

The first variant reading involves a portion of the OT text which the gospels have left out, but, interestingly, is found in Acts. This is one of the passages in Acts which are commonly cited as siding with the Samaritan Pentateuch against the MT, and, therefore, which suggest to some that herein are witnessed an early alternate OT text. While this possibility need not be rejected, only two LXX minuscules have this variant, while the vast majority of LXX witnesses have the MT text. The plural 'btyk makes better sense in this context. Hence, the scribes for the two LXX minuscules could easily have made this change intentionally. The same change may have been made in the Samaritan Pentateuch and in 
Acts for the same reason. In other words, while the external evidence may offer fascinating possibilites, the truth of the matter may lie in the much more mundane and simpler explanation of the internal evidence. Based on the principle of lectio difficilior, then, the text stands. With regard to the second variant text, a comparison with similar phrases in $v v 15,16$ and in 4:5, quickly demonstrates that the matter of the use of the conjunction is fairly consistent over these verses. The Samaritan Pentateuch and the LXX have included the conjunction. The fact that some Hebrew manuscripts have done likewise may have been a matter of adhering to a more normal Hebrew style. In this case, the preferred text could be supported on the basis of lectio difficilior. On the other hand, there is no intrinsic reason why one text should be preferred over the other, and the possibility that the LXX and Samaritan Pentateuch refer back to another Hebrew recension can not be ruled out. Indeed, the matter could just as easily, especially in the case of the LXX, be simply a case of literary style. What is clear is that this is a formulaic saying. Whatever form is used will, therefore, be followed consistently in that witness.

That the Greek eimi has no correspondent word in the Hebrew reflects simply a stylistic change in the Greek. The two texts can be regarded as equivalent here. The phrase tou patros sou in the singular corresponds to the preferred 
Hebrew text, which, considering that this is the more difficult Hebrew text, tends to confirm it. As for the kai after Abraam, all that can be said is that some Greek manuscripts of Origen's time had the conjunction, while Origen's Hebrew manuscript did not. More important is that this is a formulaic saying and seems to be rendered consistently within a given witness. The use of the conjunction is then simply a matter of style. Overall, then, the LXX and Hebrew are virtually equivalent. Because the Hebrew and Greek OT are Virtually equivalent, it is impossible to say which text was the source of the citation. The only hint regarding the synoptic relationship is the verb eimi. It is unlikely that this verb would be removed if it appeared in the source of an evangelist, but it might be added. This would favour the two-document hypothesis. Greek usage does not require the verb eimi here, but its lack in Mark suggests that his source lacked the verb. This citation has a formulaic character, and was probably cited frequently by early christians. It is found in Acts 7:32, for example, without eimi. Without the verb (the verbless sentence), the citation indicated the timeless relationship of God to his people, and more closely resembled the Semitic form. Gundry claims that the present tense, whether expressed or understood, is necessary to the argument concerning resurrection.>0 If he is right, this would be grounds for Matthew adding eimi to the Marcan 
version. It is unlikely that Matthew corrected Mark towards the LXX because if Mark had the articles Matthew failed to remove them in accordance with the LXX, and if Mark lacked them Matthew added then against Mark and against the LXX. The synoptic relationship is evident when the synoptic citation is compared to that in Acts. The synoptic version lacks the OT phrase which appears in the LXX as theos tou patros sou and in Acts with patros in the plural form. The synoptics use the article throughout, with the possible exception of Mark. Mark is not likely to have used Matthew and Luke and corrected them towards the LXX by omitting the articles, or he would also have retained eimi.

Matt 15:4a:

tima ton patera kai tên mêtera.

Variant readings for this citation are: sou appears after patera in C=KMUWYTh, ph,565, most old Latin manuscripts, the Syriac manuscripts, the Sahidic and Boharic translations; sou appears after metera in NW, most old Latin manuscripts, the Syriac manuscripts, the Sahidic and Boharic translations.

All the Greek manuscripts for the two variants are of the Koine group. Old Latin manuscripts represent the Western group, which is not a strong witness to the original text. Syriac manuscripts here show assimilation to Mark, probably because of the relationship these have to Tatian's gospel 
harmony. The Sahidic and Bohairic versions suffer from lack of critical texts. Assimilation to Mark or to the Lxx in Exadus or Deuteronomy is quite likely. Hence, there is no good evidence for rejecting the preferred text. The preferred text of Mark 7:10a differs from its Matthean parallel in that sou is found after patera and mêtera.

There is only one variant reading: sou is omitted after metera in DTh and a few other manuscripts. Scanty support in one Western and one Caesarean manuscript is insufficient evidence to reject the preferred reading. Codex $B$ of the LXX for Exod 20:12 differs from the Matthean text in that sou appears after patera.

There is one significant variant: metera (first hand of B, a later scribal correction to $F$; in $A$, one minuscule, and Philo)] mêtera sou (two later scribal corrections to $B$, the first hand of $F$, in $M$, the rest of the Greek minuscules, and the Sahidic, Bohairic, and Syro-Hexaplar).

The better Greek uncials favour the text of $B$. The variant is probably an assimilation to the MT, so the text of $B$ is the preferred text.

The LxX for Deut 5:16 differs from the Matthean text in that sou appears after patera and after metera.

The MT for Exod 20:12 reads:

$k b d^{\prime} t$-'byk $w ' t-\cdot m m k$. 
The MT for Deut 5:16 is identical to that of Exod $20: 12$.

The LXX of Deut 5:16 corresponds exactly to the text of the MT, but that of Exod 20:12 lacks a sou to correspond to the pronominal suffix of the MT's 'mmk. For this reason the text of Deuteronomy likely was the source of this citation. Since the $L X X$ and $M T$ of this text correspond, one reason for saying that the Greek text was used, rather than the MT, is that the LXX is usually considered the Bible of the early Christians unless there is specific evidence to the contrary. In addition the gospels have tima rather than the alternate possibility doxaze found in Aquila, suggesting they did not make an original translation, and certainly did not use a recension such as that of the latter. When so common a text is in question, the possibility that the text of the gospels did mot come directly from the Bible but from liturgical or catechetical forms used in synagogue/church, must not be overlooked.

The citation in Mark is identical to that of Deut 5:16 in the LXX. Matthew differs in leaving out the possessive pronouns. Both versions are equally good Greek for "your father" and "your mother". This opens the possibility that Matthew translated directly from the Hebrew. More likely, however, is that Matthew removed the pronouns to parallel the following citation from Exod 21:17. Whereas Mark credits the citation to Moses, Matthew calls it God's commandment. 
In both gospels the contrast between God's commands and the traditions of men is central. Thus, for Mark to talk of Moses confuses things by offering a hint of tradition. Matthew cleans this up by following the previous verse's reference to God's commandments. While it is possible that Matthew preceded Mark and Mark corrected Matthew towards the Lxx, it is highly unlikely that Mark would alter Matthew to a less polished rendition. Therefore, although the evidence is not overwhelming, Mark probably preceded Matthew.

Matt 19:18-19:

ou phoneuseis, ou moicheuseis, ou klepseis, ou pseudomartyrêseis, tima ton patera kai tên mêtera, kai agapêseis ton plêsion sou hôs seauton.

Variant readings are: ou moicheuseis, ou klepseis] ou moicheuseis (the Sinaitic 0ld Syriac), text is lacking in the original hand of $A$; sou after patera (C=WPh, ph,33,565,700, and many other minuscules, the vulgate and some ald Latin manuscripts, most of the Syriac, the Sahidic and Bohairic versions); agapêseis ton plêsion sou hôs seauton] omitted in some of the Palestinian Syriac translations.

The first variant is of little value, having only one minor witness. The omission of ou moicheuseis, ou klepseis in the first hand of $A$ is puzzling, despite the fact that this manuscript often tends to brevity. Even though this is 
a strong witness, its isolation rules out its reading as original.

With regard to sou after patera, all the Greek uncials for this variant are of the Koine group. Of the Greek minuscules, 33 is generally Alexandrian, although it does have strains of the Koine. This seems to be one of those places. Likewise, 565, and 700, while often of great value, are not so in Matthew. Old Latin manuscripts and the Syriac represent the western text, which is not a good witnesss to the original text. The Sahidic version often represents the Western reading for the gospels, while Bohairic manuscripts are late.> Assimilation to Mark and Luke or to the LXX in Exodus is quite likely. Hence, there is no good evidence for rejecting the preferred text.

Omission of agapêseis ton plesion sou hâs seauton in some of the Palestinian Syriac translations only, suggests assimilation to Mark and Luke.

The parallel citation in Mark 10:19 has so many minor differences from the Matthean citation that it is cited in ful1:

mê phoneusês, mê moicheusês, mề klepsês, mê pseudomartyrêsês, mê aposterêsês, tima ton patera sou kai tên mêtera.

Variant readings for the Marcan text are: mê phoneusês, mê maicheusês (BAforrCDPs and a few other uncials, the Sinaitic old Syriac, the Sahidic and Bohairic versions)] mê moicheusês, mê porneusês ( $D$ and the old Latin manuscript $k$ ), 
mê moicheusês, mê phoneusês (KAWTh, ph and a great many minuscules, the Vulgate and some old Latin manuscripts), mê moicheusês (the original hand of $A$ ), mê phoneusês ( 1 and some other minuscules); mê aposterêsês] omitted (first hand of B, WDPs, 1,700, and other minuscules, the Sinaitic old Syriac); mêtera] mêtera sou (first hand of A, CWTh, 565 and other minuscules, most of the old Latin witnesses, the old Syriac, the Sahidic and Bohairic versions).

The variant readings for mê phoneusês, mê moicheusês must all be ruled out as witnesses to the original text. Other than $A^{\prime} s$ witness to mê moicheusês, which demonstrates its tendency to brevity, and because it stands alone must be ruled out, the only other proto-Alexandrian witness is that of $B$, which is to the preferred text. In some cases the witness is too singular (mê moicheusês, mê porneusês), in some it is too weak ( $m \hat{e}$ phoneusês). In the case of $m \hat{e}$ moicheusês, mê phoneusês, the witnesses of the uncials are Koine, and the other witnesses are Western and Caesarean at best. Moreover, this is an obviaus assimilation to Luke. Whether the original Marcan text had mêtera or mêtera sou is a difficult problem. The latter is well attested in a wide range of text-types: proto-Alexandrian (A), Caesarean (Th, 565), western (01d Latin). It has the advantage in that it is not an assimilation to Matthew and Luke or to Exodus, although it could be an assimilation to Deuteronomy. The former is witnessed by the proto-Alexandrian $B$ and the rest 
of the Alexandrian uncials. This favours it over the latter, but the assimilation picture is the opposite of the latter and so does not favour metera. Hence, no clear decision is possible.

Whether the original Marcan text had mê aposteresês or not is an even more difficult problem.so The best witnesses, the proto-Alexandrian manuscripts, are split. Omitting the text are the two Alexandrian witnesses, $D$ and Ps. So there is good witness to an original text which lacks mê aposteresess. On the other hand, omission could simply signify assimilation to Matthew and Luke. It could also result if a copyist deemed it inappropriate in a list of the Ten Commandments.ol for these reasons, while there is no clear decision, the text containing me aposteresês is favoured.

The parallel citation in Luke 18:20 reads:

mê moicheusês, mê phoneusês, mề klepsês, mê pseudamartyrêsês, tima ton patera sou kai tên mêtera. Variations on the Lucan text include: mê moicheusês, mê phoneusês, mê klepsês, mê pseudomartyrêsês] ou moicheuseis, ou phoneuseis, ou klepseis, ou pseudomartyrêseis (D); mêtera (BADLWTh,078, 1,33,1241, and some other minuscules, the Vulgate and some 0ld Latin witnesses)] mêtera sou (AKDPh, 131 and many other minuscules, old Latin witnesses $a, b, c$, the Sahidic and Bohairic versions). 
The first variant, represented by only one manuscript of the weak Western witness, and an obvious assimilation to the Lxx text of Deuteronamy, yields to the preferred text. In favour of the text metera is the proto-Alexandrian $B$ and the Alexandrian L, 33, and 1241. For metera sou there is only the proto-Alexandrian $A$; the rest of the uncials are Koine. Western witnesses favour both texts. The preferred text has a slight edge with regard to external evidence. Internal evidence would revolve around the possibility of assimilation, but this is too complex here, especially since the same problem occurs with the Marcan text.

Exod 20:12-16 in Codex $B$ of the LXX reads:

tima ton patera sou kai tên mêtera.... ou moicheuseis, ou klepseis, ou phoneuseis, ou pseudomartyrêseis kata tou plêsion sou martyrian pseude.

Variant readings include: mêtera ffirst hand of $B$, a later scribal correction to $F$, in $A$, one minuscule, and Philo)J mêtera sou (two later scribal corrections to $B$, the first hand of $F$, in $M$, the rest of the Greek minuscules, and the Sahidic, Bohairic, and Syro-Hexaplar); ou moicheuseis, ou klepseis, ou phoneuseisl ou phoneuseis, ou moicheuseis, ou klepseis (AFM, a large number of minuscules, the Bohairic translation, the Syro-Hexaplar); ou moicheuseis, ou klepseis, ou phoneuseis] ou moicheuseis, ou phoneuseis, ou klepseis (minuscules jn, and Philo). 
For the first variant the better Greek uncials favour the text of $B$. The variant is probably an assimilation to the MT, so the text of $B$ is the preferred text.

The first variant with respect to order has greater support among the uncials and other witnesses than does the text of Codex B. The Syro-Hexaplar, based on Origen's fifth column, tends towards the Hebrew and must be discounted here. Against the preponderance of witnesses is the possibility of assimilation to the Hebrew. Since internal and external evidence conflict, the text cannot be determined.

The second variant with respect to order must be ruled out because of its meagre support. As well, Philo may not be directly referring to the biblical text.

Deut 5:16-20 in the LXX reads:

tima ton patera sou kai tên mêtera sou .... ou moicheuseis, ou phoneuseis, ou klepseis, ou pseudamartyrêseis kata tou plêsion sou martyrian pseude.

Variant readings include: ou moicheuseis, ou phoneuseis, ou klepseis (BV, papyrus 963 , a few minuscules, some patristics)] ou phoneuseis, ou moicheuseis, ou klepseis (AFM, and the remaining witnesses); ou phoneuseis, ou klepseis, ou pseudomartyrêseis] kai ou phoneuseis, kai ou klepseis, kai ou pseudomartyresseis (the Ethiopic version). While the greater number of witnesses support the first variant, the second-century papyrus 963 is of great 
importance in determining the original text, even for a minority reading. In addition, the variant is likely an assimilation to the Hebrew. Hence, the text stands.

The triple use of the conjunction, as found in the Ethiopic version, must be rejected. Although this version is conjectured to have originated in the fourth century, the oldest extant manuscripts date from the thirteenth century. Some think the translation was based on the Alexandrian text-type of the Greek; others, the Lucianic. It has long been observed that the Ethiopic version frequently agrees with the MT against the LXX. This has led some to speculate that the Hexapla provided the Vorlage for this version.a= Until more work has been done, however, its critical value is indeterminate. In this case, such an isolated witness probably indicates assimilation to the Hebrew. The text stands.

The MT for Exod 20:12-16 reads:

$k b d$ ' $t$-'byk $w^{\prime} t$-'mmk ...; 1'trsh; $1^{\prime} \operatorname{tn}^{\prime} \rho ; 1 \cdot \operatorname{tgnb;}$ $l^{\prime}-t$ 'nh br' $k$ 'd sqr.

Variant readings cited in BHS include: l'trsh; I' tn' $p ; 1^{\prime} \operatorname{tgnb]~} I^{\prime} \operatorname{tn}^{\prime} P ; I^{\prime}$ trsh; $I^{\prime}$ tgnb (Nash Papyrus and Philo); sqr] sw' (Nash Papyrus).

The Nash Papyrus is a somewhat damaged text of the Decalogue and the Shema, dating from perhaps as early as the Maccabean period. The text is a mixture of Exodus and Deuteronomy, and its sequence indicates that it comes from a 
liturgical, devotional, or instructional collection, rather than a biblical scroll. For the second variant the Nash Papyrus may have chosen its reading from Deuteronomy, as the text is a conflation anyway. The first variant is probably due to the fact that this is a liturgical text and not a biblical one. This may also be the reason Philo has this order. While it is possible that both sources may witness a variant biblical text, the preferred text is likely.

The MT for Deut 5:16-20 reads:

$k b d$ ' $t$-'byk $w ' t-' m m k$...; l' trsh; wI' tn'p; wI' tgnb; $w l^{\prime}-t \cdot n h b r^{\prime} k$ 'd $s w^{\prime}$.

Variant readings cited in BHS include: wl' th'p] l' tn'p (Hebrew manuscript 107 (according to B. Kennicott's designation), a few other manuscripts, the Samaritan Pentateuch, the Peshitta, and Targum Pseudo-Jonathan (according to M. Ginsburger, 1903)); wl' tgnb] $l^{\prime}$ tgnb (Hebrew manuscript 107 (according to B. Kennicott's designation), a few other manuscripts, the Samaritan Pentateuch, the Peshitta, and Targum Pseudo-Jonathan (according to M. Ginsburger, 1903)); w $\left.I^{\prime}-t^{\prime} n h\right] 1^{\cdot}-t^{\prime} n h$ (Hebrew manuscript 107 (according to B. Kennicott's designation), two other manuscripts, the Samaritan Pentateuch, the Peshitta, and Targum Pseudo-Jonathan (according to M. Ginsburger, 1903)). These variants may have resulted from assimilation to the Exodus passage. 
The best place to begin discussion of the synoptic relationship is with Mark's use of mê aposterêsês against Matthew and Luke. Metzger's text-critical analysis assumes the two-document position.s.s He proposes that it was found in Mark, and then deleted by Matthew and Luke because they considered it inappropriate in a list of the Ten Commandments. Gundry also assumes the two-document position in trying to determine the text.84 As he sees it, since Matthew and Luke lack mê aposterêsês, the words may have been lacking in the original text of Mark, but introduced from "the unregulated tradition".

The assumption of a position with regard to the synoptic problem in order to determine the text is just the sort of issue which the present research hopes to discourage. If text-critical analysis has determined that Mark does not have mê aposterêsês, then in this respect all three gospels would be equivalent and no conclusions regarding their synoptic relationship could be made. On the other hand, if text-critical analysis has determined that Mark does have mê aposterêsês, the question of synoptic relationship can be broached.

Whence came Mark's mê aposterêsês? It is not part of the biblical Decalogue. Stendahl's proposal that there were several forms of the Decalogue used for catechetical purposes is tempting.os He nates that the commandment not to defraud (aposterein) was well-known in Jewish ethical 
teaching, and found its way into the LXX in AFMV in Deut 24:14. It would not seem unlikely, then, that such a strain would find its way into Mark.

Because the Decalogue was such a common piece, appearing even in the MT and the LXX in the two forms of Exodus and Deuteronamy, it would be poor method to put too much weight on any small details of wording or to look only at the biblical passages as sources for the gospel citation of the Decalogue. 80 The Hebrew Nash Papyrus exemplifies a genre which could have liturgical, devotional, or instructional use. Likewise, the gospel citations of the Decalogue should perhaps be viewed from a form critical, rather than a strictly source critical, perspective. In this light, "citation" might not be the most appropriate word for the passages here under consideration. "Citation" implies citation of some biblical text.

How chaotic things become if we insist on a strictly source critical perspective with regard to this "citation" can be demonstrated simply by observing the order of the three commandments, "do not murder", "do not commit adultery", and "do not steal", as they are found in various biblical texts. Let these three commandments be labelled "a", "b", and "c", respectively. The MT has the same order for both Exodus and Deuteronomy, but this might only be the result of assimilation. The Nash Papyrus and Philo (b-a-c) could witness to an alternate form of the Exodus text which 
became assimilated to the order found in Deuteronomy. The order in the LXX for Exodus is b-c-a for the preferred text and b-a-c for codices AFM (the same as Philo and the Nash Papyrus\}. In Deuteronomy the LXX's order is b-a-c for the preferred text, but a-b-c for the codices AFM. With so many combinations in the LXX, and perhaps only covered over in the MT by standardization, it is possible that even the OT texts were influenced by the liturgical/catechetical genre. If we do not insist on strictly source critical assumptions, we do not have to ask whether, for example, Luke got his order, which differs from that of Mathew and Mark, from LXXAFm's Exodus, or LXX's Deuteronomy. We do not have to ask whence came the mê-plus-the-subjunctive form found in Luke and Mark (but also in Jas 2:11), against Matthew and all forms of the LXX, especially in view of the fact that Mark and Luke do not use the same order. The importance of form critical concepts in the study of this "citation" having been noted, does anything remain to be said concerning the synoptic relationship here?

The use of me with the subjunctive as found in Mark and Luke (also Jas 2:11) presents no problem.er This is the correct grammatical form for expressing prohibition. The LXX's use of ou plus the future indicative is a literal reflection of the Hebrew mode of expressing a permanent prohibition, the use of the negative $l^{\prime}$ with the second person imperfect. In any case, this issue offers no help in 
resolving the synoptic relationship. Matthew uses the LXX's form. On the two-document hypothesis, he would have corrected Mark toward the LXX, whereas Luke simply used Mark. On the Griesbach hypothesis, Matthew's form would have been put into a preferable grammatical form by Luke, and then Mark, who had access to both Matthew and Luke, would have chosen the Lucan version. Now the problem of order is added to that of grammatical form. Assuming that the order of the commandments is not overly important (the LXX has a different order in different books, and various manuscripts of the LXX have a different order in the same book, and the orders found in the LXX seldom correspond to the order found in the MT, and the Hebrew Nash Papyrus differs from the MT), any of the gospels could change the order of the others, unless they were restricting themselves to the order of a biblical text. If the use of the same grammatical form as that in the LXX indicates that Matthew used the LXX, then why did he not use the order of the LXX also? Stendahl suggests that he used LXXA. Matthew has the order of the Hebrew, yet it is unlikely that Matthew translated the Hebrew. He usually follows the LXX's ou plus the future indicative in quotations. $\rightarrow 0$

If to the above is added the other differences among the gospel citations, the following is a possible scenario. Under the Griesbach hypothesis, Mark can refer to Matthew 
and Luke. He takes his order from Matthew but corrects the grammar according to Luke. Luke had probably changed the Matthean order to conform with the LXX. Mark sees that Matthew has agapêseis ton plêsion sou hôs seauton while Luke does not. Luke likely left this out because it was not part of the Decalogue, and Mark would probably reason the same way. Besides, both use this citation in another place. The clause, tima ton patera sou kai tên mêtera, is adopted by Mark in its Lucan form, perhaps because Exodus has the single sou in the LXX. It is noteworthy that, while Luke and Matthew use the same form of this citation here as they did elsewhere, Mark omits the second sou as does Luke, which Mark included in his other use of this citation. This strongly suggests Mark has copied Luke here. Under the Griesbach hypothesis, then, a very complex citation can be explained as an eclectic text in Mark.

The scenario under the two-document hypothesis follows. Luke changes the order in Mark to conform with that of the LXX, and deletes mê aposterêsês because it is not part of the Decalogue. Matthew alters the grammatical form towards the LXX but keeps the order of Mark. He too deletes mê aposterêsês because it is not part of the Decalogue, and adds the common agapêseis ton plêsion sou hôs seauton. 91 This leaves two problems. Why does Matthew omit sou from tima ton patera sou kai tên mêtera?ax Perhaps this is simply a matter of internal consistency; the sou is not 
necessary in Greek. Why does Matthew adopt the grammatical form of the LXX but not its order? Perhaps he used a Greek text with the same order as the Hebrew.

In the final analysis, the two-document hypothesis has a slight edge over the Griesbach hypothesis here in that it makes better sense that Matthew and Luke would delete mê aposteresês than that Mark and Luke would delete agapesseis ton plesion sou hôs seauton, because the latter was part of Jesus' Great Commandment.

Matt 22:37:

agapêseis kyrion ton theon sou en holê tê kardia sou $k a i$ en hole tê psyché sou kai en holê tê dianoia sou.

Variant readings for the Matthean text include: hole tê kardia (corrector of A, DL, 1 and many other minuscules)] hole kardia (the original hand of A, BkWTh,0138,0161, ph and some other minuscules); holê tê psychê] holê psychê. (BKWTh,O138, $p h$ and some other minuscules); tê dianaia] te ischyi dianoia (0ld Latin manuscript c, the old Syriac), ischyi sou kai en holê tê dianoia ( $T h$, ph and other minuscules, the Peshitta).

There are strong witnesses for both the first variant (the original hand of $A, B, 0138$ ) and the text ( $L$ is an Alexandrian manuscript). The strongest witnesses (the protoAlexandrian) are split, although the preponderance of Alexandrian witnesses support the text. Hence, the text 
cannot be decided, although the evidence favours the preferred text. The same applies to the second variant concerning the article.

The last two variants have weak support. The final variant probably is the result of assimilation to the Lucan text, with the appropriate orthographic changes.

The parallel passage in Mark 12:29-30 reads:

akoue, Israêl, kyrios ho theas hêmôn kyrios heis estin, kai agapêseis kyrion ton theon sou ex hales tês kardias sou kai ex holês tês psychês sou kai ex holès tês dianoias sou $k a i$ ex holês tês ischyos sou.

Marcan variants include: the second occurrence of kyrios] omitted ( $F$, old Latin $a, b, k$, and the Sinaitic old Syriac); holês tês kardias] holês kardias (B, the first hand of $D$, and a few other manuscripts); holês tês psychês] holês psychês (B); holês tês dianoias] holês tês dianoias (B); kai ex holês tês dianoias soul omitted (D, most of the old Latin).

The support for the first variant is weak ( $F$ is koine). It is a natural stylistic variation, as can be seen by the numerous, but weak, support the same variant has in the LXX. The rest of the variants have weak support, with the exception of $B$, but the latter is isolated. The text stands.

The parallel passage in Luke 10:27 reads:

agapêseis kyrion ton theon sou ex holês tês kardias sou kai en holê tê psychê sou kai en holê tê ischyi sou kai en holê tê dianoia sou. 
Variants for the Lucan text include: ton theon sou] ton theon ( $H$ and the first hand of $B$ ); ex holess tess kardias] en hole tê kardia ( $D, I$ and a few other minuscules, most of the old Latin); holes tês kardias (ACKAWTh, ph and many other minuscules)] holés kardias (papyrus 75, $B x, 0124$, and a few other manuscripts); kardias sou kai] kardias sou (papyrus 75, B); en hole te psyché (papyrus 75, BAX and a few other manuscripts)] ex holess tês psychess (CKAWTh, ph and a great many other minuscules, several old Latin manuscripts); en hole tê ischyi (papyrus 75, BAX and a few other manuscripts)] ex holess tês ischyos (CKAWTh, ph and a great many other minuscules, several dol Latin manuscripts); en holê tê dianoia (papyrus 75, BAX and a few other manuscripts)] Ex holês tês dianoias (CKAWTh, ph and a great many other minuscules, several old Latin manuscripts); kai en holé tê dianoia souj omitted ( $D$, most of the old Latin, and a few other manuscripts).

The first Lucan variant is supported by the strong Codex $B$, but as this is an isolated witness the text stands. Whether or not the article was originally in the phrase holês tês kardias is the most difficult textual problem in this Lucan citation. The only very strong witness for the preferred text is the proto-Alexandrian $A$, to which are added the Alexandrian manuscripts which are not explicitly mentioned, but understood to support the text. Supporting the omission of the article are the proto-Alexandrian $B$ and 
papyrus 75 which dates from the early third century, and two other fairly strong witnesses, $x$ and 0124 . This split evidence perhaps slightly favours inclusion of the article. The same must be said for inclusion of the kai in kardias sou kai. Here the preponderance of the Alexandrian witnesses which are not explicitly mentioned as supporting the text outweigh the two very strong, but isolated witnesses to the exclusion of the $k a i$, papyrus 75 and $B$. The three phrases beginning with en found in the preferred text are all supported by the three proto-Alexandrian witnesses, papyrus 75, $B$, and $A$. The three corresponding variant texts beginning with ex have no Alexandrian support. In all three cases, therefore, the preferred text stands. Other variant readings have weak support.

In the LXX, Deut $6: 4-5$ reads:

akoue, Israêl, kyrios ho theos hêmôn kyrios heis estin, kai agapêseis kyrion ton theon sou ex holes tes dianoias sou kai ex holes tês psychês sou kai ex holes tês dynameôs sou.

Among the variant readings are: kyrios ho theos hêmôn kyrios heis] kyrios heis (Ethiopic manuscript based on the Greek Codex M, manuscript 3 of the Sahidic); hêmôn] hymôn (a few minuscules), sou (a few minuscules, Ethiopic manuscript based on the Greek Codex C, the Bohairic and Palestinian Syriac versions, and manuscript 17 of the Sahidic); kyrios heis] heis (a few minuscules, Ethiopic manuscript based on the Greek Codex C, the Bohairic and Palestinian Syriac 
versions, and manuscript 17 of the Sahidic); estin] omitted (318); dianaias (BMmeroxm, papyrus 963, several minuscules, the Bohairic version)] kardias (AFMV, and all other manuscripts); dianoias sou] dianoias sou kai ex holes tas kardias sou (minuscules 56,246, and the Bohairic version); tês psyches] tês ischyos (Mmaroxn, two large groups of minuscules), tess ischyôs (minuscules 767,799), tês psychês soul tess psychess sou kai ex hales tês ischyos sou la few minuscules); dynameôs] dianoias (two large groups of minuscules).

The above variant readings are only a fraction of those found for this passage. Here again is an example of a liturgical text, the shema. $>$ For this reason, there is a great number of variants. Those above were chosen to illustrate this. However, for text-critical purposes, only one requires discussion, as most variant readings are not found in the Greek uncials.

The preferred text (BMmarosn, papyrus 963, several minuscules, the Bohairic version) of the LXX has dianoiaspsychês-dynameâs, which we shall label a-b-c, regardless of orthographic differences within each of these terms. The variant text (AFMV, and all other manuscripts) has kardiaspsychês-dynameâs (d-b-c). Alfred Rahlfs 94 has Wever's variant as his text, and Wever's text as a variant. Unlike Wevers, who for dianoias cites Codex B, Rahlfs cites Br, which indicates the "rescriptor" of Codex B, "one who, in 
his correction, has so completely set aside the original text that it is no longer recognisable". A rescriptor, then, differs from a "corrector" only in that the corrector leaves the passage he has corrected in such a state that it can still be read. Is it possible that the rescriptor is the scribe who wrote $B$ itself, and simply crossed out what he had originally written, realizing that he had made a mistake? If this is what wevers thought, this would be grounds for giving greater value to dianoias. Wevers notes that the phrase "with thy whole heart and with thy whole soul" is common in Deuteronamy. $\rightarrow$ The word kardia is used in every case but this one. This suggests to Wevers that here the original translator "intentionally chose" dianoias, and that the variant resulted from assimilation to the common wording.90 Wevers also gives papyrus 963 pre-eminent value as witness to the original text, especially when it aligns with Codex $B .97$

The MT for Deut 6:4-5 reads:

sm' ysr' I yhwh 'I hynw yhwh hd

w'hbt 't yhwh 'l hyk bkl-1bak wakl-npsk wbkl-m'dk.

In contrast to the confusing picture offered by the renditions of Deut $6: 5$ in the $L X X$ and the gospelso0, that of $\checkmark 4$ is starkly clear. Mark has reproduced the Lxx exactly.

Neither Matthew nor Luke use Deut 6:4. In Luke's case, it would not fit his context. Did Mark add Deut 6:4 to the 
accounts he found in Matthew and Luke, or did Matthew and Luke delete this from Mark?

First, let us consider the issue in the light of the two-document hypothesis. The implication that the Lord was Israel's God (as in Mark) would be the type of statement that Matthew or Luke, going to the gentile world, might wish to downplay.

What is interesting is that both Matthew and Luke made the same deletion, if one is to suppose Mark was their source. Matthew and Luke lack the material of Mark 12:32-34, with the exception of the end of Mark's $\vee 34$ which Matthew places in another pericope in his own text ( $v 46)$. Not only do Matthew and Luke lack the same material, they also have the same wording against Mark in several places. Both, for example, have a lawyer (nomikos (although this is uncertain in Matthew's text); compare Mark's heis tôn grammateânl test (peirazôn, ekpeirazôn) Jesus. This might suggest that this pericope is found in $Q$ as well as Mark, and that Matthew and Luke conflated the accounts found in their two sources. Both would conflate in different ways. The question Matthew has the lawyer ask is different from the question asked by Luke's lawyer. The latter asks about how to inherit eternal Iife, similar to Mark's theme of the kingdom of God. On the Griesbach hypothesis Mark would have added the citation from Deut $6: 4$ and $v \vee 32-34$. Matthew has set out his material so the Pharisees and Sadducees are clearly seen as 
groups opposing Jesus. In Matt 22:15-22 the Pharisees try to trick Jesus in their discussions, in $\vee v 23-33$ Jesus replies to a question of main concern to the Sadducees, resurrection, in $\vee v 34-40$ it is again the Pharisees who test Jesus, and in $\vee v$ 41-46 Jesus reverses the roles and asks the Pharisees a question. The chapter ends with the statement that after that day no one dared ask Jesus any more questions.

Instead of dividing the material into the types of questions asked by the two opposing groups, Mark follows the theme of resurrection with questioning by one of the scribes who comes up during the discussion with the Sadducees. After the scribe has finished his discussion, Jesus tells him that he is not far from the kingdom of God.

The Griesbach hypothesis has the advantage of accounting for the occurrence of Deut $6: 4$ in Mark. It also can account for Mark's splicing talk about the law with that about the kingdom. As well, it can encompass wording common to Matthew and Luke against Mark.

The two-document hypothesis gets around the problem that Mark would have had to have taken the theme of eternal life from a passage in Luke located at some distance from the material common to Mark and Matthew. It is much easier to understand Luke picking up on Jesus' remark about the kingdom and expanding it into a narrative which he would use in an entirely different place. 
Was the citation from Deut 6:4 added by Mark or deleted by Matthew? A detailed examination of the context was needed in an attempt to answer this, but no conclusive decision can be made. Both hypotheses explain some things; neither can explain every difficulty.

The citation of Deut 6:5 may be only an apparent citation of the OT. This is a passage which probably served in both 1 iturgical and catechetical capacities. For this reason, and because Greek anthropological terminology does not lend itself to equivalent translation of Hebrew anthropological terms, a vast number of Greek alternative translations, which try to do the impossible, result. It would be a mistaken procedure to push any attempt to draw conclusions about the gospels' relationship to the QT texts in this instance. $\rightarrow$ A few remarks will serve to illustrate this.

Both Stendahlioo and Gundryiol see Mark's use of the preposition ek as an indication of dependence on the LXX. Why would he use the preposition but not the the nouns? And what could be said about Luke's use of both prepositions on either two-document or Griesbachian grounds?

The order and selection of the nouns which express the modes of loving God and the various nouns which are used is a notorious problem. The three gospels all have kardia, psychê, and dianoia, in that order (d-b-a), although Mark and Luke include ischys to give d-b-a-e and d-b-e-a, 
respectively. All three eschew the LXX's dynamis, while including both of the two major LXX variants kardia and psychê. At the same time, all three follow the Lxx exactly in the words agapesseis kyrion ton theon sou, despite the fact that the imperative would have been better Greek than the future. Stendahl cites Matthew's and Mark's use of "the synonyms kardia and dianoia" as so unlikely a form of the shema that Matthew must have copied Mark here.100 In reducing Mark's list to three clauses (as in the shema), Matthew has omitted the wrong clause. Now he has two equivalents of $l b b$ and none for $m^{\prime} d$. This alteration suggests Matthew's use of Mark.10=

The problem of these nouns is made more complex with the consideration of two further points. First, every one of the Hebrew and Greek nouns have such a vast number of meaningsio4 that relating one to the other and even trying to determine what the meaning of the Hebrew may have been, other than the completeness of the love required (Hebrew $k$ l, Greek holos), becames a virtually pointless task. Second, although Mark 12:33 is not a citation in that it is an indirect quotation and requires certain orthographical adjustments, the nouns are different from the citation in $v$ 30. In conclusion, however, the two-document hypothesis is slightly to be favoured.

Matt 19:5: 
heneka toutou kataleipsei anthrôpos ton patera kai tên metera kai kollêthesetai te gynaiki autau kai esontai hoi dyo eis sarka mian.

Variant readings for the Matthean text include: heneka] heneken (CKDWTh, l, ph, and several other minuscules);

patera] patera autou (CEDPh, 078, $p h, 1,33,157,1424$, and some other minuscules, most of the syriac manuscripts, the Sahidic and Bohairic versions); meteral metera autou (W, G, 1241 and a few other minuscules, most of the Syriac manuscripts, the Sahidic and Bohairic versions); kollêthêsetai] proskallêthêsetai (ACLZDPh, 1,33,700, and several other minuscules).

The first variant has only weak support; most of the witnesses are Koine, with the strongest being the Caesarean families of minuscules, ph and 1 . The same applies to the second variant; here $p h, 33,157$, and 1424 represent the Caesarean text-type. In addition, against the variant reading, it could be an assimilation to Mark. For the third variant, 1241 can be late Alexandrian, but is often mixed with Koine. The latter is the case here. Proskollethesetai has some strong support, but this is isolated; $A$ is protoAlexandrian, and $L$ and 33 can be late Alexandrian. The Matthean preferred text stands in its entirety.

The preferred parallel text in Mark 10:7-8 differs from the preferred Matthean text in the following ways: heneka] henekev; patera] patera autou; kai kollethesetai tê gynaiki autouj kai proskollêthêsetai pros tên gynaika autou. 
Variants for the Marcan text are: metera] metera autou (APs, some other manuscripts, most of the old Latin and Syriac manuscripts, the Sahidic and Bohairic versions); $k a i$ proskallêthêsetai pros tên gynaika autou (KDKWThXP(ACD), ph, 892 (in the margin), and a great many other minuscules, the Vulgate and some 0ld Latin manuscripts, the Peshitta, the Sahidic and Bohairic versions)] omitted (ABP5, 892, a few other manuscripts, the Sinaitic ald Syriac).

Despite the very strong witness in $A$, the remaining witnesses provide weak support for the first variant. The second variant is problematic, as evidenced by the fact that only with the twenty-sixth edition of Nestle-Aland has kai proskollêthêsetai pros tên gynaika autou been considered the preferred text.10s The reason for this is the coincidence of the two best witnesses to the original text, $A$ and $B$, as witnesses to the omission of kai proskallethêsetai pros tên gynaika autou. Favouring its inclusion are the later Alexandrian manuscripts $D$ and $L$ (these have the clause with têe gynaiki instead of pros tên gynaika). Minuscule 892 is also late Alexandrian. The fact that the original hand of 892 lacked kai proskollêthêsetai pros tên gynaika autou and it was later added in the margin, probably indicates no more than that it was made to conform to the common koine text. The clause stands because without it hoi dyo ( $v$ B) would refer to the father and the mother. 
Why would some manuscripts lack kai proskollethessetai pros tên gynaika autou? Perhaps it was a scribal error, with the eye passing from $k a i$ to $k a i$. This would be more likely in those texts which had metera autou before the first kai. It is perhaps, then, no mere coincidence that two of the three uncials with the omission also have metera autou ( $A$ and Ps). Many later scribes might have corrected the text by inserting kai proskollethessetai pros tên gynaika autou into their work where the text they were copying lacked it, in order to give proper sense to the verse (this may have been what happened in the case of the margin of 892). The addition would have been according to the LXX text or Matthew. Note that $\mathrm{C}$ and $L$ have $k a i$ proskollethêsetai tê gynaiki autou in Mark and also in Matthew.

The preferred text of the LXX for Gen 2:24 differs from the preferred Matthean text in the following ways: heneka] henekev; patera] patera autou; kai kollethesetai tê gynaiki autou] kai proskollêthêsetai pros tên gynaika autou. Significant variants to the Lxx text include: metera (third-century papyrus 907, a large number of minuscules, including all of Wever's group b)] mêtera autou (Codex $M$ (under the asterisk), third-century papyrus 911 , and all other manuscripts); pros tên gynaika] tê gynaiki (A, and a few minuscules); gynaika autou] gynaika (Wever's groupd, and a few other minuscules). 
Rahlfs has mêtera autou in his text, and mêtera as a variant. This should be taken in its proper perspective; Rahlfs edition is based on the three uncials ABA, but since $A$ and $B$ are lacking this part of Genesis, he had no recourse but to go with $A$. The only other uncial having the variant text is M; here autou has an asterisk, indicating that it was added because the Hebrew has the possessive pronoun. Third-century papyri are split over the two alternatives. Wever's group b consists of a large number of minuscules and $B=$ (the fifteenth-century suppletion of the text lacking in Codex B, a copy of minuscule 19). Group b is not a Lucianic text, as was once thought, and tends to more omissions than additions, with the latter not revisions towards the MT. Wevers observes that LXX Genesis is relatively free compared with the Hebrew with respect to the possessive pronoun, that A rarely supports the shorter text in this respect, and that the evidence in general indicates the shorter text will be the original.106 In addition, he notes that where the MT has conjoined nouns with both having the same pronominal suffixes, LXX Genesis tends not to repeat the pronoun for the second noun.107 The preferred text is maintained because the variant is an assimilation to the MT. Pros tên gynaika is supported by one uncial, M, but has the support of many more minuscules than tê gynaiki. The latter is witnessed by $A$, but wevers finds $A$ a "deviant 
tradition" and an authority upon which one should not rely.100

With regard to the third variant, the autou has the support of the only uncials, AM, and group d (minuscules) tends to shorten the text.100 The text stands.

The MT for Gen 2:24 reads:

i-kn y'zb-'ys 't-'byw w't-'mmw wdbq b'stw whyw lbsr 'hd.

There is one variant reading cited in BHS for the MT: whyw] whyw snyhm (Samaritan Pentateuch, Targum PseudoJonathan, the LXX, and the Peshitta).

Any variant reading found in the Samaritan Pentateuch deserves special attention, if only because its value for text-criticism is not yet determined. It quite possibly witnesses to a pre-Massoretic Hebrew text-form, especially in a case such as this in which the LXX also has this variant. Targum Pseudo-Jonathan is believed to be a Palestinian targum, the foundations of which go back to preChristian times.110 Here again there may be witness to an older text-form, but caution is necessary as manuscripts of the older Palestinian targums differ from one another. The inclusion of snyhm would emphasize the contrast between the two becoming one, so it would more likely be an addition than that snytim would be deleted once in the text. Hence, the preferred text of the MT might be favoured slightly over the variant reading. The presence of hoi dyo in the Greek 
could be accounted for as an explanatory addition by the translator, but the presence of an equivalent in other versions suggests a Hebrew Vorlage departing from our MT. The preferred text of Mark is identical to the preferred text of the LXX. The only place where the LXX does not follow the Hebrew exactly is the use of only one autou for the two pronominal suffixes in the Hebrew 'byw and 'mmw. The fact that even here Mark is identical to the Lxx, indicates that he (or his source) has used the LXX, rather than translating the Hebrew independently.

It is worth observing that Matthew does not follow the LXX as closely as Mark. However, he differs only in points of style. He uses the Attic heneka rather than the Ionic and Hellenistic heneken.111 $\mathrm{He}$ is consistent in omitting the autou after patera as well as metera. In Matt 15:4a the possessive pronouns are also lacking for patera as well as metera, whereas in the parallel to that citation, Mark 7:10a, patera as well as metera have the possessive pronouns. Here, as wel1, Mark followed the Lxx exactly. This suggests that the omission of possessive pronouns in such cases may be simply Matthean style. The third point in which Matthew differs from the LxX is also one of style, the use of the simplex verb kollethesetai followed by the dative te gynaiki instead of proskollêthêsetai pros tên gynaika. 
Nevertheless, Matthew is not closer to the Hebrew than either the LXX or Mark, and in the use of heneken toutou, instead of dia, for $1-k n$, and the use of einai ... eis ... for hyh 1..., instead of ginesthai, he obviously has used the LXX text and slightly altered it for sylistic purposes. Did he get it from Mark, or did Mark correct Matthew's citation towards the LXX? Because the differences are only stylistic, there is nothing in the relationship between context and citation which helps in this decision. Mark's correcting Matthew towards the LXX might be reason for thinking that Matthew was prior here. On the other hand, Matthew may have changed the Marcan quotation for stylistic reasons. There is not enough here upon which to base a decision concerning the synoptic relationship.

Matt 26:31:

pataxô ton poimena kai diaskorpisthesontai ta probata tês poimnês.

There is one variant reading: diaskorpisthêsontai (papyrus 53, HA,047,067, ph,118,700, and other minuscules)] diaskorpisthêsetai (papyri 37,45, kDWGDThPh, 1,565, and many other minuscules).

For Matthew, papyrus 37 is Caesarean, papyrus 45 is Western, and papyrus 53 is Egyptian.11= with respect to the papyri cited, the text is favoured slightly. Diaskorpisthessontai is definitely favoured in the uncials 
and minuscules: $A$ and $B$ are the strongest witnesses (protoAlexandrian), and the rest of the Egyptian (Hesychian) group $H$, many members of which are Alexandrian ( $L T$, 33,579,892,1241). Except for the Western uncial D, all the uncial support for diaskorpisthêsetai is Koine.

The preferred parallel citation in Mark 14:27 reads: pataxô ton poimena kai ta probata diaskorpisthêsontai. Variant readings for the Marcan citation are: ta probata diaskorpisthêsontai (HDTh, and other manuscripts)] diaskarpisthêsontai ta probata (AFGDPs, 1 and other minuscules); diaskorpisthêsetai ta probata (KGPh,0116, 700 and a great many minuscules); ta probata skorpisthessetai (w).

The preferred text has the very strong support of the Alexandrian members of group $H(L T, 33,579,892,1241$, including the proto-Alexandrian $A$ and $B$ ). Support for the variant readings is either isolated (as in the third variant) or mostly Koine. The text stands.

The preferred text for Zech $13: 7$ in the Lxx reads: pataxate tous poimenas kai ekspasate ta probata. Variant readings for the LXX include: pataxate (the third-century papyrus $W, B A)]$ pataxô ( $V$ and several minuscules), pataxon (many other witnesses); tous poimenas ( $W, \mathrm{BA}$ ) ] ton poimena (many other witnesses); ekspasate ( $W$, $B A N$, the margin of B6)] diaskorpisthêsontai ( $A$ and several minuscules from the Alexandrian group, some minuscules from 
the Catena group, the Syro-Hexaplar from the Hexaplaric group), diaskorpisthesetai (the Alexandrian minuscule 407), diaskorpisthêto (later corrections to $A$, the whole Lucianic group with the exception of 36), diaskorpisthetasan (1ater corrections to $A$, the major members of the Catena group (except 490) and several others in this group, some Alexandrian minuscules), ta probata diaskorpisthêsontai (Q), ta probata diaskorpisthêtasan (later correction to $Q$, considered by Ziegler as Hexaplaric); probata (W)] probata tês poimnês ( $A$, some Alexandrian minuscules, Lucianic minuscule 36 ).

The key manuscript here is the third-century papyrus $w$. Of the uncials only $A$ and $Q$ can be grouped together (Alexandrian text-type). The others operate independently, and, therefore, if they agree this points to a common source. The more uncials from among $W, B, A$, and $V$, especially in concert with $w$, which witness a text, the greater the likelihood that that text is original. Hence, in all the above instances the text stands as it has WBA or WBAN in its support. Ziegler claims the variant readings ton poimena and diaskorpisthêsontai result from assimilation to the Matthean citation.11: As is the case here, this occurs occasionally in the Alexandrian group. Allen is undoubtedly incorrect in suggesting that Matthew added tês poimnes to assimilate to an LXX with $A^{\prime}$ s text.114 Instead, LXXA has assimiltated to Matthew. 
Zech $13: 7$ in the MT reads:

$h k \cdot t-h r \cdot h$ wtpwsyn hss'n.

One note in the critical apparatus of BHS suggests that hk should be read hkkh 'kkh (the hiphil infinitive absolute preceding the imperfect; "I shall indeed strike"), for the purposes of metre. Considering the general lack of scholarly consensus on the subject of Hebrew poetic metre, this emendation must be struck down as sheer speculation. In this regard, for example, why not simply suggest hkkh, an alternate form of the hiphil imperative?

Versional evidence is also cited in the critical notes of BHS. Some Greek manuscripts and the Arabic and Armenian versions have the equivalent of 'kkh. The Arabic version is a translation from the LXX, the Peshitta, and other versions.11s The manuscripts of this version are independent translations of quite diverse origins, so that there is in no sense a unified Arabic version. Hence, the Arabic versions are of little value for textual criticism. The Armenian version is based on the LXX with clear influence by the Peshitta.116 The place of the Peshitta in the textual criticism of the OT is not yet determined, as there exists no critical edition and its history has not yet been established. Because both the Arabic and Armenian versions are secondary (or tertiary) renditions of some form of the LXX, in this case not even the preferred text, they must be excluded from any decision on the MT text here. On 
external evidence alone, the Damascus Document (sometimes called the Zadokite Document) confirms the MT (CDCb 9:3; col.xix, 8). This document is one found in the Cairo Geniza and dates from the first or second century B. C. E.

Such ancient attestation does nothing to clear up the problem of the text, however. If it is the sword ( $h r b)$ that is being addressed here, the feminine singular imperative (hkky) is needed to correspond with the feminine noun hrb and the other imperative 'wry.11 However, a look at the context indicates that the sword is being addressed only before the words $n$ 'm yhwh sb'wt. These words break the stanza into two groups of two lines. The first two lines address the sword. To provide parallelism the subject of the second two lines are usually the same and the verbs are usually parallel. This means one of the verbs should perhaps be changed. It cannot be the second verb because of the reference to ydy ("my hand"). As well, the rest of the stanzas have the first person (God) as the principal subject (whsbty ( $(7)$, whb'ty $(\vee 9))$. Therefore, if there is to be an emendation, the obvious choice would be to substitute the first person imperfect ('kkh) for the imperative hk.110 The text can stand, however. There is no solid manuscript evidence to the contrary.

The preferred texts of the LXX and the MT differ considerably for this passage. Pataxate is the plural imperative, whereas hk is the singular. Several manuscripts 
( $A-Q$, the Lucianic and Hexaplaric recensions, and the Catena group) have the singular imperative pataxon, and thus correspond to the MT. The LXX has the plural tous poimenas against the MT's singular hr'h. Several manuscripts ( $A-Q, V$, the Lucianic and Hexaplaric recensions, and the Catena groupl have the singular ton poimena, and thus correspond to the MT.

The LXX uses ekspasate (the second person plural imperative) which means "draw out" or "pluck out".119 The MT has the qal imperfect indicative third person feminine plural tpwsyn. Several manuscripts ( $A-Q$, the Lucianic and Hexaplaric recensions, and the Catena groupl use some form of the verb diaskorpizein, and thus are closer to the MT. The Hebrew verb is intransitive. It can be interpreted in several ways120: imperfect indicative ("the flock will disperse [scatter]"), purpose ("in order that the flock may disperse"), jussive ("and may the flock disperse" or "and let the flock disperse"). Codices $A$ and $Q$ and the SyroHexaplar have the indicative (diaskorpisthessontai), but the passive, rather than the active as in the Hebrew. The Lucianic recension has the third person singular of the imperative (diaskorpisthêtô; "let it be dispersed"). The Catena groupizi and the hexaplaric corrector of $Q$ are closest to the MT; they have the third person plural of the imperative (diaskorpisthêtôsan; "let them be dispersed"). 
The gospels have clearly not used the preferred text of the LXX (pataxô instead of pataxate, ton poimena instead of tous poimenas, diaskorpisthessontai instead of ekspasate). It is also unlikely that either Matthew or Mark (or their source) directly translated from the Hebrew. Unless hk did not stand in the contemporary Hebrew text, whence comes the gospels' pataxâ? However, it is quite possible that the gospel tradition is based upon some form of the LXX which had been altered towards the Hebrew. The variant readings for the LXX demonstrate the existence of such texts at a later date. It is possible they descended from preHexaplaric texts revised toward the Hebrew.

The pataxo is unlikely to have come from any form of Lxx text, since it has survived in only one uncial, some minuscules, and a few other places: More likely it found its way into the Lxx tradition from the NT. The use of the future indicative, rather than the imperative of the LXX (for all those manuscripts which did not assimilate to the gospels), makes sense in the NT context. Jesus has just said that his closest fallowers will fall away in accordance with (gar, hoti) the prophecy given in the citation. The use of the first person singular future indicative in the citation would indicate that it is a prophecy, whereas the imperative does not. The gospels, then, either made this change from the form of the LXX text they used, or found it in their source. 
There are signs that Matthew used Mark. He has added tês poimnês. Tês poimnês would emphasize the cohesiveness of the group while the leader is present, contrasted to its dispersion without its leader. Matthew, after all, is usually recognized as the evangelist most concerned with the church. On the converse, one can hardly imagine why Mark would delete this phrase from Matthew.

The change of order from Mark's ta probata diaskorpisthêsontai to Matthew's diaskorpisthêsontai ta probata may have been a change towards the order of the LXX. Matthew's order is also more normal Greek. Mark may have changed the order from the Lxx originally in order to juxtapose shepherd and sheep. Whatever the explanation, this could certainly go in either direction, and cannot help resolve the synoptic relationship.

Outside the citation itself, the context gives some clues to the synoptic relationship. These clues are sharpened by their contrast to a context which is remarkably similar in both gospels. Matthew has en emoi ( $v 31$ ) which is lacking in Mark. This is parallel to the thought expressed by Matthew's addition of tês poimnês. It draws attention to the fact that the very reason the group exists is Jesus, just as the very reason there is a flock is the shepherd. The irony is that this is the very reason the group will break up that night. This draws a tighter relationship between the context of the citation, Jesus' prediction that 
they will fall away, and the citation itself, the prophecy concerning the shepherd. 


\section{NOTES}

1 Here we follow the standard practice of the NestleAland edition. H represents the stronger witnesses of the Alexandrian group, including $A$ and $B$ which formed the basis for critical editions of the gospels preceding Nestle-Aland. $D$ is a strong representational witness for the Western text, and $T h$ is a strong representational witness for the Caesarean text. $H, D$, and $T h$ are not given as support for the preferred text in order to avoid repetition, since their support is usually the reason the text is preferred.

= For this list see Kurt Aland and Barbara Aland, The Text of the New Testament: An Introduction the Critical Editions and to the Theory and Practice of Modern Textual Criticism (Grand Rapids: Eerdmans, 1987) 106-16.

Characteristics of particular manuscripts or groups of manuscripts which are stated in the textual discussions come principally from the fallowing works: (1) for the NT: Ibid.; Bruce M. Metzger, The Text of the New Testament: Its Transmission, Corruption, and Restoration (2d ed.; Oxford: Clarendon, 1968); (2) for the LXX: the introductory sections of the various volumes of the Gottingen Septuagint; Sidney Jellicoe, The Septuagint and Modern Study (oxford:

Clarendon, 1968); (3) for other QT textual information: Bleddyn J. Roberts, The old Testament Text and Versions: The Hebrew Text in Transmission and the History of the Ancient Versions (Cardiff: University of Wales Press, 1951); Ernst Würthwein, The Text of the old Testament: An Introduction to the Biblia Hebraica; trans. by Erroll F. Rhodes from 4 th ed. of Der Text des Alten Testaments (1973) (Grand Rapids:

William B. Eerdmans, 1979). Where other sources of textual information are used these are cited.

$=$ The quotations are presented in the following order. Quotations presented first are those which are found in more than one synoptic gospel, the text of which is identical or quite similar in those gospels. Those quotations which have similar or identical texts in three synoptics will be presented before those which are similar or identical in two synoptics. Quotations with an identical or similar text in two synoptics will precede those which occur in three synoptics but show greater diversity of text. This order of presentation cannot be exact; some might want to reverse the order of a few quotations here are there. Nevertheless, it has the merit of ranging the quatations over a gradient of similarity of text. 
4 Alfred Rahlfs (ed.), Septuaginta: Vetus Testamentum Graecum Auctoritate Academiae Litterarum Gottingensis editum, vol.10: Psalmi cum Odis (2d ed.; Göttingen: Vandenhoeck \& Ruprecht, 1967) 31.

s Ibid., 22.

s See, for example, Krister Stendahl, The School of $5 t$. Matthew and its Use of the old Testament ( $2 d$ ed.; Lund: $C$. W. K. Gleerup, 1968 ) 78.

> See Robert Horton Gundry, The Use of the old Testament in St. Matthew's Gospel with Special Reference to the Messianic Hope (Leiden: E. J. Brill, 1967) 25. Gundry suggests that because $D$ often reflects the Aramaic omission of the article in proper names, its support of the preferred text here must be discounted.

- Larry W. Hurtado, for example, notes that Western influence is seen so strongly in $T h$ that it should be regarded as the second best Greek representative of the Western text of Mark even though it does have Caesarean flavour (Text-critical Methodology and the Pre-Caesarean Text: Codex $w$ in the Gospel of Mark (Grand Rapids: Eerdmans, 1981) 87,88 .

- Robert G. Bratcher and Eugene A. Nida argue that Mark must have hypokatô on the grounds that hypopodion would be an assimilation to the LXX (A Translator's Handbook on the Gospel of Mark (Leiden: Brill, 1961) 388. On the topic of assimilation, Charles Cutler Torrey sees hypokatô as slipping into Mark from Matthew (Documents of the Primitive Church (New York: Harper \& Brothers, 1941) 82.

10 A Textual Commentary on the Greek New Testament (London: United Bible Societies, 1975) 111.

11 Cited in both ibid., xxviii, and The Text of the New Testament: Its Transmission, Corruption, and Restoration (2d ed.; Oxford: Clarendon, 1968) 210.

$1=$ A Textual Commentary, $x \times v i$ ii.

$1=$ M.-J. Lagrange favours hypokatô on the authority of $B$ and $D$ (Evangile selon Saint Marc (Paris: Gabalda, 1929) 326 .

14 Stendahl, The School, 78, ח.2.

$1=$ Both Stendahl, ibid., 78, and Gundry, The Use of the ald Testament, 25, claim that hypokatô comes from the 
influence of Ps $8: 7$. Neither gives a full argument for such a position. Both refer to other NT passages in which Ps 109:1 or Ps 8:7 are cited. Gundry states that "the quotations in Heb and 1 Cor illustrate the freedom with which the similar expressions in Ps 110 [LXX Ps 109] and Ps 8 were interchanged". However, when these are checked, where echthrous (Heb $1: 13$ ) or echthroi (Heb 10:13) appear, which indicate reference to Ps 109:1, so does hypopodion. Where there is no reference to enemies, and the reference is obviously to Ps. 8:7, hypokato appears. The writer of Hebrews seems, then, to have had no difficulty in keeping his references clear. There is no reason why Mark would not have been equally clear.

Cf. as well, A. E. J. Rawlinson who argues that Mark had hypokatô on grounds that he used Ps 8:6 as justification for the Son of Man title (St Mark, with Introduction, Commentary, and Additional Notes (London: Methuen, 1925) 175. In similar vein Rudolf Pesch notes the combination of Ps 8:6 with 110:1 in 1 Cor 15:25-27; Eph 1:20-22; Heb 1:3; 2:6-8 (Das Marcusevangelium, vol.2 (Freiburg: Herder, 1977) $254)$.

1o See, for example, Gundry, The Use of the old Testament, 25, and the critical apparatus of Nestle-Aland.

$1>$ For an opposing view see W. F. Albright and C. S. Mann, Matthew: Introduction, Translation, and Notes (Garden City, New York: Doubleday, 1971) 275.

19 It is noteworthy that one of Stendahl's general observations run into counter-evidence in this citation. Matthew's use of hypokato, a deviation from any known Greek or Hebrew text for this verse of Psalms, counters Stendahl's statement that "the intention to quote literally, and the practice of checking the text with the Greek text available may be taken for granted in the synoptic material" (The School, 163-4).

19 The Use of the Old Testament, 184 .

20 Die symoptischen Evangelien: Ihr Ursprung und geschichtlicher Charakter (Leipzig: Engelmann, 1863) 263. 168.

$=1$ So Aland and Aland, The Text of the New Testament,

$=$ = Gundry (The Use of the old Testament, 9-10.) makes additional arguments that the gospels used the LXX, rather than the MT. He claims that it renders l'l hynw with a "possessive construction", and, therefore, differs from the 
Hebrew. Aquila, Symmachus, and Theodotion translate tô theô hêmôn, suggesting Gundry's understanding of the text.

Gundry's other argument for the gospel's use of the LXX is that the gospels, I ike the LXX, construe bmobr with ql qwr rather than with pnnw.

Against Gundry it can be argued that the Greek and Hebrew are the same. It is important to realize that it is only the Massoretic accents that suggest the Hebrew be broken up in this manner. Likewise, there is no indication in the Greek that this is how we are to understand the composition of the verse. The Greek word order here follows the Hebrew exactly, perhaps because the translator was unsure of the syntax. Hence, neither the Hebrew nor the Greek text indicates how the verse is to be broken up. The only way we can infer that the gospels meant en tê erêmô to go with phônê boôntos is that John was in the wilderness, and that the prophecy concerned one who was in the wilderness. This is an inference we make from the NT context of the citation, and not from the wording of the citation itself. The Hebrew and Greek (in both LXX and NT) passage on its own is ambiguous in this syntactical respect.

$$
\text { = So Stendahl (The School, 48) but not so Gundry (The }
$$
Use of the 0ld Testament, 10).

$$
\text { =4 Septuaginta, vol.14: Isaias, 27. Ziegler does not }
$$
cite this passage as one of his examples.

$=$ Torrey (Documents, 45, 55) asserts that identical quotations are the result of the evangelists' striving to present a "solid front". He claims it was felt to be desirable that quotations found in two or more of the Greek gospels should agree with one another as well as with the $L X X$.

$$
\text { 96 The quotation in Matt 11:10; Mark 1:2; Luke 7:27 }
$$

will be considered in detail below.

$\Rightarrow$ In Hebrew, however, the same idiom ( $p$ nh with drk) is found in the MT of Mal 3:1 and Isa 40:3. This suggests that those familiar with the Hebrew may have originally linked the two verses. If so, the combination of quotations in Mark cannot be the result of literary dependence on the Greek texts of Matthew and Luke, as the Griesbach hypothesis requires.

se Cf. W. D. Davies and Dale C. Allison, A Critical and Exegetical Commentary on the Gospel According to Saint Matthew, vol.1 (Edinburgh: T. \& T. Clark, 1988) 292-94. 
$=9$ See Traugott Holtz, Untersuchungen über die alttestamentlichen Zitate bei Lukas (Berlin: Academic Press, 1968) 161, for an explanation of Luke's omission.

as At the time this research is being carried out the Gottingen edition of the LXX for Exodus by John William Wevers is not yet published. Hence, for Exodus, reference is to Alan England Brooke and Norman McLean (eds.), The old Testament in Greek According to the Text of Codex Vaticanus, Supplemented from Other Uncial Manuscripts, with a Critical Apparatus Containing the Variants of the Chief Ancient Authorities for the Text of the Septuagint; vol.1: The octateuch, part 2: Exodus and Leviticus (Cambridge: Cambridge University Press, 1909). As the rather long title indicates, the text supplied is that of Codex B. Hence, we shall not speak about a "preferred text" when citing the Lxx Exodus.

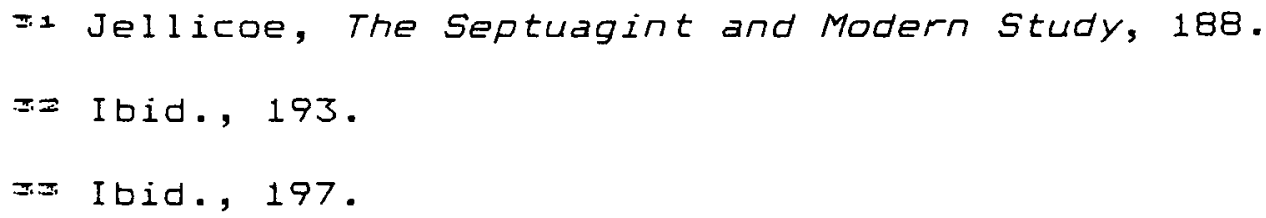

\$4 It is debatable whether this passage should be included in our discussion of the citations. It is not always a clear case whether a passage is a citation or simply an allusion. John C. Hawkins, in his discussion of quotations from the OT (Horae Synopticae: Contributions to the Study of the Synoptic Problem (Oxford: Clarendon, 1909) 154-6.), does not include this passage in his list of quotations, nor does he include it with "other places in which Matthew, without expressly quoting ... seems to be influenced by ... [OT] language" (Ibid., 158.).

On the other hand, Henry Barclay Swete does include it in his list of quatations from the LXX in the synoptic gospels (An Introduction to the old Testament in Greek (New York: KTAV, 1968) 386-7.). Swete's criterion for differentiating "formal" or "direct citations" from "mere allusions and reminiscences" is the presence of an introductory formula, or, in the absence of such, evidence that it was the intention of the NT writer to make a formal citation (Ibid., 381-2.).

Intention of the writer must be determined, of course, by examination of the text. Swete suggests that either the context of the problematic passage, or the verbatim agreement of the NT passage with with some OT passage, will indicate this intention of the writer or its lack. Stendahl simply adopts Swete's criteria (The School, 46.). Judgment 
as to whether a passage is a formal citation or an allusion, then, must necessarily be subjective, and, hence, moot. In Matt 19:4 Jesus asks the Pharisees if they have not read (anegnote), presumably in the scriptures, what follows. The previous verse indicates that the general context is a discussion of the law, for which recourse must be to the content of the Torah. This suggests that citations from the Torah might be expected. Clearly $\checkmark 5$ is meant to be a formal citation of the OT. Hawkins (Horae Synopticae, 155.) does include this verse in his list of quotations, despite his exclusion of $v 4$. While he gives no reason for excluding $v$ 4 , one is not difficult to find. The wording of the verse seems to suggest an indirect quote. While hoti can be used to introduce a direct quote, it can also indicate merely indirect quotation. Context will determine which. Here the text in question is preceded by ouk anegnote hoti ho ktisas $a p^{\prime}$ archês, none of which appears in the OT text, suggesting that the hoti does not introduce a direct citation. Nothing in the context of the parallel passage, Mark 10:6, suggests direct citation either.

Nevertheless, two factors sway the decision in the other direction. One is the general context which leads the reader to expect direct quotation, and the direct citation in the following verse. The other factor is the word autous in the text in question. This has its place in the OT passage, but what does it refer back to here?

\section{: $=$ Metzger, Text of the NT, 47 .}

I: Metzger says that $W$ exhibits characteristics of the Western and Koine groups in other parts of the synoptic tradition, but represents the Caesarean group for this part of Mark. Moreover, it belongs to the first stage in the development of the Caesarean text, the old Egyptian text which Origen brought to Caesarea, often called the preCaesarean text (Ibid., 57, 215). Hurtado, in his book, Textcritical Methodology, demolishes this viewpoint.

$$
\Rightarrow \text { Ibid., } 86 \text {. }
$$

=a Metzger (A Textual Commentary, 104.) suggests that "the insertion of ho theos as the subject of epoiesen must have seemed to copyists to be necessary lest the uninstructed reader imagine that the previously mentioned subject (Moses) should be carried on."

$\Rightarrow$ By adding ho theos at the end of the citation, the scribes have made this an indirect quote. This suggests that they may have seen this passage, not as a formal citation of the OT, but as simply an allusion or even just a non- 
allusive statement (supplying ho theos because this is all that could be the subject of the sentence).

40 The verse continues with hymeis de auton poieite spêlaion lêstôn. The words spêlaion lestôn are an allusion to Jer 7:11. The quotation, introduced by gegraptai, is a commandment, and as such, refers to the future ("My house shall be called a house of prayer"). The rest of Jesus" words here describe what is happening, a state of affairs in which the commandment has been breached ("but you make it a den of robbers").

\section{The Use of the 01d Testament, 19.}

$4=$ Nevertheless, Stendahl remarks, "Mark's pasin tois ethnesin most clearly shows that this gospel's quotation is primary and that Matthew left it out as less important in the context" (The School, 67.).

43 A Textual Commentary, 137. Metzger also suggests assimilation to the LXX.

44 John William Wevers, Text History of the Greek Deuteromony (Göttingen: Vandenhoeck \& Ruprecht, 1978) 48.

$4=$ Ibid., 52 .

4- Torrey (Documents, 55) counters that the fact that Matthew closely resembles the LXX need not necessarily indicate dependence. Translation from the Hebrew is possible because "there is no point at which the translation could naturally be altered." This is an argument Torrey uses again and again.

G. D. Kilpatrick ("Mt iv.4", JTS 45 (1944), 176.) claims that Matthew lacked ekporeuomenô dia stomatos. He states this claim on the basis of the text in codex $D$. Codex $D$ usually has the fuller text and also tends to fill out a text according to the LXX. Since in this case it has the shorter text, it must, considering its characteristic fullness, preserve the original Matthean text.

A comment regarding the characteristics of $D$ undermine this claim. While $D$ often does have a fuller text, it also characteristically can have a shorter text (see, for example, Metzger, The Text History of the New Testament, 50). Hence, here it may simply be manifesting this characteristic. What is noteworthy about $D$ is that it so often differs from the majority of other witnesses.

Kilpatrick's argument concerning $D^{\prime}$ 's filling out texts according to the LXX may be on more solid ground, especially considering that no manuscript of the LXX lacks ekporeuomenô dia stomatos. On the other hand, omission of ekporeuomeno 
dia stomatos does not alter the sense in any way, and seems a cleaner literary form.

Gundry (The Use of the 01d Testament, 67) also opts for a shorter Matthean text lacking ekporeuomenô dia stomatos. He bases his assertion on the observation that "the original text of LK, ending at anthropos, has been assimilated to the shorter text of Mt even in MSS which do not have the shorter text in Mt" [his italics]. It would have been preferable had Gundry expanded upon his argument here. Presumably he means that the shorter version appeared in Matthew and it was to this version that Luke was assimilated. At a later stage Matthew was filled out to correspond to the LXX. If this is a fair expansion of Gundry's argument, why was Luke also not so filled out, especially in light of Gundry's remark that "other MSS in LK assimilate to the full Septuagintal form, showing that there was a tendency to assimilate this quotation to the LXX"? In view of the fact that Gundry's overall thesis is to show that outside of the formal citations in the Marcan (and parallel) tradition citations are of a mixed text-type, it is not surprising that he pushes for a Matthean text lacking ekporeuomenô dia stomatos, since this would mean, for Gundry, that "the quotation is non-Septuagintal in form".

The problem for Kilpatrick and Gundry is explaining the Lucan manuscripts lacking ekporeuomenô dia stomatos, but continuing beyond anthrôpos. One could just as justifiably ask, assuming on their terms that Matthew had this form, where Matthew got this form.

47 That Luke has Q, see Davies and Allis
363 ; that Matthew has Q, see H. Mahnke, Die Versuchungsgeschichte im Rahmen der synoptischen Evangelien (Bern: Lang, 1978) 60-61, and H. Schürmann, Das Lukasevangelium (Freiburg: Herder, 1969) 210, $\mathrm{n} .14$.

48 Wevers, (Text History of the Greek Deuteromony, 54) considers the witness of 963 to be of "far greater importance" than even the witness of the old uncials ABFMV in helping to determine the critical text.

49 It is interesting to examine the case for the low percentage possibility that Codex $D$ preserves the original Matthean text. A case could always be made that all other manuscripts have assimilated to either Luke or the LXX. It is quickly noted that D uses the same verb, peirazô, as Aquila, Symmachus, and Theodotion. It is even strange that all of the latter three have the same verb in contrast to the LXX. It is true that the three have the plural form, while $D$ has the singular, but this difference in number is of little importance, considering that the LXX and MT differ here. That the three have the same verb might indicate that 
there was an earlier text or group of texts to which they are all related which had made changes in the LXX toward the Hebrew. It is possible that Matthew in this citation used such a text, as well, which is preserved in Codex $D$. Matthew could have found peirazo in $Q$, and Luke have assimilated this to the LXX. On the other hand, Luke's version may have been in $Q$, and Matthew's Greek $O T$, to which he changed the citation, have been one altered toward the MT. This would satisfy the two-document position.

However, it is just as easy to justify the Griesbach position. Matthew could have had peirazo, and Luke assimilated this to the LXX. Hence, such tenuous speculation in no way helps to decide the synoptic issue.

The use of peirazo by $D$ could be explained in many other ways, of course. Perhaps $D$ had access to a Greek recension which approached the MT, much like the three. Benjamin Wismer Bacon holds that Codex $D$ may be a direct translation of the Hebrew (Studies in Matthew (New York: $H$. Holt, 1930) 472.). J. H. Moulton thinks the use of peirazô by $D$ is merely a matter of style, a preference for the simplex form of the verb (The Expositor 7 (1909) 411-12). Gundry suggests $D$ has harmonized this use with that of the simplex form in Matt 4:1,3 (The Use of the old Testament, 68). None of these possibilities imply that D preserves the original Matthean text.

so Metzger, The Text of the New Testament, 47, 58 .

91 For bibliographic details, see Gundry, The Use of the old Testament, 68-9.

$=$ so Gundry, ibid., 69.

$=3$ Torrey (Documents, 56-7) says the earlier Hebrew version of Matthew had tsgd ("you shall worship") to correspond to the previous verse and for rhythm and assonance, and inserted lbdw ("only") to complete a metrical line and for rhetorical effect.

\$4 Emanuel Tov, "Proto-Samaritan Texts and the Samaritan Pentateuch", in Alan D. Crown (ed.), The Samaritans (Tübingen: Mohr, 1989) 399.

s= Roberts (01d Testament Text, 192) goes so far as to assert, "Where Septuagint and Samaritan coincide, it may be conceded that the text offered is generally preferable to the Massoretic text."

Ernst Würthwein (Text of the 0ld Testament, 43) sees the Samaritan Pentateuch as an early form of text that was not dependent upon the Hebrew text which led to the MT. This independent text is witnessed in the LXX and "some Jewish 
texts that escaped revision by official Judaism". Würthwein observes that the NT agrees in some passages with the Samaritan Pentateuch (for example, Acts 7:4,32 and Heb 9:3,4) against the MT. He suggests that in such cases the NT depends upon a Greek Pentateuch which was similar to the Samaritan Pentateuch.

Jellicoe (The Septuagint and Modern Study, 245, ח.1.) cites the same NT passages as Würthwein, perhaps because the latter may be his source. What is interesting here, of course, is that the citation here under study can also be included in this group.

so For a recent discussion of the Samareitikon see Sergio Noja, "The Samareitikon", in Alan D. Crown (ed.), The Samaritans (Tübingen: Mohr, 1989 408-412.

$\Rightarrow$ Indeed, Holtzmann (Die synoptischen Evangelien, 261.) sees the whole citation as coming from Mal 3:1. Gundry claims that the second part of the citation shows only "a very slight influence from the Hebrew text of Mal $3: 1 "$ " (The Use of the old Testament, 11).

sa The text and critical apparatus used for any of the minor prophets comes from Joseph Ziegler (ed.), Septuaginta: Vetus Testamentum Graecum Auctoritate Academiae Litterarum Gattingensis editum; vol.13: Duodecim Prophetae (2d ed.; Göttingen: Vandenhoeck \& Ruprecht, 1967).

$\Rightarrow$ Gundry (The Use of the Old.Testament, 11, n.2.) wonders why only slight influence is seen from the Exodus passage, and so much influence attributed to the Malachi passage:

Why then should we see only a slight influence from Ex 23:20, with many commentators, when the whole first clause agrees word for word with Ex 23:20 LXX?

os It appears that Gundry has simply followed Stendahl's line of argument in that, while he opts for the use of the Exodus passage over the Malachi passage, he does concede "a very slight influence from the Hebrew text of Mal 3:1" in the second half of the gospel citation (ibid, 11.). He does not state what this "very slight influence" is, but since he devotes a large fraction of his discussion of this citation to the use of the qal and piel this is likely what he has in mind.

-1 The School, 51. Stendahl's reason for saying that the LxX reads the qal here is the observation that "epiblepein is the usual rendering of pah in the qal in the LXX". The difference here is only with the pointing of the Hebrew, so that the consonantal text is ambiguous without an 
oral tradition to interpret it. The MT interprets with the piel pointing.

Other recensions of the Greek have interpreted the verb pnh differently, showing that this word was problematic.

Stendahl implies that Aquila's scholasei, Symmachus'

aposkeuasei, and Theodotion's hetoimasei all assume the piel reading. (The Gottingen LXX has the following: Aquila, aposkeuasei; Symmachus, scholazei; Theodotion, hetoimazei.) Gundry states that aposkeuasei and hetoimasei are based on the piel (The Use of the old Testament, 11). He makes no mention of scholazei, suggesting that, in contrast to Stendahl, whom otherwise he appears to be following (like Stendahl he too assigns aposkeuasei to Symmachus), he does not think scholazei is based on the piel. The verb scholazei can have the meaning of "devoting oneself to". This is much like the meaning of the qal (MT) of pnh in 2 Sam 9:8, "to concern oneself with".

In 2 Sam 9:8 the gal (MT) of pnh is translated by the LXX as epiblepein ("look upon"). Here it makes sense, although it is a literal translation. In Mal 3:1 epiblepein, if it means "look upon", makes little sense. The alternative, of course, is that epiblepein here does not mean "look upon" but something like "concern oneself with" or "devote oneself to". In this case, epiblepein would make sense in both the Samuel and Malachi passages.

It is interesting that Mark (or his source) did not use any of the alternatives offered in Aquila, Symmachus, or Theodotion.

$s$ Indeed, Stendahl himself asserts that "the quotation from Malachi is the only quotation common to the Synoptics which clearly shows influence from the Hebrew text", although he then mentions one other (ibid., 52).

s.: Die synoptischen Evangelien, 261.

\$4 The School, 51 .

$\Leftrightarrow$ Ibid., 207-17.

-o Use of a testimony is the explanation to which many scholars resort in an attempt to deal with this very difficult passage, often as what they see as the only alternative to a later scribal insertion at Mark 1:2. Cf. Albright and Mann, Matthew, 136; C. S. Mann, Mark: A New Translation with Introduction and Commentary (Garden City, New York: Doubleday, 1986) 195; D. E. Nineham, The Gospel of St Mark (Harmondsworth: Penguin, 1963) 60. 
Others do not explicitly state the use of a testimony but suggest some early common Christian form. Ezra P. Gould asserts that the quotation is a free translation of the Hebrew, which appeared in "some common Greek source, not the LXX" (A Critical and Exegetical Commentary on the Gospel According to St. Mark (New York: Scribner's, 1903) 5). Willoughby $C$. Allen claims the quotation was current in Christian Circles (A Critical and Exegetical Commentary on the Gospel According to 5 . Matthew (New York: Scribner's, 1907) 115.

or Gundry (The Use of the 01d Testament, 11.) claims that this combination was pre-Christian. Stendahl discusses such a possibility but rejects it (The School, 50).

se As we noted in our discussion of Holtzmann, the idea of a scribal insertion at Mark 1:2 has a long history. This possibility is kept alive in: Lagrange, Saint Marc, 4; Sherman E. Johnson, A Commentary on the Gospel According to St. Mark (London: Black, 1960) 33; Rawlinson, St Mark, 5.

$\Leftrightarrow$ Davies and Allison concur (Matthew, vol.1, 294).

7o Here Torrey (Documents, 70-71) sees a "two-fold process of contamination" in which the LXX assimilates to the NT and then the NT assimilates other parts of the quotation to the LXX.

71 For kbbdwny, BHS notes that 1QIsa- has kbdty. I argue that this is a misreading of the scroll, in "Confusion of taw and waw-nun in Reading 1QIsa-", accepted for publication in Revue de Qumrân.

$>$ The Book of Isaiah According to the Septuagint (Codex Alexandrinus); vol.2: Text and Notes (Cambridge: Cambridge University Press, 1906) 250.

$>$ Swete, Introduction, 320-21.

74 Stendahl (The School, 58) finds no direct connection between the Hebrew and Greek texts, and virtually despairs at the abundance of variant texts for the latter part of the Greek verse. Gundry's attempt to make sense of a difficult situation assumes "corruption of the Hebrew text" and that the LXX has reproduced another form of the Hebrew (The Use of the old Testament, 14-15).

$\Rightarrow$ Albright and Mann suggest the quotation goes back to an "old Palestinian" tradition (Matthew, 184). 
>o It is to be noted here that we have not said that Matthew reworked Mark's version. This is where Holtzmann's form of the two-document hypothesis, with its Urmarcus, has a distinct advantage over the form in which Mark is used directly by Matthew. Though Matthew's narrative is more artful than that of Mark, this does not imply that Mathew improved upon Mark and that Mark was prior to Matthew. All that can be concluded is that Matthew is more artful than Mark in his rendition of the narrative, and that Mark, who we would hope is at least artful enough to recognize good art in Matthew when he sees it, could not have used Matthew. Mark could easily have come later than Matthew, but simply not have made as artful a use of their common source.

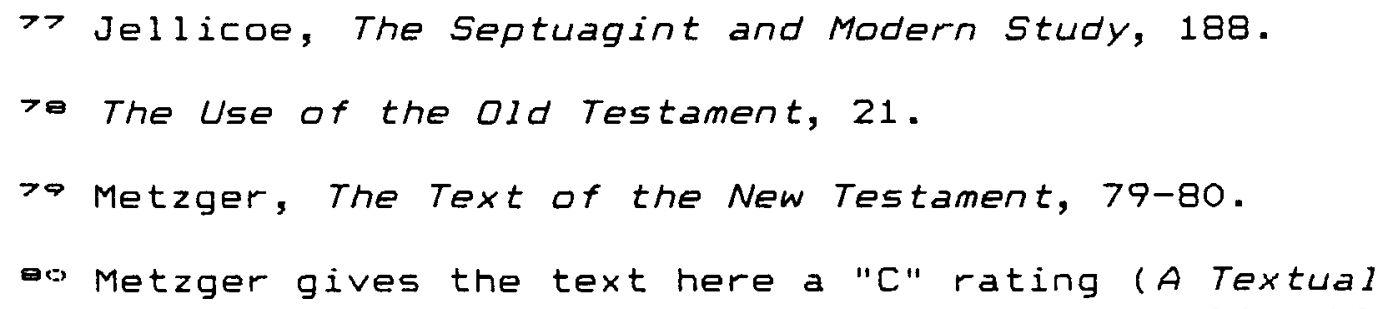
degree of doubt whether the text or the apparatus contains the superior reading" (ibid., $x \times v i$.).

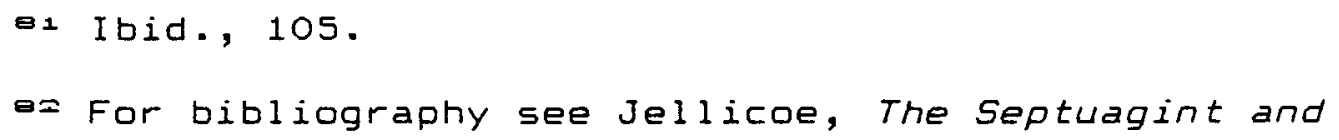


963 agrees with $A$ against $B$. In any case, he would find opposition from Wevers (Text History of the Greek

Deuteromony, 54) who observes that there is no close

relationship between 963 and any of the later text groups).

Caution needs to be exercised so that far-reaching

assertions such as Gundry has made are not founded on

insuffient evidence. His first assertion, for example, is

one used by Holtzmann and Stendahl. This should not be seen as one more brick adding to that edifice.

B> Gundry terms this construction "unusual" (The Use of

the old Testament, 17.). Does he mean "unusual" in

comparison with Matthew and the LXX, or "unusual" with

respect to Greek grammar? Whatever the case, it signifies a

special problem for him. Again, he assumes the two-document

position in the determination of his text. He states,

"Probably the Marcan text which could be the source of Lk is likely to be original, especially since Lk shares Mk's unusual me with the subjunctive". He is then forced to make two unwarranted moves to account for the texts. First, he adopts the weak reading (supported by the Koine group) concerning order so that the order of the Marcan original will correspond to that in Luke. When this order is adopted, the order in Matthew and Mark are then different. To account for this created difficulty and to avoid the alternative, that Mark used Matthew, Gundry claims that the order found in the preferred Marcan text is an assimilation to Matthew. He asserts as confirmation the fact that "A has this order against its own order in the OT". Against which order, that of $A$ in Exodus or in Deuteronomy? If Exodus, the order is the same. The logic of this "confirmation" could just as easily be used against Gundry, as, depending on which OT book is chosen, $B$ could also use a NT text which conflicts with its OT text. In conclusion, to avoid such textual acrobatics some other means of dealing with the use of mê with the subjunctive must be found.

Be The School, 62-3.

ostendahl states a general observation resulting from his work, "We will find that the catechetical quotations of Matthew are LXX in form even where they occur in material peculiar to the First Gospel" (ibid., 63.). So, whereas Stendahl finds that Matthew's citations are of a mixed textform in citations peculiar to his gospel, when those citations are of catechetical material this rule is broken and the citation takes the form of the LXX.

$\rightarrow$ Cf. Friedrich Blass and Albert Debrunner, A Greek Grammar of the New Testament and Other Early Christian 
Literature (trans. by Robert W. Funk; Chicago: Chicago University Press, 1961) 183.

$\rightarrow 1$ Stendahl proposes a number of reasons why Matthew may have added this particular citation here (The School, $63-4.1$.

$9=$ Having said that Matthew assimilates the first part of the quotation toward the LXX, and under the assumption that Matthew in general assimilates toward the LXX, Allen is puzzled as to why he lacks sou (Matthew, 209, 1xii). We shall find that Allen's assumption must be taken with a caveat.

9:- Stendahl (The School, 73) suggests that for this reason one must be cautious about drawing conclusions concerning the influence of OT texts upon such NT passages.

94 Septuaginta: Id est Vetus Testamentum Graece iuxta LXX interpretes; 2 vols. (Stuttgart: Privilegierte Württembergische Bibelanstalt, 1935).

$=$ Text History of the Greek Deuteronomy, 91-2.

90 Ibid., 59.

$\rightarrow$ Ibid., 54, 55.

$\rightarrow$ Gundry concludes his accourt of this citation with the remark that "the confusion ... defies disentangling" (The Use of the 0ld Testament, 24.). Unfortunately, so does Gundry's analysis. Usually quite illuminating, he seems to have been overcome with "the confusion" to the point of almost surrendering. He simply lists what he sees as "numerous possibilities".

$\Rightarrow$ Gundry, for example, is led to the completely unwarranted conclusion that "Mt goes directly to the Hebrew text" (ibid., 24.). His view is shared by Albright and Allison (Matthew, 274).

Allen says Matthew assimilates to the Hebrew in his use of en for ek (Matthew, 241).

100 The School, 73. Stendahl does not explicitly assert Marcan dependence on the LXX here. He writes, "Mark stands closest to the LXX with the preposition ek in all manuscripts throughout the passage." However, his next sentence, "Mark alone gives the famous first sentence of the shema, there too adhering to the LXX text", implies Marcan dependence for the preposition. 
115 Ibid., 99.
117 But see the discussion in E. Kautzsch and A. E.

Cowley, Gesenius. Hebrew Grammar (2d ed.; Oxford: Clarendon, 1910) 325-6, concerning the use of the second singular masculine in addressing feminine persons. The problem here is that there are only a few examples, of which this is one. This means that these few examples could all be errors. The attempt is to determine the original text. If the original text has faulty grammar, should we correct it?

110 Torrey insists the Hebrew had 'kkh (Documents, 84).

110 Stendahl observes that "in the LXX this verb tends to be used in bonam partem with the meaning "to save", "to redeem", as for example (in connection with the work of the shepherd) in Amos 3:12. Not only is it dangerous to assume that the same word is used the same way or has the same meaning in different parts of the LXX, considering that many hands were responsible for this collection of works, but Stendahl has chosen a singularly inappropriate example. "Rescue" might be a better word for the Amos passage. The shepherd here rescues two legs and the piece of an ear from the lion's mouth. These will be damaged, and hence perhaps useless anyway, but without the rest of the person they are entirely useless. The other analogy is the rescue of the corner of a couch and part of a bed, again entirely useless.

$1=0$ If the third person plural used the short form of the imperfect, as does the jussive in yqm, it would be possible to differentiate among these possibilities by means of morphology. Unfortunately, this cannot be done here.

131 Ziegler observes that this group is "stark hexaplarisch bearbeitete" (Septuaginata: Duodecim prophetae, 127.). 


\title{
CHAPTER FIVE: THE QUOTATIONS I I
}

\author{
Henry Barclay Swete observes that there are three \\ "distinct quotations" which are peculiar to Mark. ${ }^{1}$ His list \\ of OT citations found in the synoptic gospels= indicates \\ only two: Mark 9:48; 12:32. The third is hidden under Mark \\ "12:29f". We have treated this citation as part of the \\ citation under Matt 22:37. Mark 12:29 is part of a composite \\ citation, the part which has no parallel in Matthew or in \\ Luke. It cites the LXX exactly, and is not a fresh \\ translation of the Hebrew. \\ Considering Swete's criteria for determining what will \\ be counted a citation=, it seems strange that he has \\ included Mark 9:48 and Mark 12:32. Unlike all the other \\ citations in Mark (except Mark 10:6; 10:7-8), which had \\ parallels in Matthew, in these two cases there is no \\ introductory formula indicating that what follows is meant \\ to be understood as a citation, nor is it clear from their \\ contexts that they are intended as citations. As well, \\ unlike Mark 10:6; 10:7-8, which are identical to the LXX, \\ they fail Swete's final criterion, "verbatim" agreement with \\ a passage in the OT. It seems appropriate, therefore, to \\ classify Mark 9:48 and Mark 12:32 as allusions.
}


Swete 1 ists Luke $2: 23$ as a formal citation found only in Luke, with Exod 13:12 as the OT passage cited.4 He has defined "direct citations" as "those which are cited with an introductory formula".= In this case the introductory formula is present (kathôs gegraptai en nomô kyriou hoti), but one would be hard pressed indeed to see Exod 13:12, as found in either the LXX or the MT, as the source of the citation. Many Bibles cite the reference as Exod 13:2, indicating that the source is not clear. Here again, however, the Lucan text does not correspond to either the LXX text or the MT text. There is a resemblance of subject matter, and some common words, but no more. Luke $2: 23$, then, presents the strange case of an allusion masquerading as a formal citation, by means of its introductory formula.-

Luke $4: 18-19:^{7}$

pneuma kyriou ep' eme, hou heineken echrisen me euaggelisasthai ptôchois; apestalken me kêryxai aichmalotois aphesin kai typhlois anablepsin, aposteilai tethrausmenous en aphesei, kêryxai eniauton kyriou dekton.

Variant readings for the Lucan text include: ep' eme] epi se (the Sinaitic old Syriac); echrisen me] echrisen se (the Sinaitic ald Syriac); apestalken mel apestalken me (the Sinaitic old Syriac); apestalken mej apestalken me iasasthai tous syntetrimmenous tên kardian (KATh,0102, 1 and several other minuscules, the Peshitta); tethrausmenous] tethraumatismenous (the original hand of $D$ ). 
None of the above variant readings has strong support. The addition of iasasthai tous syntetrimmenous tên kardian, for example, has mostly Koine support and is an obvious assimilation towards the $L x X_{.}=$The text stands.

Isa $61: 1-2$ in the LXX reads:

pneuma kyriou ep eme, hou heineken echrise me; euaggelisasthai ptôchois apestalke me ..., kêryxai aichmalotois aphesin kai typhlois anablepsin, kalesai eniauton kyriou dekton ....

Variant readings for the Lxx text include: kyriou] addition of a second kyriou under an asterisk (which indicates a hexaplaric addition to correspond to the MT) in the margin of $Q$; echrise me] insertion of kyrios under an asterisk in Qmarosm to give echrise kyrios me; ptâchois] tapeinois (the original hand of $A, Q^{m a r e s n, ~ t h e ~ m a r g i n ~ o f ~}$ the Syro-Hexaplar (mskn'); kyriou dekton] tô kyriô (Qmarosn, the Syro-Hexaplar, and minuscule 88 (all witnesses to the hexaplaric recension)).

The text stands. All of the above variants are assimilations towards the MT, in the vast majority of cases in the hexaplaric recension.

Variants found in the hexaplaric tradition include: hou heineken] dioti (Aquila, Symmachus (according to the margin of minuscule 86)), anth ôn (Theodotion (according to the margin of 86)); echrise me] êleipse me kyrios (Aquila, Symmachus (according to the margin of 86)); aphesin] adeian (Aquila (according to the margin of 86)); kai typhlois] kai 
tois dedemenois (Aquila, Symmachus, Theodotion (according to the margin of 86)); anablepsin] diablepsin (Aquila (according to the margin of 86 )), apolysin (Symmachus (according to the margin of 86)), dianoixin (Theodotion (according to the margin of 86)); eniauton kyriou dekton] eudokias (Aquila, Symmachus (according to the margin of 86)).

That part cited by Luke of Isa 58:6 in the LXX reads: apostelle tethrausmenous en aphesei. There are no significant variant readings for the $L X X$ text. There is a variant found in the hexaplaric tradition: apostelle tethrausmenous en aphesei] apolye tethrausmenous eleutherous (Aquila (according to the margin of 86)), apolye tethlasmenous eleutherous (Symmachus (according to Theodoret)).

In the MT the selected portion of Isa 61:1-2 reads: rwh 'dny yhwh' 'Iy, $y$ ' $n$ msh yhwh' ty lbssr 'nwym slhny ... 1qr' lsbwym drwr wl swrym pqh-qwh, lqr' snt-rswn 1 yhwh.

There is one variant reading listed in BHS for this text. Several Hebrew manuscipts read pqhqwh with the Qumran scroll 1QIsa-, but other Hebrew manuscripts read pqwh.

The support of the 1QIsa- scroll is strong witness to the text. The fact that qwh is a hapax legomena may explain the use of pqwh in the variant manuscripts. The text stands. In the MT the selected portion of Isa 58:6 reads: wsllh rswsym hpsym. 
There are no variant readings cited in BHS for this passage.

There are at least three possible sources for Luke's citation: a Hebrew text virtually identical to the MT, the LXX, or a Greek recension which has been altered towards the Hebrew and may be a farerunner of the hexaplaric tradition.

In the first clause, pneuma kyriou ep' eme, Luke agrees verbatim with the LXX. The LXX differs from the MT in using kyriou only once. Clearly, Luke has sided with the Greek over the Hebrew in this case.?

In his use of hou heineken Luke has followed the LXX without any trace of the revisions attested in Aquila, Symmachus, and Theodotion. The same can be said about his lacking the explicit kyrios as subject of the verb echrisen. Luke's use of echrisen and apestalken against the LXX's echrise and apestalke is, of course, a simple matter of orthographic style.

Luke follows the Lxx in his use of ptochois. There is no evidence that Aquila, Symmachus, or Theodotion differed here, but the original hand of $A$, and marginal notes in $Q$ and the Syro-Hexaplar indicate that Origen's fifth column had tapeinois. The latter, in contradistinction to ptochois, indicates humility rather than material poverty.

Luke has the LXX's aphesin against Aquila's adeian, and the LXX's kai typhlois anablepsin against the alternatives found in Aquila, Symmachus, and Theodotion. The many 
alternate translations here indicate the difficulty presented by the Hebrew text. The verb pqh means "to open", but it is used in the context of "eyes" and "ears" (Gen 3:5,7; 21:19; Dan 9:18; Isa 35:5; 42:20). Here it is used with "swrym ("those bound"), rather than "wrym ("the blind"), so that the LXX clearly deviates from the Hebrew, in contradistinction to Aquila, Symmachus, and Theodotion who use dedemenois. Luke again follows the LXX.

Luke has reproduced the words from Isa 58:6 exactly as they are in the LXX,10 with the necessary grammatical change of the imperative apostelle to the aorist infinitive aposteilai. Once again Luke does not use any of the alternatives presented in Aquila and Symmachus.

Luke has followed the LXX of Isa $61: 2$ in the clause kalesai eniauton kyriou dekton except for replacing kalesai with its synonym keryxai. Here Luke may be mirroring the MT's double use of $q r^{\prime}$. It is Luke's only agreement with the MT against the LXX in this citation.11 There is no extant evidence from Aquila, Symmachus, or Theodotion here.

With this one exception, and this could be simply a matter of style, Luke has clearly followed the LXX. His failure to use any of the alternatives furnished by Aquila, Symmachus, and Theodotion, shows that he did not use a text which had been altered toward the Hebrew in their fashion. He did not himself translate the Hebrew, $1=$ or he would not 
so consistentiy have come up with the same translation as the LXX when so many possibilties exist.

Luke 22:37:

kai meta anomôn elogisthê.13

There is one variant reading: meta] meta tôn (D). Such meagre support for this variant confirms the preferred text.

In the LXX the relevant portion of Isa 53:12 reads:

kai en tois anomais elogisthê.

There are no variants to the LXX text, except those of the strictly hexaplaric tradition: kai en tois anomois elogisthê] kai tôn asebôn apescheto (Theodotion (according to the margin of 86 )), kai tôn asebôn êrithmêthê (Aquila (according to the margin of 86)), kai meta tôn asebôn êrithmêthê (Symmachus (according to the margin of 86)).

In the MT the relevant portion of Isa 53:12 reads: $w^{\prime} t-p s^{\prime} y m$ nmnh.

In absence of clear evidence to the contrary, it can be assumed that Luke did not translate the Hebrew himself.14 The LXX and Aquila, Symmachus, and Theodotion have provided alternative translations of the Hebrew. In his use of elogisthê and anomôn Luke clearly has followed the LXX rather than any of the revisions attested in Aquila, Symmachus, or Theodotion. Also, because he has chosen the words of the LXX among all the possible permutions and combinations, this indicates that he did not translate the 
Hebrew directly. The differences which do exist between Luke and the LXX are simply a matter of style. Luke's use of meta should not be misconstrued as evidence that he translated the Hebrew himself. Neither Theodotion nor Aquila, both of whom altered the LXX towards the Hebrew, used meta. This is especially noteworthy in the case of Aquila who characteristically gives stilted and slavishly literal renditions of the Hebrew. However, Luke may have taken meta from a Greek text modified in this respect as in Symmachus. $1=$

Matt $5: 21:$

ou phoneuseis.

There are no variant readings listed in Nestle-Aland for this citation.

In the LXX Exod 20:1510 is identical to the Matthean citation. There are no variant readings listed in BrookeMclean for this passage.

In the MT Exod 20:13 reads:

$I^{\cdot}$ trsh.

Matthew has used the LxX here. If he had translated the Hebrew directly he would probably have used the imperative with negation.

Matt 5:27:

ou moicheuseis. 
There are no variant readings in Nestle-Aland for this citation.

In the LXX Exod 20:13 is identical to the Matthean citation. There are no variant readings listed in BrookeMclean for this passage.

In the MT Exod 20:14 reads:

$l^{\cdot} \operatorname{tn} \rho$.

Matthew has again used the LXX here.

Matt $5: 38:$

ophthalmon anti ophthalmou kai odonta anti odontos. There are no variants 1 isted in Nestle-Aland for the citation.

The relevant portion of Exod 21:24 is identical to the Matthean citation. There are no variants 1 isted in BrookeMclean for this passage.

In the MT Exod 21:24 reads: 'yn tht 'yn sn tht sn. Matthew clearly uses the LXX here, rather than himself translating the Hebrew. This is made clear by his use of the accusatives ophthalmon and odonta. Matthew should have switched to the nominative case for his citation in its context, but he has retained the accusative case which is found in the LXX. In the LXX the accusatives are the direct objects of the verb dôsei in the previous verse (Exod $21: 23)$ 
Matt $5: 43:$

agapêseis ton plêsion sou.

There are no variants $l$ isted in Nestle-Aland for this citation.

The relevant portion of Lev 19:18 in the LXX is identical to the Matthean citation. There are no significant variants for this text.

The relevant portion of Lev 19:18 in the MT reads: w'hot $1 r^{\circ} k$.

Matthew has used the LXX here.

Swete lists two other passages from the Sermon on the Mount as formal citations of the 0T: Matt 5:31,33.17 Stendahl understates the case when he writes, "In Mt. 5:31 and $5: 33 \ldots$ the textual relation to the $0 . T$. is somewhat of a problem." 1 a

This is immediately evident when commentators scramble hither and yon in search of the OT passage cited. For Matt 5:33, Swete cites Num 30:3 with the suggestion to compare Deut 23:21. Gundry19 cites Lev 19:12 and Ps 50:14 (MT) (Ps 49:14 in the $(X X)$ with the suggestion to compare Num $30: 3$ and Deut 23:22-24, and Stendahl cites Lev 19:12. For Matt 5:31, Swete cites Deut 24:1 and, while there is no disagreement that this is the passage cited, Stendahl 
asserts that "Matthew here deviates both from the LXX and the M.T. to the extent of an allusion."

John C. Hawkins=o lists these two verses with Matt $5: 21,27,38,43$. All occur in the Sermon on the Mount. Hawkins displays some hesitancy to list these with the quotations from the OT, in his statement, "The prefixed errethê seems to mark these passages as intended to be quotations, so they are placed here for consideration." Hawkins has counted the words which the Matthean passages have in common with the LxX. Of the six passages in the Sermon on the Mount, $5: 21,27,38,43$ are identical to the Lxx, with two exceptions. In 5:38 the word kai appears in the middle of the citation. We have not counted this as part of the citation itself, but a conjunction connecting two parts of the citation. Hawkins has counted this as a word in the citation which does not appear in the cited passage in the LXX. The other exception is that Hawkins has counted the words kai miseseis ton echthron sou as part of the citation in 5:43 because "grammatically they form part of the quotation, though they are not found in the 0.T." We did not count these wards as part of the citation because they are not a citation of the OT.

This raises an interesting issue. Recall that Swete Iisted Luke 2:23 as an OT citation, but we determined that it was at best an allusion sharing some content with an DT passage and merely masquerading as a citation by means of 
its introductory formula. This shows that swete considers an introductory formula of a certain type as sufficient for a passage to be a citation. He then goes on to include some other passages as citations which do not have an introductory formula. We would define a citation as a passage which definitely corresponds closely to a particular OT passage and which is intended as a citation, whether or not there is an introductory formula.

Under this definition, the words kai misêseis ton echthron sou are not part of the citation in Matt 5:43. The introductory word errethe ("it was said") probably should not be seen as having the force of gegraptai. Moreover, where does the clause kai misêseis ton echthron sou come from? Stendahl=1 suggests that such sayings existed in Jewish catechism and that the ethical statements of the scribes and the early church were not exact quotations from Scripture. He cites the Manual of Discipline from Qumran as an example of such a catechism.

Returning to Hawkins' statistics on the number of words in "citations" which are found in the LXX, we note that only a small fraction of the words in Matt 5:31 and 5:33 come from the LXX. In this way they are strikingly different from the four citations $(5: 21,27,38,43)$ in the sermon on the Mount. This suggests that we should not let ourselves be overly influenced in our thinking by the fact that all six passages are introduced with the word errethe. The fact that 
there exists a difference of apinion as to what OT passage(5) is cited in 5:33 suggests that this passage should perhaps not even be graced with the designation "allusion", let alone "citation". Hawkins could not even decide how many words in this verse were common to the $L x x$.

The only part of 5:33 which has direct contact with Lev 19:12 are the words ouk epiorkeseis ("you [singular] shall not swear falsely"). The MT's wl'-tssb'w bsmy lssqr ("and you [plural] shall not swear by my name falsely") is rendered by kai ouk omeisthe tô onomati mou ep' adikô ("and you [plural] shall not swear by my name unjustly") in the LXX.= In the same manner the remainder of the "citation" in 5:33 merely hints at a connection with Ps 50:14 (MT) (Ps 49: 14 in the $(x x)$.

Stendahl suggests that in 5:33 Matthew is using catechetical material known to him.ss The commandment not to swear falsely would be unusual for early Christians, especially considering Jesus' command not to swear at all. Stendahl claims that the commandment not to swear falsely is Judaic catechism because it is also found in the Didache $(2: 3)$, in which "the imprint of Jewish catechism is the greatest".

In 5:31 not only is there only the faintest of verbal contact with Deut 24:1, but the Matthean "citation" does not even deal with the same subject matter as the OT passage. The passage in Matthew refers to a commandment to issue 
one's wife a certificate of divorce when one divorces her. In the OT passage the man writes (the indicative, not the imperative) his wife a bill of divorce. The concern here is what happens after a bill of divorce has been issued.

Matt 13:35:

anoixô en parabolais to stoma mou ereuxomai kekrymmena apo kataboles [kosmou].

There is one variant reading 1 isted in Nestle-Aland: kataboless [kosmou] (first hand and second correction of A,CKDKLWXDTh, ph,33,892,1241, and many other minuscules, the Vulgate and some of the 0ld Latin manuseripts, the Peshitta, the Sahidic and Bohairic versions)] kataboles (the first correction of $A, B, l$ and a few other minuscules, old Latin manuseripts $e, k$ ).

The difficulty in deciding this text is seen in the fact that up until the twenty-sixth edition of Nestle-Aland kosmou was not included in the text, and even in the twentysixth edition it appears in square brackets indicating considerable doubt in the minds of the editors. $=4$ The shorter text really has only one strong witness, B. The longer version has several Alexandrian witnesses: $A$, $33,892,1241$. On internal grounds, the longer version would seem better because it is not an assimilation to the LXX (the LXX has no kasmou to complete its archês). While against the longer version is the fact that kosmou is a 
natural way to complete kataboles,=s it would be just as natural for Matthew himself to add kosmou as for later scribes to do so. The text stands, but with reservations.

In the LXX Ps $77: 2$ reads:

anoixâ en parabolais to stoma mou phthegxomai problêmata ap' archês.

There is only one significant variant listed in Rahlfs for the LxX text: parabolais] parabole (A, Jerome's Latin translation known as the Gallican Psalter). While $A$ is the only other Greek uncial along with B in Rahlf's Lower Egyptian group, it is relatively isolated as a witness. Jerome worked with the Hebrew text, and it is therefore quite natural that he would employ the singular here to correspond with that text. The text stands.

In the MT Ps 78:2 reads:

'pthh bmsl py' 'bby'h hydwt mnny-qdm.

Matthew has the LXX text exactly for his first clause, anoixô en parabolais to stoma mou, even so far as his use of the plural parabolais, as against the collective singular msl in the Hebrew. This does not compel the conclusion that Matthew used the LXX here, since he could have translated the Hebrew himself and got the same result=o, but it appears that he did.

With the exception of the preposition apo, Matthew totally differs from the LXX for the remainder of the citation. 
Frederick Fieldz> offers the following: ombreso ainigmata ex archêthen (Aquila); anablysô problêmata archaia (Symmachus). Matthew has not a single word in common with either of these. However, his ereuxomai ("disgorge"), like Aquila's ombrêsô ("rain upon") and Symmachus" anablysô ("gush forth"), seems better to catch the flavour of the Hebrew than the LXX's phthegxomai ("utter"). The diversity of all of these forms at least leaves open the possibility that Matthew is using a Greek text which is vastly different from ours, but perhaps closer to the Hebrew. Noting that many scholars believe Matthew to have translated from the Hebrew himself in the second part of the quotation, $=9$ Torrey asks what could account for such an extraordinary proceeding, copying the Greek in one clause and in the next substituting an equivalent translation. 29 while Torrey is arguing for a Matthean translation of the whole quotation, his logic can go the other way. If Matthew so accurately copied the first half of the quotation, why would he not do the same in the second half? Besides, there are no signs that Matthew has adapted the Hebrew to suit his purposes, so why would he bother to make a fresh translation?

The parallel passage in Mark 4:33-34 lacks an OT quotation. It is difficult to imagine what reason there could be for Mark's omitting Matthew's quotation, so the two-document hypothesis is favoured here. Matthew appears to 
have added the quotation himself as a reflection on the fulfilment of the prophetic word.

Matt 21:16:

ek stomatos nêpiôn kai thêlazontôn katêrtisô ainon.

There are no variants listed in Nestle-Aland for this text.

In the LXX the relevant part of Ps $8: 3$ is identical to the Matthean text. Rahlfs cites no variants for the LXX text.

In the MT the relevant part of Ps $8: 3$ reads: mppy 'wllym wyngym yssdt' $z$.

There is one variant reading in BHS: ' $z$ ] tsowhtk (the Peshitta). This is a case in which the LXX has influenced the Peshitta, something which is especially common in the Psalms.=0 This only moves the problem down the road. Why did the Lxx translate so differently? Did the Lxx translator have a different Hebrew text? There are at least two possibilities. One is that the LXX translator found the Hebrew text so difficult to understand that he emended the text. $\approx 1$ The second is that he understood ' $z$ to mean "praise" heresa, just as it does in "Give to Yahweh kbwd and " $z$ " (Pss 29:1; 96:7) and in "Give ' $z$ to God" (Ps 68:35). As in Rev $4: 11 ; 5: 12,13$, the divine attribute praised becomes so identified with the act of praise that it comes to mean the praise itself. 


\begin{abstract}
Matthew has used the LXX here. $\equiv$ The difficulty of the Hebrew makes possible too many other renditions for Matthew's identity with the LXX to be mere coincidence.

The context in which this quatation occurs is not found in Mark or Luke. This favours the two-document hypothesis. Why would both Mark and Luke omit this pericope if they found it in Matthew?
\end{abstract}

Matt 1:23:

idou hê parthenos en gastri hexei kai texetai huion kai kalesousin to onoma autou Emmanouêl.

There is only one significant variant given in NestleAland: kalesousin] kaleseis (D, a few other manuscripts, Origen and Eusebius).

This variant is an obvious assimilation to the LXX. Because it has such isolated support, and that not consisting of strong witnesses to the original text, the text stands.

The relevant part of Isa $7: 14$ in the LXX is identical to the Matthean citation with one exception: kalesousin] kaleseis.

Variant readings for the LXX text include: hexei] le $(m) p s e t a i$ (the whole Hexaplaric recension (including BV, the Syro-Hexaplar, minuscule 88), the vast majority of the Lucianic recension (including all of the Hauptgruppe), all of the Catena group but one minuscule, and several 
minuscules of mixed text-type); kaleseis] kalesei ( $A$, mimuscules 311 , 46 of the Lucianic recension), kalesete or kaletai ( $Q$, the vast majority of the Lucianic recension (including all of the Hauptgruppe), minuscules 49,764 of the Catena group, a few minuscules of the mixed text-type, the Sahidic version), kalesousi(n) (the Alexandrian minuscules 26 and 106, a smattering of minuscules from the Lucianic recension and the Catena and mixed text-type groups, the Bohairic version).

The first variant, le(m)psetai, was likely found in Origen's fifth column. All of the witnesses point in this direction: $B$ and $V$ are the best witnesses to this text; the Lucianic text is a revision of Origen; the Catena group often witnesses to this text.

In Isaiah $A$ can be placed into no specific text-type. Hence, its support of kalesei is isolated and of little value in determining the original text.

The witness of $Q$ for kalesete or kaletai is alone among the Alexandrian group here. Sometimes $Q$ can go against the Alexandrian group in its witness to Origen's text. Perhaps this is the case here, in view of the strong Lucianic support.

The final variant, kalesousi(n), may result from assimilation to Matthew. It has thin support among minuscules in all major groups, but no uncial support. 
Following is evidence for Variant texts of Aquila, Symmachus, and Theodotion: parthenos] neanis (Aquila, Symmachus, and Theodotion (according to the margin of minuscule 710 , and Theodoret), Aquila and Symmachus (according to Eusebius)); hexei (Aquila and Theodotion (according to Irenaeus as cited in Eusebius))] syllambanei (Aquila, Symmachus (according to the margin of minuscule 710, and Eusebius)); texetai (Aquila and Theodotion (according to Irenaeus as cited in Eusebius))] tiktei (Aquila and Symmachus (according to Eusebius)); to onoma] onoma (Aquila and Symmachus (according to Eusebius)), homoiôs onoma (Aquila, Symmachus, and Theodotion (according to the margin of $Q$, and (in Latin) Jerome)).

The relevant part of Isa $7: 14$ in the MT reads: hnnh h'lmh hrh wyldt bn war't smw 'mmnw' 1 . There is one variant reading offered in BHS: wqr't] wqr' (the Qumran scroll 1QIsa*). The text of the MT, wqr't, translates as "and she will call". The variant reading, war', translates as "and [nis name] will be called", or, to put it in a literal way which elucidates the syntax, "and one will call".34 The form war could also be the pual perfect with the waw-consecutive (in the unpointed text) which would translate as "[his name] will be called", or as the qal imperative. This variant reading should be seen as just that, an alternative text. 
Matthew has the LXX's parthenos ("virgin") against the MT's h'lmh ("the young woman") and neanis ("young woman") as found in Aquila, Symmachus, and Theodotion. Matthew's selection here obviously fits his context.: =

In no part of his text does Matthew show assimilation of the Greek toward the Hebrew as in Aquila, Symmachus, or Theodotion, but uses the LXX's rendition in every case. This clearly indicates that he used the LXX, rather than translating the Hebrew himself.

It should be noted that Matthew uses kaleseis in $v 21$ in a clause which almost parallels the citation, texetai de huion kai kaleseis to onoma autou Iessoun. Here the verb is used in the sense of a personal command to Joseph. He obviously obeyed ( $\vee 25)$. If $\vee 23$ is also understood as a personal command, as would be the case if the MT is understood to mean "and she shall call"=0, then Joseph did not obey. However, $\vee 23$ is obviously not a personal command, such as the Hebrew was. It does not contradict $\vee 21$ because the sense of $\vee 23$ is "he will be acclaimed by the people as Emmanuel", and this sense is conveyed by the use of the third person plural impersonal kalesousin as contrasted with the personal second person singular kaleseis. Matthew's use of kalesousin against kaleseis as found in Aquila, Symmachus, and Theodotion and in the LXX (except for the Bohairic version and a scattering of Greek minuscules which 
have kalesousin) reflects his need to make this change to be consistent with his context.

In conclusion, Matthew has used the LXX, except for

kaleseis. His use of the impersonal kalesousin resulted from his own altering to suit his context.

Matt $4: 15-16:$

gêe Zaboulôn kai gê Nephthalim hodon thalassês peran tou Iordanou Galilaia tôn ethnôn, ho laos ho kathêmenos en skotei phôs eiden mega kai tois kathêmenois en chôra kai skia thanatou phôs aneteilen autais.

The Matthean text has the following variants: Iordanou] Iordanou potamou (the old Syriac); skotei (HKTh and many other witnesses)] skatia (the corrected hand of $A$, $B D$ ), skotia tê (W); megal omitted in the Sinaitic old Syriac; kai tois kathêmenais] hai kathêmenai ( $D$, 700, most of the ald Latin witnesses); chôra kai] lypê kai (the Sinaitic old Syriac), omitted in the Curetonian 0ld Syriac; phôs mega (the Curetonian old Syriac).

All of these variants, except skotia, must yield to the preferred text because they have such thin support. In the case of skotia, skotei would seem the obvious text because only $B$ of the strong group $H$ witnesses to the variant. Why, then, was the variant considered the preferred text until the twenty-sixth edition of Nestle-Aland? Skotei was Iikely rejected as assimilation to the LXX. The present reasoning, in favour of skotei, goes with the preponderance of 
witnesses, but it is a difficult decision. The text stands, but with the note that it cannot be definitely determined.

The relevant portion of Isa 9:1-2 in the LXX reads:

chôra Zaboulôn hê gê Nephthalim hodon thalassês... kai peran tou Iordanou Galilaia tôn ethnôn ... ho laos ho poreuomenos en skotei idete phôs mega hoi katoikountes en chôra kai skia thanatou phôs lampsei eph' hymas.

Variant readings for the Lxx text include: he gê] $k a i$ gê (the Alexandrian minuscule 106 and a few minuscules from each of the Hexaplaric recension, the Lucianic recension, and the mixed text-type group), gê (a few minuscules from each of the Catena and mixed text-type groups); Nephthalim] Nephthalein (the Hexaplaric minuscule 88 , and the mixed text-type minuscule 239), Nephthali (Q); hodon thalasses (the Bohairic version)] tines ouk echousin hodon thalassess (Qmarosn), omitted in the first hand of $A$, the whole Hexaplaric recension, most of the Lucianic recension, the most important members of the Catena group, several minuscules from the mixed text-type group, the sahidic version); Galilaia] ta merê tês Galilaias (the major portion of the Lucianic recension); ho poreuomenos] ho kathemenos ( $A$ and the Alexandrian minuscule 106, a smattering of minuscules from all the other groups and recensions except the Lucianic); idete] eide(n) (virtually the whole of the Lucianic recension, the Hauptgruppe of the Catena group, several members of the mixed text-type group, the Sahidic version); kai skia (third-century papyrus 965)] skia (the 
first hand of $A, B$, mixed text-type minuseules 534,544), skias (a very large portion of the Lucianic recension). Many of these variant readings are minor stylistic changes that have thin and scattered witness. Ziegler cites Isa $9: 1$ as a verse whose transmission is very uneven. $\Rightarrow \mathrm{He}$ thinks it quite possible, for example, that hodon thalassês comes into the LXX text from Matthew, despite the fact that $A$ and $Q$, the best Alexandrian witnesses to the original text, have this. It is very strange here that all of the Hexaplaric recension and the majority of the Lucianic recension and Catena group, which derive largely from this Hexaplaric recension, omit hodon thalassês, when the MT has the corresponding drk hyym. Aquila, Symmachus, and Theodotion, as might be expected, have some form of this phrase, which makes it even more difficult to understand why Origen would not have it in his fifth column. Ziegler's frustration with these verses, in that much of his theory regarding the relationship between and characteristics of various LXX recensions and groups seems to be confounded by these two verses, perhaps finds expression when he cites ho kathêmenos in 9:2 as one of only a handful of cases in which A has been influenced by a NT text (here Matthew). 30 For this reason he goes against $A$ for the reading of his text (ho poreuomenos). Despite all of this, Ziegler steadfastly adheres to his principle that $A$ and $Q$ together are the basis for determining the original text, and so includes hodon 
thalasses in his text. His problem, of course, is that if this were in the original text and also corresponds to the MT, why would the Hexaplaric recension alter the text away from the Hebrew? $=9$

Variations found in Aquila, Symmachus, and Theodotion include: chôra Zaboulôn hê gê Nephthalim hodon thalassês... kai peran tou Iordanou] etachyne gên Zaboulân hê ge Nephthalim kai ho eschatos ebarynen hodon tên kata thalassan peran tou Iordanou (Symmachus (according to Procopius); the margin of 710 has only that kai ho eschatos ebarynen hodon tên kata thalassan is found in Aquila, Symmachus, and Theodotion; the margin of $Q$ notes that hodon tês thalassês is found in Aquila and Theodotion; the Syro-Hexaplar notes that hodon tês thalassês is found in Theodotion; Galilaia tôn ethnôn] thinas tôn ethnôn (Aquila (according to the margin of 710), horion tôn ethnôn (Symmachus (according to the margin of 710 ) ).

The relevant portion of Isa $8: 23$ - 9:1 (including portions which are not cited in Matthew, in brackets) in the MT reads:

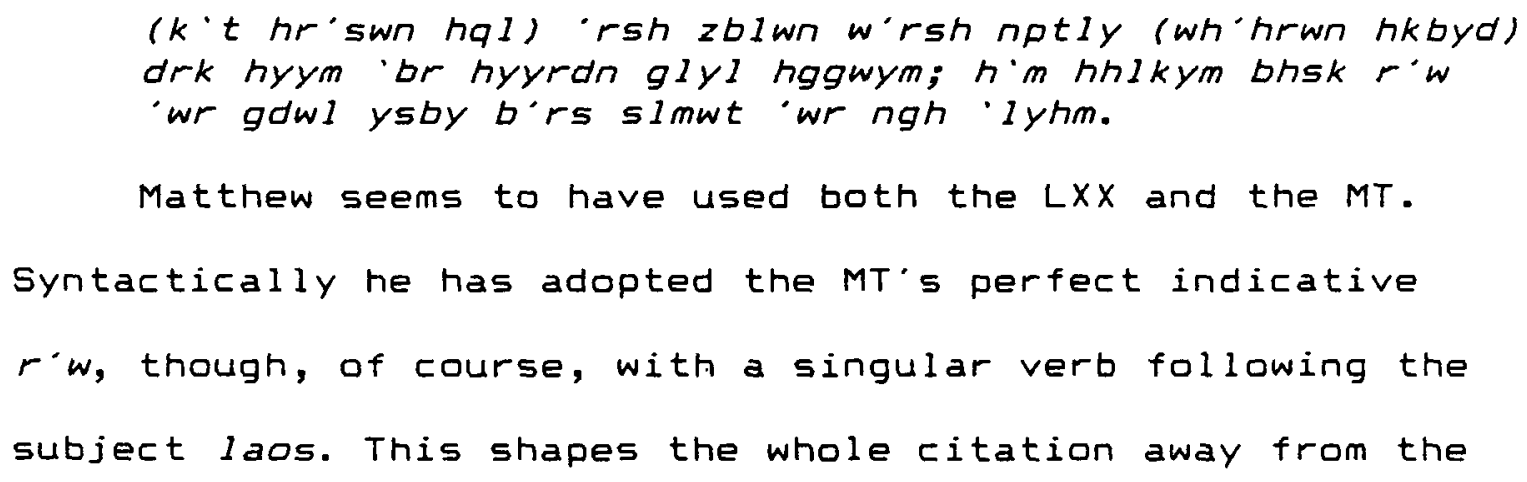


sense of the LXX which is governed by the imperative idetedo. As well, the future lampsei of the LXX is eschewed for the perfect of the Hebrew ngh. Matthew has departed from both the MT and the LXX in taking the citation out of context. His first verse consists of a group of floating nouns. In the MT the two contrasting verbs hql and hkbyd syntactically tie these nouns down as direct objects. Matthew has omitted these verbs.

On the level of word selection Matthew has used both the MT and the LXX or has used a LXX text revised toward the Hebrew. For the double use of 'rsh in the Hebrew he has used gêe twice, rather than two different words as the LXX. He has followed the LXX's Nephthalim. He has used the conjunction between Zaboulôn and Nephthalim with the Hebrew and against the LXX, and he has been consistent in his lack of the article, unlike the LXX. Matthew amits the LXX's kai hoi loipoi... katoikountes kai and ta merê tês Ioudaias. In his use of kathêmenos Matthew differs from the MT and, if Ziegler is correct in asserting that $A$ got kathêmenos from Matthew and not the reverse, from the LXX.41 The vocatives of the second verse in the LXX are eschewed by Matthew for the nominatives of the MT and the second person hymas of the LXX is, accordingly, replaced with the third person autois as in the Hebrew '1yhm.

At no place has Matthew shown evidence of using a translation akin to that of Aquila, Symmachus, or 
Theodotion. In general he has adhered more closely to the MT than to the LXX, suggesting an original translation on his parta $=$ or the use of a Greek text partially assimilated to the Hebrew. 45. Septuagintal vocabulary is quite substantial in Matthew's text. Hence, unless reasons peculiar to Matthew's concerns can be suggested for the differences between his text and that of the Lxx, his use of an assimilated LXX text remains a possibility.

This quotation appears to be an insertion into Mark 1:14-15 (Matthew's vv 12, 17 are parallel to Mark's vv 14, 15). Luke 4:14-15 does mention Jesus' return to Galilee and his teaching, but otherwise is not as close to Mark as Matthew. The quotation is peculiar to Matthew and illustrates the fulfilment of Isaiah's words. Because there is no apparent reason why both Mark and Luke would omit this quotation, if they found it in Matthew, the two-document position is favoured here.

Matt $8: 17:$

autos tas astheneias hêmôn elaben kai tas nosous ebastasen.

The relevant portion of Isa $53: 4$ in the LXX reads: houtos tas hamartias hêmôn pherei kai peri hêmôn odynatai.

Variants for the LXX include: houtos] autos (the Hexaplaric minuscule 88, the margin of the Syro-Hexaplar); hamartias] malakias (a number of Lucianic minuscules 
including the Hauptgruppe, and two mixed text-type minuscules); peri] hyper (a scattering of minuscules, none in the Alexandrian group).

None of these variants indicate the original text. None have Alexandrian witness, and most have thin support. Variant readings found in Aquila, Symmachus, and Theodotion include: ontôs autos tas nosous hêmôn anelaben kai tous polemous hêmôn hypemeinen (Aquila and Symmachus (according to the margin of minuscule 86)), ontôs tas hamartias hêmôn autos anelaben kai tous ponous hypemeinen (Symmachus (according to Procopius)), ontôs tas nosous hêmôn autos anelaben kai tous ponous hypemeinen (Symmachus (according to Eusebius)), ontôs tas nosous hêmôn autos anelaben kai tous ponous hêmôn hypemeinen (Symmachus (according to Theodoret)).

The relevant portion of Isa 53:4 in the MT reads: 'kn hlynw hw' ns' wmk bynw sblm.

There is one variant reading cited in BHS for the MT text: wmk'bynw] wmk'bynw hw' (several Hebrew manuscripts, the Peshitta, the Vulgate).

Several Hebrew manuscripts have this variant to parallel the hw' in the first clause. There is no reason to make this parallel, however, because the suffix on sblm is not in parallel with the lack thereof on $n 5^{\prime}$. As well, it is easier to explain the addition of hw' than it would be to 
explain its omission to get the present text. The text stands.

Outside of such relatively minor words as tas and hêmôn, Matthew has no words in common with the LXX. Even with respect to tense, Matthew follows the MT rather than the LXX; he uses the aorist, corresponding to the Hebrew perfect, rather than the present tense of the LXX. Indeed, there seems to be no contact with the Lxx in this citation.44 There is no evidence that Matthew has used a translation akin to that of Aquila or Symmachus, either. Matthew is in some ways close to the Hebrew, and in others not. He has the explicit autos corresponding to the Hebrew hw'. On the other hand, he has only one hemonn, whereas he would need two to follow the Hebrew literally. However, this may be Matthew's personal style to omit possessive pronouns where they are unnecessary (see Matt 15:4a, compared to Mark 7:10a). A pre-Matthean translation which is closer to the Hebrew than our LXX cannot be ruled out here.

Parallel narratives in Mark $1: 29-34$ and Luke 4:38-41 lack the quotation, but, unlike Matthew, include the statement that Jesus did not allow the demons to speak. Advocates of the Griesbach hypothesis would find it difficult to explain why both Mark and Luke omit the quotation, and why both have a similar addition to Matthew's 
narrative context. Here the two-document hypothesis is favoured.

Matt 12:18-21:

idou ho pais mou hon hêretisa, ho agapêtos mou eis hon eudokêsen hể psychê mou. thêsô to pneuma mou ep auton kai krisin tois ethnesin apaggelei. ouk erisei oude kraugasei oude akousei tis en tais plateiais tên phônên autou. kalamon syntetrimmenon ou kateaxei kai linon typhomenon ou sbesei heôs an ekbalê eis nikos tên krisin, kai tô onomati autou ethnê elpiousin.

Variant readings for this citation include: pais mou] pais mou eis (D); eis hon (the corrected hand of $A$, KWTh,0106, and many other manuscripts)] hon (the first hand of $A, B$, a few other manuscripts), en hô ( $D$ and some other manuscripts); en tais plateiais] en plateiais (minuscule 700), omitted (Sinaitic 0ld Syriac); kalamon syntetrimmenon] omitted (first hand of D); typhomenon oul typhomenon ou mê (first hand of D); kai tô onomati] kai epi tô onomati ( $W$ and a few other manuscripts), $k a i$ en tô onomati (D).

With one exception these variants are thinly supported and usually by only isolated Western witnesses like D. Hence, they do not witness to the original text. The exception is hon, which, up until the twenty-sixth edition of Nestle-Aland, was considered the text. It is not difficult to understand why; it has the support of two of the strongest witnesses to the original text, the protoAlexandrian manuscripts $A$ and $B$. The new decision must have 
been based on internal evidence. The difference between eis hon and hon is stylistic. This case must remain undecided.

In the LXX Isa $42: 1-4$ reads:

Iakôb ho pais mou, antilêmpsomai autou; Israêl ho eklektos mou, prosedexato auton hê psyche mou. edaka to pneuma mou ep' auton; krisin tois ethnesin exoisei. ou kekraxetai oude anêsei oude akousthêsetai exô hê phânê autou. kalamon tethlasmenon ou syntripsei kai linon kapnizomenon ou sbesei alla eis aletheian exaisei krisin. analampsei kai ou thrausthêsetai heâs an thê epi tês gês krisin, kai epi tô nomô autou ethnê elpiousin.

Variant readings for the LXX text include:

antilempsomai ( AAQB, third-century papyrus 965, three mixed text-type minuscules)] antilepsomai (all remaining manuscripts but one); ou kekraxetai] ou kraxetai (the Alexandrian manuscripts $A$ and 106); tethlasmenan] syntethlasmenon (the Alexandrian manuscripts $A$ and 106 , the Hexaplaric $V$, a few Lucianic minuscules, almost the whole Catena group including the Hauptgruppe); alla] all ( $V$ and a few other manuscripts); thrausthêsetai] thrauthêsetai (the first hand of the Hexaplaric B, and a few minuscules), sbesthêsetai (the first hand of A); tês gês] tês (the first hand of $B$ ); $k a i$ epi tô nomô] kai tô nomô (the Alexandrian $Q$, two Lucianic minuscules).

Even where these variants have the support of an uncial, it is always isolated within its text-type. Support by both of the Alexandrian uncials $A$ and $Q$ witnesses to the original text. Thus antilempsomai is confirmed despite the vast number of manuscripts favouring the variant reading. Ou 
kraxetai is supported by only two isolated manuscripts and not supported by $Q$, the best witness to the Alexandrian group. Syntethlasmenon lacks the support of $Q$, and must, therefore, be rejected on external evidence. All is simply the usual forn of alla before a vowel. It is a natural change, but the reverse would not be. This and the thin support of all indicate that alla was the original text. Thrauthêsetai has thin support. The same can be said for the omission of gês. Kai tô nomô is a sylistic variant; it lacks sufficient support. The entire text stands.

Variant readings found in Aquila, Symmachus, and Theodotion follow: Iakôb ho pais mou, antilêmpsomai autou; Israêl ho eklektos mou, prosedexato auton hê psychê mou] idou doulas mou antilêpsomai en autô (Aquila laccording to Eusebius)), idou ho doulos mou anthexomai autou ho eklektos mou hon eudakêsen hê psychê mou (Symmachus (according to Eusebius)), idou ho pais mou antileppomai autou ho eklektos mou hon eudakêsen hê psychê mou (Theodotion (according to the Syro-Hexaplar)\}, idau ho pais mou antilepsetai autou ho eklektos mou hon eudokêsen hê psychê mou (Theodotion (according te the margin of Q)); kai linon kapnizomenon ou sbesei] kai linon amauron ou sbesei (Aquila (according to Eusebius), Symmachus and Theodotion (according to Chrysostom), the margin of $Q$ and the Syro-Hexaplar note only that Aquila, Symmachus, and Theodotion have amauron), aude linon amauron sbesei (Symmachus (according to Eusebius)), 
kai stippyon amauron ou sbesei (Theodotion (according to Eusebius)); kai epi tó nomó autou ethnê elpiousin] kai tô nomô autou ethnê elpiousin (Aquila, Symmachus, and Theodotion (a:cording to Eusebius)).

In the MT Isa $42: 1-4$ reads:

hn 'bdy' tmk-bw bhyry rsth npsy nttty rwhy' 'lyw mspt lggwym ywsy' $I^{\prime}$ ys 'q wl' ys5' wl'-ysmy' bhws qwlw gnh

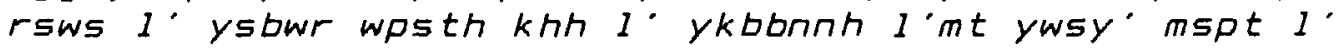
ykhh wl' yrws d-ysym b'rs mspt wltwrtw 'yyym yyhylw.

Here are the variants for the MT: 'Iyw mspt] 'Iyw wmsptw (the Qumran scroll 1QIsa-); ykbbnnh] ykbbh (the Qumran scroll 1QIsa-).

The first variant, wmsptw, has no support in the Lxx or in Aquila, Symmachus, or Theodotion. It appears to be simply a stylistic variation, adding the conjunction and a pronominal suffix.

The second variant reading, ykbbh, is simply the same form of the verb (the piel imperfect of kbh) without the pronominal suffix. It would be impossible to say which form, that with the suffix or that lacking it, would be more likely to develop from the other.

Matthew has idou against the LXX but with the MT's hn. The LXX has $\ddot{I} a k a ̂ b$ and Israêl. Matthew follows the MT here in lacking both. Matthew uses pais, like the LXX, rather than doulas, as found in Aquila and Symmachus.4s In the phrases hon hêretisa and ho agapêtos mou Matthew has differed from both the LXX and the MT, which are quite close, whereas in 
eudokêsen Matthew is closer to the Hebrew than the LXX. Matthew's use of the verb tithêmi is a more elegant translation of the Hebrew ntn than the LXX's didomi, but Matthew uses the future tense against the LXX and the MT.46 His apaggelei ("proclaim") differs from the LXX and the MT ("bring forth").

For the next verse the LxX's translation, ou kekraxetai oude anêsei oude akousthêsetai exô hể phônê autou, is a more literal rendering than that of Matthew. Matthew's en tais plateiais, however, is just as accurate a rendition for bhws as is exô.

In the first two clauses of the next verse Matthew demonstrates his independence from the LXX's translation. While both are faithful to the MT, Matthew's selection of words differs considerably. In the last clause of the verse the LXX is closer to the MT ("truth") than is Matthew ("victory").

Matthew's final verse does not render $l^{\prime}$ ykhh wl' yrws d-ysym b'rs mspt. This is translated in the Lxx but somewhat loosely (a positive "he will shine out" for a negative "he will not grow dim", for example). The LXX's rendition of the final clause, wltwrtw "yyym yyhylw ("the coasts will await his law"), 'is also quite loose ("and upon his law will the nations set their hope"), but it captures the thought of the MT.47 Matthew has completely altered the meaning of the Hebrew (and the LXX's translation). The focus 
of attention is not the law but the person of Jesus.40 Matthew cleverly applies the LXX's ethne elpiousin to the name of Jesus, instead of the law. Here Matthew's purpose is clearly seen in his reworking of the text(s) befare him. Where Aquila, Symmachus, or Theodotion translate differently than the LXX, there is no evidence that Matthew has used a text akin to the text of any of these.

Indeed, other than the final ethne elpiousin, it would be difficult to assert that there is any certain contact with the LXX.4- Sometimes the LXX is closer to the Hebrew than Matthew; sometimes the reverse holds.so This citation seems a clear example of direct translation of the Hebrew, with alteration of the meaning where this bears upon Matthew's purpose.

Both Mark 3:7-12 and Luke 6:17-19 have a narrative parallel to that in which the Matthean quotation is found. Once again they lack the quotation, suggesting that Matthew inserted it into the narrative he found in Mark. Again the two-document hypothesis is favoured over the Griesbach position because the latter would need to explain why both Mark and Luke omitted the Matthean quatation.

Matt $13: 14-15:$

akôe akousete kai ou mê synête kai blepontes blepsete $k a i$ ou mê idête. epachynthê gar hê kardia tou laou toutou kai tois ôsin bareôs êkousan kai tous ophthalmous autôn ekammysan, mêpote idosin tois 
ophthalmois kai tois ôsin akousôsin kai tê kardia synôsin kai epistrepsôsin kai iasomai autous.

Variant readings for the citation are: tois ôsin bareâs] tois ôsin autôn bareôs (AC, a few other manuscripts, most of the old Latin witnesses); tois ôsin akousôsin ] tois ôsin autôn akousôsin (the corrector's hand of $A$, a few other manuscripts), tois ôsin (C); iasomai] iasômai ( $D, 1,565$, and some other manuscripts).

The variant, tois ôsin autôn bareôs, is the only one with a strong witness, the proto-Alexandrian A. However, this witness is isolated within its group, and the variant is an obvious assimilation towards the LXX.=1 All other variants are too thinly and weakly supported. The text stands throughout.

In the LXX the relevant part of Isa 6:9-10 is identical to the Matthean citation except for the following: tois ôsin bareôs] tois ôsin autôn bareôs. This is the only real difference in the text. However, the Lxx has one consistent orthographical difference from Matthew: idôsin] idôsi; akousôsin] akousôsi; synôsin] synôsi; epistrepsôsin] epistrepsôsi.

Variant readings for the LxX text include: akousete] akousête or akousêtai (Alexandrian witnesses A, 106,710, the Hexaplaric $V$, Lucianic minuscules 22,147,233, most of the Catena group including the Hauptgruppe); blepsetel blepsête or blepsêtai ( $A$, Alexandrian minuscules 26,106, several 
Lucianic minuscules); idête] eidête (AN); tois ôsin autôn bareos] tois ôsin bareoss (the first hand of $A$, one minuscule); tous ophthalmous autôn ekammysan] tous ophthalmous ekammysan (B, minuscule 393); epistrepsôsin] epistrepsousi(n) ( $A$, Alexandrian minuscule 26, $V$, several Lucianic minuscules); iasomai] iasômai (V, Lucianic minuscules 36,46 ).

The first two variants, akousete (or akousetai) and blepsête (or blepsetai), have Alexandrian support, but both lack the support of the strongest Alexandrian witmess, $Q$. Strangely, only a few of the witnesses listed support both of these variants, which are of the same type. The rest of the variant readings are too thinly supported to witness the original text. Hence, the text stands.

Variant readings found in Aquila, Symmachus, and Theodotion include: epachynthê] elipanthê (Symmachus (according to the margin of minuscule 710)); tou laou toutou kai tois ôsin autôn bareôs êkousan kai tous ophthalmous autôn ekammysan, mêpote idôsin tois ophthalmois kai tois ôsin akousôsin kai tê kardia synôsin kai epistrepsôsin kai iasomai autous] ho laos houtos ta ota ebaryne kai tous ophthalmous autou emyse mêpôs idê en tois ophthalmois autou kai en tois âsin akousê kai hê kardia autou ou mê synê kai epistraphê kai iathê (Symmachus (according to Theodoret)), the margin of 710 notes only that Symmachus had kai ta ôta ebaryne. 
In the MT the relevant part of Isa $6: 9-10$ reads:

$s m^{\prime} w$ smw' $w^{\prime} l-t b y n w$ wr'w $r^{\prime} w w^{\prime} l-t d^{\prime} w$ hsmn lb-h'm $h z z h$ w'znyw hkbd w'ynyw hs' pn-yr'h b'ynyw wb'znyw ysm' wlbbw ybyn wsb wrp' lw.

There is one variant reading for the MT text: wlbbw] whlbbw (the Qumran scrall 1QIsa-, many Hebrew manuscripts, the Peshitta, the Targum as edited by Sperber, the LXX, the Vulgate). Clearly this reading is more closely parallel to the other phrases, $b^{\prime}$ ynyw and $b^{\prime} z n y w$. Once the preposition is in place it would not likely be removed, so that if one text followed the other the prior text would be the one without the preposition. The text stands.

Matthew has clearly used the LXX here. His omission of an autôn is consistent with his habit of eratically omitting possessive pronouns in cases where they are grammatically and stylistically unnecessary. Matthew in no place gives evidence of having used a text like that of Symmachus. The text of Symmachus only makes clear that Matthew could not have arrived coincidentally at the same translation as that of the $L X X$.

Stendahl views this exact duplication of the Lxx with suspicion. He claims that this citation was inserted at a later date, $=x$ although he does not suggest when this might have occurred or why. As evidence he points out that the same citation is given verbatim in Acts $28: 26-27$, with the implication that someone copied the citation in Acts into Matthew. Why could the copying, if any, have not gone the 
other way? Stendahl never entertains this possibility, nor even goes so far as to see whether the citation better fits the context in Acts or that in Matthew.

Without wasting much time on vanquishing a straw man, we note that the citation fits its Matthean context admirably. In the parallel passages, Mark and Luke use hina plus the subjunctive in their allusion to the Isaiah passage. As well as his formal citation, Matthew also has the allusion parallel to that in Mark and Luke, but he has hoti plus the indicative. In contrast to Mark and Luke, who use the allusion to explain Jesus use of parables, Matthew uses the allusion as a statement of facts which gives the result of Jesus' speaking in parables. Matthew then uses the citation to show that the facts given in the allusion are the fulfilment of the cited prophecy. The interpolator would hardly have so altered Matthew's text.

It should be no surprise, to someone like Stendahl, that Matthew can cite the LXX for the whole of such a long citation. $=$ If Matthew cites phrases of the LXX elsewhere (Matt 1:23, for example), why should he not on occasion do so more extensively? In other words, if the Lxx passage fits, use it. The aorists ("this people's ... eyes have closed", for example) he finds in the LXX do suit Matthew's purposes, unlike the imperatives of the MT, so he uses them. So do the other features of the Lxx translation. 
Mark 4:10-12 and Luke 8:9-10 have a narrative parallel to that in which the Matthean quotation is found. They lack the quotation, suggesting that Matthew inserted it into the narrative he found in Mark. 34 Here the two-document hypothesis is favoured over the Griesbach position because the latter would need to explain why both Mark and Luke omitted the Matthean quotation.

Matt 21:5:

eipate tê thygatri Siôn, idou ho basileus sou erchetai soi prays kai epibebêkâs epi onon kai epi pôlon huion hypozygiou.

Variant readings for this citation are: prays kai epibebêkôs] prays epibebêkôs (D, a few other manuscripts, most of the 0ld Latin witnesses); epi pôlan] pôlon (CKDWDThPh, ph, 118,209, and many other minuscules, the complete Latin tradition); huion hypozygioul hypozygiou (the corrected hand of $A, L Z$ and a few other manuscripts); hypozygioul hypozygion (D and most of the old Latin witnesses).

The only variant having Alexandrian support is the omission of huion. This has the support of the later Alexandrian uncials $L$ and $Z$, but not of the strongest members of this group, $A$ and $B$. It is easy to understand the deletion of huion; it seems redundant, and is a Semitism. Therefore, for both external and internal reasons, the text stands. 
In the LXX the relevant part of Isa $62: 11$ reads: eipate te thygatri sión ....

There are no variant readings for the LXX of the Isaiah passage, and there are no known variant readings in Aquila, Symmachus, or Theodotion.

In the LXX the relevant part of Zech 9:9 reads: idou ho basileus sou erchetai soi ... prays kai epibebekôs epi hypozygion kai pâlon neon.

There is one significant variant reading for the Zechariah passage in the LXX: prays] praos (the whole Lucianic recension except for a single manuscript). This lacks sufficient support to witness the original text, and is merely an orthographic variant of prays. The text stands.

Variant texts found in Aquila, Symmachus, and

Theodotion include: prays kai epibebekôs epi hypozygion kai pôlon neon] prays kai epibebêkâs epi onou kai epi pôlou huiou onadón (Aquila (according to Origen)), ptôchos kai epibebêkôs epi onon kai pâlon huion onados (Symmachus (according to Origen)), the margin of minuscule 86 notes only that Symmachus has onon kai pôlon huion onados, epakouôn kai epibebêkôs epi anon kai pôlan huion anou (Theodotion (according to Origen)).

In the MT the relevant part of Isa $62: 11$ reads: imrw lbt-syywn.

There are no textual variants for this passage. In the MT the relevant part of Zech 9:9 reads: 
hnnh mlkk ybw' lk ... 'ny wrkb '1-hmwr w'1-'yr bn- triwt.

There are no textual variants for this passage.

That part of the citation which comes from Isaiah is identical to the LXX text, although this does not mean that Matthew may not have translated directly from the Hebrew himself.

The first clause of Matthew's citatation from the Zechariah passage is also identical to the LXX. The LXX is such a good translation of the Hebrew, one would really expect no alternative translation. Hence, identity with the LXX does not necessitate Matthew's use of the LXX; he could have made his own translation. Nevertheless, Matthew probably did use the LXX here.

The remainder of the citation suggests that Matthew translated the Hebrew himself, but had one eye on the LXX.:I He has used prays ("humble"), like the LXX (and Aquila) to translate the Hebrew 'ny ("humble, poor"). He has used epibebekâs, which does not seem to be a very precise translation of the Hebrew. However, not only the LXX, but Aquila, Symmachus, and Theodotion all have the same translation here. He has the LXX's hypozygion, although not in the same place as the LXX, and this word is found in none of Aquila, Symmachus, or Theodotion. Moreover, it is not the most appropriate word in this case. His use of the accusative case with epi, as in the LXX and in Symmachus and 
Theodotion, but not in Aquila, may be only a matter of personal style.

Could it be argued that Matthew is close to Aquila's text? They have in common the order of the names of the animals, with the exception of the final hypozygiou in Matthew, and the use of huios. However, there are enough differences to suggest that Matthew has simply rendered the Hebrew himself.

Only Matthew, of all four gospels, has a narrative involving two animals. Did the two animals come from Matthew's understanding of the OT text, or did he know a tradition concerning two animals so that he translated the OT text to reflect this?so That such a strange prophecy, taken on the grounds of Matthew's interpretation, should come true, would all the more show Jesus as the fulfilment of prophecy. This would suggest that Matthew pushed the MT to say more than it intended, to get an unusual prophecy. He has not translated the phrase sdyk wnws" hw' ("righteous and victorious is he"), or even used the LXX's translation, dikaios kai sôzôn ("just and a saviour"), which one would have expected him to seize upon. This glaring omission suggests that the citation was given to emphasize something else. That something else is the strangeness of the two animals.

That Matthew has pushed the Hebrew for his purposes can be seen in his repetition of epi against all other Greek 
translations (except possibly Aquila, but here the second epi is doubtful). True, he has literally translated the second ' 1 , but the Hebrew is simply repeating and expanding upon the previous phrase, not intending reference to a second animal (note the citation in John 12:15). He has not translated the plural 'tnwt as plural (as did Aquila), he has not translated hw', as have all the other Greek translations, he did not use huion onwn, and he has not translated in many other places as might be expected if he were rendering a very literal translation. The only place, besides the double epi, where he has shown any propensity to be literal is his rendering of the Semitic idiom bn-'tnwt. In $v 2$ Matthew has a female ass. All the wards used in the Hebrew connote male animals, except 'tnwt and this does not refer to an animal to be ridden by the king (it is in the absolute state, bound to the preceding noun).

The narrative in which this quotation occurs in Matthew is found in Mark 11:1-3 and Luke 19:28-31, but without the quotation. The Marcan and Lucan versions have one animal, instead of Matthew's two. These similarities of Mark and Luke against Matthew are problematic for the Griesbach position, especially in light of the fact that Matthew appears to have reworked tradition and quotation to match each other. Here the two-document hypothesis is favoured.

Matt 2:18: 
phône en Rhama ekousthê klauthmos kai odyrmos polys Rhachêl klaiousa ta tekna autēs; kai ouk êthelen paraklêthênai hoti ouk eisin.

The following variant is found for this citation:

êkousthê klauthmos] êkousthe thrênos kai klauthmos (CKDW, ph and a great many other manuscripts, the sinaitic and

Curetonian old Syriac).

The text stands because there is no Alexandrian support for the variant reading, and it is an assimilation towards the $L X X$.

In the LXX the relevant part of Jer 38:15 reads: phônê en Rhama êkousthê thrênou kai klauthmou kai odyrmou; Rhachel apoklaiomene ouk ethele pausasthai epi tois huiois autês hoti ouk eisin.

Among the variants for the LXX text are found: en Rhama] en tê hypsêthê (AA, the Bohairic, Ethiopic, and Arabic versions); thrênou kai klauthmou kai odyrmou (BAA, minuscules $130,410,49$, the Hauptgruppe of the Catena group, the Arabic version)] thrênos kai klauthmos (the recension of Origen, the Bohairic version), thrênos kai klauthmos kai odyrmos (all remaining manuscripts); Rhachel] Rhachiêl (V and two minuscules); apoklaiomenê] apoklaiomenes (AAQV, a few minuscules); apoklaiomene (BA] apoklaiomenē epi tôn huiôn autês ( $A$, the Hauptgruppe of the Catena group), apoklaiomenê epi tous huious autês ( $V$, a few minuscules), apoklaiomenê epi tois huiois autês ( $Q$, most of the remaining manuscripts); apoklaiomene ouk (B, the Syro-Hexaplar, a few minuscules)] apoklaiomene kai ouk (the remaining 
manuscripts); êthele] êthelêse(n) (the Hauptgruppe of the Catena group, several minuscules); pausasthai] paraklêthênai (the margin of $B$, AV, the whole Catena group, several minuscules, the Bohairic and Arabic versions); epi tois huiois autês (BA, the recension of Origen (under the asterisk)l] omitted in the vast majority of remaining manuseripts.

The key manuscript for the determination of the original text of the book of Jeremiah is $B$, even when it is an isolated witness. $\Rightarrow 7$ For this reason the variant apoklaiomeness, supported by every other uncial collated by Ziegler, is rejected in favour of the $B$ reading. In the same way, the insertion of kai in apoklaiomenê kai ouk is rejected as the original text.

Variant readings found in Aquila, Symmachus, and Theodotion include: en Rhama] en hypsêlê (Aquila (according to the margin of minuscule 86)); thrênou kai klauthmou kai odyrmoul melos klauthmou pikrammôn (Aquila and Symmachus (according to the Syro-Hexaplar)), the margin of 86 notes only that Aquila and Symmachus have pikrammôn; pausasthai epi tois huiois autês hoti ouk eisin] paraklêthênai epi huiais autês hoti ouk eisin (Aquila (according to the SyroHexaplar)), the margin of $Q$ notes only that Aquila has paraklethênai, the margin of 86 (under an asterisk) notes only that Aquila has paraklethênai, the margin of 86 (under 
an asterisk) notes only that Aquila, Symmachus, and Theodotion have epi tois huiois autess.

In the MT the relevant part of Jer $31: 15$ reads:

qul brmh nsm' nhy bky tmrwrym rhl mbkkh '1-bnyh m'nh I hnחhm' I-bnyh ky 'ynnחw.

There is no evidence that Matthew used a Greek Jeremiah similar to any of Aquila, Symmachus, or Theodotion. He has paraklethênai in common with Aquila and Symmachus against the LXX, but this is the natural translation for lhnnhm ("to be comforted"), whereas the LXX's apoklaiomene... pausasthai ("to cease wailing") is not.

Matthew has translated the Hebrew himself. His Rhachel klaiousa ta tekna autês is an exact translation of rhl mbkkh 1-bnyh, even using the participle form. He uses the term teknase which would include male and female children, rather than huiois which would be only "sons". It is strange that Matthew uses tekna when huiois is just as possible a translation, and the latter would suit his context (Herod killed the male children). This is enough to suggest his total independence from all of the extant Greek renditions. The LXX does not follow the Hebrew closely. It begins well; phônê en Rhama êkousthê is a close translation of the Hebrew. That Matthew has the identical wording here is no indication that he uses the LXX; this is the expected translation. However, the LXX soon begins merely to paraphrase. It has three similar terms for mourning, against 
the two of the Hebrew. It has these terms in the genitive, rather than in apposition. In all of this, Matthew better reflects the MT, although his polys does mot correspond to the Hebrew tmrwrym.so The LXX then conflates the participial phrase rhl mokkh 1 -bnyh with the clause $m$ ' $n h$ lhnnhm ' l-bnyh to yield at best a paraphrase of the meaning of the Hebrew. 60 Matthew, on the other hand, simply omits translating, what he probably saw as redundant, the second 1-bnyh.o1 Matthew and the LXX end on the same note, hoti ouk eisin, but this, again, is no indication of Matthew's using the LXX, as this is the natural translation of the Hebrew. Matthew, then, has clearly adhered to the Hebrew, against the LXX. Indeed, the idea that Matthew even had reference to the LXX for this citation (note especially his use of tekna) would be difficult to substantiate.

Matt 2:15:

ex Aigyptou ekalesa ton huion mou.

There are no variants given in Nestle-Aland for this citation.

In the LXX the relevant part of Hos 11:1 reads: ex Aigyptou metekalesa ta tekna autou.

There are no significant variants for the LxX text. Variant readings found in Aquila, Symmachus, and Theodotion include: ex Aigyptou metekalesa ta tekna autou] apo Aigyptou ekalesa ton huion mou (Aquila laccording to 
Eusebius and the Syro-Hexaplar), the Syro-Hexaplar notes only that symmachus has ton huion mou, minuscule 86 gives columns two through six of the Hexapla, pointing out that Matthew and Aquila both agree with the MT: oumemmisraim karathi labani (transliteration of the Hebrew), apo Aigyptou ekalesa ton huian mou (Aquila), ex Aigyptou kekletai huios mou (Symmachus), ex Aigyptou metekalesa ta tekna autou ("the seventy"), ex Aigyptou ekalesa auton huion mou (Theodotion). In the MT the relevant part of Hos 11:1 reads: wmmmsrym gr'ty 1 bry.

Matthew clearly does not use the LXX here.s:

The fact that he does not use the LXX's metekalesa ("to call back, to recall"), when it would better suit his context, suggests that he may not even have had the LXX in front of him for reference.

It is possible that Mattiew had a Greek translation of Hosea which resembled that of Aquila, but there is no way of knowing whether this was the case or whether he simply translated the Hebrew himself. His use of the different preposition ex might favour the latter. Both translations accurately reflect the MT, unlike the LXX's "his children".

Matt $9: 13 ; 12: 7:$

eleos theló kai ou thysian.

There are no textual variants cited in Nestle-Aland for this quotation. 
The relevant part of Hos $6: 6$ in the LXX is identical to the Matthean citation.

Variant readings for the LXX text include: eleas] elean (the whole Lucianic recension, a few other minuscules); kai ou] $\hat{e}$ (B, most of the Lucianic Hauptgruppe, the Bohairic version).

Eleon simply represents the accusative of the masculine noun ho eleas rather than the neuter to eleos. The external evidence overwhelmingly supports the text as it is. In Hosea $B$ on its own does not witness the original text. ${ }^{-}=$Hence, the second variant reading must also be rejected. The text stands.

The relevant part of Hos $6: 6$ in the MT reads:

hsd hpsty wl'-zbh.

That Matthew's citation is identical to the LXX text does not necessarily imply that Matthew used the LXX.64 It is possible that he translated the Hebrew himself.ss

In Matt 9:13 the emphasis seems to be on the first clause, eleos thelô. Matthew's added gar in the following verse is inserted to connect the thought of the two verses. Jesus came to call sinners, to offer, we must infer, forgiveness. Hence, in this context, eleos is an appropriate application of the more general statement of Hos 6:6.

In both cases of its use this citation appears in Matthew inserted into a narrative which has parallels in Mark and Luke.to This seems to favour the two-document 
hypothesis. It is difficult to imagine why both Mark and Luke would have left out these words of Jesus, especially when he is citing Scripture, if they appeared in their source (per the Griesbach hypothesis). It is even more difficult to imagine why this would happen twice. In addition, the citation's insertion into its context in Matt 9 is a little rough. The word "physician" from Jesus" statement in the previous verse, that "those who are well have no need of a physician, but those who are sick", connects directly with the subject of the wards fallowing the insertion, "I" (understood). Jesus is the physician. The parallelism between the two sets of clauses ("those who are well" with "the righteous", and "those who are sick" with "sinners") in the two passages on either side of the insertion might be missed if something were inserted between. Again, this favours the two-document hypothesis. 


\section{NOTES}

1 An Introduction to the old Testament in Greek (revised ed.; New York: KTAV, 1968) 391.

$=$ Ibid., 386-7.

$=$ Ibid., 382 .

4 Ibid., 386.

= Ibid., 382 .

- Krister Stendahl, The School of St. Matthew and its Use of the 0ld Testament (2d ed.; Lund: Gleerup, 1968) 94, sees "only two quotations in the strict sense of the word" in the material peculiar to Luke; namely, Luke 4:18-19; 22:37. These are the other two listed by Swete, An Introduction, 383 .

$>$ The order of presentation of quotations in this chapter is as follows. First are the quotations peculiar to Luke, then those peculiar to Matthew. Shorter quotations and/or those which most closely resemble a known OT text are presented before those which are longer and/or the text of which does not closely resemble a known oT text.

- The preferred text of Isaiah (Joseph Ziegler (ed.), Septuaginta: Vetus Testamentum Graecum Auctoritate Academiae Litterarum Gottingensis editum; vol.14: Isaias (2d ed.; Gottingen: Vandenhoeck \& Ruprecht, 1967).) has te kardia rather than tên kardian. The latter is found in $B$ (the best witness to the hexaplaric text), the vast majority of the Lueianic recension (a revision of Origen), and minuscules from the Alexandrian, Catena, and mixed-text groups. This seems to indicate that the text of Isaiah to which this Koine assimilation took place may have been of the hexaplaric text-type.

- The phrase 'dny yhwh is not a common one in the Hebrew text. It appears six other times, all in DeuteroIsaiah (48:16; 50:4,5,7,9; 51:4). Four of these occurrences are from one of the Servant Songs, in which the Lord God sustains and helps his servant. That it should be used in the Hebrew in 61:1, wherein the Lord God has sent the speaker and placed his spirit upon him, would be consistent with its other occurrences. 
10 Michael D. Goulder suggests that Luke used Isa 58:6 instead of continuing with chapter 61 (which goes on to mention the Day of Vengeance) because he wanted to have a positive feeling (Luke: A New Paradigm, vol.1 (Sheffield: Sheffield Academic Press, 1989) 301-302).

12 Stendahl (The School, 96.) thinks the LXX used kalesai for variety, and that Luke did not need this variety because he had interpolated the citation from Isa 58:6.

$1=$ Traugott Holtz sees clear influence of the LXX in this quotation. Luke is quoting directly from a scroll of Isaiah (Untersuchungen über die alttestamentlichen Zitate bei Lukas (Berlin: Academic Press, 1968) 40-41.

Alfred Plummer thinks Luke relied on his memory here and that his quotation shows the influence of other passages (A Critical and Exegetical Commentary on the Gospel According to 5 . Luke (5th ed.; Edinburgh: T. \& T. Clark, 1922) 120 .

$1=$ This citation is repeated verbatim in Mark 15:28. This verse is not included in the text. Bruce M. Metzger, $A$ Textual Commentary on the Greek New Testament (2d ed.; New York: United Bible Societies, 1975) 119, gives several reasons why this choice for "the text is virtually certain": (1) the earliest and best witnesses of the Alexandrian and the western types of text lack $\vee 28$; ( 2 ) there is no reason why, if the text were present originally, it should have been deleted, while, on the other hand, copyists could have added the sentence in the margin from Luke, whence it came into the text itself; (3) Mark very seldom expressiy quotes the OT. Here Metzger is referring to the introductory formula found in $v 28, k a i$ eplêrôthê hê graphê hê legousa, which indicates that the following quotation has been fulfilled.

The external evidence is not that overwhelming. The preferred text, which excludes this verse, is supported by the proto-Alexandrian $B$ and $A$. This is obviously what swings the case for Metzger. Outside of this, however, the preferred text has only the late Alexandrian $C$ and, of intermediate importance, the western D, Ps, minuscule 157, and the Sahidic version, all of which are debatable witnesses to the original text. The remaining uncials are Koine. On the other hand, while inclusion of the verse is supported by the Koine group $K$, it also has the support of the late Alexandrian L, $D$, and 892 , and a very strong witness in the Caesarean group ( $T h, 1, p h, 565,700)$. While the external evidence may slightly favour exclusion of this verse, Metzger's second reason is the one which really decides the case. This verse fits admirably into the Marcan context, whereas the pericope in which it 
appears in Luke is a strange one indeed. In ather words, it would have made much more sense if the citation had appeared in Mark. But if this were the case, why would Luke remove it from its Marcan context and place it in such a contrived context? If it were found first in Luke, as wauld be the case under the Griesbach hypothesis, one could understand Mark deleting Luke's pericope and inserting the citation in the scene at the cross. However, it is important to note here that in Luke the citation is on Jesus' 1 ips, whereas in Mark there is simply the statement by Mark that this Scripture is fulfilled. It seems highly unlikely that Mark would take the words of Jesus and not reproduce them as the words of Jesus. It may be that reliance upon the sanctity of the two-document hypothesis has moved the locus of the discussion from the level of source criticism to that of text criticism, without first examining the possibilities of the former. Nevertheless, the deciding question remains. Why would any scribe delete the verse from Mark if the work he was copying had it?

14 Nevertheless, Joseph A. Fitzmyer finds Luke closer to the MT than the LXX (The Gospel According to Luke ( $X$ XXIV): Introduction, Translation, and Notes (Garden City, New York: Doubleday, 1985) 1432).

$1=$ Holtz believes Luke was true to his text; hence, although he makes no mention of Symmachus he would probably agree with our statement (Alttestamentlichen Zitate bei Lukas, 42-43).

1 - For the book of Exodus, the text of the LXX is that of Alan England Brooke and Norman Mclean (eds.), The Old Testament in Greek According to the Text of Codex Vaticanus, Supplemented from Dther Uncial Manuscripts, with a Critical Apparatus Containing the Variants of the Chief Ancient Authorities for the Text of the Septuagint; vol.1: The Octateuch; part 2: Exodus and Leviticus (Cambridge: Cambridge University Press, 1909).

$1>$ An Introduction, 387.

10 The School, 137.

1 Robert Horton Gundry, The Use of the old Testament in St. Matthew's Gospel (Leiden: Brill, 1967) 108.

wo Horae Synopticae: Contributions to the Study of the Synoptic Problem (2d. ed.; Oxford: Clarendon, 1909) 155.

=1 The School, 137-8. 
$=$ It is interesting to note that wevers, who usually is very thorough in citing NT passages which have some resemblance to the words in a given LXX verse, has no such notation for Lev 19:12. This indicates not an oversight by Wevers but that Matt 5:33 does not resemble Lev 19:12 at a11.

$=$ The School, 137-8.

24 Metzger (A Textual Commentary, 33-34.) so clearly describes the dilemma in the minds of the editors that he is worth quoting in full:

It $c$ an be argued that the shorter reading, attested by representative witnesses of the Alexandrian, Western, and Eastern types of text, was original, and that kosmou was added by scribes from 25:34, where the text is firm.

On the other hand, since the preponderance of the external evidence was taken to support the inclusion of kosmou, a majority of the Committee was reluctant to drop the word from the text entirely and therefore decided to enclose it within square brackets.

$=$ Willoughby $C$. Allen notes that kosmou is an assimilation to general NT usage (A Critical and Exegetical Commentary on the Gospel According to S. Matthew (New York: Scribner's, 1907) 154).

ao The translation of the singular msl as a collective singular would be quite natural, especially considering its parallelism with the plural hydwt. For the understanding of singular words in Hebrew as collectives, see E. Kautzsch and A. E. Cowley, Gesenius' Hebrew Grammar (Oxford: Clarendon, 1910) 394-6.

Charles Cutler Torrey says the first clause could be translated into Greek in no other way. Hence, that Matthew is identical to the LXX does not mean dependence (Documents of the Primitive Church (New York: Harper and Brothers, 1941) 69).

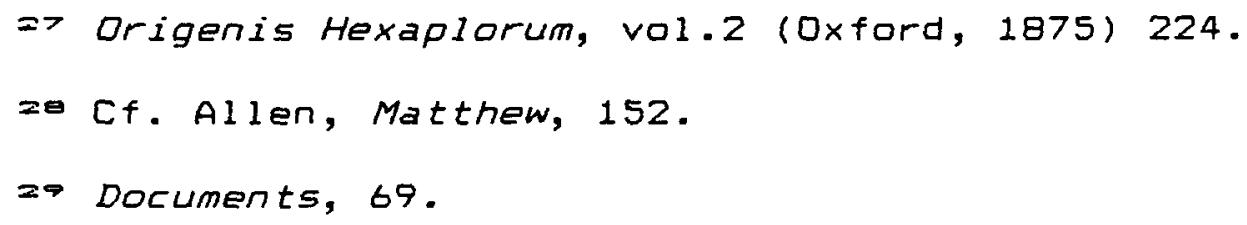


$=1$ Here he would have plenty of modern company. Gundry summarizes some modern examples (The Use of the old

Testament, 121.).

$=\approx$ For this idea and its argument I am indebted to Gundry, ibid., 121. The statements immediately following are a selection from his work.

$3:$ Torrey contends that this is the only quotation for which the Greek translator of Matthew (Torrey claims the original gospel was in Hebrew) used the LXX (Documents, 79).

$\$ 4$ This is the impersonal third person singular in which an active theme may have a passive sense (see also Gen 11:9: pr" smh bbl; "its name was called Babel"). Refer to Ronald J. Williams, Hebrew Syntax: An Outline (2d ed.; Toronto: University of Toronto Press, 1976) 29, n.160.

$3=$ Ulrich Luz claims that Matthew normally quotes the Lxx, unless he is following gospel sources, so this is not a special case for a special reason (Matthew 1-7: A Commentary (Minneapolis: Augsburg, 1989) 116).

W. D. Davies and Dale C. Allison suggest that in using parthenas the LXX probably meant no more than she who is now a virgin will conceive and bear. Despite the fact that parthenos usually translates btwih (except Gen 24:43), the LXX meant no miracle here (A Critical and Exegetica) Commentary on the Gospel According to Saint Matthew, vol.1 (Edinburgh: T. \& T. Clark, 1988) 214). Allen (Matthew, 10) asserts that Isaiah meant ' $1 \mathrm{mh}$ to have a sense of supernatural birth.

3 war't is pointed as the second masculine singular or even the second feminine singular in some Hebrew manuscripts (Gundry, The Use of the 0ld Testament, 90, n.4).

$=7$ Septuaginta: Isaias, 67 .

Ie Ibid., 27.

$=0$ I. L. Seeligmann proposes that the LXX translator, having difficulty with the Hebrew, obtained his description of the regions and districts of Palestine from Ezek 25:16 and the terms he used described the geography and the provinces of palestine as they existed in his own time (The Septuagint Version of Isaiah: A Discussion of its Problems (Leiden: Brill, 1948) 74, 80).

40 The translator for the $L x X$ may have understood $r^{\prime} w$ as the plural imperative. This might indicate that Matthew has translated the Hebrew himself and interpreted $r$ 'w 
differently than the translator for the LXX. On the other hand, it is possible that Matthew used a form of the LXX revised toward the Hebrew.

41 R. R. Ottley concludes that Matthew may have used a different LXX which was nearer the Hebrew than ours (The Book of Isaiah According to the Septuagint (Codex Alexandrinus), vol.2: Text and Notes (Cambridge: Cambridge University Press, 1906) 152-53).

$4=$ Cf. Wilhelm Rothfuchs, Die Erfüllungszitate des Matthäus-Evangeliums (Stuttgart: Kohlhammer, 1969) 67-70; Richard S. McConnell, Law and Prophecy in Matthew's Gospel: The Authority and Use of the 01d Testament in the Gospel of St. Matthew (Basel: Friedrich Reinhardt, 1969) 119.

4:- Georg Strecker suggests the use of a testimony here (Der Weg der Gerichtigkeit: Untersuchung zur Theologie des Matthäus (Göttingen: Vandenhoeck \& Ruprecht, 1971) 63-66.

44 Cf. W. F. Albright and C. S. Mann, Matthew: Introduction, Translation, and Notes (Garden City, New York: Doubleday, 1971) 94 .

$4=$ This does not necessarily imply that Matthew was referring to the LXX here. It may simply be the word he uses to translate the Hebrew. Nor can we conclude that because this goes against Matthew's normal usage (he has doulos thirty times compared to eight times for pais (Robert Morgenthaler, Statistik des neutestamentlichen wortschatzes (Zürich: Gotthelf, 1958) 90,128.)) he must be following the LXX. These statistics may only reflect what Matthew has found in his gospel tradition sources and not indicate a preference for doulas. Hawkins, for example, defines a word which is "characteristic" for Matthew as one which is found in Matthew at least twice as often as in Mark and Luke together (Horae Synopticae, 3.). Neither word makes Hawkins. list of words characteristic of Matthew.

46 Matthew may simply be rendering the "prophetic perfect" by the future.

47 The Hebrew "yyym means "coasts, islands", but it is the Gentiles who live on the coasts and the islands; hence the association. Note, for example, the phrase 'yy hggwym (Gen 10:5).

49 In the Semitic world one's name implies the person.

4 Torrey finds this one of the best examples of Matthew's way of quoting scripture: the evangelist quoted 
from memory in Hebrew, and the author of the Greek gospel translated carefully, without regard to the LXX. He also finds that it is the most cogent illustration of his theory of an original Hebrew/Semitic Matthean gospel (Documents, $64-66)$.

so Albright and Mann conclude that either Matthew made a fresh translation of the Hebrew or he used a different LXX (Mathew, 153).

s1 Here it might be countered that $A$ does not have autôn at this place in the Isaiah passage in the LXX, so how could this be a case of assimilation? This counter-argument assumes that if assimilation to the LXX occurred, the scribe of A turns to Isaiah in $A$ to confirm and correct the Matthean citation. However, there are many possible alternative scenarios, in which assimilation could occur and yet these conflicting texts exist in $A$. Codex A happens simply to be the manuscript in which this conflicting situation is extant. At one stage all the books of the Bible were separate. Evidence suggests that Isa 6:9-10 in Codex $A$ was not the majority text. The majority LxX text in ancient times had autôn. At some time in the transmission of the text, a scribe assimilated his Matthew to the majority LXX text. This Matthew, with autôn, would go its separate way. Eventually this Matthew found its way to the same place and time as an LXX Isaiah without autôn. (The latter may have at sometime resulted from assimilation to the more common Matthew (lacking autôn).) Now the stage is set for copying both into one codex.

$s=$ The School, 131-2. In view of Stendahl's classification of Matthew's citations into two neat groups, the "pesher type" (introduced by the fulfilment formula), and the "liturgical type" ( $p$. 203), we might expect that he would have to devise some explanation as to why this citation so obstinately refuses to fit his moulds.

Gundry (The Use of the 01d Testament, 116-118) does a masterful job of demolishing Stendahl's tenuous arguments here. In one refutation, however, if he is arguing against Stendahl (to be fair to Gundry, he does not explicitly say that it is Stendahl to whom he is replying in this particular case), he has pressed the latter's argument beyond its implications. Gundry begins each counter-argument with a statement of the position he is about to refute. In this case he states, "The pure Septuagintal form is out of character with Matthaean formula-citations" ( $p .118$ ). stendahl, and this is where Gundry is perhaps making a false inference, has not grouped this citation with the formula citations. He has placed its discussion in a chapter 
entitled "Quotations peculiar to Matthew, but without his introductory formula of fulfilment".

However, Gundry senses something amiss, some soft underbelly to Stendahl's whole edifice. It is the pure Septuagintal character of this citation which puts Stendahl on the defensive, but why? Stendahl argues against the Matthean authorship of this citation because the form of the citation will determine its authorship, its $S_{i} t z$ im Leben. The fact that this text comes from only the Lxx conflicts with Stendahl's narrow definition of pesher. In this case Matthew is interpreting the OT by using only the LXX against the MT.

The fulfilment formula is Stendahl's criterion for grouping the citations. This is why this citation is placed in the chapter it is. Stendahl claims that this citation is introduced by "an un-Matthaean quotation formula" (The School, 131.). Why, then, the need to exonerate the form of the citation itself? If this is not a Matthean formula citation, based on the criterion which determines what is and what is not such a citation, the introductory formula, why the felt need to go further? obviously, Stendahl does not feel satisfied with his own explanation that this formula is not that of a Matthean "formula quotation". Perhaps this is an indication that so much emphasis ought not to be placed on the introductory formula as the criterion for grouping the citations. Perhaps this is a hint that the citations do not lend themselves to artificial classification at all.

5: This is one of the only quotations which Torrey admits is unequivocally Septuagintal. For this reason he claims it is a copyist's insertion (Documents, 66-67).

=4 Allen believes Matthew uses the LXX to quote a passage suggested in Mark 4:12 (Matthew, 146).

$\Rightarrow$ Cf. Allen, Matthew, 220.

so Rabbinic tradition has only one ass. See Stendahl, ibid., 119, 200.

$\Rightarrow$ Joseph Ziegler (ed.), Septuaginta: Vetus Testamentum Graecum Auctoritate Societatis Litterarum Gottingensis editum; vol.15: Ieremias, Baruch, Threni, Epistula Ieremiae (Göttingen: Vandenhoeck \& Ruprecht, 1957) 125.

se The use of tekna suggests to Strecker a pre-Matthean origin for this quotation (Der Weg, 59).

S- See M. -J. Lagrange, Évangile selon Saint Matthieu

(Paris: Gabalda, 1927) 35. 
so Davies and Allison (Matthew, 270) find the MT corrupt in the passage quoted, and suggest that Mathew may have used a better Hebrew text.

-1 This is often rejected by modern OT commentators, so that Matthew's Jeremiah may have been lacking here. See Gundry, The Use of the Old Testament, 96, n.3.

$\therefore$ Davies and Allison concede that a mon-LXX Greek text may have been used here (Matthew, 262). Allen (Matthew, 10) prefers the theory of a testimony for this quotation (this is the case for all the formula quotations, for Allen).

$6=$ To get around the fact that Matthew is identical to the LXX, which would not suit Torrey's theory, he states that LXXad assimilated to Matthew, and that $B$ has the original text (Documents, 60).

44 That both Matthew and the LxX have the present tense for the Hebrew perfect hpsty is possible, but not certain, evidence that Matthew has used the LXX.

$s=$ If one opts for the text of LXXB (thelo $\bar{\varepsilon}$ thysian) as the original, however, as does Gundry (The Use of the old Testament, 111), then one would be justified in saying that Matthew translates the Hebrew independently.

wo Matt 9:13 occurs in a narrative (9:10-13) which has parallels in Mark 2:15-17 and Luke 5:29-32. Matt 12:7 occurs in a narrative (12:1-8) which has parallels in Mark $2: 23-28$ and Luke 6:1-5. 


\title{
CHAPTER SIX: SUMMARY AND CONCLUSIONS
}

\author{
Of the thirty-six OT citations examined, fifteen are \\ found only in Matthew, two are found only in Luke, four are \\ found in Matthew and Luke, six are found in Matthew and \\ Mark, and nine are found in all three synoptics. \\ The vast number of eitations peculiar to Matthew, when \\ cambined with the number of common quotations, would \\ immediately suggest that Mark may have been the source of \\ Matthew and Luke and that Matthew added these citations on \\ his own, whereas Luke, who did not know Matthew's gospel, \\ also lacked these. This is the reasoning that is often used \\ in favour of the two-document hypothesis, in a general \\ context, not specific to the OT citations. It rests on the \\ question why Mark and Luke would have omitted so much of \\ Matthew, if Matthew were the gospel used as the source of \\ the other two. This argument can be transferred to this \\ study and applied to the citations. It provides a problem \\ embarrassingly difficult to handle for advocates of the \\ Griesbach hypothesis. \\ There are no citations peculiar to Mark, unless one \\ wishes to count Mark 12:29, which we included in our \\ examination of Matt 22:37 and parallels. Here Mark quotes \\ the LXX verbatim. Whether Matthew and Luke chose to omit
}


this passage from their Marcan source, or Mark added it to what he found in his sources (Matthew and Luke), cannot be determined. However, under the two-document hypothesis it is possible for material to be common to both sources, Mark and Q. Here, on the two-document hypothesis, Mark would have a part of the quotation which $Q$ lacked. In this single instance Matthew and Luke would both happen to have chosen to go with $Q$ and omit the quotation.

As for the citations peculiar to Luke, Luke $4: 18-19$ is found in a context shared by the other synoptics, but only in the broadest of senses, while Luke $22: 37$ is in a context peculiar to Luke. Lucan quotations are not crucial to either the two-document or the Griesbach positions. There is never a need to explain why a Lucan quotation should be omitted in two gospels, as there would be for Matthean quotations under the Griesbach hypothesis, and for Marcan ones under the twodocument hypothesis.

With respect to the appearance, or non-appearance of quotations, then, the two-document hypothesis is clearly favoured over the Griesbach position.

In their grouping of the citations peculiar to Matthew, Holtzmann, Stendahl, and Gundry have both merits and deficiencies.

Holtzmann is correct to say that for the most part Matthew has Septuagintal citations where these are found in 
Mark or Luke. On this point our study of the quotations goes further.

All four of the quotations common to Matthew and Luke are found in one location, the temptation narrative. This is in agreement with the general conception of $Q$. With the exception of Luke 4:11, which contains a few additional words from the quotation, and Luke 4:4 which omits a few words of the quotation, the Matthean and Lucan versions are identical. Moreover, Matt 4:10 and Luke 4:8 are identical but differ slightly from the OT passage, indicating a common gospel tradition which altered the LXX to suit the context of the narrative in which the quotation appears. In all four cases this tradition quoted the LXX, in two cases verbatim. This is consistent with the $Q$ hypothesis.

Just as in the example of Mark 12:29, above, the view that $Q$ and Mark can contain slightly different versions of the same narrative, proves useful in helping to resolve problems that troubled Holtzmann and those before and since. Mark 1:2, for example, is combined with the following quotation in $\vee 3$ in Mark and in pre-Marcan tradition. The two quotations, it is suggested, were found separately in two different narratives in Q. Matthew and Luke then simply chose the $Q$ versions, rather than that of Mark. In only four cases among those quotations common to Matthew and Mark or Matthew, Mark, and Luke (Matt 21:42= Mark 12:10-11 = Luke 20:17; Matt 19:4 = Mark 10:6; Matt 
22:39 = Mark 12:31 = Luke 10:27b; Matt 21:13= Mark 11:17)

is the LXX quoted verbatim. However, this small fraction of common quotations does not militate against Holtzmann's argument. All of the quotations common to Mark and Matthew or to Mark, Matthew, and Luke are basically Septuagintal. Indeed, Matthew is identical to Mark in three instances (Matt 22:44= Mark 12:36; Matt 3:3= Mark 1:3; Matt 15:4b= Mark 7:10b) in which their quotation differs from the LXX. Matt 15:8-9 and Mark 7:6-7 demonstrate similarity in the face of vast differentiation among known oT texts. Again, this indicates a common tradition.

While the quotation in Matt 26:31 is quite similar to its parallel Mark 14:27, locating the OT source poses some difficulty. Analysis of the vocabulary indicates that the source must be septuagintal, but the gospel versions differ considerably from our LXX, and display some similarity to the Hebrew. The vast number of LxX variants may hold a clue here. It is possible that the gospel quotations come from a version of the LXX which was assimilated to the Hebrew. In the case of Matt 15:4b = Mark 7:10b, the quotation is more like the LXX than the Hebrew. Here it is possible that the gospel quotation comes from a Greek text which differs from those known to us.

Apparent correction of the quotation of one evangelist by that of another toward the LXX cannot be used as a criterion for favouring either the two-document or the 
Griesbach theory over the other. Twice Matthew appears to correct the other synoptics toward the LXX (11:10; 15:8-9), and twice Mark appears to correct the other synoptics toward the $\operatorname{LXX}(7: 10 a ; 10: 7-8)$

This is particularly the case with Luke. Luke 20:42-43 appears to correct Matthew and Mark toward the LXX. However, Luke on his own apparently alters the LXX (3:5-6, despite the fact that in the first part of the same quotation, common to Matthew and Mark, Luke is identical to the other two synoptics in their closeness to the LXX; $4: 18-19$; $22: 37)$

Indeed, Luke's handling of his material shows great variation. If we use the two-document position as reference, Luke adds to Matt $3: 3$ and 4:6, but omits from Matt 4:4 and 21:42. He alters away from a Hebraism in Matt 21:13, and has an allusion where Matt 22:32 and Mark 12:26 have an explicit quotation. Again, it is possible, in Luke 3:5-6 that he has used a LXX which was assimilated toward the Hebrew. Holtzmann is deficient in that he does not adequately treat the large number (at least seven) of citations peculiar to Matthew in which the Lxx text is used. To preserve the division between the synoptic quotations, which are Septuagintal, and the quotations peculiar to Matthew, in which Matthew prefers the Hebrew text, Holtzmann separates off the four quotations found in the Sermon on the Mount as coming from a special Matthean source. He does not, however, 
fully recognize the other three Septuagintal quotations as peculiar to Matthew $(21: 16 ; 9: 13=12: 7 ; 13: 14-15)$, preferring to see them as coming from source $A$, but receiving different treatment by Mark.

Stendahl separates those citations peculiar to Matthew into two groups: those introduced by the fulfilment formula (of mixed text-type), and those lacking this formula (use of the $L X X$ ). He thus corrects Holtzmann's deficiency (al though he nevers specifically deals with Holtzmann's work).

Some adjustments may be necessary to Stendahl's neat division. We have argued that 13:14-15 has a formula much like that of Stendahl's formula quotations, yet it has a Septuagintal text. Pressed to the wall, Stendahl simply claims this is a later insertion. Matt $1: 23$ is also a Septuagintal formula quotation. In addition, the first part of formula quotation $13: 35$ is identical to the LXX, and that part of formula quotation 21:5 which comes from Isa $62: 11$ is identical to the LXX.

Stendahl asserts ${ }^{1}$ that Matthew has not simply translated the MT himself, but has used several OT sources, and interpreted these to suit his context. Our research suggests that this is not the case. To begin with, there is only one full quotation which gives clear evidence that Matthew altered the OT text to suit his purposes $(12: 18-21)$ and part of another (second half of 13:35). On the contrary, there are two clear instances in which Matthew could, and perhaps 
should, have made alterations to his OT text to suit his purposes but did not $(2: 15 ; 2: 18)$.

Stendahl observed that a LXX tradition other than that now found in Codex B, among other sources, has been used by Matthew. Peter Katz suggests that one should not ask whether the quotations follow Codex $A$ or $B .2$ In the LXX no manuscript is homogeneous throughout. In the process of replacing scrolls by codices, the components need not have been of equal textual nature. The question which should be asked is: does a quotation follow a primitive or an edited text? Here is where our work has incorporated the findings of contemporary LXX research.

In our analysis of the quotations we have used textual data on the LXX some of which was unavailable to Stendahl (and Gundry). Dur observations indicate that Matthew followed his sources accurately, making only minor changes. Evidence for this is found in the fact that his quotations common with other symoptics are often identical in the face of a different LXX text. This indicates that Matthew may have used the other synoptic sources. We know that the direction of usage is from Mark to Matthew, and not from Matthew to Mark, through the results of our analysis of the common quotations with respect to their synoptic relationship. Here ten of these citations favoured the twodocument hypothesis, compared to only one for the Griesbach hypothesis (eight citations favoured neither hypothesis over 
the other). Further evidence that Matthew follows his sources is his use of LXX texts against his purposes. Using the latest textual research on the LXX, we have found some texts which offered the possibility of preMatthean assimilation of a LXX text toward the Hebrew. Matt 2:15 is not only not altered to suit Matthew's purposes, it bears striking resemblance to the text of Aquila, where the LXX is rigorously assimilated toward the Hebrew. While no other examples of Matthean quotations so closely resembled extant texts of Aquila, Symmachus, or Theodotion, there are some quotations which are Septuagintal in form but differ from our LXX in several details, often approaching the Hebrew. These include Matt 4:15-16; 8:17; and those mentioned above. Since in none of these cases has Matthew altered the text to suit his purposes, it is possible that Matthew may have used a LXX which was partly assimilated toward the Hebrew. This would make Stendahl's theory of Matthew the targumist unnecessary.

Gundry groups all of the citations peculiar to Matthew together. This allows him to say that these citations are of a mixed text-type, in contrast to the formal citations common to Matthew and Mark which alone are almost purely Septuagintal. While it is true that there are different text-types within the group peculiar to Matthew, it is somewhat misleading to say that the group is of mixed texttype. This might be misconstrued as meaning that all of the 
citations in this group were individually of a mixed texttype.: In seeming contrast to this, in his summary of his examination of the citations, Gundry states, "Of the twenty formal quotations peculiar to Mt, seven are Septuagintal".4 This number is confirmed by our research. However, we do not agree with Gundry in his statement that only the formal quotations common to Mark and Matthew have a single textform. These do have one text-form, but there is no reason to separate this group off from the many quotations with Septuagintal form. Gundry's way of grouping the quotations is misleading.

While the analyses of the symoptic relationship for the individual quotations may not be conclusive, evidence does favour the two-document hypothesis. Dur observation concerning the care with which Matthew handles his sources should form a basis for further research on the synoptic problem. In addition, this observation allows the distinct possibility that the gospels used a form of the LXX which in places was assimilated toward the Hebrew. We have seen evidence for this in quotations common to Matthew and Mark, in a quotation peculiar to Luke, and in some of the "formula" quotations peculiar to Matthew. That this evidence is found in such diverse strata of the gospel tradition makes it all the more cogent. 
NOTES

1 The School of St. Matthew and its Use of the 01d Testament, (2d ed.; Lund: Gleerup, 1968) 127.

z "The Quotations from Deuteronomy in Hebrews", ZNW 49 (1958) 221-22.

: The wording Gundry uses in his abstract can be confusing:

Formal quotations which Mt shares with Mk are almost purely Setuagintal. In ... peculiarly Matthaean [material] - the text-form is very mixed. This mixture stands in contrast to the prevailingly Septuagintal form of OT quotations throughout the rest of the NT (The Use of the Old Testament in 5t. Matthew's Gospel (Leiden: Brill, 1967) xi).

4 Ibid., 149. 


\section{B I BL IOGRAPHY}

\section{A. PRIMARY SOURCES}

Baillet, Maurice (ed.). Discoveries in the Judaean Desert. 7 vols. Oxford: Clarendon, 1955-82.

Berliner, Abraham (ed.). Targum Onkelos. vol.1: Noten. vol.2: Einleitung und Register. Berlin: Gorzelanczyk, 1884 .

Brooke, Alan England, and Norman McLean (eds.). The old Testament in Greek According to the Text of Codex Vaticanus, Supplemented from Other Uncial Manuscripts, with a Critical Apparatus Containing the Variants of the Chief Ancient Authorities for the Text of the Septuagint; vol.1: The Octateuch, part 2: Exodus and Leviticus. Cambridge: Cambridge University Press, 1909 .

Burrows, Millar, and John C. Trever and William H. Brownlee (eds.). The Dead Sea Scrolls of St. Mark's Monastery; vol.1. New Haven: American Schools of Driental Research, 1950-51.

Carmignac, Jean (ed.). Les Textes de Qumran: traduits et annotés. 2 vols. Paris: Letourzey et Ané, 1961, 1963.

Driver, Godfrey Rolles (ed.). The Judaean Scrolls: The problem and a Solution. Oxford: Blackwell, 1965.

Elliger, Karl, and Wilhelm Rudolph (eds.). Biblia Hebraica Stuttgartensia. Stuttgart: Deutsche Bibelgesellschaft, $1967-77$.

Field, Frederick (ed.). Origenis Hexaplorum. Dxford, 1875.

Lohse, Eduard (ed.). Die Texte aus Qumran. Munich: Kösel, 1964 .

Nestle, Erwin, and Kurt Aland (eds.). Novum Testamentum Graece. 26th ed. Stuttgart: Privilegierte württembergische bibelanstalt, 1979. 
Ralphs, Alfred (ed.). Septuaginta: Id est Vetus Testamentum Graece Iuxta LXX Interpretes. 2 vols. Stuttgart: Privilegierte Württembergische Bibelanstalt, 1935.

(ed.). Septuaginta: Vetus Testamentum Graecum Auctoritate Academiae Scientiarum Gottingensis editum; vol.10: Psalmi cum Odis. 3rd ed. Gottingen: Vanderhoeck \& Ruprecht, 1979.

Roberts, Colin Henderson (ed.). Twa Biblical Papyri in the John Rylands Library. Manchester, 1936.

Sperber, Alexander (ed.). The Bible in Aramaic; vol.1: The Pentateuch According to the Targum Onkelos; vol.2: The Former Prophets According to Targum Jonathan; vol.3: The Latter Prophets According to Targum Jonathan. Leiden: Brill, 1956-62.

Stenning, John Frederick (ed.). The Targum of Isaiah. Oxford, 1949.

Strack, Hermann Leberecht, and Paul Billerbeck. Kommentar zum Neuen Testament aus Talmud und Midrasch. 6 vols. Munich: Beck, 1922-1928.

Sukenik, Eleazar Lipa (ed.). The Dead Sea Scrolls of the Hebrew University. Jerusalem: Magnes, 1955.

Trever, John C. (ed.). Scrolls from Qumran Cave 1. Jerusalem: The Albright Institute of Archaealogical Research, The Shrine of the Book, 1972.

Wevers, John William (ed.). Septuaginta: Vetus Testamentum Graecum Auctoritate Academiae Scientiarum Gottingensis editum; vol.3.2: Deuteronomium. Göttingen: Vandenhoeck \& Ruprecint, 1977 .

(ed.). Septuaginta: Vetus Testamentum Graecum Auctoritate Academiae Scientiarum Gottingensis editum; vol.1: Genesis. Göttingen: Vandenhoeck \& Ruprecht, 1974 .

(ed.). Septuaginta: Vetus Testamentum Graecum Auctoritate Academiae Scientiarum Gottingensis editum; vol.2.2: Leviticus. Göttingen: Vandenhoeck \& Ruprecht, 1986.

(ed.). Septuaginta: Vetus Testamentum Graecum Auctoritate Academiae Scientiarum Gottingensis editum; vol.3.1: Numeri. Göttingen: Vandenhoeck \& Ruprecht, 1982 . 
Ziegler, Joseph (ed.). Septuaginta: Vetus Testamentum Graecum Auctoritate Academiae Scientiarum Gottingensis editum; vol.13: Duodecim Prophetae. 2nd ed. Gottingen: Vandenhoeck \& Ruprecht, 1967.

(ed.). Septuaginta: Vetus Testamentum Graecum Auctoritate Academiae Scientiarum Gottingensis editum; vol.15: Ieremias, Baruch, Threni, Epistula Ieremiae. 2nd ed. Göttingen: Vandenhoeck \& Ruprecht, 1976.

(ed.). Septuaginta: Vetus Testamentum Graecum Auctoritate Academiae Scientiarum Gottingensis editum; vol.14: Isaias. 2nd ed. Göttingen: Vandenhoeck \& Ruprecht, 1967.

\section{B. SECONDARY SOURCES}

Ackroyd, P. R. "The Place of the old Testament in the Church's Teaching and Worship". ExpTim 74 (1962-63), $164-7$.

Aland, Kurt, and Barbara Aland. The Text of the New Testament: An Introduction to the Critical Editions and to the Theory and Practice of Modern Textual Criticism. Grand Rapids: William B. Eerdmans, 1987.

Albright, W. F., and C. S. Mann. Matthew: Introduction, Translation, and Notes. Garden City, New York: Doubleday, 1971.

Allegro, J. M. "Fragment of a Scroll of Eschatological Midrashim". JBL 77 (1958), 350-4.

"Further Messianic References in Qumran Literature". JBL 75 (1956), 182-7.

Allen, Willoughby Charles. A Critical and Exegetical Commentary on the Gospel According to S. Matthew. New York: Charles Scribner's Sons, 1907.

"The old Testament Quotations in St. Matthew and
St. Mark". ExpTim 12 (1900-01), 281-3.

Allenbach, J. Biblia Patristica: Index des citations et allusions bibliques dans la litterature patristique. Paris: Centre national de la recherche scientifique, 1975. 
Argyle, Aubrey William. The Gospel According to Matthew. Cambridge: Cambridge University Press, 1963.

Bacon, Benjamin Wisner. Studies in Matthew. New York: $H$. Holt, 1930.

Barrett, Charles Kingsley. "Luke/Acts". In D. A. Carson and H. G. M. Williamson (eds.), It is Written: Scripture Citing Scripture. Cambridge: Cambridge University Press, 1988. (pp.231-44).

Luke the Historian in Recent Study. 2nd ed. Philadelphia: Fortress, 1970.

Bartnicki, Roman. "Das Zitat von Zach 9:9-10 und die Tiere im Bericht von Matthäus über dem Einzug Jesu in Jerusalem (Mt 21:1-11)". NovT 18 (1976), 161-6.

Barthélemy, Dominique. Les Devanciers d'Aquila. Leiden: E. J. Brill, 1963.

Baumstark, A. "Die Zitate des Mt.-Evangeliums aus dem Zwolforophetenbuch". Bib 37 (1956), 296-313.

Bellinzoni, Arthur J., Jr., and Joseph B. Tyson, and William 0. Walker, Jr. (eds.). The Two-Source Hypothesis: A Critical Appraisal. Macon, Georgia: Mercer University Pres5, 1985.

Blass, Friedrich, and Albert Debrunner and Friedrich Rehkopf. A Greek Grammar of the New Testament and Other Early Christian Literature. Translated by Robert W. Funk. Chicago: University of Chicago Press, 1961.

Bleek, Friedrich. Beiträge zur Einleitung und Auslegung der heiligen Schrift; vol.1: Beiträge zur EvangelienKritik. Berlin: G. Reimer, 1846.

Bloch, R. "Écriture et tradition dans le Judaisme: Aperçus sur l'origine du midrash". Cahiers Sioniens 8 (1951), 9-34.

"Midrash". DBSup 5 (1957), cols. 1263-81.
"Note methodologique pour 1'etude de la
litterature rabbinique". RSR 43 (1955), 194-227.

Böhl, Eduard. Die alttestamentlichen Citate im Neuen Testament. Vienna: Wilhelm Braumüller, 1878. 
Borgen, Peter. Bread from Heaven. Leiden: E. J. Brill, 1965 .

Forschungen nach einer Volksbibel zur Zeit Jesu
und deren Zusammentiang mit der Septuaginta-ubersetzung.
Vienna: W. Braumüller, 1873 .

Bratcher, Robert G., and Eugene A. Nida. A Translator's Handbook of the Gospel of Mark. Leiden: Brill, 1961.

Brown, Raymond $E$. The Birth of the Messiah. London: Cassel1, 1977.

Bruce, Frederick Fyvie. Biblical Exegesis in the Qumran Texts. Grand Rapids: Eerdmans, 1959.

Burkitt, Francis Crawford. The Gospel History and its Transmission. 2d ed. Edinburgh: T. and T. Clark, 1907.

Burrows, Millar. "Orthography, Morphology, and Syntax of the St. Mark's Isaiah Manuscript". JBL 68 (1949), 195211 .

- "Variant Readings in the Isaian Manuseript". BASOR 111 (Oct. 1948), 16-24; 113 (Feb. 1949), 24-33.

Butler, B. C. The Originality of St Matthew: A Critique of the Two-Document Hypothesis. Cambridge: Cambridge University Press, 1951.

Carson, D. A. and H. G. M. Williamson (eds.). It is Written: Scripture Citing Scripture. Cambridge: Cambridge University Press, 1988.

Cerfaux, L. "Un chapitre du livre des 'testimonia' (P Ryl. Gr. 460)". ETL 14 (1937), 69-74.

Chester, Andrew. "Citing the old Testament". In D. A. carson and H. G. M. Williamson (eds.), It is written: Scripture Citing Scripture. Cambridge: Cambridge University Press, 1988. (pp.141-69).

Coleman, R. D. "Matthew's Use of the old Testament". Southwestern Journal of Theology 5 (1962), 29-39.

Cope, D. Lamar. Matthew: A Scribe Trained for the Kingdom of Heaven. Washington: The Catholic Biblical Association of America, 1976. 
Coppens, J. "L'interprétation d'Is. VII,14 a la lumiere des etudes les plus recentes". In Heinrich Gross and Franz Mussner, Lex tua Veritas. Trier: Paulinus, 1961.

Corley, Bruce (ed.). Colloquy on New Testament Studies: A Time for Reappraisal and Fresh Approaches. Macon, Georgia: Mercer University Press, 1883.

Credner, Karl August. Einleitung in das Neue Testament; vol.1. Halle: Verlag der Buchhandlungdes Waisenhauses, 1836 .

Cross, Frank Moore, Jr. The Ancient Library of Qumran and Modern Biblical Studies. 2nd ed. New York: Doubleday, 1961.

"The Contribution of the Qumran Discoveries to the Study of the Biblical Text". IEJ 16 (1966), 81-95. , and Shemaryahu Talmon (eds.). Qumran and the History of the Biblical Text. Cambridge, Massachusetts: Harvard University Press, 1975.

Dahl, N. A. "Die Passionsgeschichte bei Matthaus". NTS 2 $(1955-56), 17-32$.

Daube, David. "The Earliest Structure of the Gospels". NTS $5(1958-59), 174-187$.

The New Testament and Rabbinic Judaism. London: University of London, 1956.

Davies, William David. The setting of the Sermon on the Mount. Cambridge: Cambridge University Press, 1964.

and Dale C. Allison, Jr. A Critical and Exegetical Commentary on the Gospel According to Saint Matthew; vol.1: Introduction and Commentary on Matthew I-VII. Edinburgh: T. \& T. Clark, 1988.

Dearing, Vinton Adams. A Manual of Textual Analysis. Berkeley: University of California Press, 1959.

Delling, G. "plèroô". TDNT o (1968), 286-298.

Derrett, J. Duncan M. "Matt 23:8-10 a midrash on Isa 54:13 and Jer 31:33-34". Bib 62 (1981), 372-386.

de Saussure, Ferdinand. Cours de linguistique generale. Lausanne: Payot, 1916. 
Devisch, M. "Le Document $Q$, source de Matthien Problematique actuelle". In M. Didier (ed.), L'Évangile selon Matthieu: Redaction et thélogie. Gembloux: J. Duculot, 1972. (pp.71-97).

de Waard, J. A Comparative Study of the old Testament Text in the Dead Sea Scrolls and in the New Testament. Leiden: Brill, 1965.

Diez Macho, A. "The Recently Discovered Palestinian Targum: Its Antiquity and its Relationship with the Other Targums". VTSup 7 (Congress vol.). Leiden: Brill, 1960. PP. 222-45.

Dodd, C. H. According to the Scriptures: The Substructure of New Testament Theology. London: Nisbet, 1952.

Doeve, Jan Willem. Jewish Hermeneutics in the Synoptic Gospels and Acts. Assen: Van Gorcum, 1953.

Dungan, D. L. "Mark - the Abridgement of Matthew and Luke". In Donald G. Miller and Dikran Y. Hadidian (eds.), Jesus and Man's Hope. Pittsburgh: Pittsburgh Theological Seminary, 1970.

Dupont, J. "L'utilisation apologetique de l'Ancien Testament dans les discours des Actes". ETL 29 (1953), $289-327$.

Edgar, S. L. "Respect for Context in Quotations from the old Testament". NTS $9(1962-63), 55-62$.

Ehrman, Bart D. "Methodological Developments in the Analysis and Classification of New Testament Documentary Evidence". NovT 29 (1987), 22-45.

Ellis Edward Earle. "Gospels Criticism: A Perspective on the State of the Art". In Peter Stuhlmacher (ed.), Das Evangelium und die Evangelien. Tübingen: J. C. B. Mohr, 1983. (pp.27-54).

"Midrash, Targum, and New Testament Quotations". In Edward Earle Ellis, and M. Wilcox (eds.), Neotestimentica it Semitica. Edinburgh: T. \& T. Clark, 1969.

Paul's Use of the Old Testament. Edinburgh: Dliver \& Boyd, 1957.

Prophecy and Hermeneutic. Tübingen: J. C. B. Mohr, 1978. 
Farmer, William R. "A 'Skeleton in the Closet' of Gospel Research". $B R$ 6 (1961), 18-42.

(ed.). New Synoptic Studies: The Cambridge Gospel Conference and Beyond. Macon, Georgia: Mercer University Press, 1982.

The Synoptic Problem: A Critical Analysis. Dillsboro, North Carolina: Western North Carolina Press, 1976.

Fee, Gordon D. "Modern Text Criticism and the Synoptic Problem". In Bernard Orchard, and Thomas R. W. Longstaff (eds.), J. J. Griesbach: Synoptic and Textcritical Studies, 1776-1976. Cambridge: Cambridge University Press, 1978.

Findlay, J. A. "The First Gospel and the Book of Testimonies". In H. G. Wood (ed.), Amicitiae Corolla. London: University of London Press, 1933.

Fitzmyer, Joseph A. The Dead Sea Scrolls: Major Publications and Tools for Study. Missoula, Montana: Scholars Press, 1977.

$(1957), 513-37$.

" $4 Q$ Testimonia" and the New Testament". TS 18 The Gospel According to Luke $(x-x x I V)$ : Introduction, Translation, and Notes. Garden City, New York: Doubleday, 1985. A.D.". "The Languages of Palestine in the first Century
CBQ $32(1970), 501-531$.

"The Priority of Mark and the ' $Q$ ' Source in Luke". In Jesus and Man's Hope. vol.1. Pittsburgh: Pittsburgh Theological Seminary, 1970. (pp.131-70).

"The Use of Explicit old Testament Quotations in Qumran Literature and in the New Testament". NTS 7 $(1960-61), 297-333$.

France, Richard T. "The Formula-quotations of Matthew 2 and the Problem of Communication". NTS 27 (1981), 233-51.

Freed, Edwin D. Old Testament Quotations in the Gospel of John. Leiden: Brill, 1965. 
Frieerich, G. "prophêtês, D: Prophets and Prophecies in the New Testament". TDNT o $(1968)$, 828-61.

Garland, D. E. The Intention of Matthew 23. Leiden: Brill, 1979 .

Gärtner, B. "The Habakkuk Commentary (DSH) and the Gospel of Matthew". ST 8 (1954), 1-24.

Gerhardsson, B. Memory and Manuscript: Dral Tradition and Written Transmission in Rabbinic Judaism and Early Christianity. Uppsala: Gleerup, 1961.

Gloag, Paton James. Introduction to the Synoptic Gospels. Edinburgh: T. and T. Clark, 1895.

Gnilka, J. "Das Verstockungsproblem nach Mt 13, 13-15". Abhandlungen zur christlichen-jüdischen Dialog 2 $(1967), 119-28$.

Die Verstockung Israels: Isaias 6, 9-10 in der Theologie der Synoptiker. Munich: Kösel, 1961.

Goodman, F. W. "Sources of the First Two Chapters in Matthew and Luke". CQR 162 (1961), 136-43.

Gould, Ezra P. A Critical and Exegetical Commentary on the Gospel According to Saint Mark. New York: Charles Scribner's Sons, 1896.

Goulder, Michael D. Luke: A New Paradigm. 2 vols. Sheffield: Sheffield Academic Press, 1989.

Grech, P. "The 'Testimonia' and Modern Hermeneutics". NTS $19(1972-73), 318-24$.

Greimas, A. J. Sémantique structurale: Recherche de methode. Paris: Larousse, 1964.

Grindel, John A. "Another Characteristic of the Kaige Recension". CBQ 31 (1969), 499-513.

. Matthew 12:18-21". CBQ 29 (1967), 110-15.

Grogan, G. W. "The New Testament Interpretation of the old Testament: A Comparative Study". Tyndale Bulletin 18 $(1967), 54-76$.

Gundry, Robert Horton. "The Language Milieu of First Century Palestine: Its Bearing on the Authenticity of the Gospel Tradition". JBL 83 (1964), 404-408. 
The Use of the old Testament in St. Matthew's Gospel. Leiden: E. J. Brill, 1967.

Hanhart, Robert. "Die Bedeutung der Septuaginta in neutestamentlicher Zeit". ZTK 81 (1984), 395-416.

"Das Neue Testament und die griechische überlieferung des Judentums". TU 125 (1981) 293-303.

"Die Septuaginta als Problem der Textgeschichte, der Forschungsgeschichte und der Theologie". VTSup 22 $(1971), 185-200$.

Harris, James Rendel and Vacher Burch. Testimonies. 2 vols. Cambridge: Cambridge University Press, 1916,1920.

Hartman, Lars. Prophecy Interpreted: The Formation of Some Jewish Apocalyptic Texts and of the Eschatological Discourse Mark 13 Par. Lund: C. W. K. Gleerup, 1966. - "Scriptural Exegesis in the Gospel of St. Matthew and the Problem of Communicataion". In M. Didier (ed.), L'Evangile selon Matthieu: Redaction et théologie. Gembloux: J. Duculot, 1972. (pp.131-152).

Hatch, Edwin. Essays in Biblical Greek. Dxford, 1889.

Haupt, Erich. Die alttestamentlichen Citate der vier Evangelien. Colberg: C. Jancke, 1871.

Hawkins, John C. Horae Synopticae: Contributions to the Study of the Synoptic Problem. 2d ed. Oxford: Clarendon, 1909.

Heater, Homer. "Matthew 2:6 and its old Testament Sources". Journal of the Evangelical Theological Soriety $26(1983)$, 395-7.

Hebert, Arthur Gabriel. The Authority of the old Testament. London: Faber and Faber, 1947.

Hengel, M. "Die Begegnung von Judentum und Hellenismus im Palästina der vorchristlichen Zeit". In 0 . Bocher and K. Haacker (eds.), Verborum Veritatis. Wuppertal, 1970 .

Hilgenfeld, Adolf. Das Marcusevangelium: nach seiner Composition, seiner Stellung in der Evangelienliteratur, seinem Ursprung und Charakter. Leipzig: Breitkopf und Härtel, 1850. 
Hill, David. "On the Use and Meaning of Hosea 6:6 in Matthew's Gospel (Hos 6:6; Matt 9:13, 12:7; Mk 2:13-17, 23-27)". NTS 24 (1977), 107-19.

Hillyer, N. "Matthew's Use of the Old Testament". EvQ 36 $(1964), 12-26$.

Hirsch, Emanuel. Frühgeschichte des Evangeliums. 2 vols. Tübingen: J. C. B. Mohr, 1941.

Holtz, Traugott. Untersuchungen über die alttestamentlichen Zitate bei Lukas. Berlin: Akademie Verlag, 1968.

Holtzmann, Heinrich Julius. Hand-commentar zum Neuen Testament; vol.1. Die Synoptiker, Die Apostelgeschichte. 2d ed. Freiburg: Mohr, 1892. - Lehrbuch der histarisch-kritischen Einleitung in das Neue Testament. 3rded. Freiburg: J. C. B. Mohr, 1892 . - Die synoptischen Evangelien: Ihr Ursprung und geschichtlicher Charackter. Leipzig: Engelmann, 1863.

Hooker, Morna D. "Mark". In D. A. Carson and H. G. M. williamson (eds.), It is Written: Scripture Citing Scripture. Cambridge: Cambridge University Press, 1988. ( $p$. 220-30).

Howard, George. The Gospel of Matthew according to a Primitive Hebrew Text. Macon: Mercer University Press, 1987.

- "The Quinta of the Minor Prophets: A First Century Septuagint Text?" Bib 55 (1974), 15-22.

Hummel, Reinhart. Die Auseinandersetzung zwischen Kirche und Judentum im Matthäusevangelium. 2nd ed. Munich: Kaiser, 1966.

Hurtado, Larry w. Text-critical Methodology and the PreCaesarean Text: Codex $W$ in the Gospel of Mark. Grand Rapids: Eerdmans, 1981.

Jackson, Henry Latimer. "The Present State of the Synoptic Problem". In Henry Barclay Swete (ed.), Essays on Some 
Biblical Questions of the Day. London: Macmillan, 1909. (PP.421-60).

Jellicoe, Sidney. The Septuagint and Modern Study. oxford: Clarendon, 1968.

. Studies in the Septuagint: Origins, Recensions, and Interpretations. New York: KTAV, 1974.

Johnson, Sherman E. "The Biblical Quotations in Matthew". HTR 36 (1943), 135-53.

- A Commentary on the Gospel According to Saint Mark. London: Black, 1960.

Jones, Genesius. Approach to the Purpose. London: Hodder and Stoughton, 1964.

Jongeling, B. A Classified Bibliography of the Finds in the Desert of Judah, 1958-1969. Leiden: E. J. Brill, 1971.

Kahle, Paul Ernst. The Cairo Geniza. London: Oxford University Press, 1947.

"Untersuchungen zur Geschichte des

Pentateuchtextes". TSK 88 (1915), 399-439.

Karnetzki, M. "Die galiläische Redaktion im Markusevangelium". ZNW 52 (1961), 238-72.

Katz, Peter. "Das Problem des Urtextes der Septuaginta". $T Z 5(1949), 1-24$.

"The Quotations from Deuteronomy in Hebrews". ZNW $49(1958), 213-223$.

"Septuagintal Studies in Mid-Century: Their Links with the Past and their Present Tendencies". In $W$. D. Davies and D. Daube (eds.), The Background of the New Testament and its Eschatology. Cambridge: Cambridge University Press, 1956.

Keck, L. "The Introduction to Mark's Gospel". NTS 12 $(1965-66), 352-70$.

Kent, H. A. "Matthew's Use of the old Testament - a Study in Hermeneutics". BSac 121 (1964), 34-43. 
Kingsbury, Jack Dean. The Parables of Jesus in Matthew 13: A Study in Redaction-Criticism. Richmond: John Knox, 1969.

Kilpatrick, G. D. The Origins of the Gospel According to St. Matthew. Oxford: Clarendon, 1946.

Klein, Ralph w. Textual Criticism of the old Testament: The Septuagint after Qumran. Philadelphia: Fortress, 1974.

Knox, Wilfred Lawrence. The Sources of the Synoptic Gospels; vol.1: St. Mark; vol.2: St. Matthew and St. Luke. Cambridge: Cambridge University Press, 1953, 1957 .

Koch, Dietrich-Alex. Die Schrift als Zeuge des Evangeliums: Untersuchungen zur Verwendung und zum Verständnis der Schrift bei Paulus. Tübingen: J. C. B. Mohr, 1986.

Kraft, R. A. "Septuagint: Earliest Greek Versions". IDBSup $(1976), 811-15$.

Kretzer, Armin. Die Herrschaft der Himmel und die Söhne des Reiches. Würzburg: Echter, 1971.

Kümmel, Werner Georg. Introduction to the New Testament. Nashville: Abingdon, 1966.

The New Testament: The History of the Investigation of its Problems. New York: Abingdon, 1972 .

Lagrange, Marie-Joseph. Evangile selon Saint Marc. Paris: J. Gabalda, 1929.

Gabalda, 1927 .

Le Deaut, R. "Apropos a Definition of Midrash". Int 25 $(1971), 259-82$.

"Un phénomene spontané de l'hermeneutique juive ancienne: le "targumisme". Bib 52 (1971), 505-25.

- "La tradition juive ancienne et l'exegese chretienne primitive". RHPR 51 (1971), 31-50.

Lindars, Barnabas. New Testament Apologetic: The Doctrinal Significance of the Old Testament Quotations. London: SCM, 1961 . 
Loewinger, S. "The Variants of DSI II". VT 4 (1954), 15563.

Lowy, 5. "Some Aspects of Normative and Sectarian Interpretation of the Scriptures". ALUOS 6 (1969), 68163.

Luz, Ulrich. Matthew 1-7: A Commentary. Minneapolis: Augsburg, 1989.

Mahnke, H. Die Versuchungsgeschichte im Rahmen der synoptischen Evangelien. Bern: Lang, 1978.

Mann, C. S. Mark: A New Translation with Introduction and Commentary. Garden City, New York: Doubleday, 1986.

Marshall, I. H. "Palestinian and Hellenistic Christianity: Some Critical Comments". NTS 19 (1972-73), 271-87.

Martin, Raymond A. Syntactical Evidence of Semitic Sources in Greek Documents. Cambridge: Society of Biblical Literature, 1974.

Martini, C. M. "La problématique génerale du texte de Matthieu". In M. Didier (ed.), L'Evangile selon Matthieu: Redaction et thélogie. Gembloux: J. Duculot, 1972. (pP.21-36).

Marxsen, Willi. Mark the Evangelist: Studies in the Redaction History of the Gospel. Nashville: Abingdon, 1969 .

Introduction to the New Testament: An Approach to its Problems. Philadelphia: Fortress, 1968.

Massebieau, Eugene. Examen des citations de 1'Ancien

Testament dans l'Evangile selon Matthieu. Paris:

Fischbacher, 1885.

McCasland, S. "Matthew Twists the Scriptures". JBL 80 $(1961), 143-8$.

McConnel1, Richard S. Law and Prophecy in Matthew's Gospel: the Authority and Use of the old Testament in the Gospel of St. Matthew. Basel: Friedrich Reinhardt, 1969.

Mead, R. T. "A Dissenting Opinion about Respect for Context in Dld Testament Quotations". NTS 10 (196364), 279-89. 
Metzger, B. M. "The Formulas Introducing Quotations of Scripture in the New Testament and the Midrash". JBL $70(1951), 297-307$.

The Text of the New Testament: Its Transmission, Corruption, and Restoration. 2d ed. Oxford: Clarendon, 1968 .

- A Textual Commentary on the Greek New Testament. 2d ed. New York: United Bible Societies, 1975.

Meyer, Ben F. The Aims of Jesus. London: SCM, 1979.

Morgenthaler, Robert. Statistik des neutestamentlichen wortschatzes. Zürich: Gotthelf-Verlag, 1958.

Moule, C. F. D. "Fulfilment-Words in the New Testament: Use and Abuse". NTS $14(1967-68), 293-320$.

Neirynck, F. De Jésus aux evangiles: Tradition et rédaction dans les évangiles synoptiques. Paris: Gembloux, 1967. ( = "La redaction mathéenne et la structure du premier évangile". ETL 53 (1967), 41-73.)

- "The Gospel of Matthew and Literary Criticism". In M. Didier (ed.), L'Evangile selon Matthieu:

Rédaction et theologie. Gembloux: J. Duculot, 1972. (pp.37-69).
"Hawkins's Additional Notes to His 'Horae
, Symopticae". ETL 46 (1970), 78-111.
Nei11, Stephen. The Interpretation of the New Testament, 1861-1961. London: Dxford University Press, 1964.

Nellessen, Ernst. Das Kind und seine Mutter: Struktur und Verkündigung des 2. Kapitels im Matthäusevangelium. Stuttgart: Verlag Katholisches Bibelwerk, 1969.

Nepper-Christensen, P. Das Mattäusevangelium ein judenchristliches Evangelium?. Aarhus: Universitetsforlagst, 1958.

Nineham, D. E. The Gospel of St Mark. Harmondsworth: Penguin, 1963.

Noja, Sergio. "The Samareitikon". In Alan D. Crown, The Samaritans. Tübingen: Mohr, 1989. (pp.408-412).

D'Connel1, K. G. "Greek Versions (Minor)". DBSup (1976), $377-381$. 
Orchard, Bernard. Matthew, Luke \& Mark. Manchester: Koinonia, 1976.

Orchard, Bernard, and Harold Riley. The Order of the Symoptics: Why Three Symoptic Gospels?. Macon, Georgia: Mercer University Press, 1987.

Orchard, Bernard, and Thomas R. W. Longstaff (eds.). J. J. Griesbach: Synoptic and Text-critical Studies, 17761976. Cambridge: Cambridge University Press, 1978.

Orlinsky, H. M. "Current Progress and Problems in Septuagint Research". In Harold R. Willoughby (ed.), The Study of the Bible Today and Tomorrow. Chicago: University of Chicago Press, 1947. (pp.141-61). JAOS $61(1941), 81-91$.
JAn the Present state of Septuagint Studies". "Qumran and the Present State of old Testament
Text Studies: The Septuagint Text". JBL 78 (1959), 26-
33 . JQR $_{43}$ "Studies in the $5 t$. Mark's Isaiah Scroll, IV".

"The Textual Criticism of the old Testament". In George Ernest Wright (ed.), The Bible and the Ancient Near East. New York: Doubleday, 1961.

O'Rourke, J. J. "Explicit ald Testament Citations in the Gospels". Studia Montis Regii 7 (1964), 37-60.

- "The Fulfillment Texts in Matthew". CBQ 24 $(1962), 394-403$.

Ottley, R. R. The Book of Isaiah According to the Septuagint (Codex Alexandrinus); vol.2: Text and Notes. Cambridge: Cambridge University Press, 1906.

Pesch, Rudolf. "Eine alttestamentliche Ausführungsformel im Matthäus-Evangelium". BZ n.s.10 (1966), 221-245; n.S.11 (1967), 79-95.

"Der Gottessohn im matthäischen Evangelienprolog (Mt 1-2): Beobachtungen zu den Zitationsformein der Reflexionszitate". Bib 48 (1967), 395-420. 1977

Das Marcusevangelium. 2 vols. Freiburg: Herder, 
Plummer, Alfred. A Critical and Exegetical Commentary on the Gospel According to 5 . Luke. 5th ed. Edinburgh: T. \& T. Clark, 1922 .

Politzer, H. "The Gentle Craft of Interpretation". Research Studies 14 (1966), 107-22.

Prigent, Pierre. L'Êf̂tre de Barnabé I-XVI et ses sources: les testimonia dans le christianisme primitif. Paris: J. Gabalda, 1961.

Rahlfs, Alfred. "über Theodotion-Lesarten im Neuen Testament und Aquila-Lesarten bei Justin". ZNW 20 $(1921), 182-99$.

Rawlinson, A. E. J. St Mark, with Introduction, Commentary and Additional Notes. London: Methuen, 1925.

Reicke, Bo. "From Strauss to Holtzmann and Meijboom". NovT $29(1987), 1-21$.

The Roots of the Synoptic Gospels. Philadelphia: Fortress, 1986 .

Rese, M. "Die Rolle des Alten Testaments im Neuen Testament". VF 12 (1967), 87-97.

Roberts, Bleddyn Jones. "Bible Exegesis and Fulfilment in Qumrân". In Peter R. Ackroyd, and Barnabas Lindars (eds.), Words and Meanings. London: Cambridge University Press, 1968.

The old Testament Text and Versions: The Hebrew Text in Transmission and the History of the Ancient Versions. Cardiff: University of Wales Press, 1951. - "The Textual Transmission of the old Testament (including modern critical editions of the Hebrew Bible)". In G. W. Anderson (ed.), Tradition and Interpretation: Essays by Members of the Society for old Testament Study. Oxford: Clarendon, 1979.

Robinson, James M. "On the Gattung of Mark (and John)". In Jesus and Man's Hope; vol.1. Pittsburgh: Pittsburgh Theological Seminary, 1970.

Robinson, John Arthur Thomas. Redating the New Testament. London: SCM, 1976. 
Rothfuchs, Wilhelm. Die Erfüllungszitate des MatthäusEvangeliums. Stuttgart: W. Kohlhammer, 1969.

Rowley, H. H. "The Proto-Septuagint Question". JQR n.5.33 $(1943), 497-9$.

Sanday, william (ed.). Studies in the Synaptic Problem. Oxford: Clarendon, 1911.

Sanders, E. P. The Tendencies of the Synoptic Tradition. London: Cambridge University Press, 1969.

Schaller, Berndt. "exxei ek sion ho ruamenas: Zur Textgestalt von Jes 59:20f in Röm 11:26f". In Albert Pietersma and Claude Cox (eds.), De Septuaginta: Studies in Honour of John Wevers on his Sixty-fifth Birthday. Mississauga, Canada: Benben, 1984.

- "Zum Textcharakter der Hiobzitate im paulinischen Schriftum". ZNW 71 (1980), 21-26.

Schenk, Wolfgang. Die Sprache des Matthäus: Die TextKonstituenten in ihren makro- und mikrostrukturellen Relationen. Göttingen: Vandenhoeck \& Ruprecht, 1987.

Schleiermacher, Friedrich Ernst Daniel. "uber die Zeugnisse des Papias von unsern beiden ersten Evangelien". In his Theologische Studien und Kritiken. 1832. (pp.735768 ).

Schniewind, Julius Daniel. Das Evangelium nach Matthäus. 5 th ed. Gättingen, 1950.

Schreiber, Johannes. Theologie des Vertraumens. Eine redaktionsgeschichtliche Untersuchung des Markusevangeliums. Hamburg: Furche, 1967.

Schreiner, Josef. "Die neutestamentliche Botschaft und das alttestamentliche Gottswort". In J. Schreiner (ed.), Gestalt und Anspruch des Neuen Testaments. Würzburg: Echter, 1969.

Schürmann, H. Das Lukasevangelium. Freiburg: Herder, 1969.

Schwarzwaeller, K. "Das Verhältnis Altes Testament-Neues Testament im Lichte der gegenwärtigen Bestimmungen". EVT 29 (1969), 281-307.

Seeligmann, Isac Leo. The Septuagint Version of Isaiah: A Discussion of its Problems. Leiden: E. J. Brill, 1948. 
Shires, Henry M. Finding the old Testament in the New. Philadelphia: Westminster, 1974.

Silberman, L. H. "A Note on $4 Q$ Florilegium". JBL 78 (1959), 158-159.

Skehan, Patrick $W$. "The Scrolls and the old Testament Text". MCCQ 21 (1967-68), 273-83.

Smith, D. Moody, Jr. "The Use of the ald Testament in the New". In James M. Efird (ed.), The Use of the old Testament in the New and Other Essays: Studies in Honor of William Franklin Stinespring. Durham, North Carolina: Duke University Press, 1972.

Soares Prabhu, George M. The Formula Quotations in the Infancy Narrative of Matthew: An Enquiry into the Tradition History of Mt 1-2. Rome: Biblical Institute Press, 1976.

Soltau, W. "Zur Entstehung des I. Evangeliums". ZNW 1 $(1900), 219-48$.

Sowers, Sidney G. The Hermeneutics of Philo and the Hebrews. Richmond: John Knox, 1965.

Stanton, Graham. "Matthew". In D. A. Carson and H. G. M. Williamson (eds.), It is Written: Scripture Citing Scripture. Cambridge: Cambridge University Press, 1988. (PP.205-19).

"The Origin and Purpose of Matthew's Gospel:

Matthean Scholarship from 1945 to 1980". In Wolfgang Haase (ed.), Aufstieg und Niedergang der Römischen Welt. vol.2. pt.25. sect.3. Berlin: Walter de Gruyter, 1985. (pp.1889-1951).

Stanton, Vincent Henry. The Gospels as Historical Documents; Part 2: The Synoptic Gospels. Cambridge: Cambridge University Press, 1909.

\footnotetext{
"Some Points in the Synoptic Problem, II I: Some Secondary Features". Expositor series 4. 7 (1893), 265.
}

Stein, Robert $H$. The Synoptic Problem: An Introduction. Grand Rapids: Baker, 1987.

Stendahl, Krister. The School of St. Matthew and its Use of the old Testament. 2nd ed. Lund: Gleerup, 1968. 
Stephenson, T. "The old Testament Quotations Peculiar to Matthew". JTS $20(1918-19), 227-9$.

Strecker, Georg. Der Weg der Gerichtigkeit: Untersuchung zur Theologie des Matthäus. Göttingen: Vandenhoeck \& Ruprecht, 1971.

Streeter, Burnett Hillman. The Four Gospels: A Study of Origins. London: Macmillan, 1924.

Styler, G. M. "The Priority of Mark". In C. F. D. Moule, The Birth of the New Testament. 3rd ed. San

Francisco: Harper \& Row, 1982. (pp.285-316).

Suhl, Alfred. Die Funktion der alttestamentlichen Zitate und Anspielungen im Marusevangelium. Gütersloh: $G$. Mohn, 1965.

Sundberg, Albert C, Jr. The Old Testament of the Early Church. Cambridge: Harvard University Press, 1964.

"On Testimonies". Novt 3 (1959), 268-81.

Swete, Henry Barclay. An Introduction to the old Testament in Greek. 2nd ed. New York: KTAV, 1968.

Tagawa, K. "People and Community in the Gospel of Matthew". NTS $16(1969-70), 149-62$.

Taylor, Vincent. Behind the Third Gospel: A Study of the Proto-Luke Hypothesis. Dxford: Clarendon, 1926.

Thackeray, Henry St.John. A Grammar of the old Testament in Greek; vol.1. Cambridge: Cambridge University Press, 1909.

Tholuck, August. Das Alte Testament im Neuen Testament: über die Citate des Alten Testaments im Neuen Testament und über den Opfer- und Priesterbegriff im Alten und Neuen Testament. Gotha: Friedrich Perthes, 1972.

Thomas, Kenneth J. "Torah Citations in the Synoptics". NTS 24 (1977), 85-96.

Thompson, W. G. Matthew's Advice to a Divided Community: Mt. 17:22 - 18:35. Rome, 1970.

Torrey, Charles Cutler. "The Biblical Quotations in Matthew". In Charles Cutler Torrey, Documents of the Primitive Church. New York: Harper \& Bros., 1941. (pp.41-90). 
Tov, Emanuel. "Die griechischen Bibelübersetzungen". Aufstieg und Niedergang der Römischen Welt II.20.1 $(1987), 121-89$.

\section{"Proto-Samaritan Texts and the Samaritan}

Pentateuch". In Alan D. Crown, The Samaritans.

Tübingen: Mohr, 1989. (pp.397-407).

Toy, Crawford Howell. The 0ld Testament Quotations in the New Testament. New York, 1884.

Treves, M. "On the Meaning of the Qumran Testimonia". RevQ $2(1959-60), 569-71$.

Trilling, Wolfgang. Das Wahre Israel: Studien zur Theologie des Matthäus-Evangeliums. Jd ed. Munich: Kösel, 1964.

Tuckett, C. M. "The Griesbach Hypothesis in the 19th Century". Journal for the Study of the New Testament 3 $(1979), 48-60$.

The Revival of the Griesbach Hypothesis: An Analysis and Appraisal. Cambridge: Cambridge University Press, 1983.

Turner, Nigel. "The Minor Agreements of Mt. and Luke against Mk.". In Studia Evangelica series, K. Aland (ed.), The Four Gospels in 1957. Berlin: Akademie Verlag, 1959. (pp.223-234).

Turpie, David McCalman. The old Testament in the New: $A$ Contribution to Biblical Criticism and Interpretation. London: Williams \& Norgate, 1868.

Vaganay, Lén. Le probleme synoptique: Une hypothese de travail. Tournai-Paris: Desclee, 1954.

van Cangh, J. M. "La Bible de Matthieu: Les citations d accomplissement". ETL 6 (1975), 205-11.

van Dodewaard, J. A. E. "La force evocatrice de la citation". Bib 36 (1955), 482-91.

van Segbroeck, F. "Les citations d'accomplissement dans l'evangile selon saint Matthieu d'apres trois ouvrages recents". In M. Didier (ed.), L'Évangile selon Matthieu: Redaction et theologie. Gembloux: J. Duculot, 1972. (pp.107-30). 
"Le scandale de l'incroyance: La signification de Mt. XIII, 35". ETL 41 (1965), 344-72.

von Campenhausen, Hans. The Formation of the Christian Bible. Translated by J. A. Baker. Tübingen: Mohr, 1972 .

Venard, A. "Citations". DBSup 2 (1934), co1.24.

Vermes, Geza. "Bible and Midrash". In The Cambridge History of the Bible. vol.1. Cambridge: Cambridge University Press, 1970. (pp.199-231).

- "The Qumran Interpretation of Scripture in its Historical setting". ALUOS 6 (1969), 85-97.

J. Scripture and Tradition in Judaism. Leiden: E.
J.ill, 1961 .

Vollmer, Hans Arthur. Die alttestamentlichen Citate be Paulus. Freiburg: J. C. B. Mohr, 1895.

Walker, N. "The Alleged Matthean Errata". NTS 9 (1962-63), $391-4$.

Weingreen, J. Introduction to the Critical study of the Text of the Hebrew Bible. Oxford: Clarendon, 1982.

Weisse Christian Hermann. Die evangelische Geschichte kritisch und philosophisch bearbeitet; vol.1. Leipzig: Breitkopf und Härtel, 1838.

Wernle, Paul. Die synoptische Frage. Freiburg: J. C. B. Mohr, 1899.

Westcott, Brooke Foss. An Introduction to the Study of the Gospels. 8th ed. New York: Macmillan, 1882.

Westermann, C. "Prophetenzitate im Neuen Testament". EvT 27 (1967), 307-17.

Wevers, John William. Text History of the Greek

Deuteronomy. Göttingen: Vandenhoeck \& Ruprecht, 1978.

Text History of the Greek Genesis. Gottingen:

Vandenhoeck \& Ruprecht, 1974.

Text History of the Greek Numbers. Gottingen:

Vandenhoeck \& Ruprecht, 1982. 
Wilcox, Max. "Text Form". In D. A. Carson and H. G. M. Williamson (eds.), It is Written: Scripture Citing Scripture. Cambridge: Cambridge University Press, 1988. (pP. 193-204).

Wilke, Christian Gottlob. Der Urevangelist oder exegetisch kritische Untersuchung über das Verwandtschaftsverhältniss der drei ersten Evangelien. Dresden and Leipzig: G. Fleischer, 1838.

woods, F. H. "The Drigin and Mutual Relation of the Synoptic Gospels". In William Sanday (ed.), Studia Biblica et Ecclesiastica: Essays Chiefly in Biblical and Patristic Criticism; vol.2. Oxford, 1890. (pp.59104).

Wright, Addison G. The Literary Genre Midrash. Staten Island: Alba House, 1967.

Würthwein, Ernst. The Text of the old Testament: An Introduction to the Biblia Hebraica. Grand Rapids: Eerdmans, 1979.

Zahn, Theodor. Das Evangelium des Matthäus. Leipzig: A. Deichert, 1910.

Introduction to the New Testament. vol.2. Edinburgh: T. \& T. Clark, 1909.

Ziegler, J. "Studien zur Verwertung der Septuaginta im Zwölfprophetenbuch". ZAW 60 (1944), 107-31. 